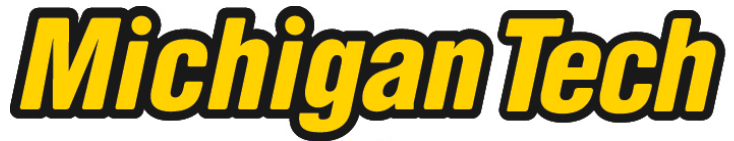 \\ Michigan Technological University Create the Future Digital Commons @ Michigan Tech
}

2014

REMEDIATION OF TETRACYCLINE FROM WATER SOURCES

USING VETIVER GRASS (Chrysopogon zizanioides L. Nash) AND TETRACYCLINE-TOLERANT ROOT-ASSOCIATED BACTERIA

Aparupa Sengupta

Michigan Technological University

Follow this and additional works at: https://digitalcommons.mtu.edu/etds

Part of the Biology Commons, Environmental Sciences Commons, and the Microbiology Commons Copyright 2014 Aparupa Sengupta

Recommended Citation

Sengupta, Aparupa, "REMEDIATION OF TETRACYCLINE FROM WATER SOURCES USING VETIVER GRASS (Chrysopogon zizanioides L. Nash) AND TETRACYCLINE-TOLERANT ROOT-ASSOCIATED BACTERIA", Dissertation, Michigan Technological University, 2014.

https://doi.org/10.37099/mtu.dc.etds/793

Follow this and additional works at: https://digitalcommons.mtu.edu/etds

Part of the Biology Commons, Environmental Sciences Commons, and the Microbiology Commons 


\title{
REMEDIATION OF TETRACYCLINE FROM WATER SOURCES USING VETIVER GRASS (Chrysopogon zizanioides L. Nash) AND TETRACYCLINE-TOLERANT ROOT-ASSOCIATED BACTERIA
}

\author{
By \\ Aparupa Sengupta \\ A DISSERTATION \\ Submitted in partial fulfillment of the requirements for the degree of \\ DOCTOR OF PHILOSOPHY \\ In Biological Sciences
}

MICHIGAN TECHNOLOGICAL UNIVERSITY

2014

Copyright $@$ Aparupa Sengupta 2014 
This dissertation has been approved in partial fulfillment of the requirements for the Degree of DOCTOR OF PHILOSOPHY in Biological Sciences

Department of Biological Sciences

Dissertation Co-Advisor: $\quad$ Dr. Rupali Datta

Dissertation Co-Advisor: $\quad$ Dr. Susan T. Bagley

Committee Member: $\quad$ Dr. Dibyendu Sarkar

Committee Member: $\quad$ Dr. Karl J. Indest

Department Chair: Dr. Chandrashekhar P. Joshi 


\section{Table of Contents}

- List of Abbreviations .................................................................................... 6

- List of Figures................................................................................................................... 8

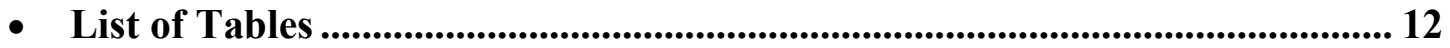

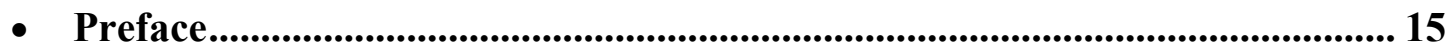

- Acknowledgements .......................................................................................... 17

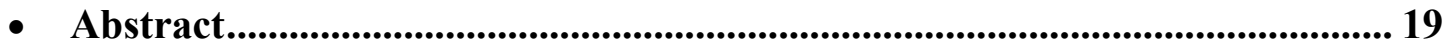

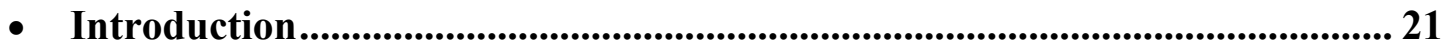

- Dissertation Objectives .............................................................................................. 28

- CHAPTER 1: Literature Review ................................................................... 30

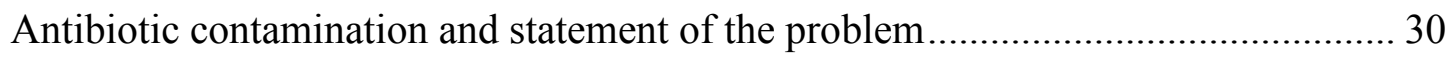

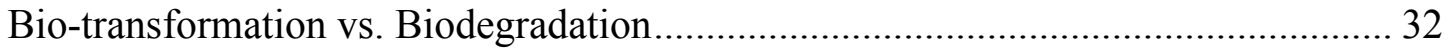

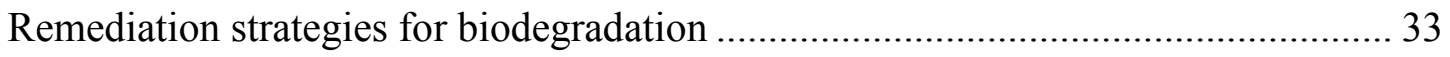

Root-secreted metabolites/enzymes and microbial enzymes and their role in antibiotic

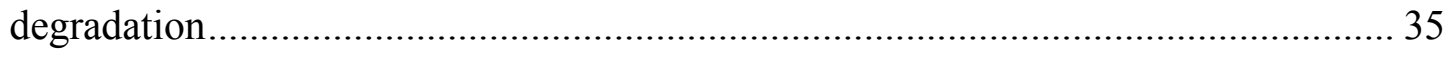

Plant and microbial metabolomics and antibiotic degradation pathway analysis....... 36

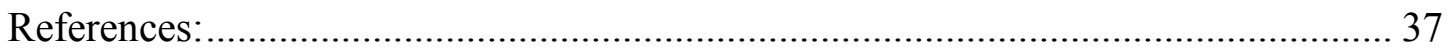

- CHAPTER 2. Tetracycline remediation and identification of tetracycline metabolites in aqueous systems using vetiver grass (Chrysopogon zizanoides

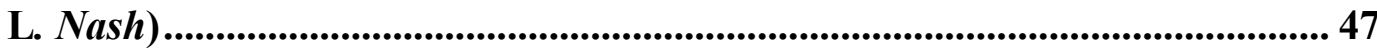

Abstract............................................................. 48 


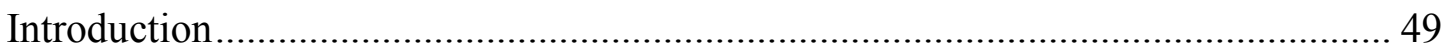

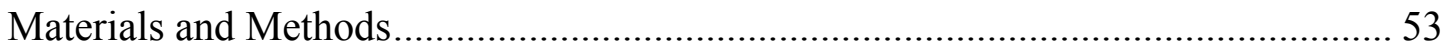

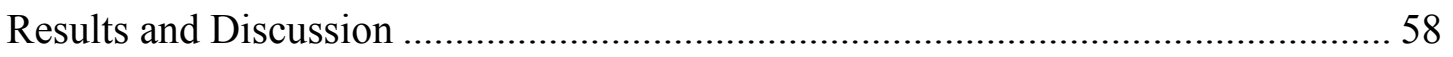

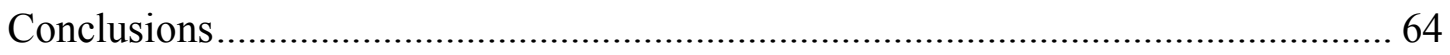

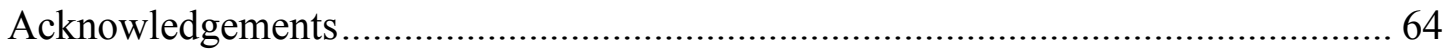

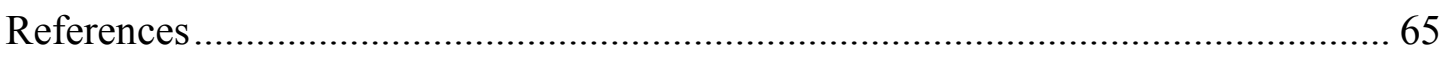

- CHAPTER 3. Role of vetiver (Chrysopogon zizanoides L. Nash) rootassociated microbes in tetracycline degradation ${ }^{\mathrm{a}}$.................................................. 78

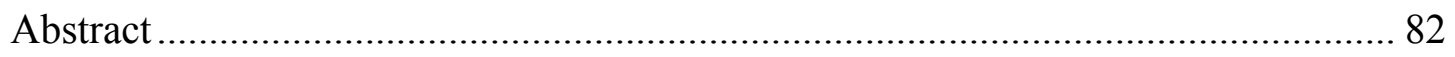

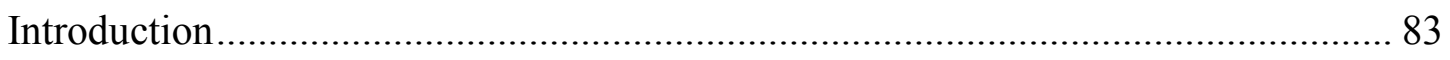

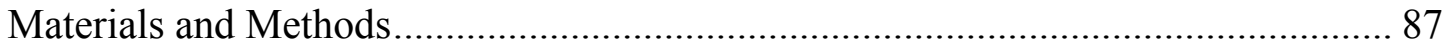

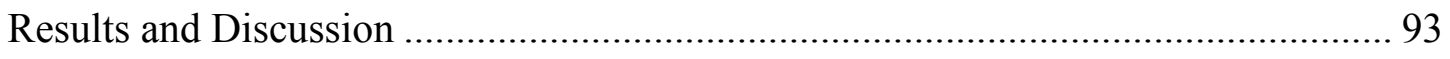

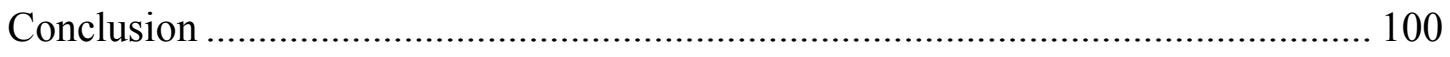

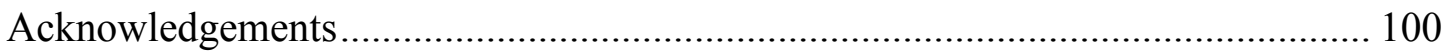

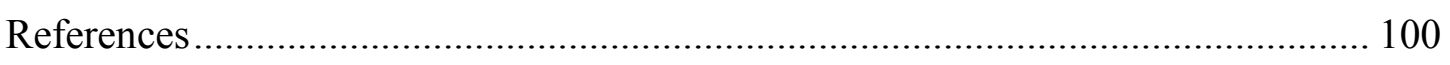

- CHAPTER 4. Role of bacterial and vetiver (Chrysopogon zizanioides) antioxidant enzymes in tetracycline detoxification ${ }^{\mathrm{a}}$........................................... 114

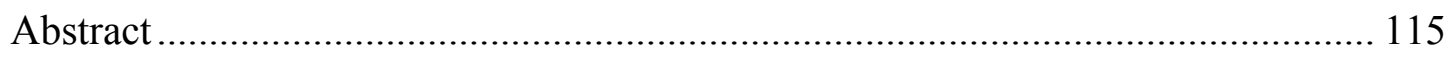

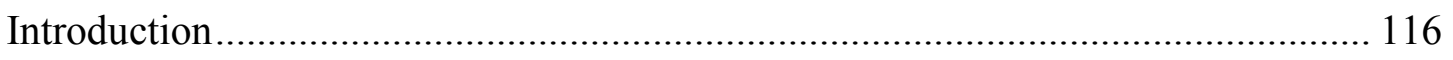

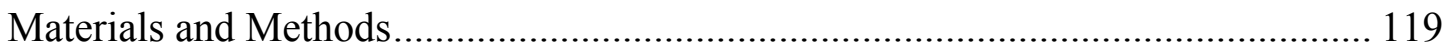

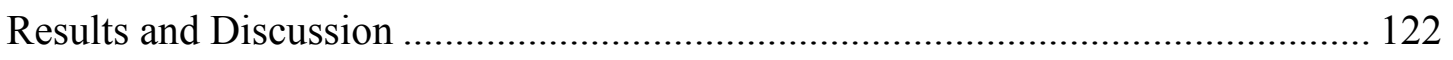

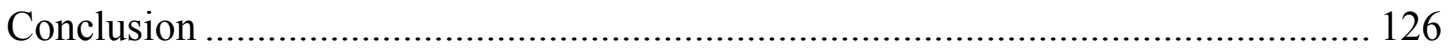

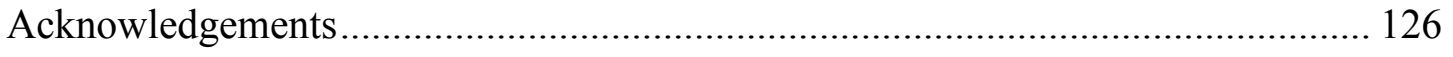

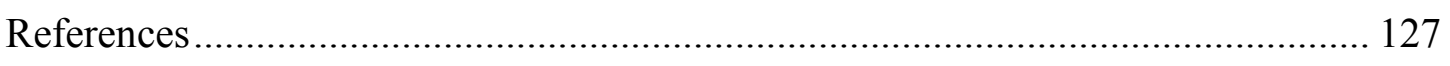

- Thesis Conclusions ...................................................................................................... 135

- Recommendations ......................................................................................................... 136 
- APPENDIX A. Additional information for Chapter 2. Tetracycline remediation and identification of tetracycline metabolites in aqueous systems using vetiver grass (Chrysopogon zizanoides L. Nash)

- APPENDIX B. Additional information for Chapter 3. Recovery of tetracycline-tolerant bacteria from vetiver (Chrysopogon zizanioides $\mathrm{L}$. Nash) root-zone and media samples and determination of their ability of maximal tetracycline-tolerance and usage (as a sole carbon and nitrogen source) 152

- APPENDIX C. Additional information for Chapter 3. Role of vetiver (Chrysopogon zizanoides L. Nash) root-associated microbes in tetracycline degradation root-zone 181

- APPENDIX D. Optimization of tetracycline-detoxification conditions of bacterial strains recovered from vetiver (Chrysopogon zizanioides) root -zone

- APPENDIX E. Additional information for Chapter 4. Role of bacterial and vetiver antioxidant enzymes in tetracycline detoxification 218

- APPENDIX F. Preparation of hairy root culture for vetiver grass (Chrysopogon zizanoides L. Nash). 


\section{List of Abbreviations}

ANOVA: Analysis of variance

ATC: Anhydro-tetracycline

BCA: Bicinchoninic acid assay

BM: Burkholderia cepacia

CAT: Catalase

CDNB: 1-chloro-2, 4-dinitrobenzene

CFU: Colony forming unit

ERM: Enriched medium

ETC: Epi-tetracycline

GC-MS: Gas chromatography-Mass spectrometry

GPX: Guaiacol peroxidase

GST: Glutathione S-transferase

HPLC: High performance liquid chromatography

HSD: Honest significant difference

LC-MS: Liquid chromatography-Mass spectrometry 
MDL: Minimum detection limit

MIC: Minimum inhibitory concentration

MS: Mass spectrometry

ROS: Reactive oxygen species

SCS: Single carbon source

SM: Serratia marcescens

SNS: Single nitrogen source

SPE: Solid phase extraction

TC: Tetracycline

TSB: Tryptic soy broth

WHO: World Health Organization

WWTP: Waste-water treatment plant 


\section{List of Figures}

Figure 1.1 Antibiotic exposure pathways........................................ 44

Figure 1.2 Structure of tetracycline .............................................. 45

Figure 1.3 Tetracycline degradation pathways.....................................46

Figure 2.1 Transformation of tetracycline in media samples........................73

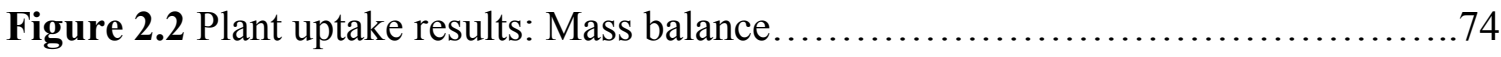

Figure 2.3 Plant uptake results: Translocation factor................................74

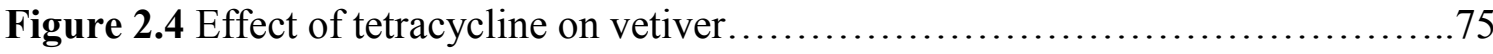

Figure 2.5 Heat maps of plant metabolomics........................................ 76

Figure 3.1 Growth study result of Serratia marcesens and Burkholderia cepacia in single carbon source medium supplemented with tetracycline $(1 \mathrm{~g} / \mathrm{L}) \ldots \ldots \ldots \ldots \ldots \ldots \ldots \ldots \ldots \ldots \ldots$ Figure 3.2 Tetracycline removal by Serratia marcescens and Burkholderia cepacia in single carbon source medium...................................................... 109 Figure 3.3 Tetracycline transformations by Serratia marcescens and Burkholderia cepacia in single carbon source medium........................................110

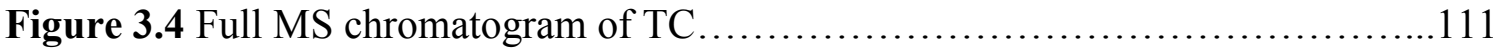

Figure 3.5 Growth study result of Serratia marcescens and Burkholderia cepacia in single nitrogen source medium..................................................113

Figure 4.1 Glutathione S-transferase activity results for Serratia marcescens and

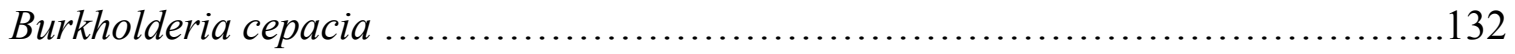

Figure 4.2 Glutathione S-transferase activity results for vetiver root.................133

Figure 4.3 Guaiacol peroxidase activity results for vetiver root.....................134 
Figure A.1.1 Total tetracycline concentration accounted at the end of hydroponic trial

Figure A.2.1 Full MS/MS chromatogram of anhydrotetracycline from tanks not treated with plant. 141

Figure A.3.1 Removal and transformation of tetracycline in tryptic soy broth medium (comparing light and dark)

Figure A.4.1 Removal and transformation of tetracycline in tryptic soy broth medium (with 5 ppm of TC).

Figure A.4.2 Removal and transformation of tetracycline in tryptic soy broth medium

(with $35 \mathrm{ppm}$ of TC)

Figure B.2.1 Initial bacterial screening growth study

Figure B.3.1 Growth study results of isolate \#1, \#2, and \#3 .................... 158

Figure B.4. 16S rRNA sequences....................................... 162

Figure B.4.3.1. Phylogenetic tree construction for Serratia marcescens...............166

Figure B.4.3.2. Phylogenetic tree construction for Serratia marcescens...............167

Figure B.5.1 Growth study result of Serratia marcescens and Burkholderia cepacia in tryptic soy broth medium with and without TC

Figure B.5.2 Growth study result of Serratia marcescens and Burkholderia cepacia in single carbon source medium with glucose

Figure B.6.1 Minimum inhibitory concentrations (of tetracycline) results of Serratia marcescens and Burkholderia cepacia.... 
Figure C.1.1 Tetracycline removal by Serratia marcescens and Burkholderia cepacia in tryptic soy broth medium..............................................182

Figure C.2.1 Tetracycline transformation by Serratia marcescens and Burkholderia cepacia in tryptic soy broth medium....................................... 183

Figure C.3.1.1 Heat map for B. cepacia extracellular metabolomics analysis...........189

Figure C.3.1.2Heat map for B. cepacia intracellular metabolomics analysis...........189

Figure C.3.1.3 Heat map for $S$. marcescens extracellular metabolomics analysis.......189

Figure C.3.1.4 Heat map for S. marcescens intracellular metabolomics analysis.......189 Figure D.1 pH optimization results of Serratia marcescens and Burkholderia cepacia in single carbon source medium.

Figure D.2 pH optimization results of Serratia marcescens and Burkholderia cepacia in

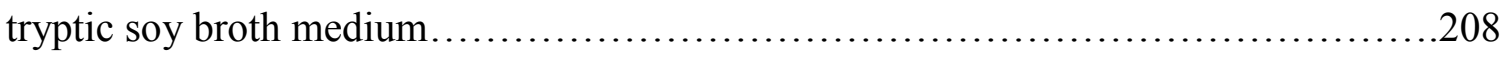

Figure D.3 pH optimization results of Serratia marcescens and Burkholderia cepacia in

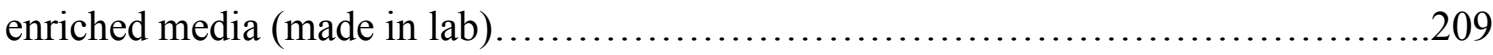

Figure D.4 Temperature optimization results of Serratia marcescens and Burkholderia cepacia in tryptic soy broth media........................................... 210

Figure D.5 Oxygen optimization results of Serratia marcescens and Burkholderia cepacia in single carbon source media.........................................211

Figure D.6 Growth results for isolate \#1, \#2, and \#3 (before adaptation).............212

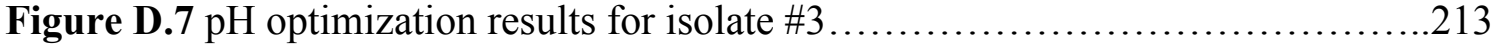

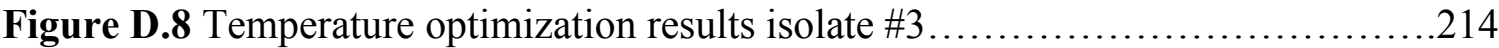

Figure D.9 Calculated growth rate constant curve for $\mathrm{pH}$ optimization study..........215 
Figure D.10 Calculated growth rate constant curve for temperature optimization

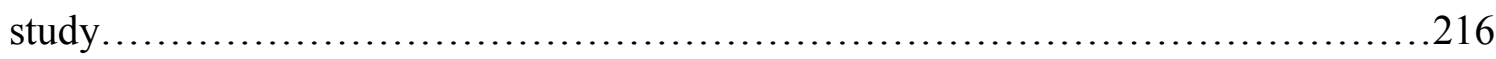

Figure D.11 Calculated growth rate constant results for optimized conditions in single

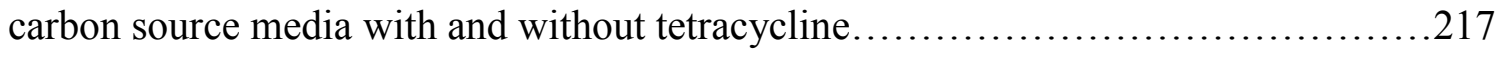

Figure D.12 Calculated growth rate constant results for optimized conditions in tryptic soy broth media with and without tetracycline...............................217

Figure E.2.1 GST activity in B. cepacia during its late-log phase ..................221 


\section{List of Tables}

Table 2.1 Metaboanalyst analyzed statistical significant plant metabolites............77

Table 3.1 Intracellular metabolomics results for Serratia marcescens and Burkholderia

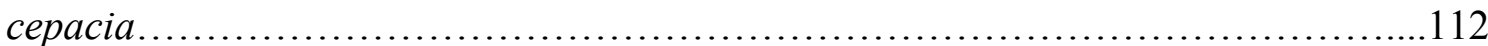

Table A.1.1 Tetracycline and its isomers epitetracycline detected in hydroponic

$\operatorname{tanks}$

Table A.5.1 Metabolites detected in plant roots treated with tetracycline

Table A.5.2 Metabolites detected in plant roots not treated with tetracycline

Table A.5.3 Fold change in metabolite concentration between roots treated with tetracycline vs. not treated with tetracycline

Table A.6.1 Statistical analysis details from 2-way Anova and Tukey's HSD test for TC disappearance in media samples (with vs. without plant tanks)

Table A.6.2 Table of $p$ values for TC disappearance compared in light vs. dark $\operatorname{tanks}$

Table A.6.3 Statistical analysis details from 2-way Anova and Tukey's HSD test for

phytotoxicity analysis.

Table B.1.1 Viable count results from media samples.

Table B.1.2 Viable count results from plant samples 153 
Table B.2.1 Direct count results from initial screening growth study... 156

Table B.3.1 Basic bacterial characterization results 160

Table B.4 MALDI-TOF and 16 Sinformation on unknown isolates 161

Table B.7 Growth rates of Serratia marcescens and Burkholderia cepacia from different growth studies

Table B.8.1 Statistical detailed results for SCS media (with TC) treated with B. cepacia vs. abiotic treatment 173

Table B.8.2 Statistical detailed results for TSB media (with TC) treated with B. cepacia vs. abiotic treatment flasks 175

Table B.8.3 Statistical detailed results for SCS media (with TC) treated with $S$. marcescens vs. abiotic treatment flasks.

Table B.8.4 Statistical detailed results for TSB media (with TC) treated with $S$. marcescens vs. abiotic treatment flaks

Table C.3.1 Burkholderia cepacia intracellular and extracellular metabolite table 185

Table C.3.2 Serratia marcescens intracellular and extracellular metabolite table 187

Table C.4.12 Composition of different media (used to grow bacteria) 190 
Table E.1 Catalase activity in vetiver root.

Table E.3.1 Table of p values from statistical analysis for bacterial samples (for GST

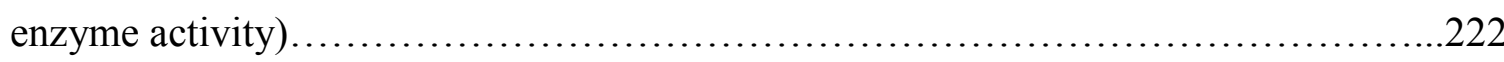

Table E.3.2 Table of $p$ values from statistical analysis for vetiver root samples (for GST

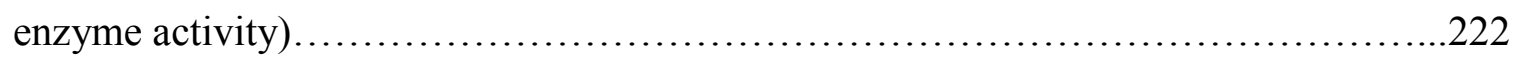




\section{Preface}

Several chapters included in this dissertation have been written and formatted with the purpose of publishing them in peer-reviewed journals.

- Chapter 2. "Tetracycline remediation and identification of tetracycline metabolites in aqueous systems using vetiver grass (Chrysopogon zizanioides L. Nash)" was written to be submitted to the "International Journal of Phytoremediation" and was prepared according to the journal's guidelines. The study was designed and conducted by Aparupa Sengupta with the help of Kate Waring and with the guidance from Susan Bagley and Rupali Datta. Conception of the project and technical help was provided by Rupali Datta and Dibyendu Sarkar. The manuscript was written by Aparupa Sengupta. All the other authors guided, edited and supported in the preparation of the manuscript. All authors read and approved the final manuscript.

- Chapter 3. "Role of vetiver (Chrysopogon zizanioides L. Nash) root-associated microbes in tetracycline degradation" was written to be submitted in "Journal of Applied and Environmental Microbiology" and was prepared according to the journal's guidelines. The study was designed and conducted by Aparupa Sengupta with guidance from Susan Bagley and Rupali Datta. The manuscript was written by Aparupa Sengupta. The other authors commented, guided, and supported in the preparation of the manuscript. All authors read and approved the final manuscript.

- Chapter 4. "Role of bacterial and vetiver (Chrysopogon zizanoides L. Nash) rootsecreted antioxidant enzymes in tetracycline degradation" was written to be 
submitted in "Science of the Total Environment" and was prepared according to the journal's guidelines. The study was designed and conducted by Aparupa Sengupta with guidance from Susan Bagley and Rupali Datta. The manuscript was written by Aparupa Sengupta. The other authors commented, guided, and supported in the preparation of the manuscript. All authors read and approved the final manuscript.

- Appendix D. "Optimization of tetracycline-detoxification conditions of bacterial strains recovered from vetiver (Chrysopogon zizanioides) root -zone was written to be submitted in "Journal of Industrial Microbiology and Biotechnology' and was prepared according to the journal's guidelines. The study was designed and conducted by Aparupa Sengupta with guidance from Susan Bagley and Rupali Datta. The manuscript was written by Aparupa Sengupta. The other authors commented, guided, and supported in the preparation of the manuscript. All authors read and approved the final manuscript. 


\section{Acknowledgements}

Emotions cannot be expressed in words accurately. I will still try to articulate my emotions to the best of my ability in form of this acknowledgment to appreciate everyone who believed in me and supported me to bring me to this day. Firstly, I would like to extend my gratitude and special thanks to my advisers Dr. Rupali Datta and Dr. Susan Bagley who have been tremendously supportive throughout my time as a Ph.D. student. They have not only presented me with a multitude of opportunities but also have helped me transform from a graduate student into a professional.

I would also like to thank my advisory committee; Dr. Rupali Datta, Dr. Susan Bagley, Dr. Dibyendu Sarkar, and Dr. Karl Indest. Their input, guidance and support were invaluable during my Ph.D. work. I really appreciate the time they took out of their busy schedules to be on my dissertation committee.

I would like to thank my lab groups from Dr. Datta's and Dr. Bagley's labs. A special mention to all my undergraduate research assistants Zack Anthony, Andrew Kennedy, Kate Waring, Mike Potes, Jen Connors, Jenny Isaacson, and Yuritzi Garcia, who have worked tirelessly on different aspects of my research project with me. I would also like to thank my peers and colleagues, Dr. Stephanie Groves, Dr. Kefeng Li, Claire Doskey, and Emily Bouckaert, for their support and help in different aspects of my project. A special mention of Jerry Lutz from the Dept. of Chemistry, for helping me with running my samples on liquid chromatography/ mass spectrometry and gas chromatography/mass spectrometry in their lab. 
I would like to thank all the groups/organizations that provided the financial resources that made it possible for me to conduct my research project smoothly and successfully, and present my work across the country. These resources included the teaching assistantship provided by the Dept. of Biological Sciences, Michigan Tech, a graduate research grant provided by Center for Water and Society, Michigan Tech, and travel grants provided by the Biotechnology Research Center and the Center for Water and Society. I would also like to take this opportunity to thank our Dept. chair, Dr. Shekhar Joshi, faculty members, and all the staff members of Dept. of Biological Sciences for their constant help and support throughout my Ph.D. career.

Last but never the least; I would like to thank my incredible family for their unconditional support and love. I would like to extend special thanks to my parents, Dilip and Tanusree Sengupta, and my sister, Dr. Anindita Roy, brother-in-law, Kaushik Roy and niece, Aishwarya, for being there for me through every thick and thin even from thousands miles away. This day wouldn't be a reality without their constant inspiration and encouragement.

Finally, I would like to mention that the last couple of years have not been easy, especially being so far apart from my country, family and loved ones. Without the help and moral support of my friends here at Michigan Tech, today's success would not have been possible. I would like to thank all my friends here at Tech for making my stay here such a pleasant and memorable one. 


\section{Abstract}

Antibiotics are emerging contaminants worldwide. Due to insufficient policy regulations, public awareness, and the constant exposure of the environment to antibiotic sources has created a major environmental concern. Wastewater treatment plants (WWTP) are not equipped to filter-out these compounds before the discharge of the disinfected effluent into water sources (e.g., lakes and streams) and current available technologies are not equipped to remediate these compounds from environmental sources. Hence, the challenge remains to establish a biological system to remove these antibiotics from wastewater. An invitro hydroponic remediation system was developed using vetiver grass (Chrysopogon zizanioides L. Nash) to remediate tetracycline (TC) from water. Comparative metabolomics studies were conducted to investigate the metabolites/pathways associated with tetracycline metabolism in plants and TCdegrading bacteria. The results show that vetiver plants effectively uptake tetracycline from water sources. Vetiver root-associated bacteria recovered during the hydroponic remediation trial were highly tolerant to $\mathrm{TC}$ (as high as $600 \mathrm{ppm}$ ) and could use $\mathrm{TC}$ as a sole carbon and energy source. Growth conditions $(\mathrm{pH}$, temperature, and oxygen requirement) for $\mathrm{TC}$-tolerant bacteria were optimized for higher $\mathrm{TC}$ remediation capability from water sources. The plant (roots and shoots) and bacterial species were further characterized for the metabolites produced during the TC degradation process using GC-MS to identify the possible biochemical mechanism involved. Also, the plant root zone was screened for metabolites/enzymes that were secreted during antibiotic degradation and could potentially enhance the degradation process. The root zone was 
selected for this analysis because this region of the plant has shown a greater capacity for antibiotic degradation compared to the shoot zone. The role of antioxidant enzymes in TC degradation process revealed glutathione-S-transferase (GSTs) as an important group of enzymes in both plant and bacteria potentially involved in TC degradation process. Metabolomics results also suggest potential GST activity in the TC remediation/ transformation process used by plants. This information could be useful in gaining insights for the application of biological remediation systems for the mitigation of antibiotics from waste-water. 


\section{Introduction}

Antibiotics are emerging contaminants and are considered a serious concern worldwide (Martinez, 2009). The World Health Organization (WHO) review states that every year there are 440,000 cases of multidrug-resistant tuberculosis (MDR-TB) reported and at least 150,000 of these cases result in death (WHO 2012, http://www.who.int/mediacentre/factsheets/fs194/en/). Excessive use of antibiotics, improper disposal, and lack of policy regulations pose a serious environmental and health concern.

Constant exposure to antibiotics in the environment not only disturbs natural ecological processes, but can also be fatal to humans in the form of multi-antibiotic resistant bacteria. These bacteria are present in environmental sources (e.g., water, soil, and sediments) and can readily transfer their resistance to pathogenic bacteria via horizontal gene transfer, resulting in a global antibiotic resistance problem (Martinez, 2009). The major challenge faced by WWTP facilities is that they are not equipped to remove antibiotics from the effluent. Hence, wastewater that is considered "treated" is still contaminated with antibiotics when it is released back into different water sources (streams, lakes, and rivers) (Watkinson et al., 2009).

The most common and broad spectrum antibiotics used for human health and veterinary purposes are penicillins, aminoglycosides and tetracyclines (Sarmah et al., 2006). Tetracyclines (TC) are a broad spectrum class of antibiotics and are widely used for veterinary and human health purposes (Ding and He, 2010; Kummerer et al., 2009; 
Sarmah et al., 2006). Under varying environmental conditions, TC can easily transform to its isomers, epi-TC (ETC) and anhydro-TC (ATC), and the process is usually $\mathrm{pH}$ mediated. Under $\mathrm{pH}$ 2-6, TC usually epimerizes reversibly to form ETC and 4-epi TC, and under higher acidic conditions, dehydration of TC take places and it changes form into ATC (Halling-Sørensen et al., 2002, Pena et al., 1998). Although formation of TC isomers usually takes place under acidic conditions, the epimerization of TC into ETC can also take place under neutral conditions (Halling-Sørensen et al., 2002). In some cases, TC isomers, ETC and ATC are more harmful than the parent compound itself (Jia et al., 2009). Hence, a decontamination system is required to clean-up TC and its isomers from various environmental sources.

In the last two decades, progress has been made to address the antibiotic contamination problems in many environmental sources using various remediation technologies. Several physical and chemical degradation methods such as chemical oxidation, adsorption, membrane filtration, ozonation, photo-fenton, and biotic degradation methods such as activated sludge, membrane reactor, and fixed bed reactor treatment have been applied to many antibiotics including TC with the purpose of degrading them in environmental sources (Ötker and Akmehmet-Balcioğlu, 2005, Elmolla et al., 2009, Homem et al., 2011, Ben et al., 2009, Kummerer et al., 2009). However, these remediation technologies are highly condition-based (e.g., $\mathrm{pH}$, and molar ratio) and potentially expensive based on the concentration of the contaminant present in the environmental source (antibiotic) that needs to be degraded. However, the biological remediation method using plants and microbes has several advantages over the 
conventional biotic, physical, and chemical methods. Phytoremediation combined with bioremediation methods do not require any specific condition (e.g., $\mathrm{pH}$, temperature, and molar ratio) to be applied in order to clean-up contaminated sites. With this combination of remediation methods the root-associated bacteria naturally helps the plants to take up the contaminant, and compared to the other methods (mentioned above) it is an inexpensive and effective technology (Gujrathi et al., 2005, Farkas et al., 2007, Park, 2010, Kummerer et al., 2009).

Phyto/microbial transformation studies can be used to understand the biochemical mechanism and enzyme/ metabolites involved in TC degradation vs. transformation (Gujrathi et al., 2005; Farkas et al., 2007; Dantas et al., 2008; Park and Choung, 2010). Using a metabolomics approach and by analyzing unknown metabolites present in plant and root-associated bacteria in presence of $\mathrm{TC}$, important pathways can be revealed that are used during TC degradation.

Vetiver (Chrysopogon zizanioides) grass has been used as a model organism for remediating tetracycline contaminated water system in this study, as it is a suitable candidate for phytoremediation (Troung et al., 2010). It is a subtropical/tropical grass with a deep and well developed root system (up to $3 \mathrm{~m}$ deep). It is a non-invasive species, has a very good adaptation capability in any climate (hot and cold), and is quite robust in extreme conditions (drought, flood, acidity, and alkalinity) (Troung et al. 2010). Vetiver has been well-studied world-wide as a model for phytoremediation of heavy metals and toxic contaminants because of these unique attributes (Makris et al., 2007, Truong et al., 2010). A preliminary study using vetiver grass in a hydroponic system to remediate TC 
contaminated water yielded promising results. TC was completely removed by the plant after 40 days in our lab (Datta et al., 2013).

In the last decade, there have been multiple attempts to remediate TC in environmental sources using both abiotic and biotic techniques. However, the degradation pathways associated with the breakdown/detoxification of these compounds and complete role of plant and/or microbes in the breakdown process is still not clear. The goal of this project was to establish a biological remediation system to decontaminate antibioticcontaminated wastewater using vetiver grass and rhizobacteria. Hence, a series of experiments were proposed to unravel the mechanism of bio-degradation/transformation pathway/s used by plant and microbes to breakdown this organic compound. The focus was also to understand the specific role of plant (vetiver) and/or microbes in the breakdown of this compound, and to identify the metabolites/enzymes/pathways associated with tetracycline degradation by using comparative metabolomics and enzymes assays in the plant tissues (root and shoot) and TC-degrading bacteria.

\section{References}

1. Ben W, Qiang Z, Pan X, Nie Y (2012) Degradation of veterinary antibiotics by ozone in swine wastewater pretreated with sequencing batch reactor. J. Environ. Eng. 138: 272-277.

2. Dantas G, Sommer MOA, Oluwasegun RD, Church GM (2008) Bacteria subsisting on antibiotics. Science 320:100-103. 
3. Datta R, P. Das, S. Smith, P. Punamiya, Ramanathan DM, Reddy R, Sarkar D (2013) Phytoremdiation potential of tetracycline by vetiver grass (Chrysopogan zizanioides L. nash) for tetracycline. Int. J. Phytorem. 15:343-351.

4. Ding, C., and He, J (2010) Effect of antibiotics in the environment on microbial populations. Appl. Microbiol. Biot. 87:925-941.

5. Elmolla ES, Chaudhuri M (2009) Degradation of the antibiotics amoxicillin, ampicillin and cloxacillin in aqueous solution by the photo-Fenton process. J. Hazard. Mater. 172: 1476-1481.

6. Farkas MH, Berry OM, Aga DS (2007) Chlorotetracycline detoxification in maize via induction of glutathione S-transferases after antibiotic exposure. Environ. Sci. Technol. 41:1450-1456.

7. Gujrathi NP, Haney B, Linden J (2005) Phytoremediation potential of M. aquaticum and $P$. stratiotes to modify antibiotic growth promoters, tetracycline, and oxytetracycline in aqueous wastewater systems. Int. J. Phytorem. 7:99-112.

8. Halling-Sørenson B, Sengelov G, Tjornelund J (2002) Toxicity of tetracycline degradation products to environmentally relevant bacteria, including selected tetracycline resistant bacteria. Arch. Environ. Con. Tox. 42: 263-271.

9. Homem V, Santos L (2011) Degradation and removal methods of antibiotic from aqueous matrices- A review. J. Environ. Manage. 92: 2304-2347.

10. Jia A, Xiaoa Y, Hua J, Asamib M, Kunikane S (2009) Simultaneous determination of tetracycline and their degradation products in environmental waters by liquid 
chromatography-electrospray tandem mass spectrometry. J. Chromatogr. 1216:46554662.

11. Kim K-R, Owens G, Kwon S-I, So K-H, Lee D-B, Ok YS (2011) Occurrence and environmental fate of veterinary antibiotics in the terrestrial environment. Water Air Soil Poll. 214:163-174.

12. Kummerer, K (2009) Antibiotics in the aquatic environment-A review-Part I. Chemosphere 75:417-434.

13. Makris KC, Shakya K, Datta R, Sarkar D, Pachanoor D (2007) High uptake of 2,4,6 TNT by vetiver grass-Potential for phytoremediation? Environ Pollut. 146:1-4.

14. Martinez JL (2009) Environmental pollution by antibiotics and by antibiotic resistance determinants. Environ. Pollut. 157:2893-2902.

15. Ötker HM, Akmehmet-Balcioğlu (2005) Adsorption and degradation of enrofloxacin, a veterinary antibiotic on natural zeolite. J. Hazard. Mater. 122: 251258.

16. Park H (2012) Reduction of antibiotics using microorganisms containing glutathione S-transferases under immobilized conditions. Environ. Toxicol. Pharmacol. 34: 345350.

17. Park H, Choung YK (2010) Evaluation of the biodegradation feasibility of antibiotics by three bacteria involving glutathione S-transferases. Can. J. Civil Eng. 37:814-819.

18. Pena A, Carmona A, Barbosa A, Lino C, Silveira I, Castillo B (1998) Determination of tetracycline and its major degradation products by liquid chromatography with fluorescence detection. J. Pharmaceut. Biomed.18:839-845. 
19. Sarmah AK, Meyer MT, Boxall AB (2006) A global perspective on the use, sales, exposure pathways, occurrence, fate and effects of veterinary antibiotics (Vas) in the environment. Chemosphere. 65:725-759.

20. Truong PNV, Foong YK, Guthrie M, Hung Y-T (2010) Phytoremediation of heavy metal contaminated soils and water using vetiver grass, p.233-275. In L.K. Wang, JW. Tay, S.T.L. Tay, Y-T. Hung (ed.), Environmental Bioengineering, Handbook of Environmental Engineering, Vol. 11. Humana Press, New York, NY.

21. Watkinson A.J., Murby EJ, Koplin DW, Costanzo SD (2009) The occurrence of antibiotics in an urban watershed: From wastewater to drinking water. Sci. Total Environ. 407:2711-2723. 


\section{Dissertation Objectives}

The overall goal of this project was to develop a biological remediation system involving vetiver grass and its root-associated bacteria to decontaminate tetracycline (TC) from contaminated water systems. The specific objectives of the project were as follows:

Objective 1: Evaluate the remediation potential of vetiver grass in the tetracycline contaminated water system and identify TC degradation metabolites in plant tissues and contaminated water.

Objective 2: Recover, identify and characterize vetiver root-associated bacteria and determine their role in TC degradation.

2.1. Evaluate if vetiver root-associated bacteria are TC resistant and can utilize TC as their carbon/nitrogen source.

2.2. Evaluate the role of bacteria in TC degradation.

Objective 3: Evaluate the role of vetiver root and root associated microbe secreted enzymes/ metabolites in TC degradation.

3.1. Evaluate if vetiver roots and root-associated bacteria produce stress-induced enzymes/metabolites that may play a role in degradation of $\mathrm{TC}$ in the water systems. 
Objective 4: Identify the metabolites/ pathways associated with TC degradation in plants and rhizospheric bacteria using comparative metabolomics.

4.1. Analyze vetiver root and root-associated bacteria in the presence of $\mathrm{TC}$ using metabolic profiling. 


\section{CHAPTER 1: Literature Review}

\section{- Antibiotic contamination and statement of the problem}

Antibiotics, naturally produced by microorganisms, are important compounds that are effective against bacteria that cause diseases. Wide usage and improper handling and disposal of antibiotics over decades have created environmental concern worldwide. Although antibiotics have been present in the environment for quite some time, their long-term impact on the environment and human health was not studied until recently (Kim et al., 2011, Kummerer et al., 2009). Antibiotics are discarded from a number of sources (hospitals, industries, animal farms, and households) eventually end up in water, soil and sediments (Kummerer et al., 2004, Thiele- Bruhn et al., 2003), mainly due to the lack of regulations. Current reviews report the global challenges of antibiotic contamination in various environmental sources, which cause ecological imbalance, including uptake of antibiotics by food crops irrigated with water contaminated with antibiotics (Michael et al., 2013, Rehman et al., 2013, Boonsaner et al., 2012). Usually antibiotics are present in such low levels in the environment that it is very difficult to measure them. However, with the advent of high performance liquid chromatography (HPLC) and mass spectrometry-mass spectrometry (MS-MS), low levels of antibiotics are now being detected.

Figure 1.1 shows the antibiotic exposure pathway and entry of antibiotics from WWTP into different environmental sources (soil, water sources). WWTPs are typically not equipped to remove these compounds, so the antibiotic contaminated water is released 
back into different water sources (Xie et al., 2011,Kummerer et al., 2004, Boxall et al., 2004, Fatta-Kassinos et al., 2011, Le-Minh et al., 2010, Martines et al., 2009, Batt et al., 2006, Christian et al., 2003). The consequences of constant exposure to antibiotics in the environment are: 1) development of multi-antibiotic resistant bacteria, 2) potential negative health impact on humans and animals, 3) perturbed aquatic life and 4) a disturbed ecosystem (Boxall 2004, Baquero et al., 2008, Thiele-Bruhn 2003). Antibiotic resistance is commonly acquired by non-pathogenic soil bacteria due to the continuous exposure to antibiotics (Kummerer et al., 2004). However, due to close phylogenetic relationships among bacteria, it is possible for non-pathogenic bacteria to transfer the antibiotic resistant gene/s to pathogenic bacteria (Dantas et al., 2008).

The most common and broad spectrum antibiotics used for human health and veterinary purposes are penicillins, aminoglycosides and tetracyclines. (Sarmah et al., 2006). Among these, the most studied group of antibiotics are ß-lactam / penicillins. The common degradation products of penicillin are penilloic acid, penicillamine, and penicilloadlehyde, which are formed by highly unstable intermediates penillic acid, penicilloic acid and penicillenic acid (Dantas et al., 2008, Deshpande et al., 2004).

Tetracyclines (TC, CTC, OTC) are commonly used for veterinary and human disease control purposes (Ding and He, 2010, Kumar et al., 2005). They are also used as growth promoters in animal farms. They are broad spectrum antibiotics and effectively used against both gram-positive and gram-negative bacteria. They have a partially conjugated four ring structure with a carboximide functional group. The chemical formula of 
tetracycline is $\mathrm{C}_{22} \mathrm{H}_{24} \mathrm{~N}_{2} \mathrm{O}_{8}$, oxy-tetracycline is $\mathrm{C}_{22} \mathrm{H}_{24} \mathrm{~N}_{2} \mathrm{O}_{9}$, and chloro-tetracycline is $\mathrm{C}_{22} \mathrm{H}_{23} \mathrm{C}_{1} \mathrm{~N}_{2} \mathrm{O}_{8} \bullet \mathrm{HCl}$. The general skeleton of TC is presented in figure 1.2.

These compounds are commonly detected in the environment (wastewater, surface water,

drinking water, soil and sediments) (Sarmah et al., 2006). Although concentrations of TCs are relatively low (110-400 $\mathrm{ng} / \mathrm{L}$ ) in environmental sources (ground water, surface water; Boxall et al., 2004, Krapac et al., 2005), the long-term and constant exposure of these antibiotics has several adverse impacts on human, animals, and on ecosystem functions.

\section{- Bio-transformation vs. Bio-degradation}

As per the definition provided by USEPA, biodegradation is the process in which microorganisms can alter the structure of a chemical/compound either during a metabolic process or during an enzyme-mediated reaction (http://toxics.usgs.gov/definitions/biotransformation.html). However, the biotransformation process is the structural alteration of a compound in a natural (depending on $\mathrm{pH}$, temperature) condition, which is usually not mediated by a biological process (Halling-Sørensen et al., 2002, Jia et al., 2009). The result of bio-transformation is sometimes isomerization of the compound, and under some circumstances, the isomer could be more harmful than the parent compound itself.

In the field of antibiotic remediation, the term (bio) degradation is often used loosely. Most studies mostly refer to the chemical transformation process, which are isomeric structural changes in the compounds (which are not mediated biologically) (Halling- 
Sørensen et al., 2002, Jia et al., 2009,Pena et al., 1998, O’Connor et al., 2007). Common transformation products of TC are ETC, 4-ETC, and ATC. Usually transformation of TC is $\mathrm{pH}$ mediated, as the acidic ( $\mathrm{pH} 2-6)$ condition causes epimerization and dehydration reactions to occur. However, epimerization of TC and formation of ETC can also occur under neutral conditions (pH 7-7.5) (Halling-Sørensen et al., 2002).

The chemical structure of TC and its transformed products are explained by Jia et al., 2009. Other TC groups of compounds (CTC and OTC) follow the same trend as TC in terms of formation of transformation products (as described in fig. 1.3) as reported in several studies under various pH conditions. (Pena et al., 1998, Halling-Sørensen et al., 2002, Jia et al., 2009).

The degradation/transformation metabolites identified are infact isomers of the parent compounds. The actual degradation products of TCs by enzymatic/non-enzymatic breakdown have not been identified yet.

\section{- Remediation strategies for biodegradation}

Recently, there have been several studies describing the removal techniques of different antibiotics in nature using biotic and abiotic methods (Jiang et al.,. 2010, Elmolla et al., 2009, Onesios et al., 2009, Kummerer et al., 2009 a \& b). The conventional methods used to degrade antibiotics are sorption, hydrolysis, photolysis, oxidation and reduction (Kummerer et al., 2009). However, there are some limitations associated with these methods. They are expensive, unsustainable and are all condition based (e.g., pH, temperature, composition of matrix, and latitude) (Kummerer et al., 2009) Hence, there is 
a need for an inexpensive biotic degradation method for remediating these antibiotics from environment. It is important that the technology is sustainable so that it is not only inexpensive, but also provides complete removal/ degradation of the contaminant without having any adverse effects on the environment. There are several studies which describe the antibiotic remediation potential of various plants along with plants and /or microbes (Dolliver et al., 2007 Gujrathi et al., 2005, Farkas et al., 2007, Park, 2010, Kummerer et al., 2009, Nnenna et al., 2011).

An interesting study by Dantas et al., 2008, showed the role of antibiotic-resistant bacteria in the complete degradation of antibiotics. The study showed that bacteria that are resistant to antibiotics can actually subsist on them, and hence degrade them in the media over time. These resistant bacteria break down penicillin to benzylpenilloic acid, formed by an intermediate, benzylpenicilloic acid. Depending on the degradation product, they proposed a possible penicillin catabolic pathway.

However, a recent publication by Walsh et al. (2013) challenges the concept of Dantas et al., 2008, by showing contradictory results and disproving the concept of antibiotic catabolizing ability of resistant bacteria shown by the earlier study. This study reports that soil bacteria that exhibit the antibiotic catabolizing phenotype do not actually catabolise antibiotics. The antibiotics used in this study were penicillin, carbenicillin, streptomycin, and trimethoprim and the authors reported the involvement of a generic resistance mechanism (like $\beta$ - lactamse activity for penicillin) in the degradation of these antibiotics. 
- Root-secreted metabolites/enzymes and microbial enzymes and their role in antibiotic degradation

Studies involving phyto-transformation and/or microbial-transformation can identify enzymes/metabolites produced by plants and bacteria that may play a role in TC degradation. The phytoremediation studies on Halianthus annus used for TC degradation show that the reactive oxygen species (ROS) present in the plant root may be involved in the oxidative degradation of TCs (Gujrathi et al., 2005). Reactive oxygen species formation is usually related to a stress condition and lack of oxygenation. Antioxidant enzymes inhibit the formation of ROS species (Blokhina et al., 2003). Plant studies on maize (Zea mays) show that glutathione-S-tranferases (GSTs - stress-induced enzymes) may be associated with the plant root when detoxifying TCs (Farkas et al., 2007). The study reports that root exudates (prepared from hairy root culture) of maize produced GST that effectively detoxified the TC group of antibiotics. Studies by Gujrathi et al., (2005) and Gujrathi and Linden (2005) have shown that under stress conditions hairy roots of Helianathus annuus produce antioxidants. Some of the antioxidant enzymes are ascorbate peroxidase (APX), catalase (CAT), and guaiacol peroxidase (GPX). This was shown by the in the native antioxidant enzyme activity of the plant species.

Bacterial GSTs also play an important role in degradation of xenobiotics and the protection of the cell against oxidative damage and other potential damages (Allocati et al., 2009). The role of microbial GST activity in TC degradation is also evident from a study (Park and Choung, 2010) that showed three bacteria species with enhanced GST activity efficiently reduced the concentration of antibiotics (tetracycline, ampicillin and 
sulfathiazole). In a recent study by Park, 2012, it was demonstrated that bacterial GSTs not only reduced the inhibitory effect of antibiotics but could also successfully remove antibiotics in a bioreactor. These studies on plants and microbes indicate the role of GSTs and other antioxidant enzymes (GPX and CAT) in TC degradation.

- Plant and microbial metabolomics and antibiotic degradation pathway analysis

To study the interaction between an organism and its environment in a given condition pertaining to its metabolite level is defined as environmental metabolomics (Viant et al., 2012). Environmental metabolomics gives a global view of different metabolites that are expressed in the cell during a particular biochemical process, which also helps in identifying the pathway that plays a key role during that particular environmental condition (Viant et al., 2012). By understanding the metabolic profile of an organism, the intermediary enzymes could be identified and their expression level could be quantified using MS coupled with gas chromatography (GC). This information can then be related to the biochemical pathway that may be associated with the process (Dunn et al., 2013, Lisec et al., 2006). Metabolomics studies have been conducted to evaluate metabolite profiles of different organisms (plant and bacteria) under variousenvironmental conditions [e.g., plants under metal stress and bacteria recovered from metal contaminated soil $(\mathrm{Li}, 2012)]$. However, there are no specific metabolic profiling data available on bacteria or plants in presence of any antibiotic. A review article by Villas-Bôas and Bruheim (2007) states that metabolomics is a useful tool in the 
field of bioremediation studies. They clarify how the metabolomics approach can be utilized in the field of therapeutics, biomarker discovery, and cancer therapy. Also, the metabolomics approach can reveal the degradation pathway of xenobiotic compounds. According to a recent published review by Brunetti et al. (2013), plant environmental metabolomics is a developing field of study and can be used to understand the physiology of the plant under certain ecological stresses with unique laboratory based methods. They also described how this process would be useful in developing an understanding of metabolism and production of various secondary metabolites in the plants under various environmental conditions. Previously, studies have been conducted to understand the role of different plants and microbes in antibiotic degradation and/or transformation (Gujrathi et al., 2005, Farkas et al., 2007, Datta et al., 2012, Dantas et al., 2008). However, none of these studies have reported an antibiotic degradation pathway used by a plant and its root-associated bacteria using a metabolomics approach.

Vetiver root-associated microbial dynamics have been previously studied for the purpose of understanding oil metabolism by Guidice et al., (2008). However, vetiverroot associated microbial flora has never been explored for their role in any xenobiotic/ contaminant degradation. This is a novel work to understand the biochemical mechanisms and identify the metabolites associated with tetracycline degradation/transformation in vetiver grass and tetracycline- tolerant root-associated bacteria.

\section{References:}

1. Allocati N, Federici L, Masulli M, IIio CD (2009) Glutathione transferases in bacteria. FEBS J. 276: 58-75. 
2. Baquero F, Martinex J-L, Canton R (2008) Antibiotic and antibiotic resistance in water environments. Curr. Opin. Biotech. 19:260-285.

3. Batt AL, Bruce IB, Aga DS (2006) Evaluating the vulnerability of surface waters to antibiotic contamination from varying wastewater treatment plant discharges. Environ Pollut. 142:295-302.

4. Blokhina O, Virolainen E, Fagerstedt KV (2003) Antioxidants, oxidative damage and oxygen deprivation stress: a review. Ann. Bot. 91:179-194.

5. Boonsaner M, Hawker DW (2012) Investigation of the mechanism of uptake and accumulation of zwitterionic tetracyclines by rice (Oryza sativa L.). Ecotox. Environ. Safe. 78: 142-147

6. Boxall ABA (2004) The environmental side effects of medication. EMBO J. 5:11101116.

7. Brunetti C, George RM, Tattini M, Field K, Davey MP (2013) Metabolomics in plant environmental physiology. J. Exp. Bot. doi:10.1093/jxb/ert244

8. Christian T, Schneider R, Farber HA, Skutlarek D, Meyer M, Goldbach HE (2003) Determination of antibiotic residues in manure, soil and surface waters. Acta Hydroch. Hydrob. 31:36-44.

9. Dantas G, Sommer MOA, Oluwasegun RD, Church GM (2008) Bacteria subsisting on antibiotics. Science. 320:100-103. 
10. Datta R, Das P, Smith S, Punamiya P, Ramanathan DM, Reddy R, Sarkar D (2013) Phytoremdiation potential of tetracycline by vetiver grass (Chrysopogan zizanioides(L.) for tetracycline. Int. J. Phytorem. 15:343-351.

11. Desphpande AD, Baheti KG, Chatterjee NR (2004) Degradation of B-lactam antibiotics. Curr. Sci. 87:1684-95.

12. Ding C, He J (2010) Effect of antibiotics in the environment on microbial populations. Appl. Microbiol. Biot. 87:925-941.

13. Dolliver H, Kumar K, Gupta S (2007) Sulfamethazine uptake by plants from manureamended soil. J. Environ. Qual. 36:1224-1230.

14. Dunn WB, Hankemeier T (2013) Mass spectrometry and metabolomics: past, present and future. Metabolomics. 9:S1-S3

15. Elmolla ES, Chaudhuri M (2009) Degradation of the antibiotics amoxicillin, ampicillin and cloxacillin in aqueous solution by the photo-Fenton process. J. Haz. Mater.172: 1476-1481

16. Farkas MH, Berry OM, Aga DS (2007) Chlorotetracycline detoxification in maize via induction of glutathione S-transferases after antibiotic exposure. Environ. Sci Technol. Lett. 41:1450-1456.

17. Fatta-Kassinos D, Kalavrouziotis IK, Koukoulakis PH, Vasquez MI (2011) The risk associated with wastewater reuse and xenobiotics in the agroecological environment. Sci. Total Environ. 409:3555-3563. 
18. Giudice LD, Massardo DR, Pontieri P, Bertea CM, Mombello D, Carata E, Tredici SM, Tala A, Mucciarelli M, Groudeva VI, Stefano MD, Vigiliotta G, Maffei ME, Alifano P (2008) The microbial community of vetiver root and its involvement into essential oil biogenesis. Environ. Microbiol. 10: 2824-2841.

19. Gujrathi NP, Haney B, Linden J (2005) Phytoremediation potential of M.aquaticum and $P$. stratiotes to modify antibiotic growth promoters, tetracycline, and oxytetracycline in aqueous wastewater systems. Int J Phytorem. 7:99-112.

20. Halling-Sørenson B, Sengelov G, Tjornelund J (2002) Toxicity of tetracycline degradation products to environmentally relevant bacteria, including selected tetracycline resistant bacteria. Arch. Environ. Contam. Toxicol. 42: 263-271

21. Jia A, Xiaoa Y, Hua J, Asamib M, Kunikane S (2009) Simultaneous determination of tetracycline and their degradation products in environmental waters by liquid chromatography-electrospray tandem mass spectrometry. J. Chromatogr. 1216:46554662.

22. Jiang M, Wang L, Ji R (2010) Biotic and abiotic degradation of four cephalosporin antibiotics in a lake surface water and sediment. Chemosphere. 80:1399-405.

23. Kim K-R, Owens G, Kwon S-I, So K-H, Lee D-B, Ok YS (2011) Occurrence and environmental fate of veterinary antibiotics in the terrestrial environment. Water Air Soil. Poll. 214:163-174. 
24. Kumar K, Gupta SC, Chander Y, Singh AK (2005) Antibiotic use in agriculture and its impact on the terrestrial environment. Adv. Agron. 87: 1-54.

25. Kummerer K (2009 a) Antibiotics in the aquatic environment-A review-Part I. Chemosphere. 75:417-434.

26. Kummerer K (2009 b). The presence of pharmaceuticals in the environment due to human use-present knowledge and future challenges. J. Environ. Manage. 90:23542366.

27. Kummrer K (2004) Resistance in the environment. J. Antimicrob. Chemoth. 54:311320.

28. Le-Minh N, Khan SJ, Drews JE, Stuetz RM (2010) Fate of antibiotics during municipal water recycling treatment processes. Water Res. 44:4295-4323.

29. Lisec J, Schauer N, Kopka J, Willmitzer L, Fernie AR (2006) Gas chromatography mass spectrometry-based metabolite profiling in plants. Nature Protocols. 1: 387-396.

30. Martinez JL (2009) Environmental pollution by antibiotics and by antibiotic resistance determinants. Environ. Pollut. 157:2893-2902.

31. Michael I, Rizzo L, McArdell CS, Manaia CM, Merlin C, Schwartz T, Dagot C, Fatta-Kassinos D (2013) Urban wastewater treatment plants as hotspots for the release of antibiotics in the environment: A review. Wat. Res. 47: 957-995.

32. Nnenna F-P, Lekiah P, Obemeata O (2011) Degradation of antibiotics by bacteria and fungi from the aquatic environment. J Tox. Env. Health Sci. 3:275-285. 
33. O'Connor S, Aga DS (2007) Analysis of tetracycline antibiotics in soil: Advances in extraction, clean-up, and quantification. Trend. Anal. Chem. 26: 456-465.

34. Park H, Choung YK (2010) Evaluation of the biodegradation feasibility of antibiotics by three bacteria involving glutathione S-transferases. Can. J. Civil Eng. 37:814-819.

35. Park H (2012) Reduction of antibiotics using microorganisms containing glutathione S-transferases under immobilized conditions. Environ. Toxicol. Phar. 34:345-350.

36. Pena A, Carmona A, Barbosa A, Lino C, Silveira I, Castillo B (1998) Determination of tetracycline and its major degradation products by liquid chromatography with fluorescence detection. J. Pharmaceut. Biomed. 18:839-845.

37. Rehman MSU, Rashid N, Ashfaq M, Saif A, Ahmad N, Han J-I (2013) Global risk of pharmaceutical contamination from highly populated developing countries. Chemosphere. http://dx.doi.org/10.1016/j.chemosphere.2013.02.036

38. Sarmah AK, Meyer MT, Boxall AB (2006) A global perspective on the use, sales, exposure pathways, occurrence, fate and effects of veterinary antibiotics (Vas) in the environment. Chemosphere. 65:725-759.

39. Thiele- Bruhn S (2003) Pharmaceutical antibiotic compounds in soils-a review. J Plant Nutr. Soil Sci. 166:145-167.

40. Truong PNV, Foong YK, Guthrie M, Hung Y-T (2010) Phytoremediation of heavy metal contaminated soils and water using vetiver grass, p.233-275. In L.K. Wang, JW. Tay, S.T.L. Tay, Y-T. Hung (ed.), Environmental Bioengineering, Handbook of Environmental Engineering, Vol. 11. Humana Press, New York, NY. 
41. Viant MR, Sommer U (2013) Mass spectrometry based environmental metabolomics: a primer and review. Metabolomics. 9:S144-S158.

42. Villas- Bôas SG, Bruheim P (2007) The potential of metabolomics tools in bioremediation studies. OMICS J. Integr. Biol. 11: 305-313.

43. Watkinson A.J., Murby EJ, Koplin DW, Costanzo SD (2009) The occurrence of antibiotics in an urban watershed: From wastewater to drinking water. Sci. Total Environ. 407:2711-2723.

44. Xie X, Zhou Q, Lin D, Guo J (2011) Toxic effect of tetracycline exposure on growth, antioxidative and genetic indices of wheat (Triticum aestivum L.). Environ. Sci. Pollut. Res. Int. 18:566-575. 


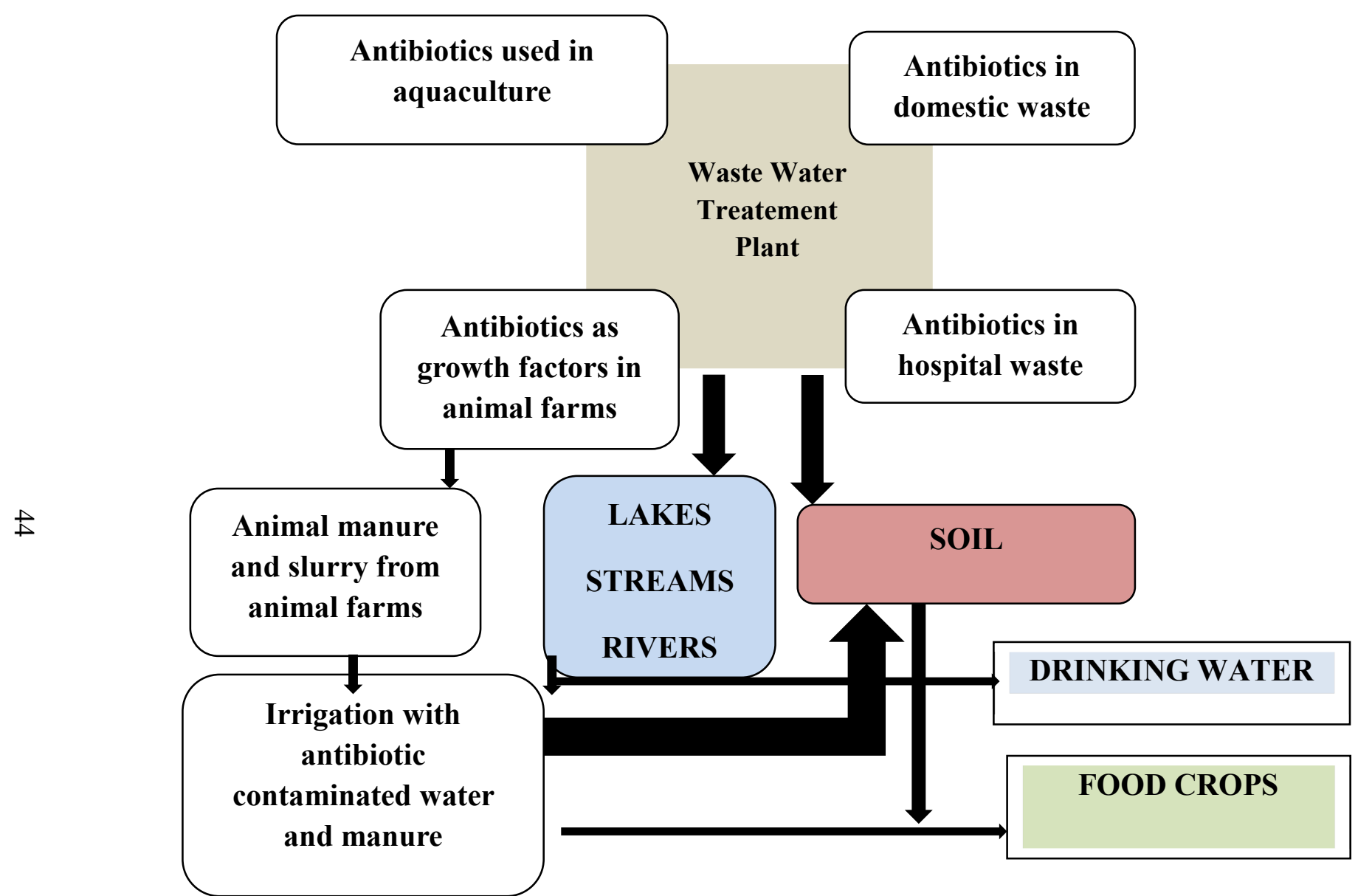

Figure 1.1. Antibiotic exposure pathway and entry into different environmental sources (modified from Xie et al., 2011, Fatta -Kassinos et al., 2011, Boxall et al., 2004, Kummerer et al., 2004) 


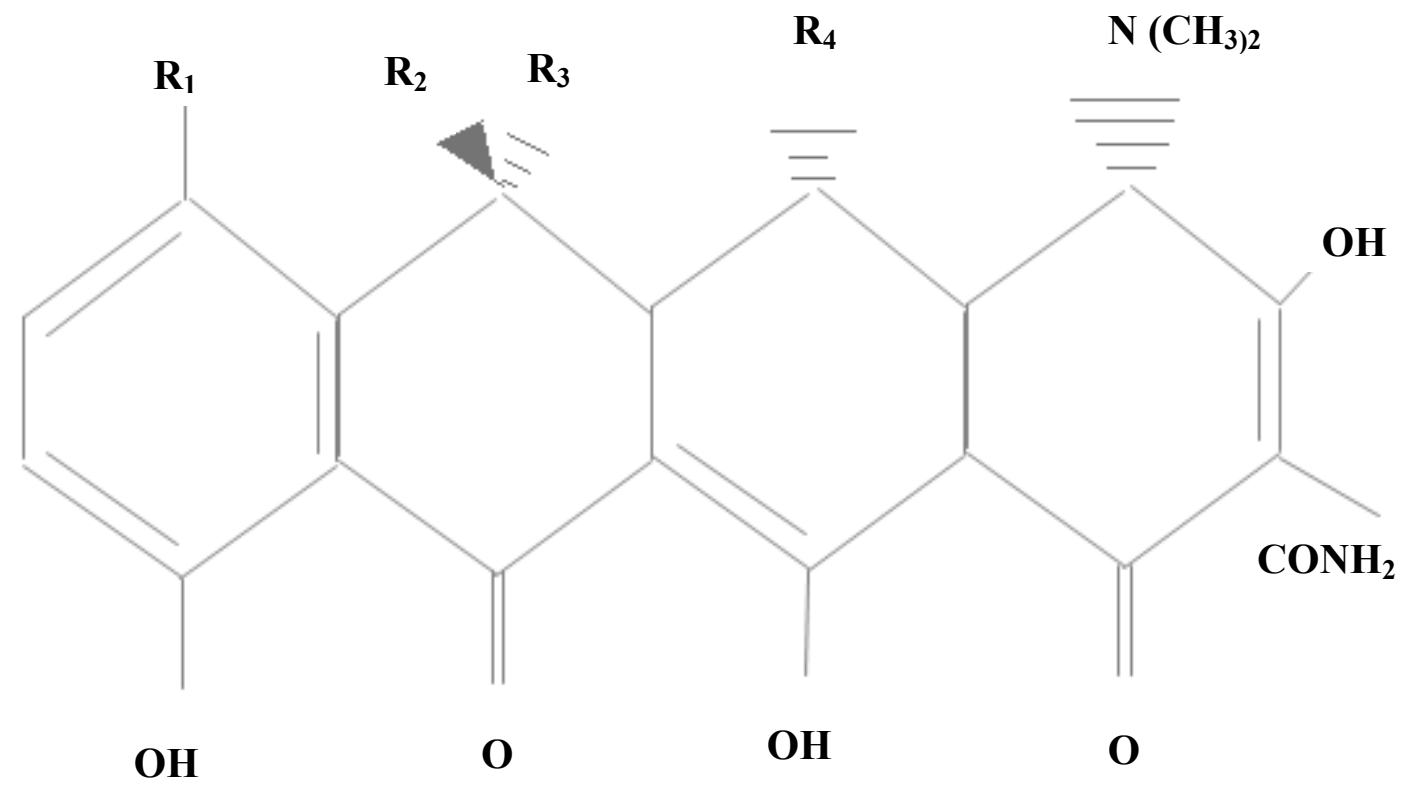

Figure 1.2 Structure of Tetracycline 


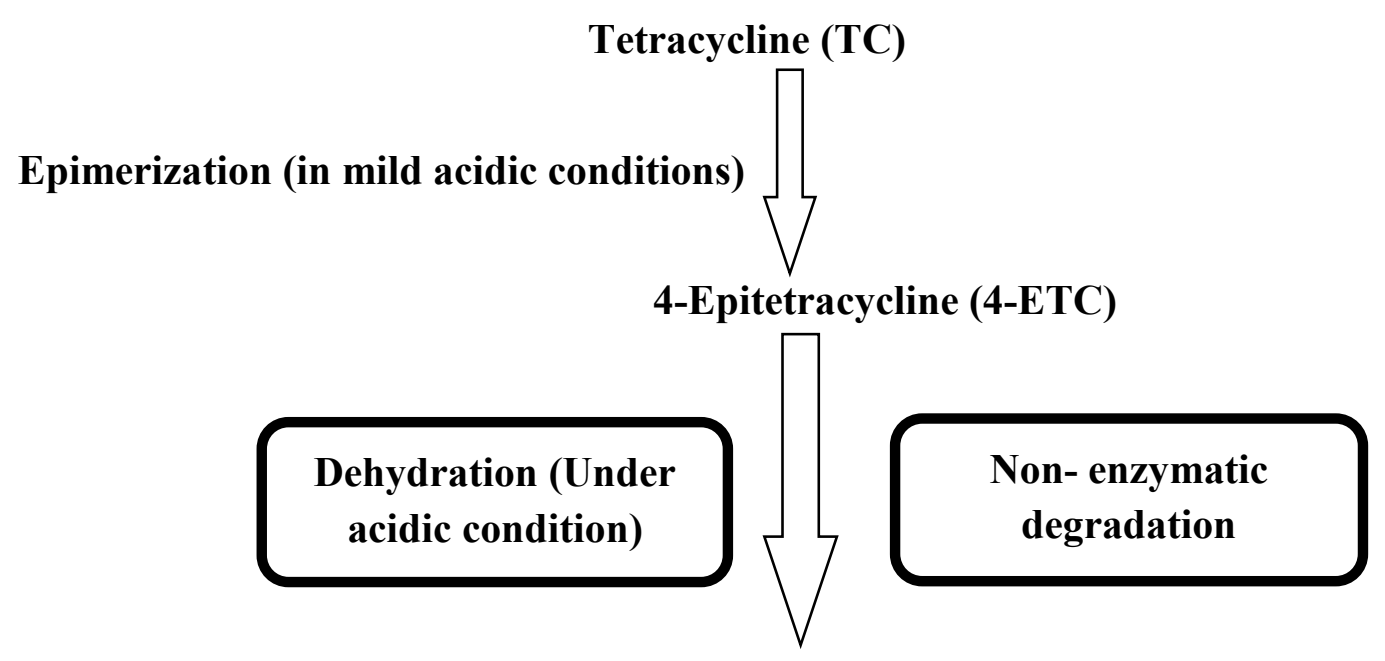

4-Epianhydrotetracycline (4-EATC)

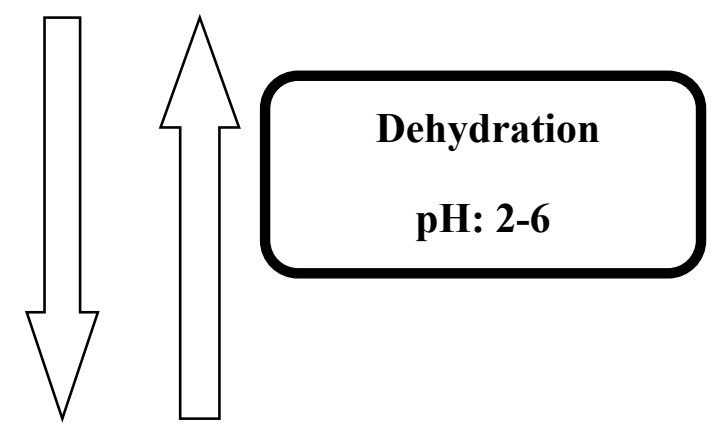

Anhydrotetracycline (ATC)

Figure 1.3. TC transformation pathway (modified from Pena et al., 1998, HallingSørensen et al., 2002, Jia et al., 2009) 
CHAPTER 2. Tetracycline remediation and identification of tetracycline metabolites in aqueous systems using vetiver grass (Chrysopogon zizanoides L. Nash) ${ }^{\mathrm{a}}$

The study was designed and conducted by Aparupa Sengupta with the help of Kate Waring and with guidance from Susan Bagley and Rupali Datta. Rupali Datta and Dibyendu Sarkar helped in the conception of the study and provided technical support. The manuscript was written by Aparupa Sengupta. All the other authors guided, edited, and supported in the preparation of the manuscript.

\section{Supplementary results are presented in appendix A.}

Appendix A is divided into six parts:

A.1. Total TC concentrations in hydroponic tanks ( $75 \pm 5 \mathrm{ppm}$ TC used $)$

A.2. MS/MS results for hydroponic tanks (with $75 \pm 5 \mathrm{ppm}$ TC) without plants on day 30

A.3. Hydroponic remediation study with TC comparing light vs. dark condition

A.4. Hydroponic remediation studies results with varying TC concentrations $(0,5,35$ ppm)

A.5. Metabolites detected during metabolic profiling in vetiver in the presence of TC (75 ppm) vs. control (no TC)

A.6. Statistical analysis detailed results from 2-way Anova and Tukey's HSD test

${ }^{a}$ The following document is to be submitted for publication in the International Journal of Phytoremediation. 
Chapter 2. Tetracycline remediation in aqueous systems and identification of tetracycline metabolites using vetiver grass (Chrysopogon zizanoides L. Nash)

Aparupa Sengupta ${ }^{1}$, Kate Waring ${ }^{1}$, Dibyendu Sarkar ${ }^{2}$, Susan Bagley ${ }^{1}$, and Rupali Datta ${ }^{1}$

${ }^{1}$ Michigan Technological University, Houghton, MI, 49931-1295 USA.

${ }^{2}$ Montclair State University, Montclair, NJ 07043

Corresponding Author: Aparupa Sengupta, asengupt@mtu.edu, (906)-370-8593

\begin{abstract}
Environmental contamination by antibiotics not only perturbs the ecological balance, but also adversely impacts human health by promoting the growth of multi-antibiotic resistant bacteria. This study focuses on determining the potential of using vetiver grass (Chrysopogon zizanoides L. Nash) to remediate tetracycline (TC), a broad-spectrum antibiotic widely used in humans and animals. A hydroponic remediation system using vetiver grass was used to monitor uptake and transformation of TC $(0,5,35,75 \mathrm{ppm})$ over a 30 day period. A method was developed by optimizing the conditions suitable for eluting TC and its isomers anhydrotetracycline (ATC) and epitetracycline (ETC) on a C18 column using isocratic and gradient elution in HPLC and LC-MS/MS. Transformation of TC (media samples) mainly occurred during the first 5 days. The HPLC data indicated that there was a decrease in the parent compound and an increase in the concentration of the isomers (ATC and ETC) between 5 and 15 days. Concentrations of ATC and ETC decreased and eventually disappeared from the tanks treated with plants between 15 and 30 days. Pathway analysis in vetiver identified glutathione detoxification
\end{abstract}


as a possible mechanism involved in TC remediation. Keywords: Teteracycline (TC), Vetiver, Antibiotics, Water sources, Phytoremediation

Introduction

Antibiotics have been regarded as emergent contaminants and are a global concern (Rehman et al., 2013, Kummerer et al., 2009 a\&b). Antibiotics are detected in various environmental sources (Sarmah et al., 2006, Hu et al., 2010, Fatta-Kassinos et al., 2011) as there are no strict policy regulations for handling and disposal of these compounds and furthermore wastewater treatment plants are not equipped to decontaminate water from these compounds (Boxall, 2004, Michael et al., 2013). Current literature reviews state that antibiotic contamination in environmental sources causes an ecological imbalance and adversely impacts human on a global scale (Michael et al., 2013, Rehman et al., 2013; Kim et al., 2011). Also, plants can uptake antibiotics when irrigated with antibiotic-contaminated manure, water, and soil, and if ingested could potentially be harmful for human and animal health (Boonsaner et al., 2012, Chitescu et al., 2012, Holling et al., 2012, Moshe et al., 2011, Kumar et al., 2005)

Tetracycline (TC) is commonly used in human and veterinary medicine. It has been detected in many environmental sources such as water and animal manure. TC generally breaks down to its isomers; epi-TC (ETC) and anhydro-TC (ATC). When the pH ranges from 2-6, the epimerization of TC forms ETC and the hydration of TC forms ATC. Both processes are reversible under slightly alkaline $(\mathrm{pH} 8)$ conditions (Halling-Sørensen et al., 2002, Jia et al., 2009). Dos Santos et al., (1998) reported that ATC is more toxic and 
harmful than the parent compound (TC). Hence, a remediation system/technology must decontaminate both TC and its harmful isomers from environmental sources.

In addition, TC is a broad-spectrum antibiotic that is effective against both gram-positive and gram-negative bacterial infections (Sarmah et al., 2006). Therefore, there is a high probability of bacterial strains developing TC-resistance if a remediation method is not applied to contaminated environmental sources. These TC resistant bacteria could present a serious threat to human health.

Several physical and chemical remediation methods have been used to remove antibiotics from environmental sources. However, these remediation methods can be expensive and non-sustainable (Kummerer et al., 2009). Comparatively, phytoremediation is less expensive and potentially more effective at removing antibiotics from water sources hence a more sustainable technology. Phytoremediation is a natural biological process and it is free of stringent remediation condition requirements, such as $\mathrm{pH}$, temperature, oxidation, and light requirements (Salt et al., 1998).

There are several studies (Carvalho et al., 2012, Gujrathi et al., 2005, Farkas et al., 2007) that describe the potential of various plants to decontaminate water systems that have been contaminated with the TC group of compounds: TC, oxy-TC (OTC), and chloro-TC (CTC). Gujrathi et al., (200) report the TC and OTC remediation potential of Myriophyllum aquaticum (parrot feather) and Pistia stratiotes (water lettuce) in hydroponic system and Farkas et al., (2007) report phytoremediation potential of maize in CTC detoxification. In a recent study by Carvalho et al., (2012) it was reported that 
Phragmites australis, a large perennial grass from tropical and temperate regions, could successfully remediate several antibiotics including TC from an aqueous system. When irrigation water is contaminated with TC and OTC, it can have toxic effects on crop plants such as alfalfa (Kong et al., 2007) and wheat (Xie et al., 2011). All these plant species discussed above as potential phytoremediation models for antibiotics are however undersirable from an ecological point of view as they all are invasive (Global invasive species database (http://www.issg.org).

Using a metabolomics approach in plants, the changes in gene expressions could be quickly related to functional changes in the organism (Fiehn et al., 2000). Abiotic stresses such as temperature, salinity, and exposure to contaminants such as heavy metals can lead to the adjustment of metabolic pathways in plants (Tuteja et al., 2011). Metabolic profiling is an important tool that can identify the expression of metabolites in the presence of specific xenobiotics and reveal possible associated metabolic pathways This is a relatively new tool in the field of bioremediation (Villas-Bôas and Bruheim 2007). Although a plant metabolomics approach has never been explored in the field of antibiotic remediation, it has been validated by several scientists as an important step in the field of environmental remediation (Hill and Roesnner 2013, Villas-Bôas and Bruheim 2007). Environmental metabolomics and metabolomics in plant environmental physiology are two very important fields of study developing these days (Brunetti et al., 2013). With this approach, the physiology of the plant and production of secondary metabolites and their role could be studied under certain environmental/ ecological conditions. 
Like Phragmites australis, vetiver (Chrysopogon zizanioides) is a tropical grass with a deep and well developed root system that can extend $3 \mathrm{~m}$ into the soil. Vetiver is not an invasive plant and is tolerant to variations in climate and extreme conditions, such as drought, floods, and acidic and alkaline substrates. These characteristics make vetiver a more optimal phytoremediation candidate than other grass/ plant systems that have previously been studied (Troung et al., 2010). Vetiver has been extensively used as a model for phytoremediation of heavy metals and toxic contaminants because of these unique attributes (Makris et al., 2007, Chen et al., 2004, Truong et al., 2010).

The phytoremediation potential of vetiver grass in TC uptake was recently described by Datta et al., (2013). Following the same methods as Datta et al., 2013, hydroponic tanks were set-up with and without TC using different concentrations of TC $(0,5,35$, and 75 ppm). These concentrations were chosen in conjunction with an earlier study by Datta $e t$ al., (2013) with an increase in the TC concentrations to understand the capability of vetiver in remediating higher concentrations of TC. Hydroponic growth systems are commonly used for green house/ lab studies, and are controlled systems to understand different physiological processes used by plants especially in the field of phytoremediation (Baldwin and Butcher 2006, Kurzbaum et al., 2013, Conn et al., 2013, Datta et al., 2013).

The purpose of the study was to assess the phytoremediation capability of vetiver in an aquatic system, to understand how and if vetiver grass takes up and transforms TC in respect to similar studies by Dolliver et al., (2007) and Datta et al., (2013), to evaluate if there are any toxic effects of $\mathrm{TC}$ on vetiver, and to perform metabolomics of vetiver in 
the presence of TC to identify the TC metabolism pathway used by vetiver and/or to identify the metabolites that are impacted in the plant during TC metabolism process.

Materials and Methods

\section{- Hydroponic Study}

Vetiver grass was obtained from Agriflora Tropicals, Puerto Rico (http://agrifloratropicals.com/) as small plantlets and was grown in regular potting soil until they were medium-sized $(55-60 \mathrm{~cm})$. Once they reached the appropriate height, they were uprooted and washed thoroughly with tap water to remove soil, patted dry, and weighed. Two plants weighing about $60 \mathrm{~g}$ each were then placed in plastic tanks $(3 \mathrm{~L})$ equipped with bubble stones connected to air pumps that were used to supply oxygen to the hydroponic system (Datta et al., 2013). The plants were acclimatized in 3L of 0.5 strength Hoagland solution for two weeks in the tanks.

Biotech research grade tetracycline hydrochloride (99\% pure; obtained from Thermo Scientific) and deionized autoclaved water were used to prepare a 10,000 ppm of TC stock solution, which was then filter-sterilized using $0.2 \mu \mathrm{m}$ filters. Working concentrations of $5 \mathrm{ppm}, 35 \mathrm{ppm}$, and $75 \mathrm{ppm}$ were then prepared from the stock solution. Usually the level of TC detected in waste water and surface water is $0.1-1 \mathrm{ppm}$ (Meyer et al., 2003) and hence concentrations used here are comparatively higher to test if this phytoremediation system can be effective in remediation of TC. Experimental and control tanks were set-up in replicates of three. Different types of tanks were set-up 
for each treatment as described a) tanks with plants (experimental set) and without plants (positive control) for each TC concentration used (5, 35, and $75 \mathrm{ppm})$, and b) tanks with plants and no antibiotics (negative control). To assess the possibility of photodegradation of TC in the tanks, three of the tanks containing only TC solution $(75 \mathrm{mg} / \mathrm{L})$ were covered with a black cloth. Hydroponic trials were conducted in the growth chamber where the temperature was maintained at $28-30^{\circ} \mathrm{C}$, the $\mathrm{pH}$ was 7 , and light levels mimicked a natural cycle of 12 light hours and 12 dark hours.

\section{- Sampling Plan}

Media samples were collected from tanks on days $0,1,2,3,5,15$, and 30 . On day 0 , the media samples were collected 20 minutes after the start of the experiment to ensure the antibiotic was mixed well in the tanks. Media samples were taken by pipetting $3 \mathrm{~mL}$ aliquots into eppendorf tubes. Plant samples were measured for weight, root length, and shoot length at day 0 and day 30 . Media and plant samples were frozen at $-80^{\circ} \mathrm{C}$ until further analysis to avoid degradation/transformation of TC. Water/hydroponic (media) solution remained constant at a $\mathrm{pH}$ of 7 for the duration of the study and were constantly aerated with a bubble stone and air pump used in the tanks.

\section{- Sample Preparation for HPLC and MS-MS}

Media (liquid) samples were thawed and $1 \mathrm{~mL}$ aliquots were filtered through $0.2 \mu \mathrm{m}$ Supelco filters into amber vials for high performance liquid chromatography (HPLC) analysis. Plant samples were prepared for HPLC analysis following extraction 
procedures modified from a previously reported method (Dolliver et al., 2007). After the sample was eluted from the solid phase extraction (SPE) cartridge using $2 \mathrm{~mL}$ of methanol, approximately $1 \mathrm{~mL}$ of the eluent was filtered through a $0.2 \mu \mathrm{m}$ filter into an amber vial for HPLC analysis.

\section{- Plant Sample Analysis for Accumulation of TC}

Plant samples were collected and harvested on day 0 and day 30 of the hydroponic remediation experiment. During TC accumulation analysis in plant tissues (roots and shoots) harvested on day 30 of the remediation trial, mass balance, and translocation factor were calculated to understand the amount of TC accumulated in plant roots and shoots. Methods of calculation were followed from Doskey (2012). Mass balance was calculated and expressed in percentage of TC present accumulated in vetiver tissues (summing up root and shoot accumulation) in relation to the initial concentration of TC used in the particular tank. Translocation factor was also expressed in percentage by dividing mass of TC recorded in vetiver shoot in relation to the mass recorded in total plant.

\section{- Plant Sample Preparation for Metabolomics}

Plant samples were prepared for GC-MS analysis following extraction procedures modified from a previously reported method (Lisec et al., 2006 and Li, 2012). Plant tissues (root and shoot separately) weighing $0.1 \mathrm{~g}$ were crushed (each sample in replicates of 3) with a mortar and pestle, using liquid nitrogen to maintain the frozen condition. One 
$\mathrm{mL}$ of water/chloroform/methanol $(1: 1: 2.5)$ solution was aliquoted in each tube. Tubes were vortexed and then $10 \mu \mathrm{L}$ adonitol (2 mg adonitol/1 $\mathrm{mL}$ chloroform) was added to each sample as an internal standard and vortexed again. The rest of the extraction procedure was followed as per Lisec et al., 2006.

\section{- Sample Analysis Method for HPLC and LC-MS-MS}

TC and its isomers were analyzed in the water and plant samples by HPLC. The methods for this analysis were described by Pena et al. (1998) and Sokol and Matisova, (1994), but were slightly modified as described here. Isocratic mobile phase consisting of $0.01 \mathrm{M}$ aqueous oxalic acid: acetonitrile: methanol (150:20:20 by volume) was used. The mobile phase was mixed and sonicated for 5 minutes and then filtered through 0.22 $\mu \mathrm{m}$ nylon filtration units. The flow rate was maintained at $1.0 \mathrm{ml} / \mathrm{min}$, with an injection volume of $25 \mu 1$, the ultraviolet-diode array detector (UV-DAD) was set at Sig $=355,20$ Ref $=600,100$ in an Agilent HPLC (model no. 1100) with a Fisher Scientific Hypersil BDS CN 100x $4 \mathrm{~mm}$ ID $3 \mu \mathrm{m}$ (C18 column). Samples were run for 10 minutes at ambient temperature. The LC-MS method was followed using Jia et al.. (2009), however the mobile phase gradient was slightly modified as: A: Acetonitrile; B: Water $+0.1 \%$ Formic acid (v/v). The following gradient was used: A- 10\%; B-90\% for 5 minutes., A$20 \%$, B- $80 \%$ for 4 minutes., A-30\%, B-70\% for 1 minute, A- 50\%, B-50\% for 1 minute, A- 70\%, B-30\% for 1 minute, A-90\%, B- 10\% for 1 minute, and A- $100 \%$ B- $0 \%$ for 1 minute. Finally, the gradient was returned to the initial concentration exactly the same way and held at equilibrium for 2 minutes. 


\section{- Sample Analysis Method for GC-MS}

The derivatized samples were analyzed following the method from Lytovchenko et al., (2009) and Li K, (2012) using a Shimadzu GC-17A coupled with MS-QP5050, using helium as a carrier gas. One $\mu \mathrm{L}$ of sample was injected into a DB-5 column using the splitless injection mode. The inlet temperature was set to $250^{\circ} \mathrm{C}$. The initial column temperature was held at $70{ }^{\circ} \mathrm{C}$ for 5 minutes and then increased to $5^{\circ} \mathrm{C} /$ minute to $310^{\circ} \mathrm{C}$ and held for 1 minute. The peaks were analyzed with the Shimadzu GCMS solution version 1.2 software. The results were normalized by dividing the peak area of the unknowns by the peak area of the internal standard and were further normalized by the plant weight that was measured during extraction process.

\section{- Statistical analysis}

Statistical analyses were performed as described below. All the p-values and statistical analyzed data are presented in Appendix A.6.

a) Results were compared between samples collected from tanks without plants vs. with tanks with plants for each concentration of TC $(5,35,75 \mathrm{ppm})$ on each sampling day $(0,1,2,3,5,15$, and 30 days). Two-way ANOVA analysis was conducted on results from each sampling day where, $p$ values $(p<0.05)$ were compared between i) different concentrations; ii) with and without plant; and iii) their interaction effect using JMP IN version 8.0 (Sall et al., 2005). To understand significant difference among treatment means Tukey-Kramer honest significant difference (HSD) test was performed if interaction among the factors were found significant. 
b) Results were compared between samples collected from tanks without plants exposed to 75 ppm of TC in dark vs. light on each sampling day $(0,1,2,3,5,15$, and 30 days) using the Student's t-test $(\mathrm{p}<0.05)$ to understand the effect of light in TC degradation using Excel 2010 package .

c) Basic phytotoxicity parameters (plant mass, shoot and root length) were tested for vetiver plant samples collected from tanks with and without TC on day 0 and day 30 during hydroponic study. Results were analyzed using 2-way ANOVA $(\mathrm{p}<0.05)$ from each sampling day $(0$ and 30$)$ where, $\mathrm{p}$ values $(\mathrm{p}<0.05)$ were compared between i) different concentrations; ii) with and without plant, and iii) their interaction effect using JMP IN version 8.0 (Sall et al., 2005). To understand significant difference among treatment means Tukey-Kramer honest significant difference (HSD) test was performed if interaction among the factors were found significant.

d) Statistical and hierarchical cluster analysis for metabolic analysis experiments was performed using the Student's t-test $(\mathrm{p}<0.05)$ and Pearson's co-relation comparison using Multiarray Viewer software version 4.7.4 (MeV) statistical package. Pathway analysis was performed using MetaboAnalyst 3.0, followed by the plant metabolic network and KEGG databases (Xia et al., 2012).

\section{Results and Discussion}

This study was conducted to evaluate the ability of vetiver grass to remediate and uptake TC from aquatic systems. The results reported here are an in depth analysis of the vetiver plant's ability to remediate TC from aqueous sources. This invitro TC hydroponic 
remediation study presents comparative results between tanks treated with plants vs. tanks without plants (Fig. 2.1). Results for the highest concentration of TC ( $75 \pm 5 \mathrm{ppm}$ ) are reported here (Fig. 2.1). Results for 5 and $35 \mathrm{ppm}$ TC are not shown here but show similar trends (as $75 \mathrm{ppm}$ ) throughout (Appendix A, Fig. A.4.1 and A.4.2).

The results from hydroponic tanks treated with vetiver (Fig. 2.1) show the complete removal of TC from the aquatic media within 30 days. This result is consistent with the preliminary study conducted by Datta et al., 2013 where complete removal of TC by vetiver grass took place within 40 days. However, the study conducted by Datta et al., 2013 showed that compared with tanks with plants removal of TC from tanks in control (no TC) plants was significantly higher. This result is not consistent with what was observed in the current study. The differences in the result could be due to the difference in analytical method or the experimental set-up.

Other studies have shown that the majority of TC removal/transformation from media samples occurs between days 0 and 5 (Gujrathi et al., 2005), and the removal/transformation process was faster in tanks treated with TC compared to tanks without plants (Carvalho et al., 2012). In this study, the accumulation of ETC and ATC was observed in both tank treatments (with and without plants), along with removal of TC (Fig. 2.1 B, C). However, accumulation of ETC and ATC was lower in tanks with plants compared to tanks without plants. The major accumulation of ATC takes place between days 5 and 15 . The accumulation was lower in tanks with plants, and eventually disappears between days 15 and 30 . On day 30 , MS/MS analysis revealed the complete removal of TC and TC isomers in tanks treated with vetiver using MS/MS, however 
traces of ATC were observed in samples from untreated tanks (Figure A.2.1). These concentrations were not detected during HPLC analysis because the concentrations were below the minimum detection limit. These results show for the first time, that vetiver grass not only removes or transforms $\mathrm{TC}$ from the aqueous system, but also degrades/metabolizes the potentially harmful isomers of TC (Dos Santos et al., 1998), which normally persist in nature if they are not contained using a remediation technology. However the earlier study reported that there was no drop in TC concentration in media samples collected from tanks without plants which is not consistent with the result of this study. Statistical analyses shows that on day 0 there is no statistical significance between samples collected from tanks with plants and without plants and there is no interaction between the factors either. On day 1, plant treatment was found not significant individually $(\mathrm{p}=0.1603)$ but the combination effect was significant and Tukey's HSD shows there was a difference between tanks with and without plants in 35 and $75 \mathrm{ppm}$ TC treatment.

On days 2,3 , and 5 both the factors and their interactions were significant $(\mathrm{p}<0.0001)$ and Tukey's HSD test shows there was a difference between tanks with and without plants in all the treatments $(5,35$, and $75 \mathrm{ppm})$.

To understand effect the effect of light on TC isomerization/degradation process tanks were set-up in in presence and absence of light. The results indicated that the light treatment did not have any significant effect on the TC transformation or removal process (Figure A.3.1). 
Uptake and degradation of TC by multiple plant species has been observed in aquatic systems (Kong et al., 2007, Carvalho et al., 2012). A detailed investigation of the uptake of TC in vetiver roots and shoots was conducted in this study. Following the methods and calculations (discussed in methods) from Doskey C, (2012), mass balance and tranlocation factor were calculated in order to quantify the amount of TC being absorbed by plant tissue at the end of the remediation trial. The mass balance results (Fig 2.2) indicate the mass or amount of TC that was taken up by the plant root and shoot tissues during the remediation trial. The results show compared to $5 \mathrm{ppm}, 35 \mathrm{ppm}$ and $75 \mathrm{ppm}$ there is some accumulation in the roots and mostly in the shoots (Fig 2.2). The roots could have readily degraded TC or its isomers with an enzymatic detoxification mechanism or it could have translocated TC to the shoots for further breakdown into harmless metabolites (translocation factor results compared to Datta et al., 2013). The translocation factor calculation (Fig 2.3) reports how the TC was distributed between the plant roots and shoots. All of these results confirm that, although there is a process of TC translocation involved between root and shoot of vetiver, the major transformation or degradation of TC occurs in the root zone (Gujrathi et al., 2005). Based on literature reviews, it can be speculated that TC degradation may occur in the root zone, which may be an oxidative degradation process and/or an antioxidant mediated detoxification process (Gujrathi et al., 2005 a, Farkas et al., 2007).

Basic toxicity parameters were run on vetiver grass to assess if there were any toxic effects of TC on the plants. This was done by measuring the plant mass, root and shoot length before and after the remediation trial. Statistical analysis shows that, before and 
after TC treatment plant biomass was not significantly different $(\mathrm{p}=0.059)$ and interaction between different factors was also not significant $(\mathrm{p}=0.5451)$. For shoot and root length, before and after TC treatment the parameters were not significantly different ( $p=0.25, p=0.36$ respectively) however interaction between different factors were found to be significant for both shoot and root length. Tukey's HSD test shows there was no significant difference between parameters checked before and after TC treatment. Hence, overall it was concluded that vetiver is a robust plant species and can be used as a suitable model for TC remediation.

Metabolic profiling of plants in the presence of antibiotic has never been conducted, so the results obtained in this study cannot be compared to other research. However, the results obtained from this study and earlier studies (Gujrathi et al., 2005, Datta et al., 2013) suggest that, most TC detoxification activity is found in the plant root zone. Hence, the vetiver root zone was investigated for metabolic profiling in presence of TC (75 ppm).

A total of 32 metabolites were detected by comparing the samples of vetiver roots treated with 75 ppm of TC vs. the control plant (negative control; tanks with plant but no TC). Statistical analysis (Figure 2.6; hierarchical cluster results) showed that there were significant metabolites present in the TC-treated vetiver root on day 30 of the hydroponic trial. A total of three metabolites, cis aconitate acid, 5 -methoxyindoleacetate and inositol 1, 3,4,5,6 -pentakisphospate, were identified using MetaboAnalyst. Upon investigation in the KEGG database, it was found that all three of these metabolites are associated with multiple metabolic or biochemical pathways (Table 2.1). Upon 
investigation using Metaboloanalyst and KEGG pathway analysis, it was found that in the presence of TC these three metabolites were associated with glyoxylate and dicarboxylate metabolism, and the citric acid cycle (TCA cycle). Both of these metabolic pathways were found to be important in plants. Hence it was hypothesized that, increased level of these metabolites may be associated with increased activity if this pathway. Glyoxylate metabolism is important for amino acid biosynthesis (Sinha et al., 1965). To understand the role of this pathway in TC metabolism, investigation of the role of the pathway was conducted by using literature search. It was found that glutathione is an important root-secreted metabolite that is secreted from plants as a response to stress (Farkas et al., 2007). Glycine was another compound that was found to be increased in presence of TC. Photorespiration in plants creates glycine, a metabolite that contributes to the synthesis of glutathione (Wingler et al., 2000). Thus it is speculated that glyoxylate metabolism which is responsible for synthesis of glycine may increase glutathione production that eventually leads to the degradation of TC in vetiver root zone.

Additional metabolites were detected during this study, and have been investigated for their possible role in the TC degradation process. Some of the metabolites were expressed only in the TC-treated plant roots (such as glycine, tyrosine, butanoic acid) and were completely absent in the control plant roots (Appendix A, Table A.5.2). Fewer metabolites were detected only in control plant roots and completely absent in the TCtreated plant roots samples (Appendix A, Table A.5.3). These metabolites were matched against both KEGG and the plant metabolic network database; however no link could be established between the reported metabolites and any metabolic pathways related to these 
metabolites that could be a part of TC metabolization process. Since this is the first time metabolic information on plants under TC influence is being reported, all of the information collected by the metabolic profiling of vetiver could be useful to the further the understanding of the detoxification mechanisms used by plants to remediate TC.

\section{Conclusions}

This study demonstrates that vetiver could be a suitable model for the remediation of antibiotics (such as tetracycline) from water sources. Vetiver plants demonstrated the capability of remediating TC from media samples within 15-20 days in ahydroponic experiment. Vetiver was found to remediate TC from the water source by taking up TC into its roots and translocating it to the shoot, and by metabolizing or transforming the TC. TC and its isomers, ATC and ETC, were not detected in tanks with plants unlike the control tanks which had no plants. The light vs. dark experiment showed no significant effect of light on the TC transformation or metabolization process. Metabolic profiling of vetiver identified the possible involvement of glutathione pathway in $\mathrm{TC}$ detoxification process. Also, no harmful effects of TC or its isomers were observed on the plant survival.

\section{Acknowledgements}

The authors would like to acknowledge the Departments of Biological Sciences and Chemistry at Michigan Tech for providing the laboratory facilities, and Jerry Lutz from the Deptartment of Chemistry for providing technical assistance with LC-MS/MS and GC-MS. 


\section{References}

1. Baldwin P, Butcher D (2007) Phytoremediation of arsenic by two hyperaccumulators in a hydroponic environment. Microchem. J. 85:297-300.

2. Boonsaner M, Hawker DW (2012) Investigation of the mechanism of uptake and accumulation of zwitterionic tetracyclines by rice (Oryza sativa L.). Ecotox. Environ. Safe. 78:142-147.

3. Boxall ABA (2004) The environmental side effects of medication. EMBO J. 5:1110-1116.

4. Brunetti C, George RM, Tattini M, Field K, Davey MP (2013) Metabolomics in plant environmental physiology. J. Exp. Bot. 64:4011-4020.

5. Carvalho PN, Basto MCP, Almeida CMR (2012) Potential of Phragmites australis for the removal of veterinary pharmaceuticals from aquatic media. Bioresour. Technol. 116:497-501.

6. Chen Y, Shen Z, Li X (2004) The use of vetiver grass (Vetiveria zizanioides) in the phytoremediation of soils contaminated with heavy metals. Appl Geochem. 19:1553-1565.

7. Chitescu CL, Nicolau AI, Stolker AAM (2012) Uptake of oxytetracycline, sulfamethoxazole and ketoconazole from fertilized soils by plants. Food Addit. Contam. Part A Chem. Anal. Control Expo. Risk. Assess. 30:1138-1146 
8. Conn SJ, Hocking B, Dayod M, Xu B, Athman A, Henderson S, Aukett L, Conn V, Shearer M, Fuentes S, Tyerman SD, Gilliham M (2013) Protocol: optimizing hydroponic growth systems for nutritional and physiological analysis of Arabidopsis thaliana and other plants. Plant Methods.9:4.

9. Dantas G, Sommer MOA, Oluwasegun RD, Church GM (2008) Bacteria subsisting on antibiotics. Science. 320:100-103.

10. Datta R, Das P, Smith S, Punamiya P, Ramanathan DM, Reddy R, Sarkar D (2013) Phytoremdiation potential of tetracycline by vetiver grass (Chrysopogan zizanioides(L.) for tetracycline. Int. J Phytorem. 15:343-351.

11. Dolliver H, Kumar K, Gupta S (2007) Sulfamethazine uptake by plants from manure-amended soil. J. Environ. Qual. 36:1224-1230.

12. Doskey, CM (2012) Phytoremediation of hexahydro-1, 3, 5-trinitro-1, 3, 5triazine by Chrysopogon zizanioides. M.S. thesis. Michigan Technological University, Houghton, MI.

13. Dos Santos HF, De Almeida WB, Zeener MC (1998) Conformational analysis of the anhydrotetracycline moleculae: a toxic decomposition product of tetracycline. J. Pharm Sci. 87: 190-195.

14. Farkas MH, Berry OM, Aga DS (2007) Chlorotetracycline detoxification in maize via induction of glutathione S-transferases after antibiotic exposure. Environ. Sci. Technol. 41:1450-1456. 
15. Fatta-Kassinos D, Meric S, Nikolaou A (2011) Pharmaceutical residues in environmental waters and wastewater: current state of knowledge and future research. Anal. Bioanal. Chem. 399:251-275.

16. Fiehn O, Kopka J, Dörman P, Altmann T, Trethewey RN, Willmitzer L (2000) Metabolite profiling for plant functional genomics. Nat. Biotech. 1157-1161.

17. Furtula V, Stephenson GL, Olaveson KM, Chamber PA (2012) Effects of the veterinary pharmaceutical salinomycin and its formulation on the plant Brassica rapa. Arch Environ. Cont. Tox. 63:513-522.

18. Gujrathi NP, Haney B, Linden J (2005) Phytoremediation potential of $M$. aquaticum and $P$. stratiotes to modify antibiotic growth promoters, tetracycline, and oxytetracycline in aqueous wastewater systems. Int. J. Phytorem. 7:99-112.

19. Halling-Sørenson B, Sengelov G, Tjornelund J (2002) Toxicity of tetracycline degradation products to environmentally relevant bacteria, including selected tetracycline resistant bacteria. Arch. Environ. Con. Tox. 42: 263-271.

20. Herklotz PA, Gurung P, Heuvel BV,Kinney CA (2010) Uptake of human pharmaceuticals by plants grown under hydroponic conditions. Chemsophere. 78:1416-1421.

21. Hill, C. B. and Roessner, U. (2013) Metabolic Profiling of Plants by GC-MS. The Handbook of Plant Metabolomics (eds. W. Weckwerth and G. Kahl). Wiley-VCH 
Verlag GmbH \& Co. KGaA, Weinheim, Germany. doi: 10.1002/9783527669882.ch1.

22. Holling CS, Bailey JL, Heuvel BV, Kinney CA (2012) Uptake of human pharmaceuticals and personal care products by cabbage (Brassica campestris) from fortified and biosolids-amended soils. J. Environ. Monitor. 14-3029-3036.

23. $\mathrm{Hu} \mathrm{X}$, Zhou Q, Luo Y (2010) Occurrence and source analysis of typical veterinary antibiotics in manure, soil, vegetables and ground water from organic vegetable bases, northern China. Environ. Pollut. 158:2992-2998.

24. Huang CH, Renew JE, Smeby KL, Pinkston K, Sedlak DL (2011) Assessment of potential antibiotic contaminants in water and preliminary occurrence analysis. J. Contemp. Water Res. and Educ. 120: 4.

25. Jia A, Xiaoa Y, Hua J, Asamib M, Kunikane S (2009) Simultaneous determination of tetracycline and their degradation products in environmental waters by liquid chromatography-electrospray tandem mass spectrometry. J. Chromatogr. A. 1216:4655-4662.

26. Kim K-R, Owens G, Kwon S-I, So K-H, Lee D-B, Ok YS (2011) Occurrence and environmental fate of veterinary antibiotics in the terrestrial environment. Water Air Soil Poll. 214:163-174. 
27. Kong WD, Zhu YG, Liang YC, Zhang J, Smith FA, Yang M (2007) Uptake of oxytetracycline and its phytotoxicity to alfalfa (Medicago sativa L.). Environ. Pollut. 147:187-193.

28. Kumar K, Gupta SC, Baidoo SK, Chander Y, Rosen J (2005) Antibiotic Uptake by Plants from Soil Fertilized with Animal Manure. J. Environ. Qual. 34:20822085.

29. Kummerer K (2009 a) Antibiotics in the aquatic environment-A review-Part I. Chemosphere. 75:417-434.

30. Kummerer K (2009 b). The presence of pharmaceuticals in the environment due to human use-present knowledge and future challenges. J. Environ Manage. 90:2354-2366.

31. Kurzbaum E, Kirzhner F, Armon R (2014) A hydroponic remediation system for growing gnotobiotic vs. sterile plants to study phytoremediation processes. Int. J. Phytorem. 3:267-274.

32. $\mathrm{Li}, \mathrm{K}$ (2012) Isolation of plant growth promoting bacteria from torch lake sediments and their role in phytoremediation of metal contaminated soil. Ph.D. Thesis. Michigan Technological University, Houghton, MI.

33. Lisec J, Schauer N, Kopka J, Willmitzer L, Fernie AR (2006) Gas chromatography mass spectrometry-based metabolite profiling in plants. Nat. Protocols. 1: 387-396. 
34. Lytovchenko A, Beleggia R, Schauer N, Isaacson T, Leuendorf JE, Hellmann H, Rose JKC, Fernie AR (2009) Application of GC-MS for the detection of lipophilic compounds in diverse plant tissues. Plant Methods. 5:4.

35. Makris KC, Shakya K, Datta R, Sarkar D, Pachanoor D (2007) High uptake of 2,4,6 TNT by vetiver grass-Potential for phytoremediation? Environ Pollut. $146: 1-4$

36. Michael I, Rizzo L, McArdell CS, Manaiad CM, Merline C, Schwartz T, Dagot C, Fatta-Kassinos D (2013) Urban wastewater treatment plants as hotspots for the release of antibiotics in the environment: A review. Wat. Res. 47:957-995.

37. Moshe Shenker, Daniella Harush, Julius Ben-Ari, Benny Chefetz (2011) Uptake of carbamazepine by cucumber plants - A case study related to irrigation with reclaimed wastewater. Chemosphere. 82:905-910.

38. Park H, Choung YK (2010) Evaluation of the biodegradation feasibility of antibiotics by three bacteria involving glutathione S-transferases. Can. J. Civil Eng. 37:814-819.

39. Pena A, Carmona A, Barbosa A, Lino C, Silveira I, Castillo B (1998) Determination of tetracycline and its major degradation products by liquid chromatography with fluorescence detection. J. Pharmaceut. Biomed. 18:839-845. 
40. Rehman MSU, Rashid N, Ashfaq M, Saif A, Ahmad N, Han JI (2013) Global risk of pharmaceutical contamination from highly populated developing countries. Chemosphere. http://dx.doi.org/10.1016/j.chemosphere.2013.02.036.

41. Sall J, Creighton L, Lehman A (2005) JMP Start Statistics, third ed. SAS Institute, Cary, NC and Pacific Grove, CA.

42. Salt DE, Smith RD, Raskin I (1998) Phytoremediation. Annu. Rev. Plant. Phys. 49:643-668.

43. Sarmah AK, Meyer MT, Boxall AB (2006) A global perspective on the use, sales, exposure pathways, occurrence, fate and effects of veterinary antibiotics (Vas) in the environment. Chemosphere. 65:725-759.

44. Sinha SK and Cossins EA (1965) The importance of glyoxylate in amino acid biosynthesis in plants. Biochem. J. 96: 254-261.

45. Sokol, J and Matisova, E (1994) Determination of tetracycline antibiotics in animal tissues of food-producing animals by high-performance liquid chromatography using solid-phase extraction. J. Chromatogr. A. 669(1-2):75-80.

46. Tuteja N, Gill SS, Tuteja R (eds.) (2011) Omics and plant abiotic stress tolerance, p. 39-64. Benthan Science Publishers.

47. Truong PNV, Foong YK, Guthrie M, Hung Y-T (2010) Phytoremediation of heavy metal contaminated soils and water using vetiver grass, p.233-275. In L.K. Wang, J-W. Tay, S.T.L. Tay, Y-T. Hung (ed.), Environmental Bioengineering, 
Handbook of Environmental Engineering, Vol. 11. Humana Press, New York, NY.

48. Viant MR, Sommer U (2013) Mass spectrometry based environmental metabolomics: a primer and review. Metabolomics. 9:S144-S158.

49. Villas-Bôas SG, Bruheim P (2007) The potential of metabolomics tools in bioremediation studies. OMICS J. Integr. Biol. 11:305-13.

50. Wingler A, Lea PJ, Quick WP, Leegood RC (2000) Photorespiration: metabolic pathways and their role in stress protection. Philos. Trans. R. Soc. Lond. B. Biol. Sci. 355: 1517-1529.

51. Xia J, Mandal R, Sinelnikov I, Broadhurst D, Wishart DS (2012) MetaboAnalyst 2.0-a comprehensive server for metabolomics data analysis. Nucl. Acids Res. 40: W127-W137.

52. Xie X, Zhou Q, Lin D, Guo J, Bao Y (2011) Toxic effect of tetracycline exposure on growth, antioxidative and genetic indices of wheat (Triticum aestivum L.). Environ Sci. Pollut. Res. Int. 18:566-575. 

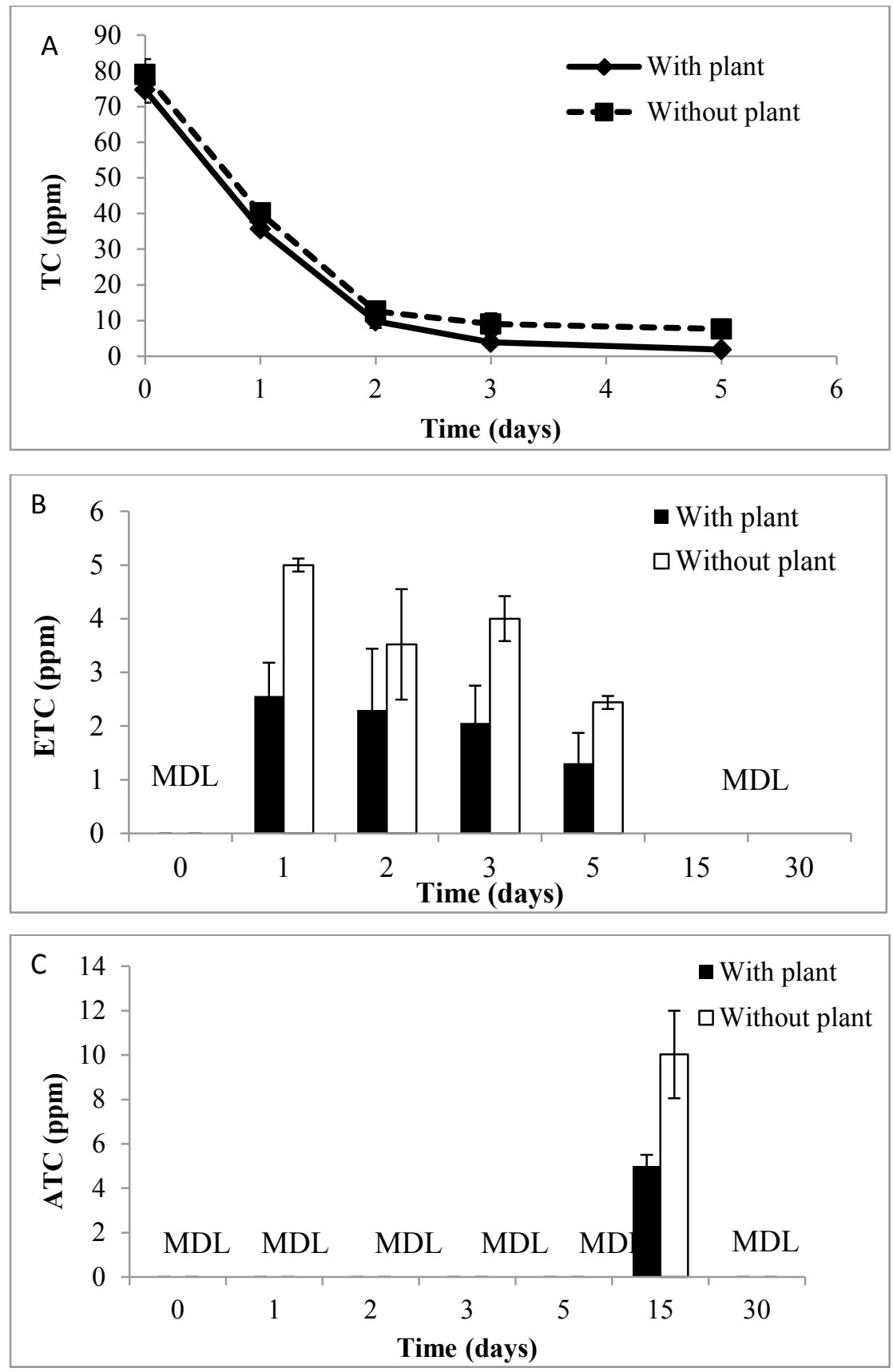

Figure 2.1. Transformation of $\mathrm{TC}$ in media samples collected from hydroponic tanks treated with plants vs. without plants (A) TC disappearance during 30 day remediation trial, (B) accumulation of ETC over time, (C) accumulation of ATC on day 15 of remediation trial. MDL on the charts signifies that compounds were $<$ minimum detection limit with HPLC. Results presented as mean $(n=3) \pm 1$ SD. 


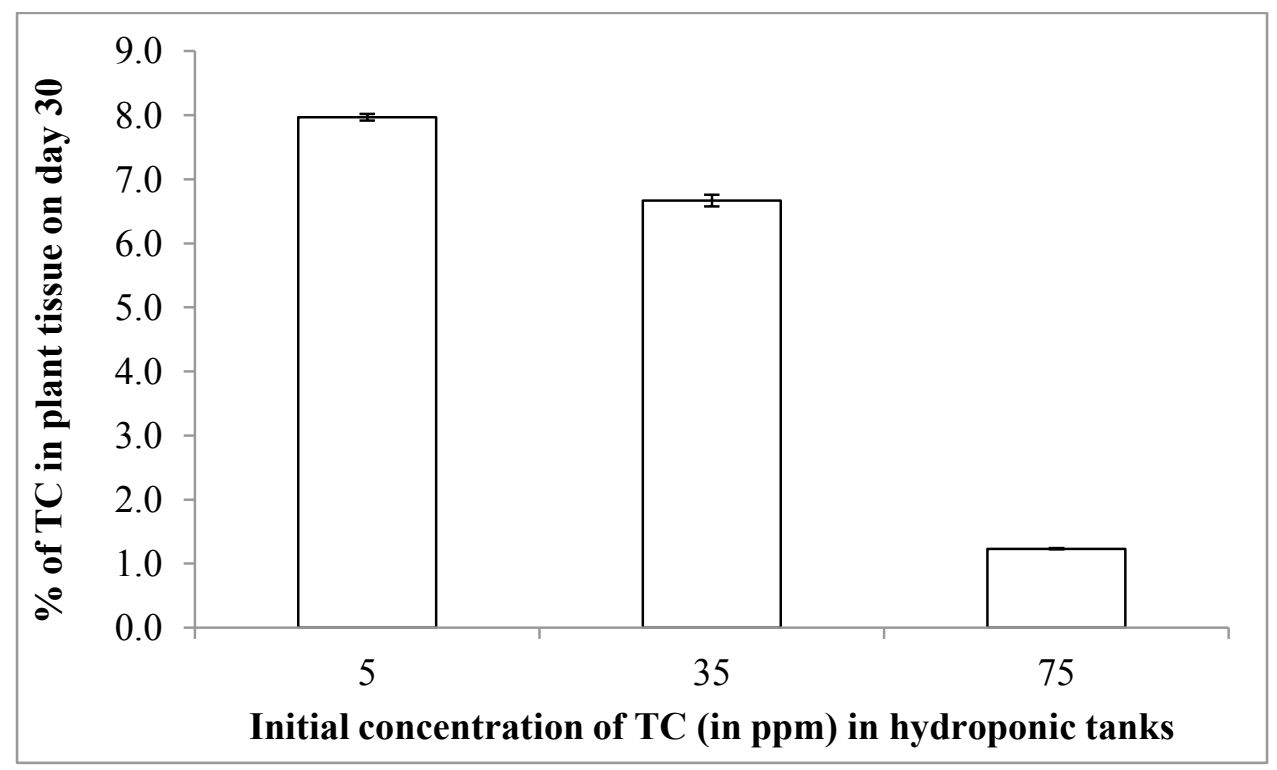

Figure 2.2. Mass Balance of TC in plant tissues on day 30 (Results shown here are normalized with water results). Results presented in mean $n=3, \pm 1 \mathrm{SD}$.

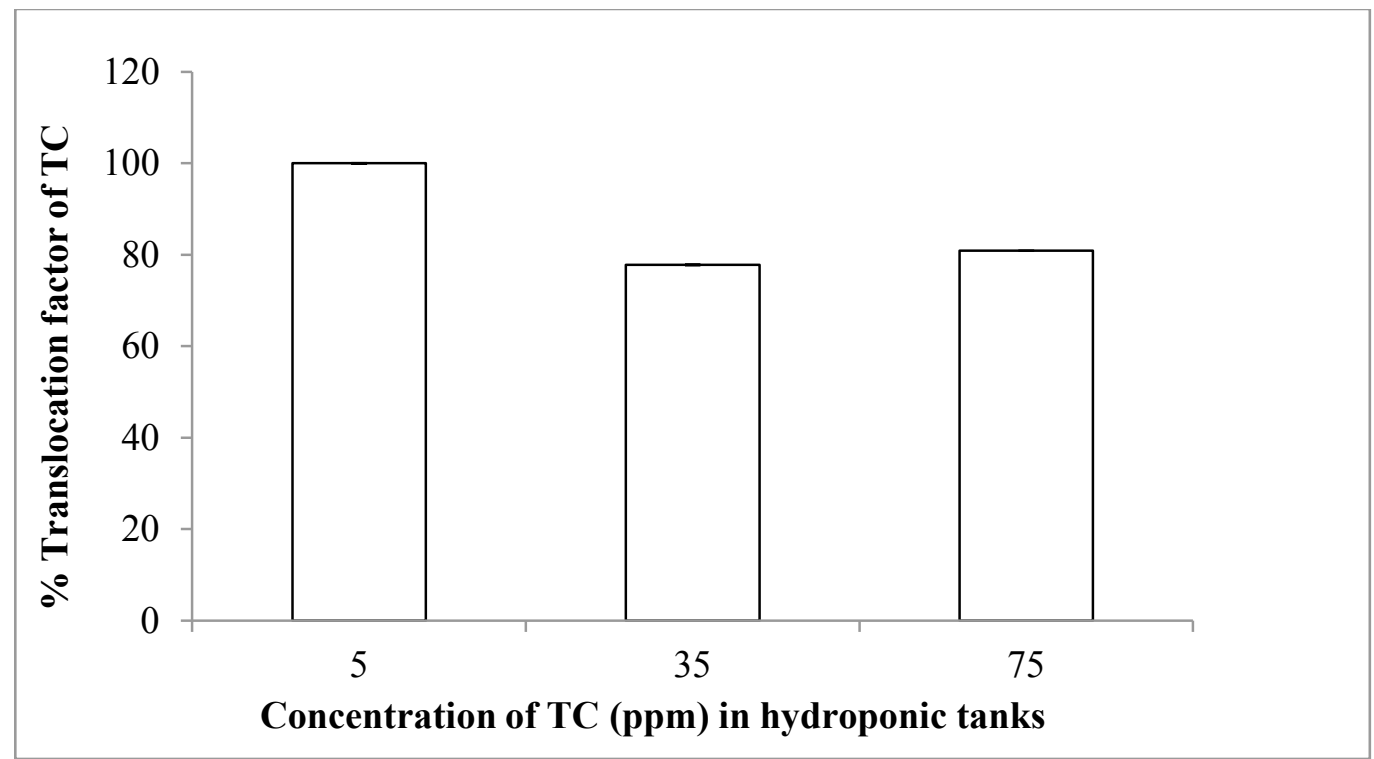

Figure 2.3. Translocation Factor (in \%) of TC in plant tissues (from root to shoots) on day 30. Results are normalized with water results. Results presented in mean $(n=3)$, $\pm 1 \mathrm{SD}$ 

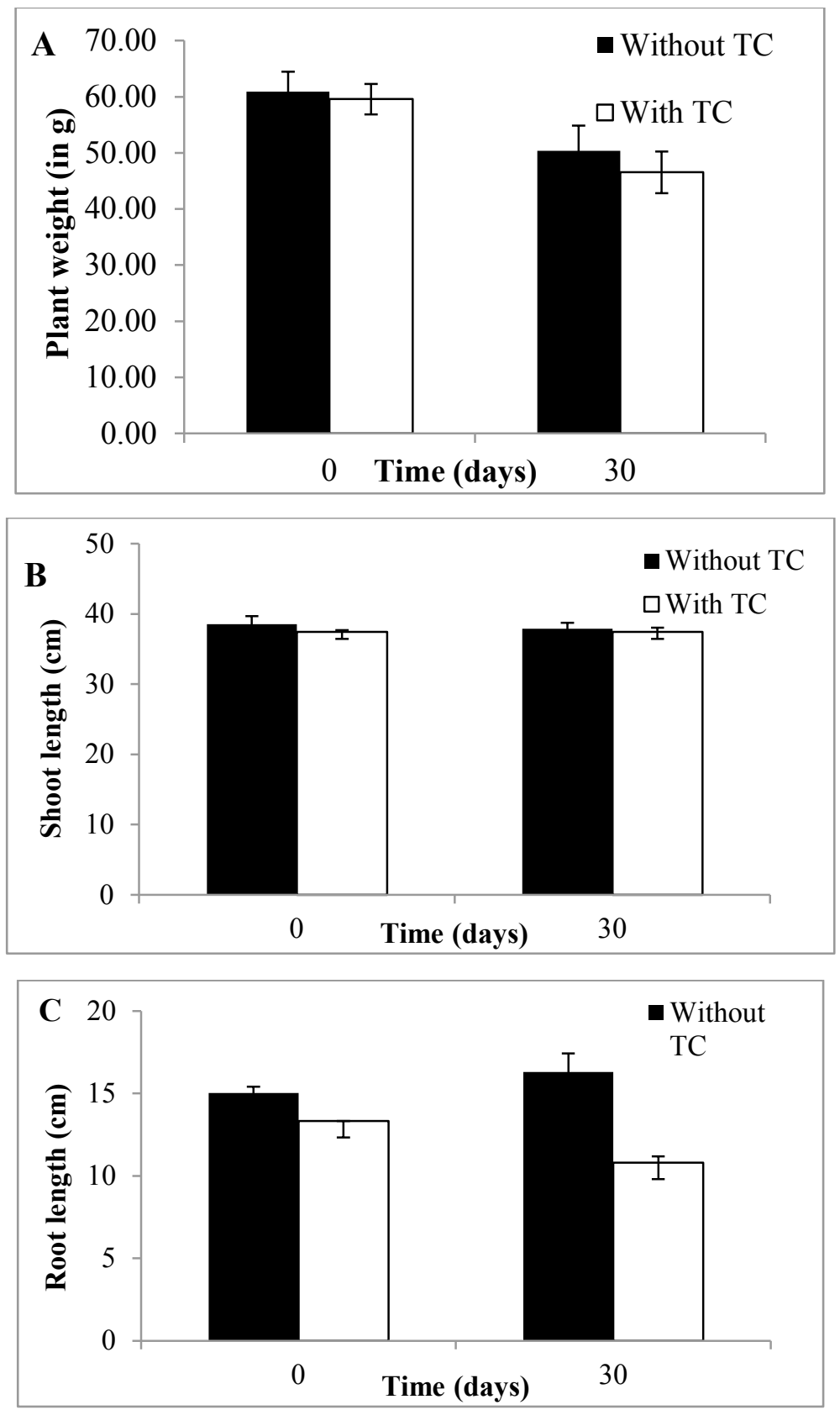

Figure 2.4. Effect of TC ( $75 \pm 5 \mathrm{ppm})$ on growth parameters of vetiver grass compared between days 0 and 30 (start and end of hydroponic trial, respectively) and between vetiver treated with and without TC. Figures represent A) plant mass, B) shoot length, C) root length. Statistical analysis shows no significant effect of TC on vetiver difference between days 0 and 30 in plants treated with and without TC $(\mathrm{p}>0.05)$. 

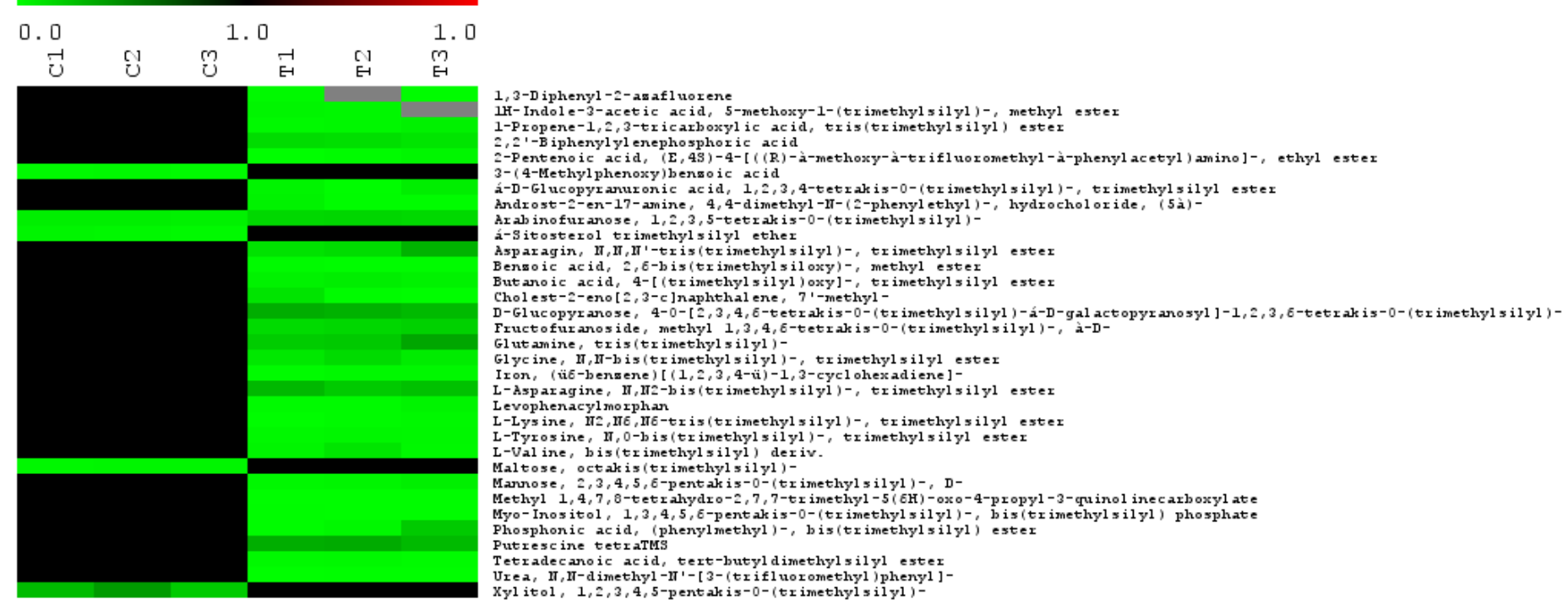

Figure 2.5. Heat map shows hierarchical cluster of statistical significant metabolites (t-test, $p<0.05$, Pearson's corelation) present during TC treated $(75 \mathrm{ppm})$ vetiver root on day 30 of hydroponic trial (compared to vetiver root not treated with TC) 
Table 2.1. Metaboanalyst analysed result shows ID standardization (match from Pub Med and KEGG analysis) and associated pathways matched with statistical significant metabolite identified in tetracycline treated vetiver root on day 30 of hydroponic trial

\begin{tabular}{|c|c|}
\hline Metabolite & Associated Pathways/Metabolism \\
\hline Cis Aconinate & $\begin{array}{ll}\text { - } & \text { Citrate cycle (TCA cycle) } \\
\text { - } & \text { Glyoxylate and dicarboxylate metabolism } \\
\text { - } & \text { C5-Branched dibasic acid metabolism } \\
\text { - } & \text { Biosynthesis of plant secondary metabolites } \\
\text { - } & \text { Biosynthesis of phenylpropanoids } \\
\text { - } & \text { Biosynthesis of terpenoids and steroids } \\
\text { - } & \text { Biosynthesis of alkaloids derived from shikimate pathway } \\
\text { - } & \text { Biosynthesis of alkaloids derived from ornithine, lysine and nicotinic acid } \\
\text { - } & \text { Biosynthesis of alkaloids derived from histidine and purine } \\
\text { - } & \text { Biosynthesis of alkaloids derived from terpenoid and polyketide } \\
\text { - } & \text { Biosynthesis of plant hormones } \\
\text { - } & \text { Metabolic pathways } \\
\text { - } & \text { Biosynthesis of secondary metabolites } \\
\text { - } & \text { 2-Oxocarboxylic acid metabolism } \\
\end{array}$ \\
\hline $\begin{array}{l}\text { Inositol } 1,3,4,5,6- \\
\text { pentakisphosphate }\end{array}$ & $\begin{array}{l}\text { - } \quad \text { Inositol phosphate metabolism } \\
\text { - } \quad \text { Phosphatidylinositol signaling system }\end{array}$ \\
\hline
\end{tabular}


CHAPTER 3. Role of vetiver (Chrysopogon zizanoides L. Nash) root-associated microbes in tetracycline degradation ${ }^{\text {a }}$

The study was designed by Aparupa Sengupta with guidance from Susan Bagley and Rupali Datta. The experiments were conducted by Aparupa Sengupta. The manuscript was written by Aparupa Sengupta. The other authors guided, edited and supported in the preparation of the manuscript.

${ }^{\mathrm{a}}$ Chapter 3 has been written and formatted for submission to the Journal of Applied and Environmental Microbiology 
Additional information including figure and tables that are not included in the chapter can be found in Appendices B and $\mathbf{C}$.

Appendix B is divided into 7 sections (C.1-C.7). The sections are summarized below:

Appendix B.1- Supplemental data for bacteria recovered during the hydroponic remediation experiment from the water and vetiver roots.

Appendix B.2- Initial screening for TC tolerance for the five bacterial strains that were recovered from the hydroponic remediation experiment.

Appendix B.3- Preliminary growth study using defined and enriched media, for the three bacterial strains that were best able to tolerate TC.

Appendix B.4- Results of 16S rRNA sequencing and MALDI-TOF for strain identification

Appendix B.5- Results of the growth study of Serratia marcescens and Burkholderia cepacia using both defined and enriched media after (consistently) increasing the concentration of TC.

Appendix B.6- The minimum inhibitory concentration (MIC) levels of TC for Serratia marcescens and Burkholderia cepacia.

Appendix B.7- Growth rate tables for each growth study for both defined and enriched media, with and without TC.

Appendix B.8- Statistical detailed analysis results for 2-way Anova analysis and Tukey's HSD test. 
Appendix C is divided into 4 sections (B.1-B.4). The sections are summarized below:

Appendix C.1- Supplemental data from the TC removal study which used TSB medium supplemented with TC.

Appendix C.2 - Supplemental data for TC transformation study which used TSB medium supplemented with TC.

Appendix C.3 - Supplemental data for the intracellular and extracellular metabolomics studies conducted on $S$. marcescens and B. cepacia.

Appendix C.4 - Recipes of different media used in various experiments. 
Role of vetiver (Chrysopogon zizanoides L. Nash) root-associated microbes in tetracycline degradation

Aparupa Sengupta, ${ }^{\mathrm{a}} \#$ Rupali Datta, ${ }^{\mathrm{a}}$ Susan T. Bagley ${ }^{\mathrm{a}}$

Department of Biological Sciences, Michigan Technological University, Houghton, Michigan, $\mathrm{USA}^{\mathrm{a}}$;

Running Head: Tetracycline detoxification capability of bacteria

\#Address correspondence to Aparupa Sengupta, asengupt@mtu.edu. 
Abstract

The excessive use, improper handling and disposal of antibiotics have created negative impacts on environmental and human health. Biological remediation systems using plants and/or microbes could be used to remove these organic compounds from water sources. Two bacterial strains that are associated with vetiver roots were recovered during an invitro remediation study and were identified as Serratia marcescens and Burkholderia cepacia. These two strains were tetracycline (TC) tolerant and were evaluated for their ability to tolerate, degrade, use, or transform TC. These bacteria were successfully transformed TC into its isomers, epi-TC (ETC) and anhydro-TC (ATC), within five days, and transformation was faster in treated flasks than in the untreated (abiotic) controls. The potentially harmful isomer of TC, ATC, disappeared within a 15day period in the treated flasks (with bacteria) compared to the abiotic flasks, which still showed traces of these compounds. In general, B. cepacia showed a higher level of TC utilization and transformation than S. marcescens. To understand the metabolic pathways impacted during TC degradation in bacteria, extracellular and intracellular metabolomic pathway analysis was performed on both $S$. marcescens and B. cepacia using GC-MS. The results indicated that the fatty acid biosynthesis pathway was significantly expressed during TC metabolism in both bacteria, hence revealing one of the possible pathways that are potentially impacted during TC metabolism in these bacteria.

Keywords: Tetracycline, water sources, antibiotics, bioremediation, vetiver grass, metabolic pathway 
Introduction

Antibiotic contamination in the environment is of serious global concern (Rehman et al., 2013). Wastewater treatment facilities are not effective at removing these organic compounds from the waste stream, leading the contaminated water to be discharged into surface water system, and eventually into groundwater, irrigation water, and drinking water resources (Michael et al., 2013, Watkinson et al., 2009). Prolonged exposure to antibiotics in the environment causes human health problems in the forms of multiantibiotic resistant bacteria, and an overall disturbed ecosystem (Fatta-Kassinos et al., 2011, Gonzalez-Pleiter et al., 2013).

In last several decades, several biotic and abiotic remediation technologies have been widely used to detoxify environmental sources from personal care products, hormones, and antibiotics (Randhawa et al.,2011, Jiang et al., 2010, Kummerer et al., 2009a). However, most of the conventional techniques are expensive and time-consuming compared to the bioremediation process. The terms biodegradation or bioremediation have not been well defined in practice (Jia et al., 2009, Pena et al., 1998). Generally, biodegradation refers to the complete breakdown or removal of the parent compound. However, many studies use the term biodegradation to refer (Jia et al., 2009, Pena et al., 1998) to the transformation of the parent compounds into their isomers. In some cases, the isomers are more harmful than the parent compound; hence the process should be termed as biotransformation and not biodegradation (USGS; http://toxics.usgs.gov/definitions/biodegradation.html). Biological treatment systems that can biodegrade or completely remove the parent compound and its harmful isomers would be a useful technology for antibiotic remediation. The goal of the biological 
treatment system would be to treat the wastewater effluent, removing these antibiotics and transformation products before the final disposal of the wastewater effluent into surface water sources (Michael et al., 2013).

The most common and broad spectrum antibiotics used for human health and veterinary purposes are penicillins, aminoglycosides, and TCs (Sarmah et al., 2006). Among these TCs are most commonly detected in various environmental sources. Also, the TC group of antibiotics is a broad spectrum class of antibiotics and is effective at killing both gram positive and gram negative bacteria. (Ding et al.,2010, Kummerer et al.,2009, Sarmah et al., 2006).

Studies of microbial antibiotic degradation show that the microbes recovered from antibiotic contaminated systems could have the ability to degrade antibiotics because they are acclimatized to these compounds (Nnenna et al., 2011). Dantas et al. (2008) demonstrated that microbes (including Burkholderia and Serratia sps.) recovered from antibiotic-contaminated soil can not only use various antibiotics as their sole carbon source, but can also catabolize antibiotics via a degradation pathway. In addition, a study conducted by Barnhill et al., (2010) showed that multi resistant Salmonella sps. are able to degrade antibiotics. Ooishi and Tosa (2010) showed that tetracycline (TC)-degrading bacteria were also TC-resistant could grow on it while degrading it in different water sources tested.

However, a recent publication by Walsh et al., 2013 challenges the concept of Dantas et al., (2008), by showing contradictory results that disprove the concept of antibiotic 
catabolizing by resistant bacteria. Instead, Walsh et al., 2013 found the antibiotics were detoxified by bacteria via resistance mechanisms and enzyme degradation as oppose to having a unique mechanism to do so. The study was performed with the objective of validating the results proposed by Dantas et al.(2008) who found that penicillin-resistant soil bacteria could utilize and degrade penicillin as the sole carbon source. However, the results obtained by Walsh et al., 2013 indicate that there is no additional degradation mechanism involved in the penicillin breakdown process except for $\beta$-lactamase activity. The authors also pointed out that the defined media (single carbon source media; SCS) with penicillin as the only carbon source described by Dantas et al. (2008) actually had an additional source of carbon in the media in the form of EDTA. There was also evidence of bacterial growth in SCS media flasks that had not been supplemented with penicillin.

Both studies Dantas et al., (2008) and Walsh et al., (2013) were designed and performed with separate objectives and were conducted in different ways. However, the conflict in these results still remains that whether or not antibiotic resistant bacteria can utilize and degrade antibiotics as the sole carbon source (Dantas et al., (2008), Barnhill et al., (2010) Nnenna et al., (2011), Walsh et al., (2013)). Although these studies did not specifically examine the TC group of antibiotics, TC-resistant bacteria should still be studied using the same concepts in order to determine their possible role in degrading the TC group of antibiotics.

Vetiver (Chrysopogon zizanioides) is a sub-tropical grass and has shown its capability to decontaminate various xenobiotic compounds (Makris et al., 2007, Truong et al., 2010). 
It has been established as a successful phytoremediation model for TC removal from water sources (Datta et al., 2013, Chapter 2 of thesis). In this study, two vetiver rootassociated TC-tolerant bacteria, identified as Serratia marcescens and Burkholderia cepacia, were recovered from hydroponic remediation tanks with the purpose of identifying the role of these root-associated bacteria in TC degradation. These strains were cultured and evaluated for their role in the TC detoxification and remediation process. For each bacterium, the minimum inhibitory concentration (MIC) of TC was measured, and their ability to use $\mathrm{TC}$ as the sole carbon and nitrogen source was determined (Figure 3.1 and Figure 3.5). Growth conditions including pH, temperature, and oxygen requirements were determined for each strain in presence of TC. These growth conditions were optimized in a companion study (Appendix D), with the objective of providing the best growth conditions for these bacteria when using them for TC remediation.

Environmental metabolomics reveals the effect of environment on the metabolic changes that occur in living organisms due to the interaction effect (Viant et al., 2012). Metabolic profiling of organisms used in the field of bioremediation is gaining attention due to its potential application in the field (Villas-Bôas and Per Bruheim, 2007). Derewacz et al., (2013) recently noted that there could be a significant metabolism shift in the microorganism as a result of antibiotic resistance. Hence, to understand the TC metabolism process in these TC-tolerant vetiver-root associated bacteria, intracellular and extracellular metabolic profiling was conducted in both $S$. marcescens (SM) and $B$. 
cepacia $(\mathrm{BC})$ in presence of TC. The results were compared to the abiotic control flasks to understand the effect of TC on the metabolism of these bacteria.

Materials and Methods

\section{- Isolation of TC-tolerant bacteria and sampling}

Hydroponic tanks were set up as part of a 30 day TC remediation study using vetiver plants (as per chapter 2 description, Sengupta et al., 2013 a). Bacteria were isolated and cultured from both hydroponic media samples (from the tanks set-up for remediation study; Ch.2) and vetiver root samples. Media samples were collected from different tanks on days $0,5,15$, and 30 . Plant root samples were collected on days 0 and 30 .

\section{- Recovering and culturing TC-tolerant bacteria}

Viable count analyses were performed on the plant and media samples using the spread plate technique. The media samples were serially diluted and root samples were crushed with liquid nitrogen in an autoclaved mortar and pestle following the method from Trivedi et al., (2011), and then plated on enriched medium (R2A agar) with five different concentrations $(0,10,25,50,100 \mathrm{mg} / \mathrm{L})$ of TC $(99 \%$ pure obtained from Thermo Scientific). Three dilutions were tested in duplicates with each sample. All the plates were incubated at $30^{\circ} \mathrm{C}$ for $24-72$ hours. The plates with maximum colony types were selected for further analysis. A total of 23 bacterial colonies were recovered and among them five bacterial colonies that could tolerate $50 \mathrm{ppm}$ of $\mathrm{TC}$ were selected for further 
studies. Among these 23 colonies, 13 colonies were recovered from plant roots on day 30 and 10 colonies were recovered from media samples on days 5, 15, and 30. Among these colonies, five colonies were randomly chosen for further analysis and were streaked for isolation on enriched medium (R2A agar) supplemented with TC (100 mg/L). These colonies were labelled as \#1 through \#5. Isolates \#1, \#2 and \#3 were recovered from plant root and isolates \#4 and 5 were recovered from media samples.

\section{- Growth studies}

An initial screening of all five bacteria was conducted on SCS (Table C.4) supplemented with 10 and 50 ppm of TC (appendix B.2). The medium was modified from Dantas et al., (2013) as the SCS media used in this study, showed some growth in it even without supplementing the media with a carbon source (modified medium recipe is in appendix C.4, the purpose of modification was to make sure there are no additional carbon sources other than TC added to the media such as EDTA ). The purpose of this experiment was to evaluate if these bacteria can use and tolerate TC. Bacterial colonies that demonstrated comparative higher growth (\#1, \#2, and \#3) in both flasks (with 10 and 50 ppm of TC) were selected for further studies (Figure B.2.1). These colonies were also streaked for isolation on R2A agar plates supplemented with $100 \mathrm{ppm}$ TC on a weekly basis, to ensure the purity of the culture and to keep the natural process of selective

pressure on the bacteria to enhance their TC utilization capability. After the initial screening growth study, isolates $\# 1, \# 2$, and \#3 were evaluated for their growth in presence of $75 \mathrm{ppm}$ of $\mathrm{TC}$ (TC concentration was increased to match the remediation 
studies, which was conducted in higher TC concentrations) in both SCS (defined) and enriched (tryptic soy broth; TSB) medium (Appendix B.3). The inoculum flasks were centrifuged individually and the pellet was washed with buffer twice to eliminate any nutrient transfer in the flasks set-up for growth and optimization studies. For all growth and optimization studies (involving single carbon source media), bacterial inoculum was grown in TSB supplemented with $100 \mathrm{ppm}$ TC overnight at $30^{\circ} \mathrm{C}$ in a gyratory shaker at $160 \mathrm{rpm}$ and centrifuged (as discussed above) then transferred repeatedly (at least 3times) in SCS media (to minimize nutrient carry over) before inoculating the SCS media flasks for experiments. All absorbance values were measured at $660 \mathrm{~nm}$ using spectrophotometer and converted to dry weight $(\mathrm{mg} / \mathrm{L})$ using the formula $\left[\left((364.74 *\right.\right.$ Absorbance $)+\left(6.7 *\right.$ Absorbance $\left.\left.\left.^{2}\right)\right)\right]($ Handbook of Microbiology $)$.

\section{- Screening for minimum inhibitory concentration (MIC)}

Bacteria that were able to grow in the highest concentration of TC $(75 \mathrm{mg} / \mathrm{L})$ were screened for their MIC of TC. A range of TC concentrations $(0,15,60,250$, and 1000 ppm of TC) were tested on both of these bacteria and 96 well plates were set up with inoculated and not inoculated controls in replicates of three (Andrews, 2001). The plates were incubated at $30^{\circ} \mathrm{C}$ and absorbance was measured at $660 \mathrm{~nm}$ every 24 hours starting at 0 hour, until a stationary phase was observed (48 hours). 


\section{- Characterization and identification studies of unknown bacterial isolates}

Bacterial colony types were characterized using standard methods and biochemical tests in the lab (Table B.3.1) and were identified using MALDI-TOF and 16S rRNA analyses (at MIDI Labs Inc, Newark, DE). The sequences are submitted to the gene bank.

\section{- TC utilization study design}

Bacterial colonies were maintained on R2A agar plates with $100 \mathrm{ppm}$ of TC and were transferred weekly. Inocula were prepared overnight in $250 \mathrm{~mL}$ erlenmeyer flasks. The cells were centrifuged $(10,000 \mathrm{x}$ g for $10 \mathrm{~min})$ and the pellet was re-suspended in the flasks with the SCS (defined) medium (Table C.4.1) or TSB medium (enriched) before inoculating the experimental flasks in order to avoid any extra nutrient transfer. SCS is a defined medium and TC added as the sole carbon source (75 $\pm 5 \mathrm{ppm}$ and $10 \pm 3 \mathrm{ppm})$. TSB is an enriched medium containing multiple nutrients; along with TC, which is supplemented as a carbon source $(75 \pm 5 \mathrm{ppm}$ and $10 \pm 3 \mathrm{ppm})$ (composition in Table C.4). Erlenmeyer flasks $(250 \mathrm{~mL})$ were filled with $50 \mathrm{~mL}$ of each type of medium and were compared to un-inoculated (medium with TC and without bacteria) and inoculated controls (medium without TC and with bacteria). The TC utilization experiments were carried out for 7 days at $30^{\circ} \mathrm{C}$ and the samples were collected every 24 hours for the analysis of TC and its isomers anhydro-TC (ATC) and epi-TC (ETC) using HPLC LCMS/MS. 


\section{- Bacterial sample preparation for metabolomics}

Bacterial strains (\#1 and \#2) were prepared for GC-MS analysis following extraction procedures modified from a previously reported method (Frimmersdorf et al., 2006), and following the modified method from Chapter 2 (Sengupta et al., 2013 a). The bacterial inocula were prepared as mentioned in the section above and the experimental flasks were set up using erlenmeyer flasks $(250 \mathrm{~mL})$ with $50 \mathrm{~mL}$ of TSB and $75 \pm 5 \mathrm{mg} / \mathrm{L}$ of TC (this TC concentration was used to keep the study uniform with the TC remediation study). The flasks were incubated at $30^{\circ} \mathrm{C}$ for $8-10$ hours until the log phase was observed.

\section{- Analytical method for HPLC and LC/MS-MS}

All bacterial media samples collected during the TC utilization study were analyzed for presence of TC and its isomers (ETC and ATC) following the method from Chapter 2 (Sengupta et al., 2013 a) and Jia et al., 2009.

\section{- Sample Analysis method for GC-MS}

The intracellular and extracellular bacterial samples after derivitization were analyzed using GC-MS (GC-17A Shimadz coupled with GCMS-QP5050) to identify the metabolites that were involved in a possible TC degradation pathway. The methods for analysis were followed from Chapter 2 (Sengupta et al., 2013 a). 
Metacyc and Biocyc are two comprehensive metabolomics databases which allow users to match compounds against the specific organism database to understand the role of a particular compound. These databases were used to compare names of compounds, received from GC-MS analysis, against these databases.

\section{- Statistical Analysis for TC utilization study}

a) Results were compared between samples collected from treated flasks with bacteria vs. abiotic control flasks (without bacteria) on each sampling day $(0,1,2,3,5$, and 7$)$ for each concentration of TC used $(10,75 \mathrm{ppm})$ for both $S$. marcescens and $B$. cepacia (separately). Two-way ANOVA analysis was conducted on each day where, $\mathrm{p}$ values $(\mathrm{p}<0.05)$ were compared between i) different concentrations (10 and 75 $\mathrm{mg} / \mathrm{L} \mathrm{TC})$; ii) with and without bacteria; and iii) their interaction effect using JMP IN version 8.0 (Sall et al., 2005). To understand significant difference among treatment means Tukey-Kramer honest significant difference (HSD) test was performed if interaction among the factors were found significant.

b) Statistical and hierarchical cluster analysis for metabolic analysis experiments were performed using the Student's t-test $(\mathrm{p}<0.05)$. Statistical analysis was performed on both intracellular and extracellular analyzed metabolites $(75 \pm 5 \mathrm{ppm})$ of B.cepacia and $S$. marcescens to identify the statistical significant metabolites expressed in presence of TC compared to the controls (no TC) using Multiarray Viewer (MeV) software 4.7.4 and the Student's t-test (significance $\mathrm{p}<0.05$ ) and Pearson co-relation. Results were normalized with abiotic controls (no bacteria) to establish the baseline 
(Li et al., 2012) (Table 3.1). Pathway analysis was performed using MetaboAnalyst 3.0 followed by KEGG (Xia et al., 2012) and additional database online.

Results and Discussion

Wastewater effluents are identified as hotspots for antibiotic contamination because wastewater facilities are not typically equipped to remove antibiotics. Hence, these compounds are released into various water sources (Michael et al., 2013, Sarmah et al., 2006). TC usually transform into its isomers (ETC and ATC), which in some cases are more harmful than the parent compound (Jia et al., 2009). TC-tolerant bacteria were recovered and cultured in lab from both media samples and vetiver root-zone samples collected during the hydroponic TC remediation study. Bacterial colonies that were highly tolerant to tetracycline (bacterial isolates \# 1,2 and 3) were selected for further characterization (Appendix B).

Preliminary growth studies were conducted using different media (TSB and SCS) supplemented with $75 \mathrm{ppm}$ of TC for all three TC-tolerant bacteria. Two different media were used to understand the TC metabolism process in these bacteria and to compare their growth dynamics when presented with TC as the single carbon source vs. TC as one of the carbon sources in the enriched medium. Results showed growth of all three bacteria in both media types (Appendix B.3). However, the growth in SCS medium was very low compared to TSB medium (Table B.7). However, since the growth was so low in SCS medium, these three bacteria were naturally adapted over a period of 8-10 weeks with repeated transfer of culture in presence of TC. The rationale behind the natural 
adaptation process was that, placing selective pressure on the bacteria would increase their TC tolerance and use could also be effective in increasing TC catabolic ability (Nicolaou et al., 2010).

Standard characterization tests were performed on these bacterial isolates (Table B.3.1) in the lab, and then the samples were further identified using 16S rRNA sequencing and MALDI-TOF (Matrix-assisted lase desorption/ionization- time of flight) . Results from both the MALDI-TOF and 16S rRNA sequencing identified Isolates \#1 and \#3 to be Serratia marcescens (SM) and isolate \#2 to be Burkholderia cepacia (BM). Therefore, further studies were conducted using isolates only $\# 1$ and $\# 2$. Since, isolate \#1 and \#3 were very similar (Figures B.3, B.3, D.1, D.2, D.4, D.6-D.8) and they were both identified as SM, henceforth only isolate \# 1 (comparatively higher growth compared to \#3) was used for other tests.

B. cepacia and $S$. marcescens have been reported as highly resistant to antibiotics and they could be used as a bioremediation tools to degrade different antibiotics (Dantas et al., 2008, O'Sullivan LA and Mahenthirallingam E 2005). Several growth parameters were optimized for both of these bacteria in presence of TC (75 ppm) in a companion study (Figures D.1- D.5). The optimized growth conditions in the presence of TC for these bacteria were incubation temperatures of $24-30^{\circ} \mathrm{C}, \mathrm{pH}$ of $7-7.5$, and an aerobic environment (growth rates presented in appendix B.7 and figures D.11 and D.12).

S. marcescens and B. cepacia were evaluated for their maximum tolerance of TC by using a range of TC concentrations. The results (appendix B.6) demonstrate that there 
was little to no growth inhibition of these two bacteria when the TC concentration was as high as $1000 \mathrm{mg} / \mathrm{L}$. This suggests that these bacteria were well adapted to tolerate high concentrations of TC and might possibly be using TC as a carbon source. Growth of these bacteria was higher in presence of glucose but they still grew and utilized TC when grown in SCS media (Figures D.11 and D.12). Although, this may suggest a slight negative effect of TC on growth of these bacteria.

To evaluate if these bacteria could use TC as the sole carbon source, growth studies were set up using SCS medium supplemented with TC $(1 \mathrm{~g} / \mathrm{L})$. The results showed that these TC-tolerant bacteria could successfully utilize TC as the sole carbon source (Figure 3.1). These results agree with other studies which showed antibiotic resistant bacteria can use antibiotics as the sole carbon source (Dantas et al., 2008, Nnenna et al., 2011, Ooishi et al., 2010).

The TC utilization capability of $B$. cepacia and $S$. marcescens was evaluated using TSB and SCS media supplemented with TC (TSB: $75 \pm 5$ and $10 \pm 3$ ppm and SCS: $75 \pm 5$ and $10 \pm 3 \mathrm{ppm})$. The results show that these TC-tolerant bacteria can successfully utilize and transform TC on both kinds of media (Figures 3.2, 3.3, 3.4, appendix C.1 and C.2). Figure 3.2 shows TC removal from the media (SCS) supplemented with TC and Figure 3.3 shows TC transformation to ETC in the SCS media flasks supplemented with of TC respectively. Figures C.1 and C.2 show similar results as described above but in TSB media. Both of these species were previously reported to utilize and resistant to antibiotics such as when penicillins $(1 \mathrm{~g} / \mathrm{L})$ were the sole carbon source (Dantas et al., 2008). 
These results also show that the transformation and removal of TC was higher in treated flask than in the abiotic control samples between day 0 and day 7 (Figure 3.2 and C.1). Also, the formation of ETC was higher in the control samples than in the treated samples with B. cepacia and S. marcescens between day 1 and day 7 of the study (Figure 3.3 and C.2.1). Thus, the overall results indicate the involvement of a biochemical pathway in the biotransformation process of TC by $S$. marcescens and B. cepacia compared to the control samples. ATC was detected in the control on day 15, however, it was not detected in the samples treated with S. marcescens and B. cepacia (Figure 3.4) after 15 days of treatment. These isomers (ATC) have been reported to be more toxic to some living organisms than the parent compound if remained untreated (Dos Santos et al., 1998).

Statistical analyses were performed for each bacterium (SM and BC) in both media (SCS and TSB) separately. The results for SCS media (with TC) treated with BC vs. abiotic media conditions on days $1,3,5$, and 7 demonstrates that all factors and interactions were significant, whereas on day 2 the factors individually were not significant but the interaction was found significant. Tukey's HSD test shows there was significant difference between SCS media (with TC) treated with BC vs. abiotic media on all days.

The results for TSB media (with TC) treated with $\mathrm{BC}$ vs. abiotic media conditions on days $1,3,5$, and 7 demonstrates that all factors and interactions were significant, whereas on day 2 the factors individually were not significant but the interaction was significant. Tukey's HSD test shows there was significant difference between SCS media (with TC) 
treated with BC vs. abiotic media on all days, except for in $10 \mathrm{mg} / \mathrm{L}$ TC treatment on day 2 .

The results for SCS media (with TC) treated with SM vs. abiotic media conditions on days $1,2,3,5$, and 7 demonstrates that all factors and interactions were significant. Tukey's HSD test shows there was significant difference between SCS media (with TC) treated with $\mathrm{BC}$ vs. abiotic media on all days, except for in $10 \mathrm{mg} / \mathrm{L}$ TC treatment on day 2.

The results for TSB media (with TC) treated with SM vs. abiotic media conditions on days 1 and 2, factors individually were not significant but the interaction was found significant whereas, on days 3, 5, and 7 all factors and interactions were significant. Tukey's HSD test shows there was significant difference between SCS media (with TC) treated with $\mathrm{BC}$ vs. abiotic media on all days except for in $10 \mathrm{mg} / \mathrm{L} \mathrm{TC}$ treatment on days 1 and 2 .

Since the results indicated that $S$.marcescens and $B$. cepacia could use tetracycline as the sole carbon source, these bacteria were further evaluated to check if they could also use TC as nitrogen source with a purpose of developing better understanding of TC metabolism in these bacteria. Perlman et al., (1971) mentioned that antibiotic-tolerant bacteria could use antibiotics as either the carbon or nitrogen source during their transformation process. However, to the best of our knowledge, antibiotics have never been screened to be used as nitrogen source by antibiotic-resistant bacteria. Figure 3.5 show that both $S$. marcescens and B. cepacia can use TC as sole nitrogen source. 
In order to further investigate the biochemical mechanism used by $S$. marcescens and $B$. cepacia, intracellular and extracellular metabolomics analysis was performed during the TC utilization study. Samples were collected during the log phase of growth to identify the metabolites expressed during $\mathrm{TC}$ transformation and/or degradation process. Although bacterial metabolic profiling has not been evaluated before in presence of TC (or any other antibiotic), this approach has been tested during utilization of other compounds by bacteria, including but not limited to, heavy metals and casamino acids (Li, 2012, Frimmersdorf et al., 2013).

The results of extracellular metabolic profiling in both bacteria showed seven statistically significant compounds (Appendix C.3) expressed during TC metabolism (found in both bacteria), including phenols and esters, when compared to the abiotic control. However, none of these compounds established a pathway match when analyzed in MetaboAnalyst and KEGG databases. The results of intracellular metabolomic profiling in both the bacteria identified two metabolites, palmitic acid and stearic acid, which were significantly expressed $(\mathrm{p}<0.05)$ in treated flasks compared to control. Pathway analysis identified these two metabolites to be part of fatty acid metabolism (Table 3.1). N- Hexadecanoic acid which is also known as palmitic acid, had a high fold change and was matched in Biocyc for both S. marcescens and B. cepacia. Palmitic acid is a saturated fatty acid which is produced by phospholipases and triacylglycerol degradation and consumed in fatty acid oxidation. Overall, metabolic profiling of both TC-tolerant bacteria revealed that saturated fatty acids were significantly increased in flasks supplemented with TC and thus impacted the pathway of fatty acid biosynthesis. 
These results are in agreement with a recent study by Derewacz et al., (2013), which describe that the antibiotic-resistant bacteria demonstrate a change in fatty acid composition as result of change in metabolism due to the resistance acquired towards antibiotics.

Additional compounds were detected during intracellular and extracellular metabolic analysis of S. marcescens and B. cepacia in presence of TC. These compounds did not have a match in the database to relate the compound directly to a pathway used by bacteria, which is likely because metabolic profiling during antibiotic metabolism is a novel approach. However, there were differences observed between the control and treated flasks. The results were not all statistically significant but the tables calculated for fold change in metabolite concentration between the control and experimental flasks have been reported in tables C.3.1 and C.3.2).

There were also differences observed between the control and treated flask samples in terms of presence and absence of several metabolites. Some metabolites were present in control samples but completely absent in the treated samples and vice-versa for both intracellular and extracellular analyses. The metabolites which had a higher fold of change (reduced and/or increased between control and treated samples) were explored for their roles in bacterial metabolism (Appendix C.3).

Although there were no conclusive TC degradation pathways established by the metabolic profiling experiment, many compounds were detected which were different (present vs. absent, high vs. reduced) between the control and treated flasks. This 
information could provide useful insight for future molecular analysis performed during the bacterial TC removal process.

The finding of this study is in agreement with some aspects, and contradicts other aspects of a recent study by Walsh et al., (2013). The results of this study suggests that $B$. cepacia and $S$. marcescens can use TC as the sole carbon source and can also transform it, which is in agreement with the previous study by Dantas et al.,. 2008, and Barnhill et al., 2010. However, the results from this study could not confirm that the TC degradation and transformation process used by these bacteria is an intrinsic bacterial catabolic pathway. Further investigation is required to confirm and identify the biochemical pathway involved in TC biodegradation process.

\section{Conclusion}

Vetiver root-associated bacteria (Burkholderia cepacia and Serratia marcescens) were recovered from a hydroponic TC remediation system and can tolerate and grow in presence of TC concentrations as high as $1000 \mathrm{ppm}$. These bacteria were able to complete remove or biotransform both TC and its potential harmful isomers ETC and ATC within 15 days of treatment. The TC-tolerant bacteria, B. cepacia and $S$. marcescens, have a low optimum temperature range of $28-30^{\circ} \mathrm{C}$ and could potentially be used in controlled settings to remediate TC.

\section{Acknowledgements}

The authors would like to acknowledge the Department of Biological Sciences and the Department of Chemistry, Michigan Tech for providing lab facilities and resources. Zack Anthony and Andrew Kennedy for helping with the study, Jerry Lutz for providing 
support with LC-MS and GC-MS, and Department of Biological Sciences for the financial support in the form of a graduate stipend.

\section{References}

1. Andrews JM (2001) Determination of minimum inhibitory concentration. J. Antimicrob. Chemoth. 48:5-16.

2. Boxall ABA (2004) The environmental side effects of medication. EMBO J. 5:1110-1116.

3. Dantas G, Sommer MOA, Oluwasegun RD, Church GM (2008) Bacteria subsisting on antibiotics. Science.320:100-103.

4. Datta R, Das P, Smith S, Punamiya P, Ramanathan DM, Reddy R, Sarkar D (2013) Phytoremediation potential of tetracycline by vetiver grass (Chrysopogan zizanioides(L.) for tetracycline. Int. J Phytorem. 15:343-351.

5. Derewacz DK, Goodwin CR, McNees CR, McLean JA, Bachmann BO (2013) Antimicrobial drug resistance affects broad changes in metabolomic phenotype in addition to secondary metabolism. Proc Natl Acad Sci U S A. 5: 2336-41. doi: 10.1073/pnas.1218524110.

6. Ding C, He J (2010) Effect of antibiotics in the environment on microbial populations. Appl. Microbiol. Biot. 87:925-941. 
7. Dos Santos HF, De Almeida WB, Zeener MC (1998) Conformational analysis of the anyhydrotetracycline moleculae: a toxic decomposition product of tetracycline. J. Pharm. Sci. 87: 190-195.

8. Du L, Liu W (2012) Occurrence, fate, and ecotoxicity of antibiotics in agroecosystems. A review. Agron. Sustain. Dev. 32:309-327.

9. Fatta-Kassinos D, Meric S, Nikolaou A (2011) Pharmaceutical residues in environmental waters and wastewater: current state of knowledge and future research. Anal. Bioanal Chem. 399:251-275.

10. Frimmersdorf E, Horatzek S, Pelnikevich A, Wiehlmann L, Schomberg (2010) How Pseudomonas aeruginosa adapts to various environments: a metabolomics approach. Environ. Microbiol. 12:1734-1747.

11. Gonzalez-Pleiter M, Gonzalo S, Rodea-Palomares, Leganes F, Rosal R, Boltes K, Marco E, Fernandez-Pinas F (2013) Toxicity of five antibiotics and their mixtures towards photosynthetic aquatic organisms: Implications for environmental risk assessment. Water Res. 47:2050-2064.

12. Halling-Sørenson B, Sengelov G, Tiornelund J (2002) Toxicity of tetracycline degradation products to environmentally relevant bacteria, including selected tetracycline resistant bacteria. Arch. Environ. Con. Tox. 42: 263-271.

13. Hu X, Zhou Q, Luo Y (2010) Occurrence and source analysis of typical veterinary antibiotics in manure, soil, vegetables and ground water from organic vegetable bases, northern China. Environ. Pollut. 158:2992-2998. 
14. Jia A, Xiaoa Y, Hua J, Asamib M, Kunikane S (2009) Simultaneous determination of tetracycline and their degradation products in environmental waters by liquid chromatography-electrospray tandem mass spectrometry. J. Chromatogr. 1216:4655-4662.

15. Kim K-R, Owens G, Kwon S-I, So K-H, Lee D-B, Ok YS (2011) Occurrence and environmental fate of veterinary antibiotics in the terrestrial environment. Water Air Soil Poll. 214:163-174.

16. Kong WD, Zhu YG, Liang YC, Zhang J, Smith FA, Yang M (2007) Uptake of oxytetracycline and its phytotoxicity to alfalfa (Medicago sativa L.). Environ. Pollut. 147:187-193.

17. Kummerer K (2004) Resistance in the environment. J Antimicrob Chemother. 54:311-320.Liu L, Liu Y-H, Liu C-X, Wang Z, Dong J, Zhu G-F, Huang X (2013) Potential effect and accumulation of veterinary antibiotics in Phragmites australis under hydroponic conditions. Ecol. Eng. 53:138-143.

18. Kummerer K (2009 a) Antibiotics in the aquatic environment-A review-Part I. Chemosphere. 75:417-434.

19. Kummerer K (2009 b). The presence of pharmaceuticals in the environment due to human use-present knowledge and future challenges. J. Environ. Manage. 90:2354-2366.

20. Le-Minh N, Khan SJ, Drews JE, Stuetz RM (2010) Fate of antibiotics during municipal water recycling treatment processes. Water Res. 44:4295-4323. 
21. Li, K (2012) Isolation of plant growth promoting bacteria from torch lake sediments and their role in phytoremediation of metal contaminated soil. Ph.D. Thesis. Michigan Technological University, Houghton, MI.

22. Liu S, Suflita JM (1993) Ecology and evolution of microbial populations for bioremediation. Trends Biotechnol. 11:344-352.

23. Martinez JL (2009) Environmental pollution by antibiotics and by antibiotic resistance determinants. Environ. Pollut. 157:2893-2902.

24. Michael I, Rizzo L, McArdell CS, Manaiad CM, Merline C, Schwartz T, Dagot C, Fatta-Kassinos D (2013) Urban wastewater treatment plants as hotspots for the release of antibiotics in the environment: A review. Water Res. 47:957-995.

25. Nicolaou SA, Gaida SM, Papoutsakis ET (2010) A comparative view of metabolite and substrate stress and tolerance in microbial bioprocessing: From biofuels and chemicals, to biocatalysis and bioremediation. Metab. Eng. 12:307331.

26. Nnenna F-P, Lekiah P, Obemeata O (2011) Degradation of antibiotics by bacteria and fungi from the aquatic environment. JTEHS. 3:275-285.

27. O'Sullivan LA, Mahenthirallingam E (2005) Biotechnological potential within the genus Burkholderia. Lett. Appl. Microbiol. 4:8-11. 
28. Ooishi T, Tosa K (2010) Occurrence of tetracycline-resistant and tetracyclinedegrading bacteria in wastewater treatment plant effluent and environmental water systems. J. Water Envrion. Technol. 8:321-327.

29. Park H, Choung YK (2010) Evaluation of the biodegradation feasibility of antibiotics by three bacteria involving glutathione S-transferases. Can. J. Civil Eng. 37:814-819.

30. Pena A, Carmona A, Barbosa A, Lino C, Silveira I, Castillo B (1998) Determination of tetracycline and its major degradation products by liquid chromatography with fluorescence detection. J. Pharmaceut. Biomed. 18:839-845.

31. Perlman D, Sebek OK (1971) Microbial transformations of antibiotics. Adv. Appl. Microbiol. 14:637-348.

32. Randhawa GK, Kuller JS (2011) Bioremediation of pharmaceuticals, pesticides and petrochemicals with cow dung. ISRN Pharmacol. doi:10.5402/2011/362459

33. Rehman MSU, Rashid N, Ashfaq M, Saif A, Ahmad N, Han JI (2013) Global risk of pharmaceutical contamination from highly populated developing countries. Chemosphere. In press, http://dx.doi.org/10.1016/j.chemosphere.2013.02.036.

34. Sall J, Creighton L, Lehman A (2005) JMP Start Statistics, third ed. SAS Institute, Cary, NC and Pacific Grove, CA.

35. Sarmah, A.K et al., (2006) A global perspective on the use, sales, exposure pathways, occurrence, fate and effects of veterinary antibiotics (Vas) in the environment. Chemosphere 65:725-759. 
36. Sengupta A, Waring K, Sarkar D, Datta R (2013 a) Tetracycline degradation in aqueous systems using vetiver grass and identification of tetracycline metabolites in the plant. Int. J. Phytorem. Manuscript in progress. (Chapter 2 of thesis).

37. Sharafi SM, Rasooli I, Beheshti-Maal K (2010) Isolation, characterization and optimization of indigenous acetic acid bacteria and evaluation of their preservation methods. Iran. J. Microbiol. 2: 38-45.

38. Stefanowicz A (2006) The biology plate technique as a tool in ecological studies of microbial communities. Polish J. of Environ. Stud. 15:669-676.

39. Trapp S, Ücisik AS, Romano PD, Larsen M (2007) The role of plants and bacteria in phytoremediation - kinetic aspects, p.41-49. In H.J Heipieper (ed.), Bioremediation of Soils Contaminated with Aromatic Compounds. Springer.

40. Trivedi P, Spann T, Wang N (2011) Isolation and characterization of beneficial bacteria associated with citrus roots in Florida. Microbial Ecol. 62:324-336.

41. Walsh F, Amyes SGB, Duffy B (2013) Challenging the concept of bacteria subsisting on antibiotics. Int. J. Antimicrob. Ag. 41:558-563.

42. Watkinson AJ, Murby EJ, Kolpin DW, Costanzo SD (2009) The occurrence of antibiotics in an urban watershed: From wastewater to drinking water. Sci. Total Environ. 407: 2711-2723.

43. Wright, GD (2005) Bacterial resistance to antibiotics: Enzymatic degradation and modification. Adv. Drug Deliv. Rev. 57: 1451-1470. 
44. Xia J, Mandal R, Sinelnikov I, Broadhurst D, Wishart DS (2012) MetaboAnalyst 2.0-a comprehensive server for metabolomics data analysis. Nucleic. Acids Res. 40: W127-W137. 


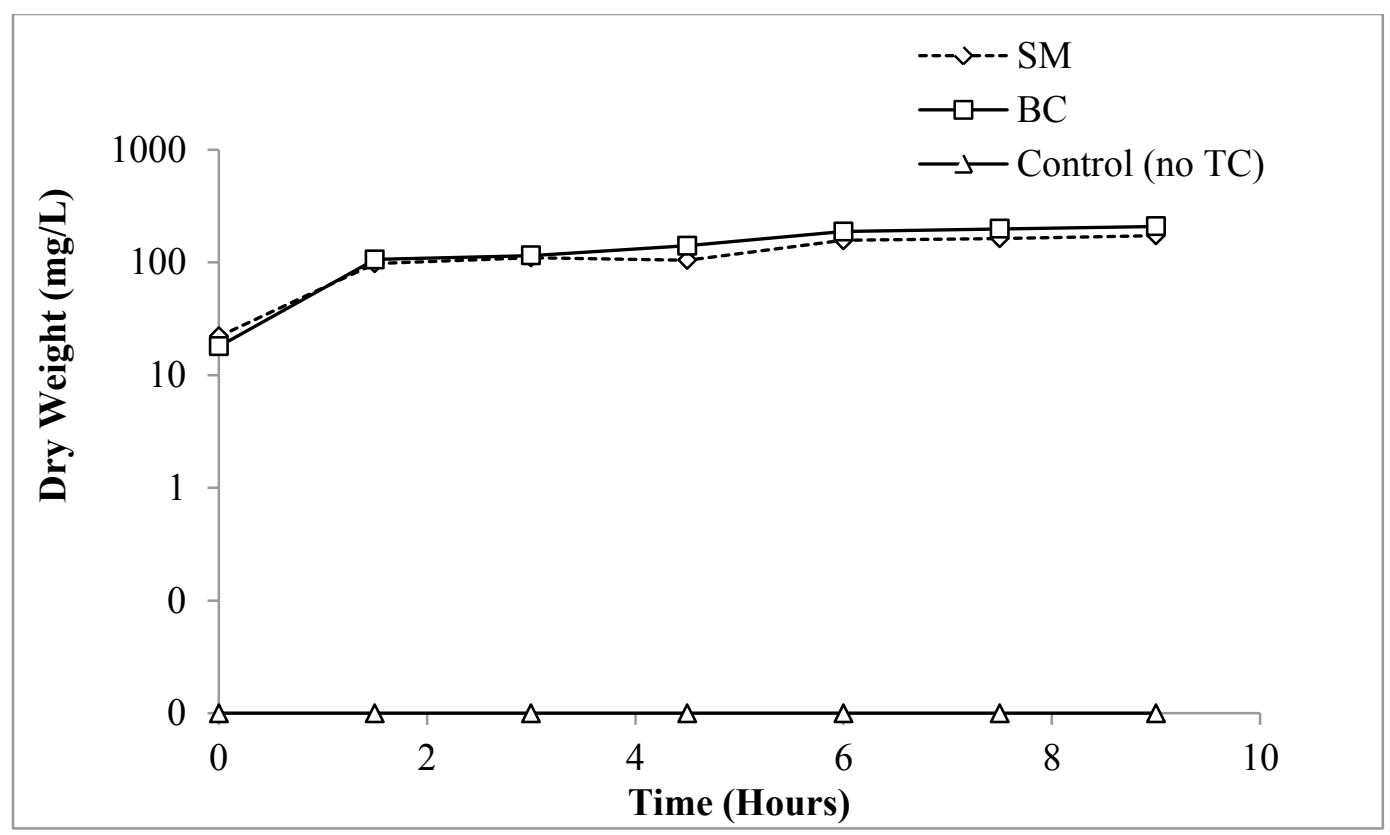

Figure 3.1. Growth study results of $S$. marcescens (SM) and B. cepacia (BC) in single carbon source (SCS) medium supplemented with TC as single carbon source (1g/L). TC. Control resuslts symbols for both SM and BC (with no TC). Results represented in mean $(\mathrm{n}=3), \pm 1 \mathrm{SD}$. 

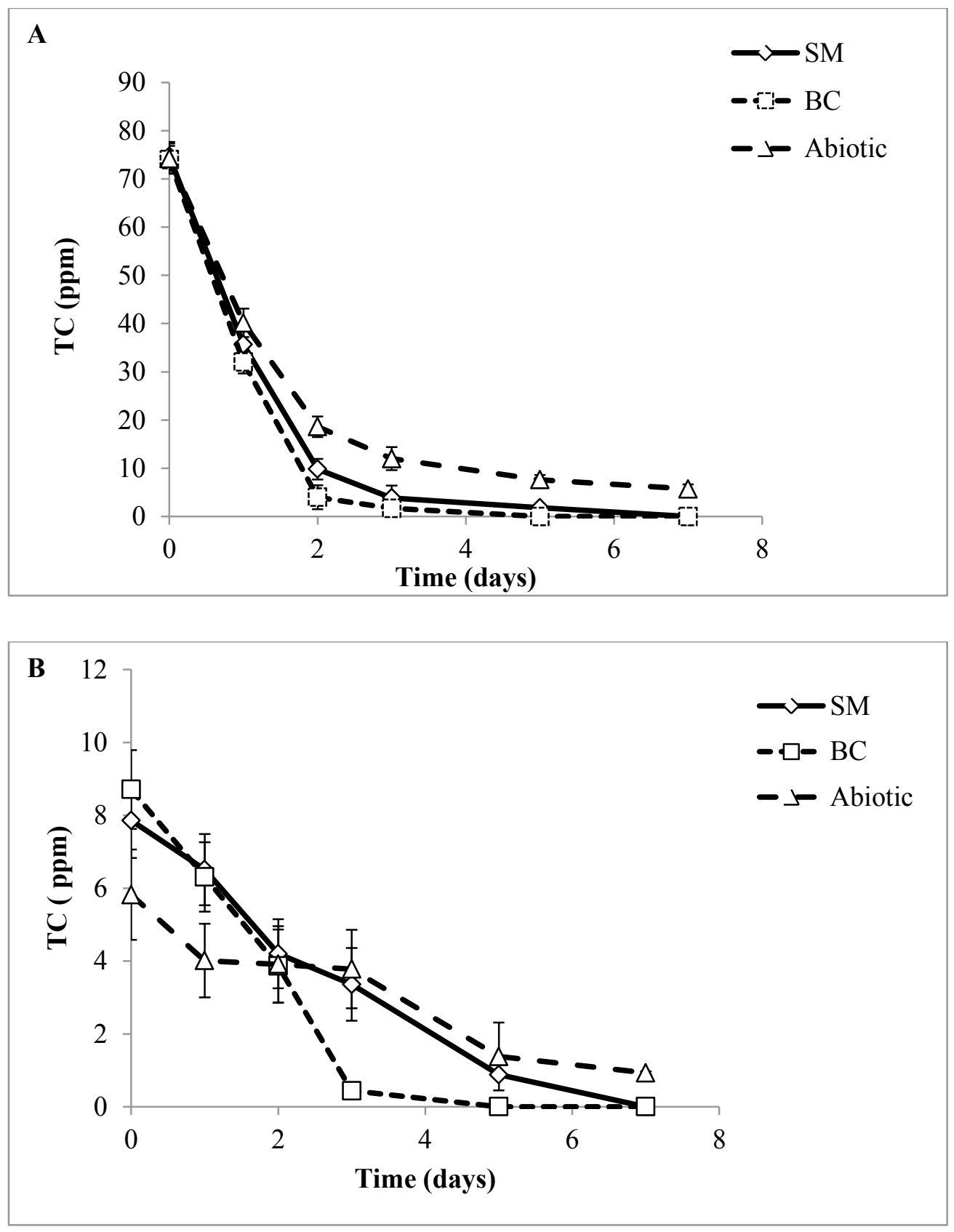

Figure 3.2. TC removal by $S$. marcescens (SM) and B. cepacia (BC) with TC vs. abiotic controls. The experiments were carried out for 28 days at $30^{\circ} \mathrm{C}, \mathrm{pH} 7$ in SCS media supplemented with A) $75 \mathrm{ppm} \mathrm{TC}$, and B) $10 \mathrm{ppm} \mathrm{TC}$. Results presented in mean ( $\mathrm{n}=3)$ \pm 1 SD. No TC was detected after 7 days. 

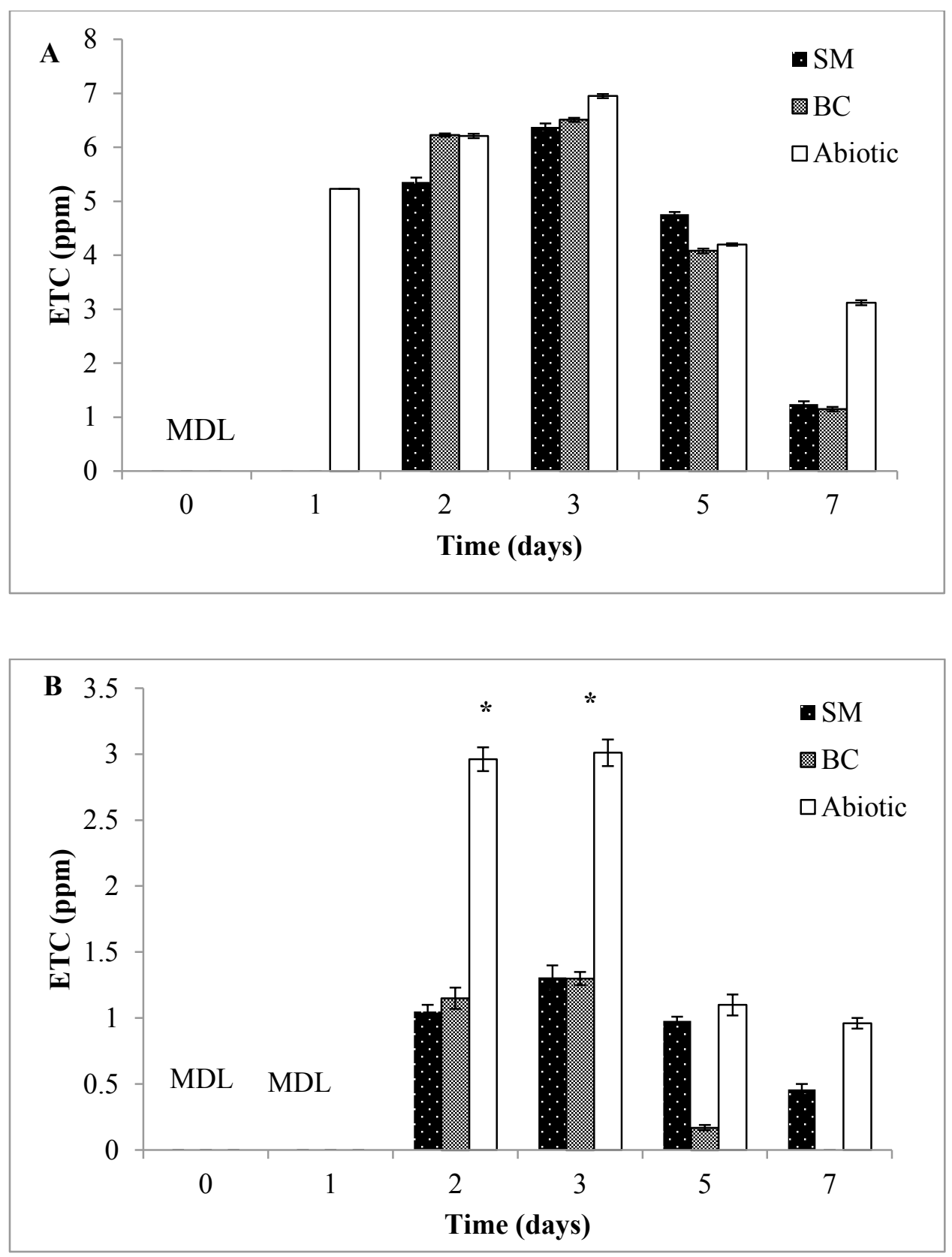

Figure 3.3. TC transformation into ETC by $S$. marcescens $(\mathrm{SM})$ and $B$. cepacia $(\mathrm{BC})$ in treated flasks vs. abiotic control flasks. The experiments were carried out for 28 days at $30^{\circ} \mathrm{C}$, pH 7 in SCS media supplemented with A) 75 ppm TC, below minimum detection limit (MDL) on day 0 , and B) $10 \mathrm{ppm}$ TC, MDL on days 0 and 1 . Results presented in mean $(n=3) \pm 1$ SD. There was no TC and ETC detected after day 7. 

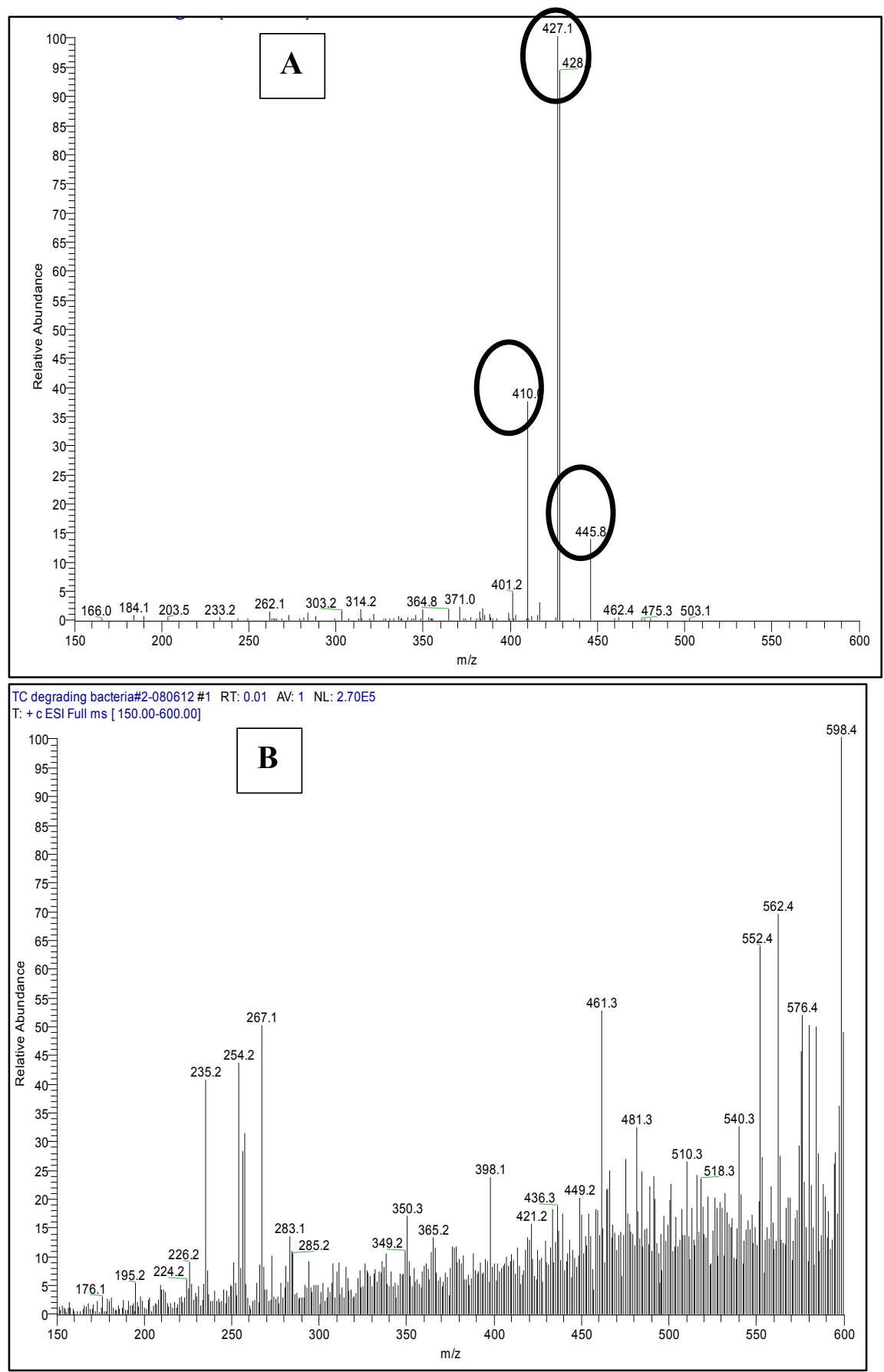

Figure 3.4. Full MS chromatogram (in LC-MS) of samples collected during TC utilization/transformation study A) Control (abiotic flask), B) B. cepacia on day 15. TC and its isomers (ATC, ETC) were not detected in the treated flask, but detected in abiotic control flask (showed with black circles). 
Table 3.1. Intracellular metabolomics results for B. cepacia and S. marcescens showed that statistically significant compounds were expressed (listed in compound match) during TC metabolism. Experiments were conducted in SCS supplemented with TC and compared to the untreated abiotic control flasks

\begin{tabular}{l|l} 
Compound match & Pathway name \\
\hline Palmitic acid and Stearic acid & $\begin{array}{l}\text { Biosynthesis of unsaturated } \\
\text { fatty acid } \\
\text { Palmitic acid }\end{array}$ \\
Fatty acid metabolism
\end{tabular}




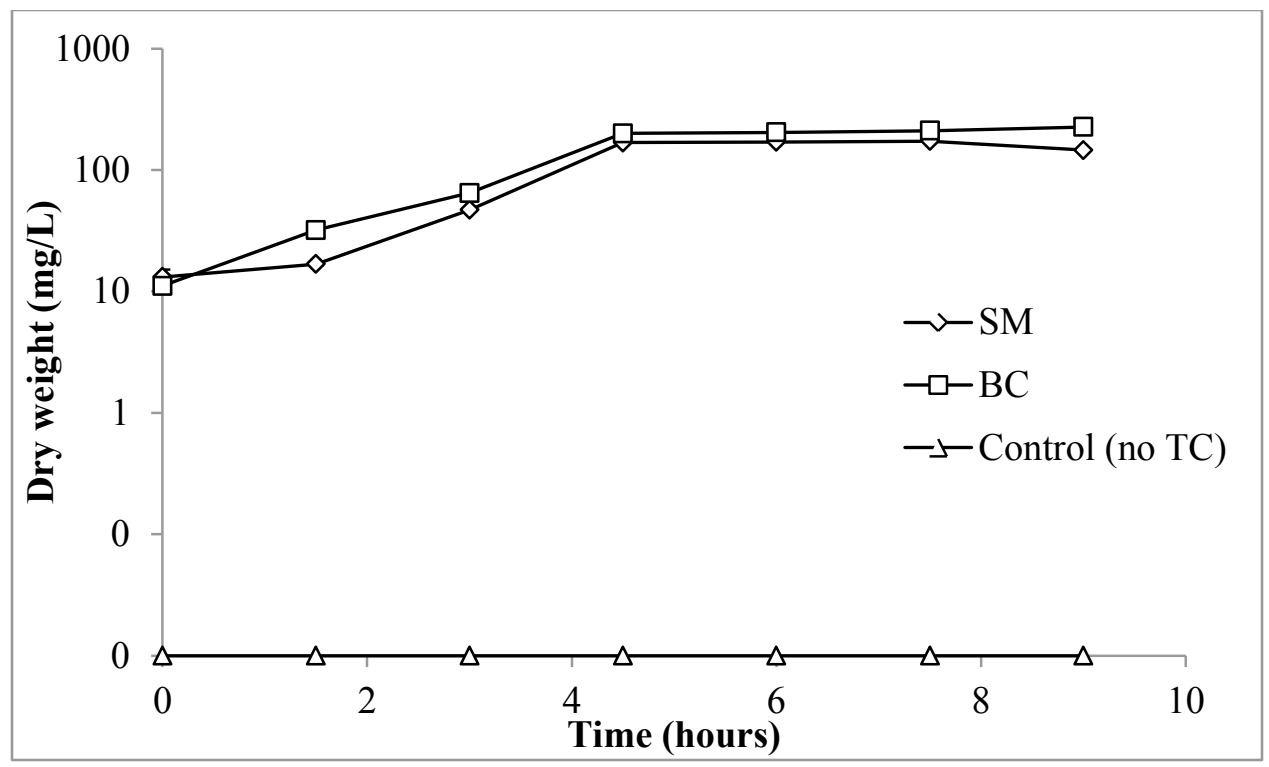

Figure 3.5. Growth study result of bacteria $S$. marcescens (SM) and B. cepacia (BC) grown in single nitrogen source (SNS) media supplemented with $\mathrm{TC}(1 \mathrm{~g} / \mathrm{L})$ at $30^{\circ} \mathrm{C}, \mathrm{pH}$ 7. Control resuslts symbols for both SM and BC (with no TC). Results presented as mean of $n=3, \pm 1 \mathrm{SD}$. 
CHAPTER 4. Role of bacterial and vetiver (Chrysopogon zizanioides) antioxidant enzymes in tetracycline detoxification ${ }^{a}$

This study was designed and conducted by Aparupa Sengupta with guidance from Susan Bagley and Rupali Datta. Rupali Datta and Dibyendu Sarkar provided technical support. All the authors guided, edited, and supported in the preparation of the manuscript.

Additional information that was not included in the chapter is presented in Appendix E.

E.1. Catalase enzyme activity of vetiver root compared to the untreated control

E.2. Equations for calculating antioxidant enzyme activities

E.2. Data for GST activity recorded in B. cepacia in the late-log phase

E.3. Tables of $p$ values from statistical analysis

${ }^{\text {a }}$ The following document is to be submitted for publication in the journal Science of the Total Environment. 
Chapter 4. Role of bacterial and vetiver (Chrysopogon zizanioides) antioxidant enzymes in tetracycline detoxification

Aparupa Sengupta ${ }^{1}$, Dibyendu Sarkar ${ }^{2}$, Susan Bagley ${ }^{1}$, and Rupali Datta ${ }^{1}$

${ }^{1}$ Michigan Technological University, Houghton, MI, 49931-1295 USA

${ }^{2}$ Montclair State University, Montclair, NJ, 07043 USA

Corresponding Author: Aparupa Sengupta, asengupt@mtu.edu, (906)-370-8593.

\begin{abstract}
Antibiotic contamination in water and other environmental sources including soils and sediments is a subject of concern worldwide. In a previous study, using an invitro biological remediation set up, vetiver grass (Chrysopogon zizanioides) and its rootassociated tetracycline-tolerant bacteria demonstrated their tetracycline (TC) detoxification ability in aquatic sources. The objective of this study was to investigate and identify the mechanism of TC detoxification used by both plants and bacteria. Protein was extracted from vetiver roots and TC-tolerant bacteria grown in presence of TC and antioxidant enzymes guaiacol peroxidase (GPX) was measured in plant roots. The level of glutathione S-transferases (GST) was measured in both plant roots and bacteria. The results indicate the involvement of oxidative stress and production of antioxidant enzymes by vetiver root and vetiver root- associated TC-tolerant bacteria Burkholderia cepacia (\#2) and Serratia marcescens (\#1) in the presence of TC. Vetiver roots showed significantly higher activity of glutathione S-transferases (GSTs) compared to control on day 2 of the experiment. TC tolerant root associated bacteria B. cepacia and
\end{abstract}


S. marcescens also showed a higher activity of GSTs, compared to controls during their exponential phase of growth. These results suggest that the glutathione pathway is possibly a TC detoxification mechanism used by both vetiver plants and bacteria.

Introduction

Antibiotic contamination has been regarded as a serious concern in recent times. This is due to the potential adverse effects of these compounds on ecological balance, microbial ecology, aquatic organisms, and human health in form of multi-antibiotic resistant bacteria (Fatta-Kassinos et al., 2011, Gonzalez-Pleiter et al., 2013). The impact and uptake of antibiotics has been studied on multiple plants and microbes (Liu et al., 2009, Yang et al., 2010, Barnhill et al., 2010, Dantas et al., 2008). These compounds are toxic to some plants, however, some plants show no toxic response as a post-effect of antibiotic treatment (Xie et al., 2011, Liu et al., 2013, Herklotz et al., 2010, Dolliver et al., 2007, Gujrathi et al., 2005). Vetiver grass (Chrysopogon zizanioides) has been widely used as a model for phytoremediation for various contaminants (Makris et al., 2007, Chen et al., 2004, Truong et al., 2010) including antibiotics (Datta et al., 2012, Sengupta et al., 2013 a Chapter 2 of this thesis). Also there was no phytotoxic effect observed in vetiver due to TC exposure (Datta et al., 2012, Sengupta et al., 2013a Chapter 2 of the thesis). The microbial community associated with vetiver root has been evaluated and assessed for their role in oil biogenesis and nitrogen-fixation property (Del et al., 2008, Vollu et al., 2012). However, to the best of our knowledge, this was the first time that the role of these microbes, and the production of antioxidant enzymes by vetiver root and rhizospheric bacteria have been assessed during tetracycline remediation/detoxification. 
To understand the activity of the root zone and the possible interaction between plant roots and rhizospheric bacteria during TC removal and transformation, root-associated bacteria were cultured and assessesed for their ability to remove TC. Two TC-tolerant bacteria, identified as Serratia marcescens and Burkholderia cepacia, were isolated from the vetiver root-zone during an invitro hydroponic remediation study demonstrated high tolerance towards TC and TC removal capability (Sengupta et al., 2013 b). Hence, in this study, vetiver root and root-associated bacteria were investigated for a possible TC removal or detoxification mechanism/(s) involving antioxidant defense in the presence of TC.

Reactive oxygen species (ROS) formation is usually related to a stress condition and a lack of oxygen (Blokhina et al., 2003). During oxidative stress, ROS are formed inside and outside of the cells, which causes damage to macromolecules including carbohydrates, proteins, and lipids (Gill and Tuteja, 2010) Antioxidant enzymes inhibit the formation of ROS species by scavenging them using enzymatic and non-enzymatic biochemical mechanisms (Blokhina et al., 2003; Gill and Tuteja, 2010). Antioxidant enzymes, such as glutathione S-transferase (GST), and guaiacol peroxidase (GPX) have been widely studied in plants under various abiotic and biotic stress conditions (Gill and Tuteja, 2010).

There have been several studies on plant and antibiotic interactions that provide some insight into the mechanism of degradation of antibiotics by examining antioxidant enzymatic activity in plants. A study on maize by Farkas et al., (2007) demonstrated that GSTs may be associated with the plant root when detoxifying TC by demonstrating root 
exudates produced GST that effectively detoxified the TC group of antibiotics. Gujrathi et al. (2005a and b) and Gurjarthi and Linden, (2005) have demonstrated that, under stress conditions and in the presence of TC, hairy roots of Helianathus annuus produce antioxidant enzymes, ascorbate peroxidase, CAT, and GPX. The results from the study also suggest that the ROS associated with the roots are involved in the oxidative degradation of $\mathrm{TC}$, which resulted in an increase of the native antioxidant enzyme activity.

A study by Park and Choung (2010) showed that bacteria possessing GST activity reduced the concentration of tetracycline, ampicillin and sulfathiazole. Whole cell preparations of bacteria were used for this purpose and the removal of antibiotics were evident, suggesting the role of microbial GSTs in the degradation of these antibiotics. Another study by Park, (2012) demonstrated that immobilized bacterial cells can effectively transform and detoxify antibiotics using GSTs.

The ability of vetiver and its root-associated bacteria to remove and transform TC is evident from previous studies (Sengupta et al., 2013 a \& b). However, it is important to understand the TC removal mechanism used by both the plants and bacteria in order to implement this biological system to remediate TC from aquatic sources. Antioxidant enzymes play important role in contaminant detoxification hence, the objective of this study was to determine the role of antioxidant enzymes in the TC removal process in vetiver roots and root-associated bacteria. 
Materials and Methods

- Hydroponic tank set-up, sampling plan, and protein extraction from vetiver plants

Hydroponic tanks with vetiver plants were set up using the same methods from Sengupta et al. 2013a; (Chapter 2 of this thesis). The tanks were set up in the growth chamber with an air temperature of $30^{\circ} \mathrm{C} \pm 2$, and a $\mathrm{pH}$ of 7 . The experimental tanks were set up with $75 \pm 5$ ppm of TC and untreated control tanks were set up without TC. This TC level was selected to go along with the earlier remediation studies in which $75 \mathrm{ppm}$ of TC was used (Chapter 2 and Chapter 3 of thesis). Both experimental and control tanks were set up in replicates of three for each sampling day, and the plant samples were harvested from each tank at time intervals: days $0,1,2,3,5$, and 7 . All the plant samples were frozen immediately upon collection and stored at $-80^{\circ} \mathrm{C}$ to avoid the further degradation and isomerization of TC.

Protein was extracted from the vetiver root samples following methods described by Farkas et al. (2007). Seventy mg of root material were collected from each plant sample and ground using liquid nitrogen with a sterilized mortar and pestle and transferred to a 3 $\mathrm{mL}$ micro-centrifuge tube. After this, $0.5 \mathrm{~mL}$ of protein extraction buffer $(50 \mathrm{Mm}$ Tris$\mathrm{HCl}, \mathrm{pH}-7.2,1 \mathrm{mM}$ EDTA , $10 \mathrm{mM} \beta$-mercaptpethanol, and $1 \mu \mathrm{L}$ of $20 \mathrm{mg} / \mathrm{mL}$ PMSF) were added to each tube. The micro-centrifuge tubes were sonicated for 30 minutes. Ice was added to the sonicator to ensure that the samples were kept cold. Then, the samples 
were centrifuged at $4^{\circ} \mathrm{C}$ for 15 minutes at $10,000 \mathrm{X} \mathrm{g}$. The supernatant was the crude protein which was collected in a sterilized micro-centrifuge tube and then stored at $-80^{\circ} \mathrm{C}$.

\section{Bacterial antioxidant experiment set-up and protein extraction from bacterial samples}

The TC-tolerant bacteria that were recovered from the vetiver roots (Chapter 3 of the thesis), Burkholderia cepacia and Serratia marcescens, were assessed for their ability to produce GSTs during the TC detoxification/catabolism process. Flasks were set up in replicates of three with a single carbon source medium (SCS) and an enriched medium (tryptic soy broth; TSB) supplemented with $75 \pm 5 \mathrm{mg} / \mathrm{L}$ of TC, and without TC for controls (media composition modified from Dantas et al., 2008 and listed in Appendix B of thesis). The experimental conditions were maintained as per the optimal growth study $\left(24-30^{\circ} \mathrm{C}, \mathrm{pH} 7-7.3\right.$, aerobic) (Appendix D of thesis) and samples were collected and harvested for protein extraction and for recording GST activity during the exponential phase of growth. Protein was extracted from samples using a bacterial protein (B-PER) extraction reagent kit (Thermo Scientific) which minimized the harsh chemical/ mechanical treatment process, and successfully lysed the bacterial cells with maximized protein yield.

\section{- Protein Quantification of plant and bacterial samples}

The Bicinchoninic acid (BCA) colorimetric assay kit (Thermo Scientific) was used to determine protein the concentration of plant and bacterial samples. For each extracted protein sample, $200 \mu \mathrm{L}$ of the working reagent was added to $25 \mu \mathrm{L}$ of protein. For the 
standards, $10 \mu \mathrm{L}$ of BSA standard was added to $200 \mu \mathrm{L}$ of working reagent, prepared as per the instruction from the kit, to construct the standard curve.

\section{- Methods of measuring antioxidant enzyme activity}

Glutathione-s-transferase activity assay:

The GST activity was measured in vetiver root and bacterial samples using a colorimetric assay kit (Sigma Aldrich), which used 1-chloro-2, 4-dinitrobenzene (CDNB) as the standard (Farkas et al., 2007). The total volume of the reaction mixture was made up to $200 \mu \mathrm{L}$ consisting of $1.0 \mathrm{mM}$ CDNB, 5.0 mM GSH, phosphate buffered saline (pH-6.5) and $20 \mu \mathrm{L}$ of protein. To initiate the reaction, the 96-well plate was agitated using a shaker. The change in absorbance was then measured at $340 \mathrm{~nm}$ with a spectrophotometer for 5 minutes at ambient temperature $\left(25-27^{\circ} \mathrm{C}\right)$. The experiment was repeated three times with different protein samples used in replicates of six, with glutathione positive control (Fisher Scientific) $(n=3)$ and negative control ( $n=3$, with only reaction mixture, no protein). The absorbance values were averaged and normalized with the controls (control absorbance values deducted from experimental absorbance values) and then were placed in the following the equation from appendix E.2.1 to calculate the GST activity in each samples (Farkas et al., 2007).

Guaiacol Peroxidase Activity Assay (GPX assay):

The GPX activity was measured in vetiver root samples following the method from Farkas et al., 2007), using a colorimetric assay with $\mathrm{H}_{2} \mathrm{O}_{2}$ as the standard substrate. The total volume of the reaction mixture was made up to $200 \mu \mathrm{L}$ consisting of $68 \mu \mathrm{M}$ 
guaiacol, $0.9 \mathrm{mM} \mathrm{H} \mathrm{H}_{2} \mathrm{O}_{2}, 50 \mathrm{mM}$ potassium phosphate buffer (pH 6.0) and $20 \mu \mathrm{L}$ of protein. To initiate the reaction, the 96 -well plate was agitated. The change in absorbance was then measured at $420 \mathrm{~nm}$ with a spectrophotometer for 5 minutes at room temperature $\left(25-27^{\circ}\right)$. GPX activity was calculated in different samples using the equation from appendix E.2.2.

- Statistical analysis of results

Results were analyzed for statistical significance of enzyme activity using Student's t-test using Excel 2010 statistical package $(\mathrm{p}<0.05)$. The results were compared between samples collected from:

a) TC-treated flasks with bacteria vs. TC-treated flasks without bacteria (control) at log phase for both $S$. marcescens and B. cepacia (separately) in two different media SCS and TSB. Student's t-test compared the statistical significance of enzyme activity at log phase between treatment flasks and control flasks (p-values reported in table E.3.1)

b) TC-treated vetiver root samples vs. vetiver root samples not treated with TC (control) on each sampling day $(0,1,2,3,5$, and 7$)$. Student's t-test compared the statistical significance of enzyme activity on different days between treatment tanks and control tanks (p-values reported in table E.3.2).

Results and Discussion

GST activity in TC-tolerant vetiver root associated bacteria Bacterial GSTs play important roles in cellular detoxification and are associated with biodegradation of contaminants, antibiotic resistance, and oxidative stress (Allocati et al., 
2009). The mechanism of the GST detoxification pathway starts with glutathione binding to the contaminant and then the GST enzyme catalyzes the removal and degradation of the compound and its highly unstable conjugates. The rationale for using two different media was to compare the results between defined and complex media to understand if TC is utilized and degraded by both $S$. marcescens and B. cepacia when present as both sole carbon source and as one of the source of carbon among other organics. SCS is a defined medium where TC is present as a single carbon source and. TSB which is a complex media where TC is present among other carbon sources. Samples were collected at hour zero and at the exponential phase of growth, which was predetermined during an optimization study, when growth was maximal, and when the maximum removal of TC was taking place (Figures D.1-D.8, B.5 and Sengupta et al., 2013 b).

Results for B. cepacia (Figure 4.1 A) showed significantly higher $(\mathrm{p}<0.05)$ GST activity for both SCS and TSB media in the presence of TC. These results are in agreement with the earlier study showing that B. cepacia, that is highly tolerant to TC can detoxify/degrade these compounds within 7 days of treatment (Figures 3.2, 3.3, A.4.1, A.4.2 of thesis). Results for S. marcescens (Figure 4.1 B) showed significantly higher GST activity when grown on enriched media with TC compared to the control, however, SCS did not show that trend. The differences in these results (lower GST production in SCS media and lower production by S. marcescens vs. B. cepacia in general) may be because of the way these two bacteria grow in these two different media. Usually growth is lower in SCS medium for both bacteria compared to the complex medium (TSB) and in general, growth is higher in presence of TC for B.cepacia compared to S. marcescens 
(Figures D.11, and D.12). Results from a companion study demonstrated (Ch. 3) that the maximum removal/ transformation of TC takes place during the log phase of the bacterial growth. The results for GST activity are in agreement with the transformation results suggesting that the activity of GST in bacteria is significantly higher during log phase compared to the control (Figure 4.1) during which transformation rate is higher. However, there were no significant differences in GST activities recorded during late log (with B. cepacia) phase of bacterial growth when compared to control.

There have not been many studies that explore the role of antioxidant enzymes in the antibiotic decontamination process using bacteria. In a study by Park and Choung, 2010, the roles of three bacteria in removal of antibiotics were reported. In another study by Park, 2012 it was reported that GST activity was higher in bacteria during the TC removal process, and the glutathione pathway was identified as a detoxification pathway for the TC removal process

GST, and GPX activities in vetiver root

The results for vetiver roots treated with TC showed significantly higher $(p=0.01)$ GST activity compared to the control samples on day 2 (Figure 4.2). The data for days $0,1,3$, 5 and 7 indicated no statistically significant difference between TC treated and control root samples. These results coincide with the TC removal/ transformation results from a different study (Ch. 2) indicating that maximum TC transformation takes place between days 1 and 2. These results are similar to the findings reported by Farkas et al., 2007; however the results from chloro-TC -treated maize showed a higher GST activity compared to control on all days (1,2 and 3). The differences in the results between these two studies could be because of the ability of vetiver plants to uptake TC which was 
maximal between day 0 and day two (Sengupta et al., 2013 a). There was no statistical difference recorded in GST activity between treated vetiver root and control beyond day 2 of treatment.

GPXs are a group of antioxidant enzymes induced during stress in plants for oxidative degradation of different TCs (Farkas et al., 2007, Gujrathi et al., 2005a, b, and Gujrathi and Linden, 2005). Results for GPX activity in TC-treated vetiver root vs. untreated control (Figure 4.3) showed no significant differences in GPX activity on days 1, 2 and 3 and no activity was recorded for day 5 and 7 . The results are different from the GST activity results, possibly because the major detoxification mechanism utilized during TC removal is the glutathione pathway, and the remaining TC and isomers were removed and/or metabolized by the vetiver plant (Sengupta et al., 2013 a).

No significant GPX activity was measured in the plant root samples in the presence of TC. This result explains that since the plant were not as much in stress, there is not much antioxidant enzyme activity measured. It could be speculated from these results that glutathione pathway is possibly the major TC detoxification pathway that vetiver is using to decontaminate TC and its isomers from water sources and the remaining concentration of TC is translocated from roots of vetiver to the shoots, which is eventually metabolized by the plant. The concentration of the enzyme is comparatively lower than from what is reported in the literature (Farkas et al., 2007). One possible explanation of these low enzyme concentrations could be that vetiver is not overly stressed by $\mathrm{TC}$, so it is producing less of the antioxidant enzyme. Alternatively, there is a possible TC catabolic mechanism present in vetiver by which the major concentration of TC is removed and 
metabolized in the plant tissue; hence less GST is produced by the plant in presence of TC.

\section{Conclusion}

This study identifies the glutathione pathway as one of the possible antioxidant mechanisms utilized by both plant and microbes to remove TC. This is the first time that a plant-microbe system, vetiver and its root-associated bacteria, has been investigated, with the objective of understanding the antioxidant defense mechanism behind the TC removal/transformation process. The findings of this study are important contributions to better the understanding of the TC removal process used by plants and bacteria, and could also be helpful for the removal of other antibiotics in future.

\section{Acknowledgements}

The authors would like to acknowledge the Department of Biological Sciences Michigan Tech for providing lab facilities, resources, financial support to Aparupa Sengupta (as graduate student stipend), the Center for Water and Society, Michigan Tech for awarding a 'Graduate research grant' to Aparupa Sengupta for conducting a part of this study, and undergraduate students Jen Connors and Jenny Isaacson for helping with the study. 
References

1. Allocati N, Federici L, Masulli M, IIio CD (2009) Glutathione transferases in bacteria. FEBS J. 276: 58-75.

2. Blokhina O, Virolainen E, Fagerstedt KV (2003) Antioxidants, oxidative damage and oxygen deprivation stress: a Review. Ann. Bot-London. 91:179-194

3. Boonsaner M, Hawker DW (2012) Investigation of the mechanism of uptake and accumulation of zwitterionic tetracyclines by rice (Oryza sativa L.). Ecotox. Environ. Safe. 78:142-147.

4. Boxall ABA (2004) The environmental side effects of medication. EMBO J. 5:1110-1116.

5. Dantas G, Sommer MOA, Oluwasegun RD, Church GM (2008) Bacteria subsisting on antibiotics. Science. 320:100-103.

6. Datta R, Das P, Smith S, Punamiya P, Ramanathan DM, Reddy R, Sarkar D (2013) Phytoremdiation potential of tetracycline by vetiver grass (Chrysopogan zizanioides(L.f) for tetracycline. Int. J Phytorem. 15:343-351.

7. Del GL, Massardo DR, Pontieri P, Bertea CM, Mombello D, Carata E, Tredici SM, Talà A, Mucciarelli M, Groudeva VI, De Stefano M, Vigliotta G, Maffei ME, Alifano P (2008) The microbial community of vetiver root and its involvement into essential oil biogenesis. Environ. Microbiol. 10: 2824-2841.

8. Ding C, He J (2010) Effect of antibiotics in the environment on microbial populations. Appl. Microbiol. Biot. 87:925-941. 
9. Dolliver H, Kumar K, Gupta S (2007) Sulfamethazine uptake by plants from manure-amended soil. J. Environ. Qual. 36:1224-1230.

10. Farkas MH, Berry OM, Aga DS (2007) Chlorotetracycline detoxification in maize via induction of glutathione S-transferases after antibiotic exposure. Environ. Sci. Technol. 41:1450-1456.

11. Fatta-Kassinos D, Meric S, Nikolaou A (2011) Pharmaceutical residues in environmental waters and wastewater: current state of knowledge and future research. Anal. Bioanal Chem. 399:251-275.

12. Gill SS, Tuteja N (2010) Reactive oxygen species and antioxidant machinery in abiotic stress tolerance in crop plants. Plant Physiol. Biochem. 48: 909-930.

13. Gonzalez-Pleiter M, Gonzalo S, Rodea-Palomares, Leganes F, Rosal R, Boltes K, Marco E, Fernandez-Pinas F (2013) Toxicity of five antibiotics and their mixtures towards photosynthetic aquatic organisms: Implications for environmental risk assessment. Water Res. 47:2050-2064.

14. Guillon S, T-Guiller J, Pati PK, Rideau M, Gantet P (2006) Hairy root research: recent scenario and exciting prospects. Curr. Opin. Plant Biol. 9:341-346

15. Gujrathi NP, Haney B, Linden J (2005 a) Phytoremediation potential of Myriophyllum aquaticum and P. stratiotes to modify antibiotic growth promoters, tetracycline, and oxytetracycline in aqueous wastewater systems. Int. J. Phytorem. 7:99112. 
16. Gujrathi NP, Haney BJ, Park HJ, Wickramasinghe SR, Linden JC (2005b) Hairy roots of Helianthus annus: A model system to study phytoremediation of tetracycline and oxytetracycline. Biotechnol. Prog. 21: 775-780.

17. Gujrathi NP, Linden JC (2005) Oxytetracycline inactivation by putative reactive oxygen species released to nutrient medium of Helianthus annus hairy root cultures. Biotechnol. Bioeng. 92:393-402.

18. Halling-Sørenson B, Sengelov G, Tjornelund J (2002) Toxicity of tetracycline degradation products to environmentally relevant bacteria, including selected tetracycline resistant bacteria. Arch. Environ. Contam. Toxicol. 42: 263-271.

19. Herklotz PA, Gurung P, Heuvel BV, Kinney CA (2010) Uptake of human pharmaceuticals by plants grown under hydroponic conditions. Chemosphere. 78: 14161421.

20. Liu F, Ying G-G, Zhao JL, Yang JF, Zhao L-F (2009) Effects of six selected antibiotics on plant growth and soil microbial and enzymatic activities. Environ. Pollut. 157: $1636-1642$.

21. Liu L, Liu Y-H, Liu C-X, Wang Z, Dong J, Zhu G-F, Huang X (2013) Potential effect and accumulation of veterinary antibiotics in Phragmites australis under hydroponic conditions. Ecol. Eng. 53: 138-143.

22. Makris KC, Shakya K, Datta R, Sarkar D, Pachanoor D (2007) High uptake of 2,4,6 TNT by vetiver grass-Potential for phytoremediation? Environ pollut. 146:1-4. 
23. McManus PS, Stockwell VO, Sundin GW, Jones AL (2002) Antibiotic use in plant agriculture. Annu. Rev. Phytopathol. 40:443-465.

24. Park (2012) Reduction of antibiotics using microorganisms containing glutathione S-transferases under immobilized conditions. Environ. Toxicol. Pharmacol. $34: 345-350$.

25. Park H, Choung YK (2010) Evaluation of the biodegradation feasibility of antibiotics by three bacteria involving glutathione S-transferases. Can J. Civil Eng. $37: 814-819$

26. Sengupta A, Waring K, Sarkar D, Bagley S, and Datta R (2013 a) Tetracycline degradation in aqueous systems using vetiver grass and identification of tetracycline Metabolites in the plant. Manuscript in preparation.

27. Sengupta A, Datta R, and Bagley S (2013 b) Tetracycline detoxification capability of bacterial strains isolated from vetiver root-zone. Manuscript in preparation.

28. Shanks JV and Morgan J (1999) Plant 'hairy root' culture. Curr. Opin. Biotech. $10: 151-155$.

29. Truong PNV, Foong YK, Guthrie M, Hung Y-T (2010) Phytoremediation of heavy metal contaminated soils and water using vetiver grass, p.233-275. In L.K. Wang, J-W. Tay, S.T.L. Tay, Y-T. Hung (ed.), Environmental Bioengineering, Handbook of Environmental Engineering, Vol. 11. Humana Press, New York, NY. 
30. Vollú RE, Blank AF, Seldin L, Coelho MRR (2012) Molecular diversity of nitrogen-fixing bacteria associated with Chrysopogon zizanioides (L.) Roberty (vetiver), an essential oil producer plant. Plant Soil. 356: 101-111.

31. Walsh F, Amyes SGB, Duffy B (2013) Challenging the concept of bacteria subsisting on antibiotics. Int. J. Antimicrob. Ag. 41:558-563.

32. Watkinson AJ, Murby EJ, Kolpin DW, Costanzo SD (2009) The occurrence of antibiotics in an urban watershed: From wastewater to drinking water. Sci. Total Environ. 407: 2711-2723

33. Wright, GD (2005) Bacterial resistance to antibiotics: Enzymatic degradation and modification. Adv. Drug Deliv. Rev. 57: 1451-1470.

34. Xie X, Zhou Q, Lin D, Guo J (2011) Toxic effect of tetracycline exposure on growth, antioxidative and genetic indices of wheat (Triticum aestivum L.). Environ Sci. Pollut. Res. Int. 18:566-575.

35. Yang Q, Zhang J, Zhang W, Wang Z, Xie Y (2010) Influence of tetracycline exposure on the growth of wheat seedlings and the rhizospheric microbial community structure in hydroponic culture. J. Environ. Sci. Heal. B. 45: 190-197. 

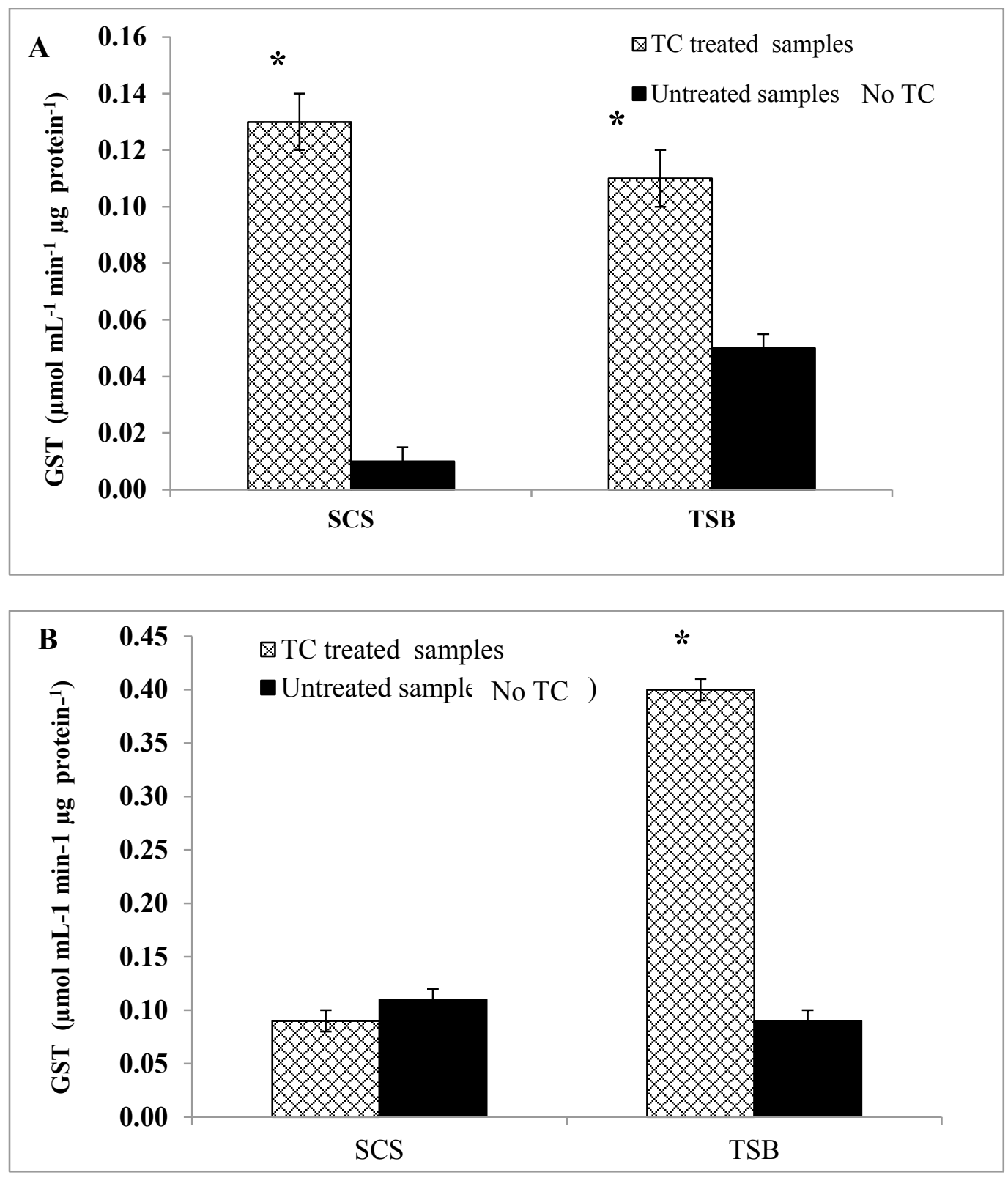

Figure 4.1. Glutathione S-transferase activities from (A) B. cepacia and (B) $S$. marcescens during exponential phase of growth $\left(10^{\text {th }}\right.$ hour from start of growth $)$ in different growth media with tetracycline (TC; $75 \mathrm{mg} / \mathrm{L})$ and without TC; single carbon source (SCS) and tryptic soy broth (TSB): media. Results are normalized with data collected on $0 \mathrm{hr}$. and presented as mean $(\mathrm{n}=3) \pm 1$ SD. Asterisk (*) indicates statistically significant result $(\mathrm{p}<0.05)$. 


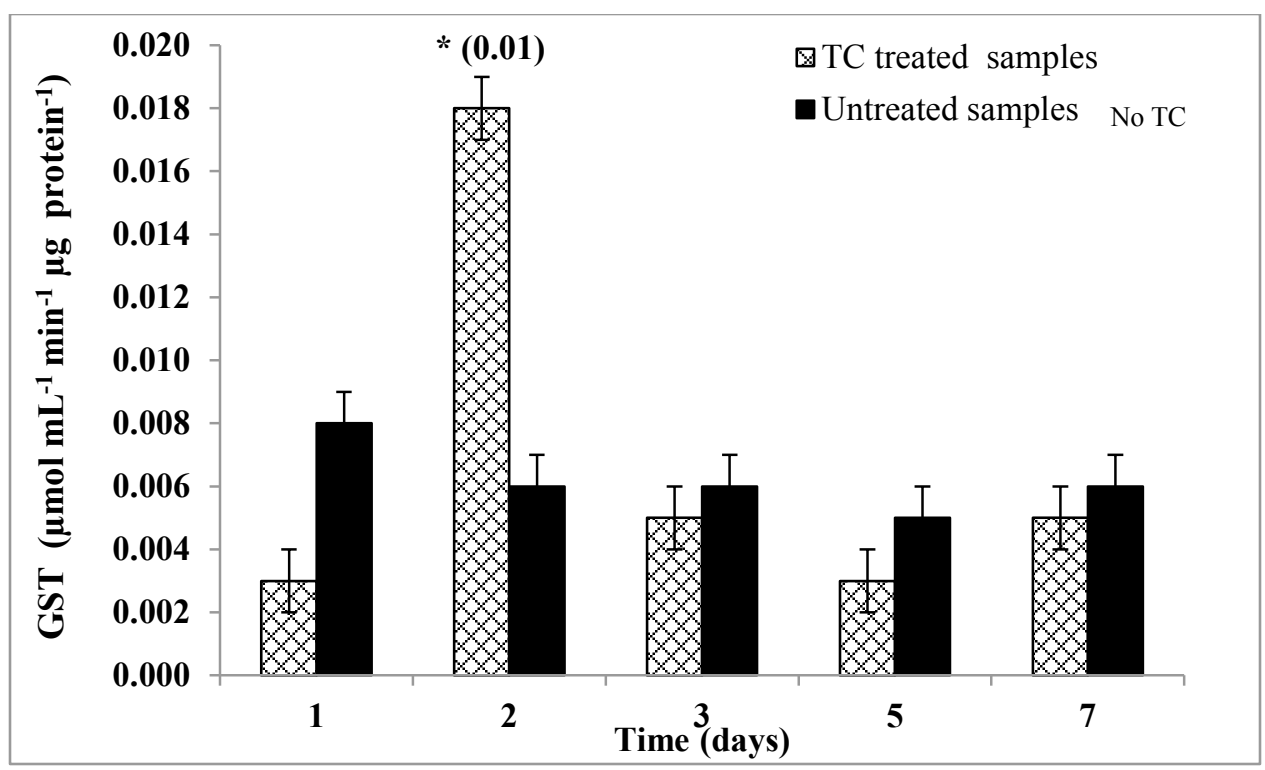

Figure 4.2. Glutathione S-transferase activities from vetiver root collected during days 1, 2, 3, 5 and 7 of experiment; treated with TC $(75 \mathrm{mg} / \mathrm{L})$ and without TC. Results are normalized with data collected on day 0 and presented as mean $(n=3) \pm 1$ SD. Asterisk $(*)$ indicates statistically significant result $(\mathrm{p}<0.05)$. 


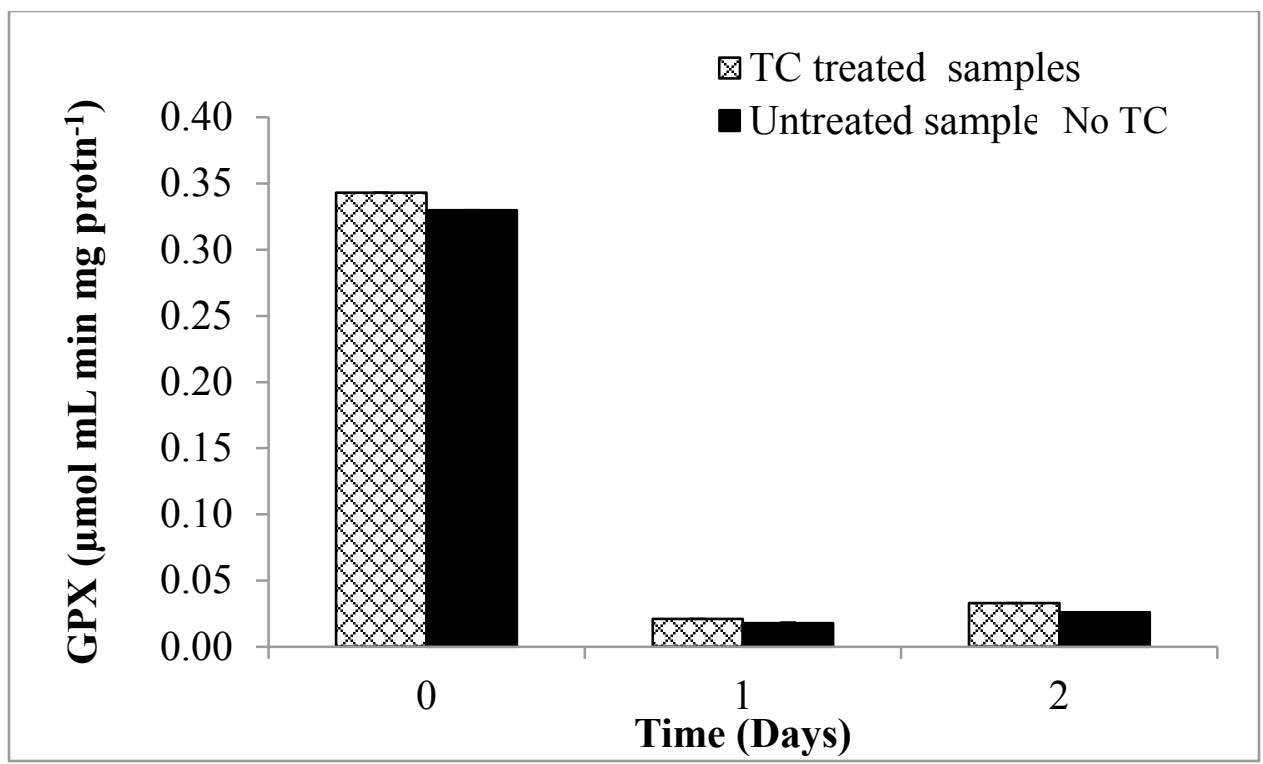

Figure 4.3. GPX activities recorded from vetiver root collected during days $0,1,2$ of experiment; treated with TC (TR 75 ppm TC) and without TC. There was no activity recorded on days 3, 5 and 7 (with no change in absorbance value). Results are normalized with data collected on day 0 and presented as mean $(n=3) \pm 1$ SD 


\section{Thesis Conclusions}

- Vetiver grass and its root-associated bacteria can effectively remove TC and its isomers from aquatic systems.

- Vetiver can be used as a model for phytoremediation of TC as, it not only uptakes and metabolizes TC but also there was no toxic effect of the compound observed on the plant.

- Both TC- tolerant bacteria (identified as $S$. marcescens and B. cepacia) can possibly use and degrade TC as sole carbon and nitrogen source. These bacteria can also use and degrade TC when it is present as one of the carbon source among lots of other organics in enriched media.

- Comparing the metabolic profiling of bacteria and plants with their respective controls suggested that fatty acid biosynthesis pathway and glutathione pathway were implicated as major pathways expressed during TC metabolism in these organisms, respectively.

- The glutathione pathway was identified and significantly expressed in both plant and bacteria during the process of TC transformation / degradation.

- This work significantly contributes and improves the understanding of TC degradation process in plants and bacteria using different approaches (such as analytical chemistry, metabolomics, and antioxidant enzyme activity). 


\section{Recommendations}

- The unknown metabolites detected in LC-MS/MS and GC/MS should be identified and the role of known metabolites should be understood to map a potential TC degradation pathway in plants.

- Plant samples should be sampled more often during the initial hydroponic remediation study time-intervals.

- The microbial metabolites should also be explored for their possible roles in TC degradation and proteomics studies should be conducted in bacteria in presence of TC to understand the expression of different proteins during TC metabolism.

- With the purpose of applying the lab scale technology to the field, floating mass of vetiver grass should be constructed in a controlled setting with waste water effluent and should be inoculated with a known concentration of one of the TC-tolerant bacteria. This biological treatment set-up should be tested to evaluate of it is effective in removing TC and its harmful isomers from wastewater effluents. 
APPENDIX A. Additional information for Chapter 2. Tetracycline remediation and identification of tetracycline metabolites in aqueous systems using vetiver grass (Chrysopogon zizanoides L. Nash)

Appendix A is divided in six parts:

A.1. Total TC concentration accounted in different tanks (for $75 \pm 5 \mathrm{ppm}$ TC used)

A.2. MS/MS results for hydroponic tanks (with $75 \pm 5 \mathrm{ppm}$ TC) without plant on day 30

A.3. Hydroponic remediation study with TC comparing light vs. dark condition

A.4. Hydroponic remediation studies results with TC concentrations $(5,35 \mathrm{ppm})$

A.5. Metabolites detected during metabolic profiling in vetiver presence of TC (75 ppm) vs. control (no TC)

A.6. Table of statistical analyzed detailed results from 2-way Anova anad Tukey's HSD test 


\section{A.1. Total TC concentration accounted for different tanks (for $75 \pm 5 \mathrm{ppm}$ TC used)}

These results account for the tetracycline (from initial concentration on day 0 to final concentration on day 30) in hydroponic tanks treated with vetiver and in control tanks without vetiver plants [Fig. A.1.1 (A \&B) and Table A.1.1]. In both experimental tanks (with plants) and control tanks (without plants), no TC was detected on day 30 in the media samples (A.1.1 a).

In experimental tanks (with plants), TC accumulated in day 30 plant tissues (root and shoot), suggesting plants may play a role in the TC transformation/ degradation process. However, compared to the initial TC concentration in the media $(75 \mathrm{mg} / \mathrm{L})$, the amount recorded in plant tissue is low. Since the analysis of plant tissues was performed on day 30 , it is possible that some of the TC taken up by plant tissue was either metabolized during the 30-day hydroponic trial period, or was degraded /transformed into unknown metabolites during the trial period. 

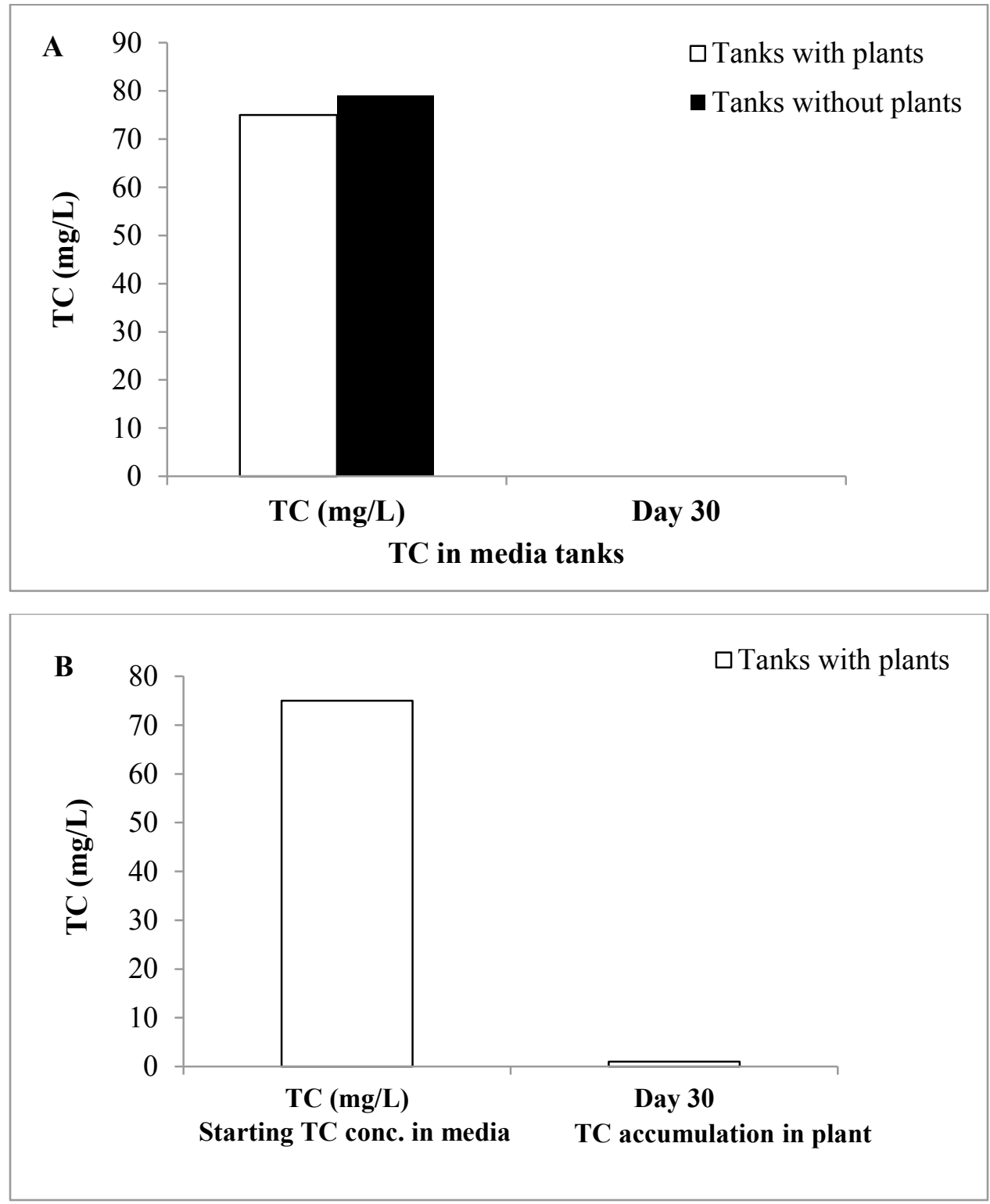

Figure A.1.1. Results show A) Total TC concentration accounted (from the beginning to the end of the hydroponic trial) in tanks treated with plants (starting at $75 \mathrm{ppm}$ TC) and tanks without plants (starting at 79 ppm TC). B) TC accumulation on day 30 in plant vs. starting conc. of TC in media on day 30 . Results presented here as mean $n=3 \pm 1$ SD on day 30 for each type of tank. 
Table A.1.1. TC and its isomers ETC and ATC concentrations detected in different tanks during the hydroponic remediation trial (data shown in figure 2.1) Results presented as mean ( $n=3) \pm 1$ SD.

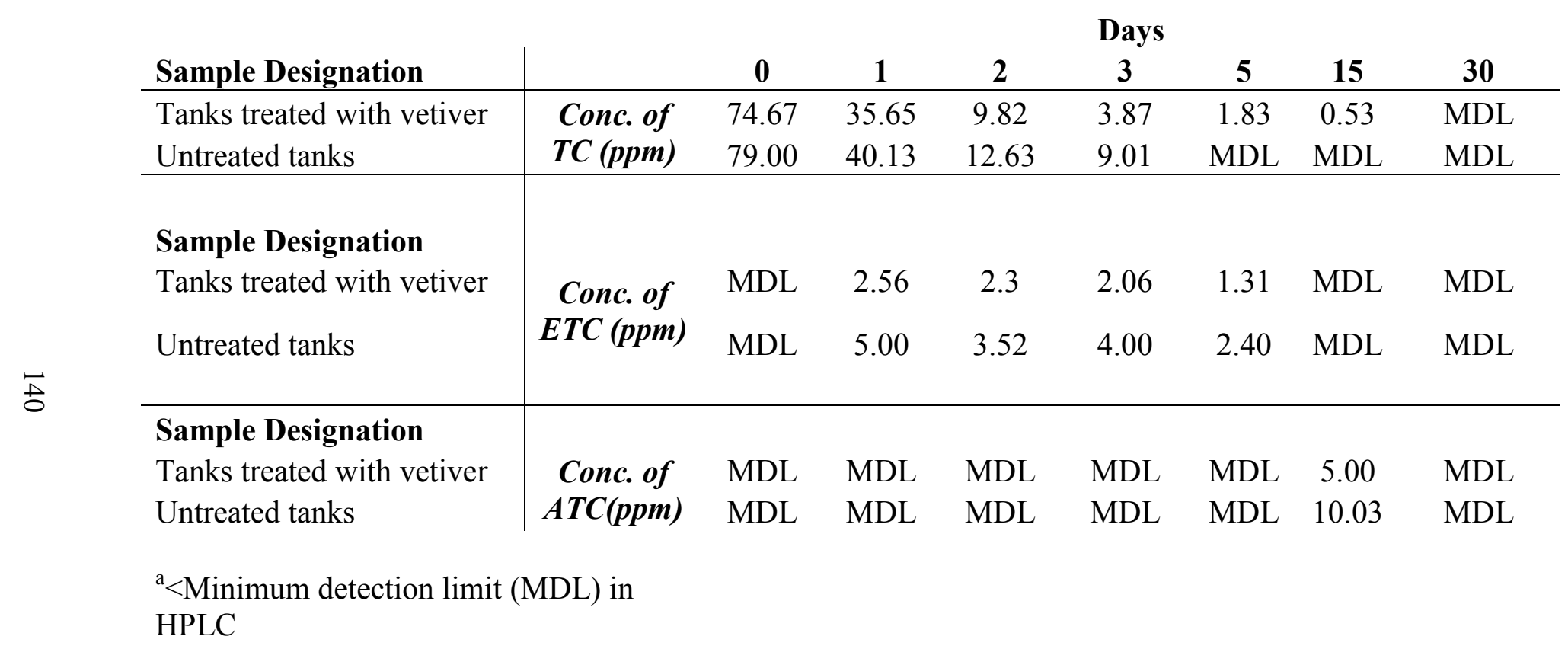




\section{A.2. MS/MS results for hydroponic tanks (with $75 \pm 5 \mathrm{ppm}$ TC) without plant on day}

30

ATC could not be quantified using HPLC (because of the conc. being $<$ minimum detection limit in HPLC of the instrument) on day 30. However, ATC was detected in samples collected from tanks without vetiver plant during hydroponic remediation experiment on day 30 in MS/MS (Fig. A.2.1). There was no trace of ATC or ETC in samples collected from tanks treated with vetiver plant on day 30 .

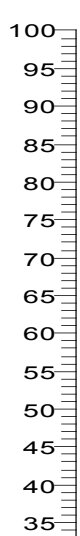$$
{ }_{30}^{35}
$$

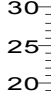$$
{ }^{20}
$$$$
\begin{gathered}
15 \\
10= \\
5
\end{gathered}
$$
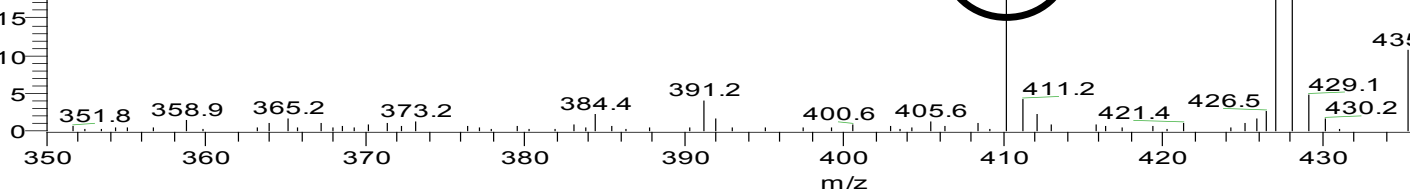

Figure A.2.1. Full MS-MS chromatogram shows ATC (circled in black) detected in samples from tank not treated with plant exposed to TC $(75 \pm 5 \mathrm{ppm})$ on day 30 . 


\section{A.3. Hydroponic remediation study with $\mathrm{TC}(75 \pm 5 \mathrm{ppm})$ comparing light vs. dark condition}

Hydroponic tanks were set-up without plants in dark (covered with black cloth) vs. light conditions to understand if there was any effect of light on $\mathrm{TC}$ transformation/degradation. There was no effect of light observed on TC transformation/degradation (Student's t-test comparing between tanks in light vs. dark on each sampling day, $\mathrm{p}<0.05)$. 

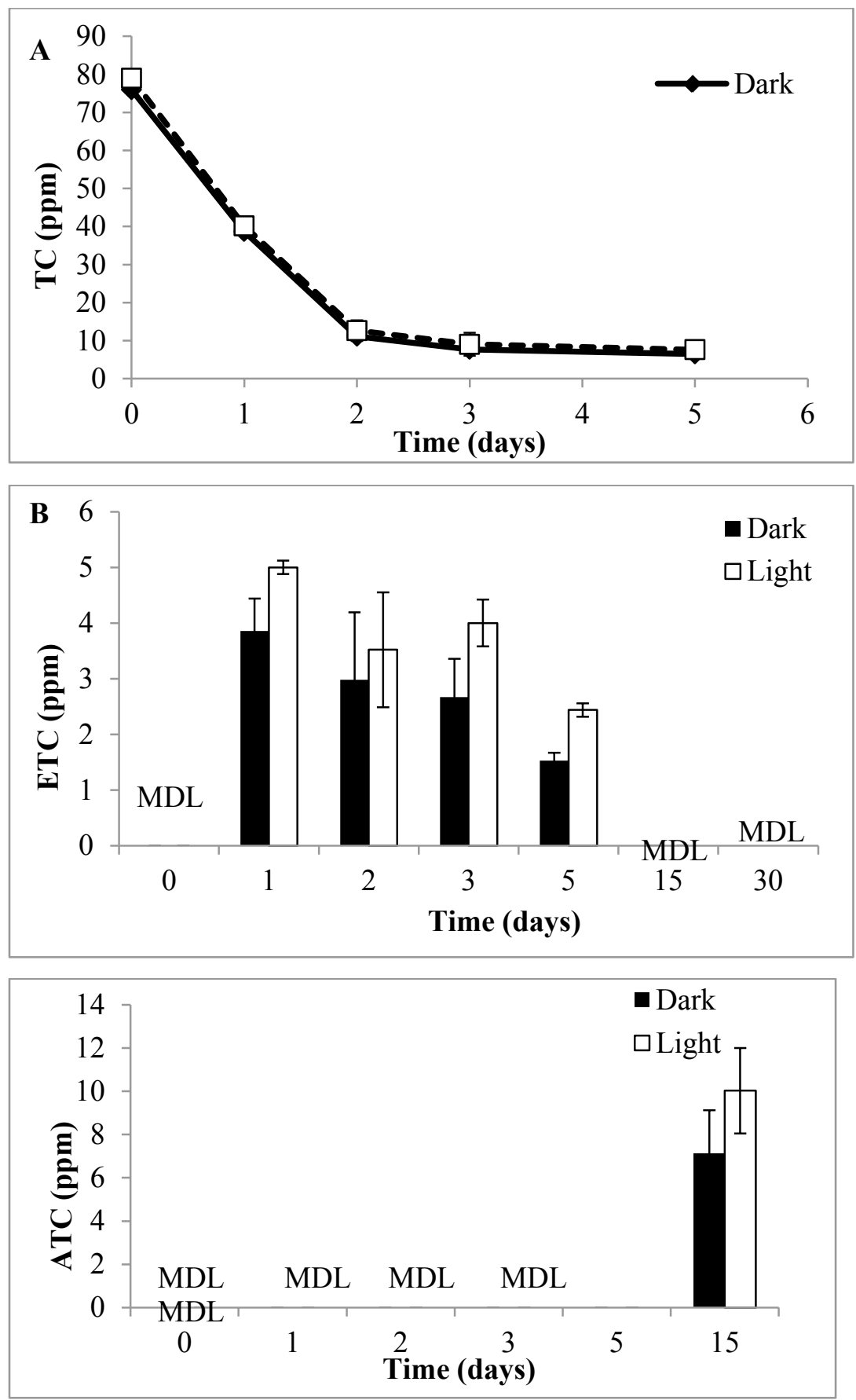

Figure A.3.1 Transformation of TC $(75 \pm 5 \mathrm{ppm})$ in TSB media samples collected from hydroponic tanks without plant in dark and light (A) TC disappearance during 30 day remediation trial, (B) accumulation of ETC), (C) accumulation of TC. MDL on the charts signifies $<$ minimum detection level of the compounds in HPLC. Results presented in mean $(n=3) \pm 1$ SD. 


\section{A.4. Hydroponic remediation studies results with TC concentrations $(5,35 \mathrm{ppm})$}

Results are reported here for tanks with and without plants with TC ( 5 and $35 \mathrm{ppm}$ ). TC disappearance and transformation of TC into its isomers ETC and ATC is reported for both concentrations.
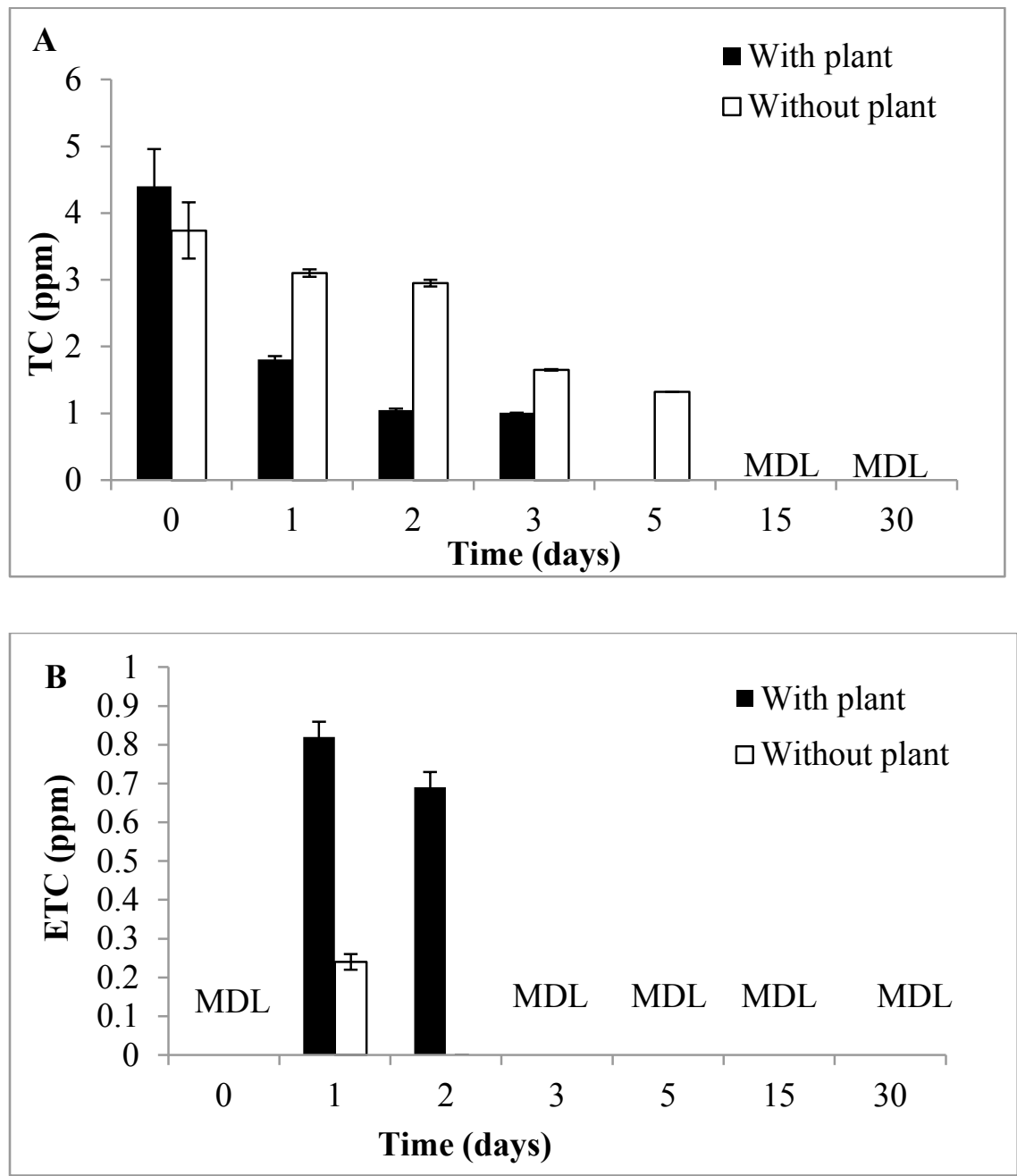

Figure A.4.1. Transformation of TC $(4.5 \pm 1 \mathrm{ppm})$ in media samples collected from hydroponic tanks with plants vs. tanks without plants (A) TC disappearance during 30 day remediation trial, (B) accumulation of ETC. ATC was not detected in any samples. MDL signifies < minimum detection level of compounds in HPLC. Results present in mean $(\mathrm{n}=3), \pm 1 \mathrm{SD}$. 

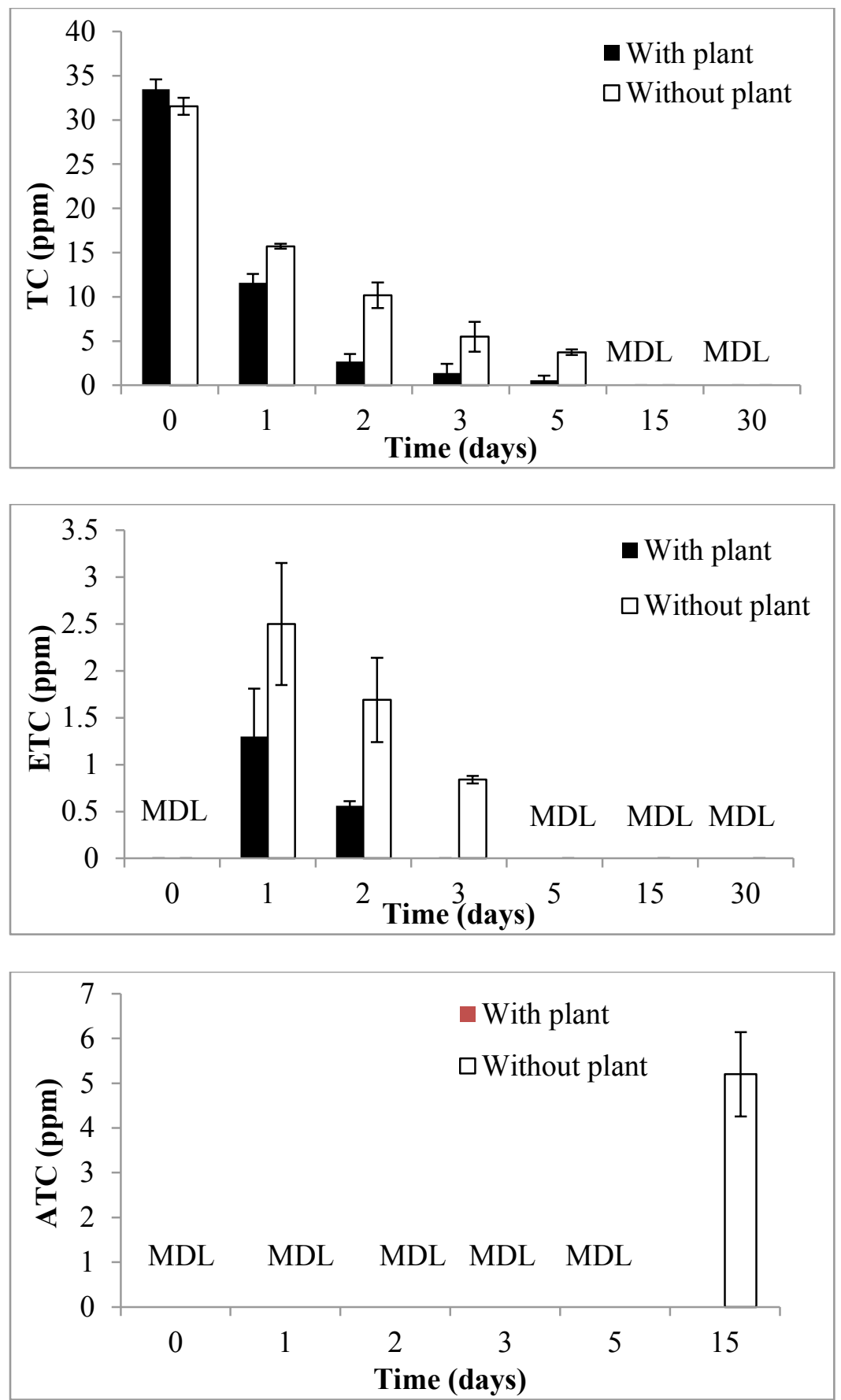

Figure A.4.2. Transformation of TC $(33 \pm 2 \mathrm{ppm})$ in media samples collected from hydroponic tanks with plants vs. tanks without plants (A) TC disappearance during 30 day remediation trial, (B) accumulation of ETC, (C) accumulation of ATC on day 15 of remediation trial. ATC was not detected in tanks with plants on day 15. MDL signifies < minimum detection limit of compounds in HPLC. Results presented as mean $(n=3) \pm 1$ SD. 


\section{A.5. Metabolites detected during metabolic profiling in vetiver in the presence of TC (75 \pm 5 ppm) vs. control (no TC)}

Results show different metabolites detected using GC-MS in vetiver root in presence of TC and compared to the control roots (no treatment of TC) on day 30.

The compounds/ metabolites detected were matched with MetaboAnalyst, and KEGG database for ID standardization and finally searched for association with possible pathways related to antibiotic metabolism in plants using KEGG and plant metabolic network database (Xia et al., 2012, www.plantcyc.org). Metabolites that were expressed only in roots treated with TC and there were no expression of these compounds detected in control plant roots are listed in Table A.5.1 and metabolites expressed only in control roots and not detected in roots treated with TC are listed in Table A.5.2 and metabolites compared in terms of fold change between roots treated with TC and control plant roots are listed in Table A.5.3. 
Table A.5.1: Metabolites detected in plant roots treated with TC. Not detected in plant roots not treated with TC. Results are presented in mean $(n=3)$

\begin{tabular}{|c|c|c|}
\hline Compounds & Conc. $(\mathrm{mg} / \mathrm{L})$ & Std. Dev. \\
\hline 1,3-Diphenyl-2-azafluorene & 0.02 & 0.01 \\
\hline 1H-Indole-3-acetic acid, 5-methoxy & 0.03 & 0.02 \\
\hline 1-Propene-1,2,3-tricarboxylic acid & 0.03 & 0.01 \\
\hline 2,2'-Biphenylylenephosphoric acid & 0.12 & 0.02 \\
\hline $\begin{array}{l}\text { 2-Pentenoic acid, (E,4S)-4-[((R)-à-methoxy-à- } \\
\text { trifluoromethyl-à-phenylacetyl)amino]-, ethyl ester }\end{array}$ & 0.02 & 0.01 \\
\hline D-Glucopyranuronic acid, 1,2,3,4-tetrakis & 0.04 & 0.02 \\
\hline $\begin{array}{l}\text { Androst-2-en-17-amine, 4,4-dimethyl-N-(2- } \\
\text { phenylethyl)-, hydrocholoride, (5à)- }\end{array}$ & 0.02 & 0.02 \\
\hline Asparagin, $\mathrm{N}, \mathrm{N}, \mathrm{N}^{\prime}$ & 0.18 & 0.08 \\
\hline Benzoic acid, 2,6-bis & 0.01 & 0.01 \\
\hline Butanoic acid & 0.05 & 0.01 \\
\hline $\begin{array}{l}\text { D-Glucopyranose, 4-O-[2,3,4,6-tetrakis-O-á-D- } \\
\text { galactopyranosyl]-1,2,3,6-tetrakis }\end{array}$ & 0.3 & 0.02 \\
\hline Fructofuranoside, methyl & 0.16 & 0.02 \\
\hline Glutamine, tris & 0.25 & 0.07 \\
\hline Glycine, N,N-bis & 0.1 & 0.03 \\
\hline Levophenacylmorphan & 0.03 & 0.01 \\
\hline L-Lysine, N2,N6,N6-tris & 0.02 & 0.01 \\
\hline L-Tyrosine, N,O-bis & 0.03 & 0.0 \\
\hline L-Valine & 0.05 & 0.03 \\
\hline Mannose, 2,3,4,5,6-pentakis-O & 0.04 & 0.01 \\
\hline $\begin{array}{l}\text { Methyl 1,4,7,8-tetrahydro-2,7,7-3- } \\
\text { quinolinecarboxylate }\end{array}$ & 0.01 & 0.0 \\
\hline Myo-Inositol, 1,3,4,5,6-pentakis-O & 0.01 & 0.02 \\
\hline Phosphonic acid, (phenylmethyl) & 0.08 & 0.07 \\
\hline Putrescine tetraTMS & 0.3 & 0.05 \\
\hline
\end{tabular}


Table A.5.2: Metabolites detected (concentration) in plant roots not treated with TC. Not detected in plant roots treated with TC. Results are presented in mean $(n=3) \pm 1$ SD

\begin{tabular}{l|l|l} 
Compounds & $\begin{array}{l}\text { Conc. } \\
(\mathbf{m g} / \mathbf{L})\end{array}$ & Std. Dev. \\
\hline 3-(4-Methylphenoxy)benzoic acid & 0.02 & 0.0 \\
Sitosterol & 0.03 & 0.01 \\
Maltose & 0.03 & 0.01 \\
Xylitol & 0.28 & 0.08
\end{tabular}

Table A.5.3: Fold change in metabolites concentration (compared between plant roots treated with TC vs. not treated with TC). Results are presented in mean $(n=3) \pm 1$ SD

\begin{tabular}{l|c|c} 
Compound & $\begin{array}{c}\text { Fold } \\
\text { Change }\end{array}$ & Std. Dev. \\
\hline Arabinofuranose, 1,2,3,5-tetrakis & 2.57 & 0.01 \\
Cis aconitic acid & 1.68 & 0.01 \\
5-methoxyindoleacetate & 0.96 & 0.05 \\
Inositol 1, 3,4,5,6 -pentakisphospate & 1.23 & 0.02
\end{tabular}




\section{Appendix A.6. Statistical analysis details}

Table A.6.1. Statistical analysis details for TC disappearance in media samples collected from hydroponic tanks with vs. without plants

Summary Table for $p$-values:

\begin{tabular}{c|c|c|c} 
Days & $\begin{array}{c}\text { p value } \\
\text { between } \\
\text { different } \\
\text { concentrations }\end{array}$ & $\begin{array}{c}\text { p value } \\
\text { between with } \\
\text { vs. without } \\
\text { plants }\end{array}$ & $\begin{array}{c}\text { p value for } \\
\text { interaction }\end{array}$ \\
\hline Day 1 & 0.160 & 0.163 & $<.00001$ \\
Day 2 & 0.62 & 0.24 & $<.00001$ \\
Day 3 & $<0.0001$ & $<0.0001$ & $<0.0001$ \\
Day 5 & $<0.0001$ & 0.0008 & 0.0016
\end{tabular}

If the interaction was significant between factors, Tukey's HSD test was conducted and the analyses are presented below.

\section{Day 1}

\begin{tabular}{|lrrrr|}
\hline \multicolumn{5}{|c|}{ Analysis of Variance } \\
Source & DF & $\begin{array}{r}\text { Sum of } \\
\text { Squares }\end{array}$ & Mean Square & F Ratio \\
Model & 5 & 4251.8334 & 850.367 & 1151.972 \\
Error & 12 & 8.8582 & 0.738 & Prob > F \\
C. Total & 17 & 4260.6916 & & $<.0001^{*}$
\end{tabular}

Day 2

\begin{tabular}{lrrrrr|}
\hline \multicolumn{5}{l}{ Analysis of Variance } \\
\multicolumn{5}{|c|}{ Sum of } \\
Source & DF & $\begin{array}{r}\text { Squares } \\
\text { Mean Square }\end{array}$ & F Ratio \\
Model & 5 & 384.73831 & 76.9477 & 18492.10 \\
Error & 12 & 0.04993 & 0.0042 & Prob $>$ F \\
C. Total & 17 & 384.78824 & & $<.0001^{*}$ \\
& & & &
\end{tabular}




\section{Day 3}

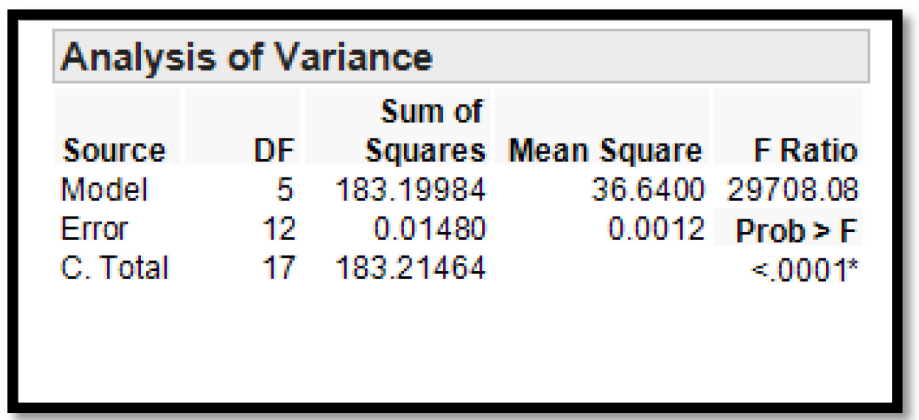

Day 5

\begin{tabular}{|lrrrr|}
\hline \multicolumn{5}{|c|}{ Analysis of Variance } \\
Source & DF & $\begin{array}{r}\text { Sum of } \\
\text { Squares }\end{array}$ & Mean Square & F Ratio \\
Model & 5 & 146.13560 & 29.2271 & 358.1023 \\
Error & 12 & 0.97940 & 0.0816 & Prob $>$ F \\
C. Total & 17 & 147.11500 & & $<0001^{*}$ \\
\hline
\end{tabular}

Table A.6.2. Table of p-values for TC disappearance (75 ppm) compared between hydroponic tanks in light vs. dark

\begin{tabular}{c|c} 
Time (days) & p values \\
\hline Day 1 & 0.381 \\
\hline Day 2 & 0.312 \\
\hline Day 3 & 0.063 \\
\hline Day 5 & 0.053 \\
\hline &
\end{tabular}


Table A.6.3. Statistical analysis details for phytotoxicity analysis

Summary Table for p-values:

\begin{tabular}{c|c|c|c}
$\begin{array}{c}\text { Phytotoxicity } \\
\text { parameters }\end{array}$ & $\begin{array}{c}\text { p valuebetween } \\
\text { different } \\
\text { concentrations }\end{array}$ & $\begin{array}{c}\text { p value between } \\
\text { day 0 and 30 }\end{array}$ & $\begin{array}{c}\text { p value for } \\
\text { interaction }\end{array}$ \\
\hline Plant mass & 0.32 & 0.059 & 0.05 \\
Shoot length & 0.62 & 0.24 & $<.00001$ \\
Root length & $<0.0001$ & 0.0097 & $<0.0001$
\end{tabular}

If the interaction was significant between factors, Tukey's HSD test was conducted and the analyses are presented below for different parameters.

\section{$\underline{\text { Plant Biomass }}$}

Interaction was not significant so Tukey's HSD test was not conducted.

\section{$\underline{\text { Shoot Length }}$}

\begin{tabular}{|c|c|c|c|c|}
\hline \multicolumn{5}{|c|}{ Analysis of Variance } \\
\hline Soul & DF & $\begin{array}{r}\text { Sum of } \\
\text { Squares }\end{array}$ & Mean Square & F Ratio \\
\hline Model & 7 & 172.24785 & 24.6068 & 84.4157 \\
\hline Error & 16 & 4.66393 & 0.2915 & Prob $>F$ \\
\hline C. Total & 23 & 176.91178 & & $<0001^{*}$ \\
\hline
\end{tabular}

Root Length

\begin{tabular}{lrrrr|}
\hline \multicolumn{5}{|c|}{ Analysis of Variance } \\
Source & DF & $\begin{array}{r}\text { Sum of } \\
\text { Squares }\end{array}$ & Mean Square & F Ratio \\
Model & 7 & 63.054263 & 9.00775 & 43.2788 \\
Error & 16 & 3.330133 & 0.20813 & Prob $>$ F \\
C. Total & 23 & 66.384396 & & $<.0001^{*}$
\end{tabular}


APPENDIX B. Additional information for Chapter 3. Recovery of tetracycline-tolerant bacteria from vetiver (Chrysopogon zizanioides L. Nash) root-zone and media samples and determination of their ability of maximal tetracycline-tolerance and usage (as a sole carbon and nitrogen source)

B.1- Data for recovery of bacteria from water (from hydroponic tanks) and vetiver root during hydroponic remediation experiment.

Bacteria were recovered on R2A media supplemented with different concentration of TC $(0,5,10,25,50,100 \mathrm{ppm})$. These results are supplementary to the materials provided in Chapter 3 and Appendix D.

Table B.1.1. Viable count results (Media samples) in CFU/ $\mathrm{mL}$ (colony forming unit).

\begin{tabular}{c|ccccc} 
Sampling Days & 0 ppm TC & $\mathbf{1 0} \mathbf{p p m}$ TC & $\mathbf{2 5} \mathbf{p p m}$ TC & $\mathbf{5 0} \mathbf{p p m}$ TC & $\mathbf{1 0 0} \mathbf{p p m} \mathbf{T C}$ \\
\hline Day 0 & $6.33 \times 10^{5}$ & $1.8 \times 10^{5}$ & $1 \times 10^{4}$ & $<1$ & $<1$ \\
Day 5 & $3.58 \times 10^{5}$ & $9.95 \times 10^{4}$ & $1.28 \times 10^{5}$ & $2 \times 10^{5}$ & $4.96 \times 10^{5}$ \\
Day 15 & $2.8 \times 10^{4}$ & $2.4 \times 10^{4}$ & $4.3 \times 10^{4}$ & $3.32 \times 10^{5}$ & $5.78 \times 10^{4}$ \\
Day 30 & $3.74 \times 10^{6}$ & $<1$ & $2.2 \times 10^{4}$ & $1.9 \times 10^{4}$ & $1.81 \times 10^{6}$ \\
& & & & &
\end{tabular}


Table B.1.2. Viable count results (Plant root samples). Results presented as mean $(n=3)$.

\begin{tabular}{c|ccccc} 
Sampling Days & 0 ppm TC & $\mathbf{1 0} \mathbf{~ p p m ~ T C}$ & $\mathbf{2 5} \mathbf{~ p p m ~ T C}$ & $\mathbf{5 0} \mathbf{~ p p m}$ & $\mathbf{1 0 0} \mathbf{~ p p m}$ \\
\hline Day 0 & $<1$ & $<1$ & $1.3 \times 10^{4}$ & $1.1 \times 10^{4}$ & $1.1 \times 10^{4}$ \\
Day 30 & $4.96 \times 10^{6}$ & $6.58 \times 10^{5}$ & $6.93 \times 10^{5}$ & $5.4 \times 10^{7}$ & $3.23 \times 10^{7}$
\end{tabular}


Appendix B.2- Data for initial screening of five bacteria (five strains) for their TC tolerance capability

Initial screening (growth study) results of five unknown bacteria recovered from hydroponic remediation tanks (3 from vetiver root-zone and 2 from media samples) during a 28 day trial. Bacterial isolates \#1, \#2, and \#3 were isolated from vetiver root and isolates \#4 and \#5 were recovered from media samples. The unknown bacterial isolates were evaluated for their initial TC tolerance ability using 10 and $50 \mathrm{ppm}$ of TC in a single carbon source medium (SCS). These results are supplementary to the materials provided in Chapter 3. 

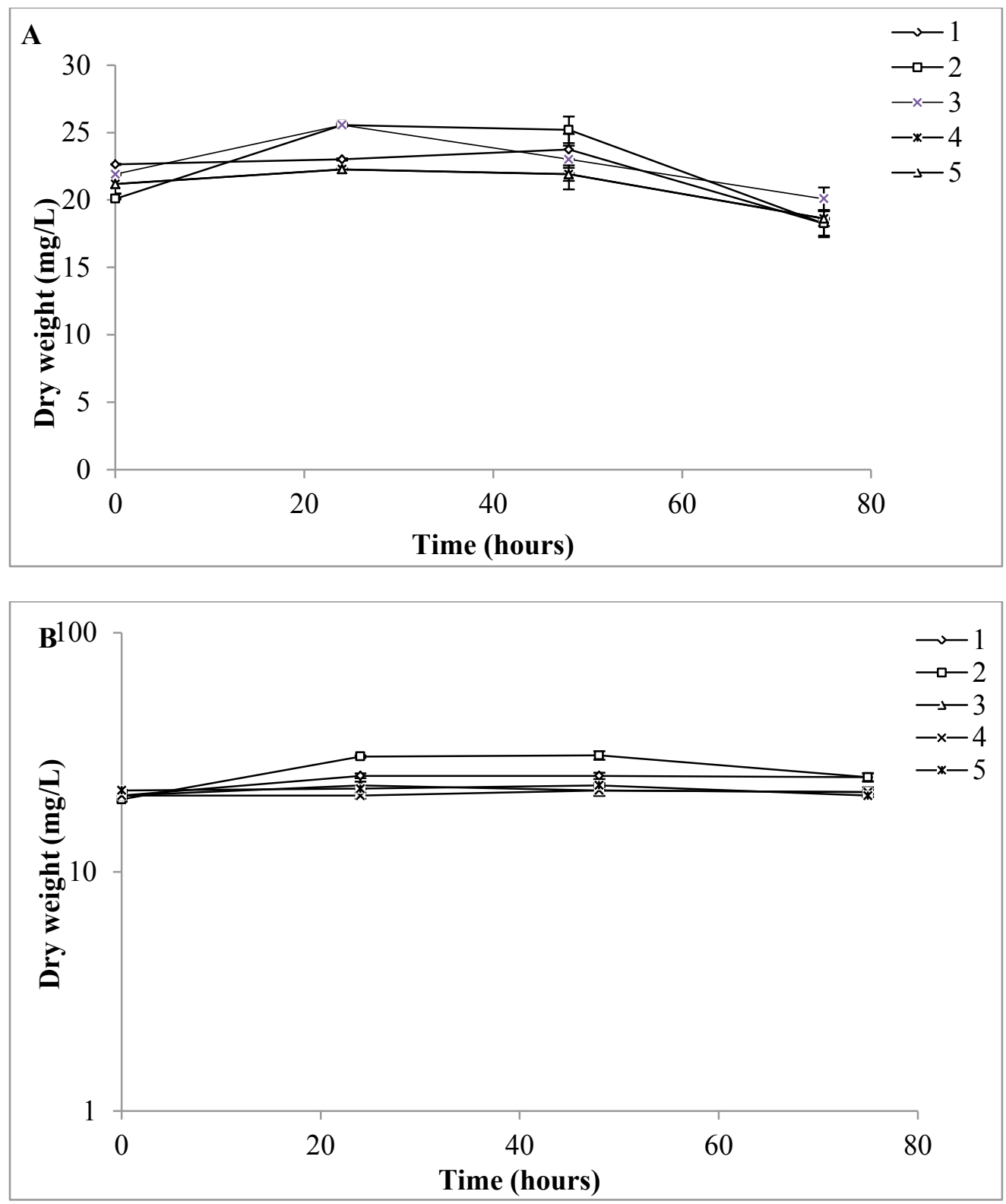

Figure B.2.1. Initial screening (growth study) result of isolated pure culture colonies of bacteria (isolates 1, 2, 3, 4, 5) grown in SCS medium supplemented with A) 10 ppm TC and $\mathrm{B}$ ) $50 \mathrm{ppm} \mathrm{TC} \mathrm{(} \mathrm{at} 30^{\circ} \mathrm{C}, \mathrm{pH}$ 7). Results presented as mean of $\mathrm{n}=3 \pm 1 \mathrm{SD}$ 
Direct counts were performed on the flasks set-up for growth studies at the end of the experiment (72 hours; Fig. B.2.1) as the initial screening results showed very low growth of bacteria in SCS supplemented with 10 and $50 \mathrm{ppm}$ of TC. Direct count results confirmed that there was growth recorded in all flasks in presence of TC (compared to 0 hour result where growth was $<1 \times 10^{6} \mathrm{CFU} / \mathrm{mL}$ ).

Table B.2.1. Direct count results $(\mathrm{CFU} / \mathrm{mL})$ of different flasks set-up for initial screening study at $72 \mathrm{hrs}$. Results presented as mean $(\mathrm{n}=3)$.

\begin{tabular}{c|ccccc}
\multirow{2}{*}{ TC conc. } & \multicolumn{5}{|c}{ Isolates recovered during hydroponic experiment } \\
\cline { 2 - 6 } & $\mathbf{\# 1}$ & $\mathbf{\# 2}$ & $\mathbf{\# 3}$ & $\mathbf{\# 4}$ & $\mathbf{\# 5}$ \\
\hline $\mathbf{1 0 p p m}$ & $6.8 \times 10^{6}$ & $4.3 \times 10^{6}$ & $1.2 \times 10^{6}$ & $2 \times 10^{6}$ & $1.2 \times 10^{6}$ \\
& & & & & \\
$\mathbf{5 0 p p m}$ & $7.2 \times 10^{6}$ & $2.8 \times 10^{7}$ & $3 \times 10^{6}$ & $1.2 \times 10^{6}$ & $1.6 \times 10^{6}$
\end{tabular}


Appendix B.3. Preliminary growth study (using defined and enriched media) and characterization results for three bacterial strains selected based on their ability to tolerate TC for further studies

After initial screening (Fig. B.2.1) and colony morphotypes on plates three bacterial isolates were selected for further studies. Experiments were conducted in both SCS (defined) and TSB (complex) media supplemented with TC (75 ppm) and flasks were incubated at $30^{\circ} \mathrm{C}$ on gyratory shaker at $160 \mathrm{rpm}, \mathrm{pH} 7$ in aerobic condition. Inoculum was grown in SCS media (for 24 hours) to avoid transfer of any nutrient trasnfer. These results are supplementary to the materials provided in Chapter 3 and Appendix D. 

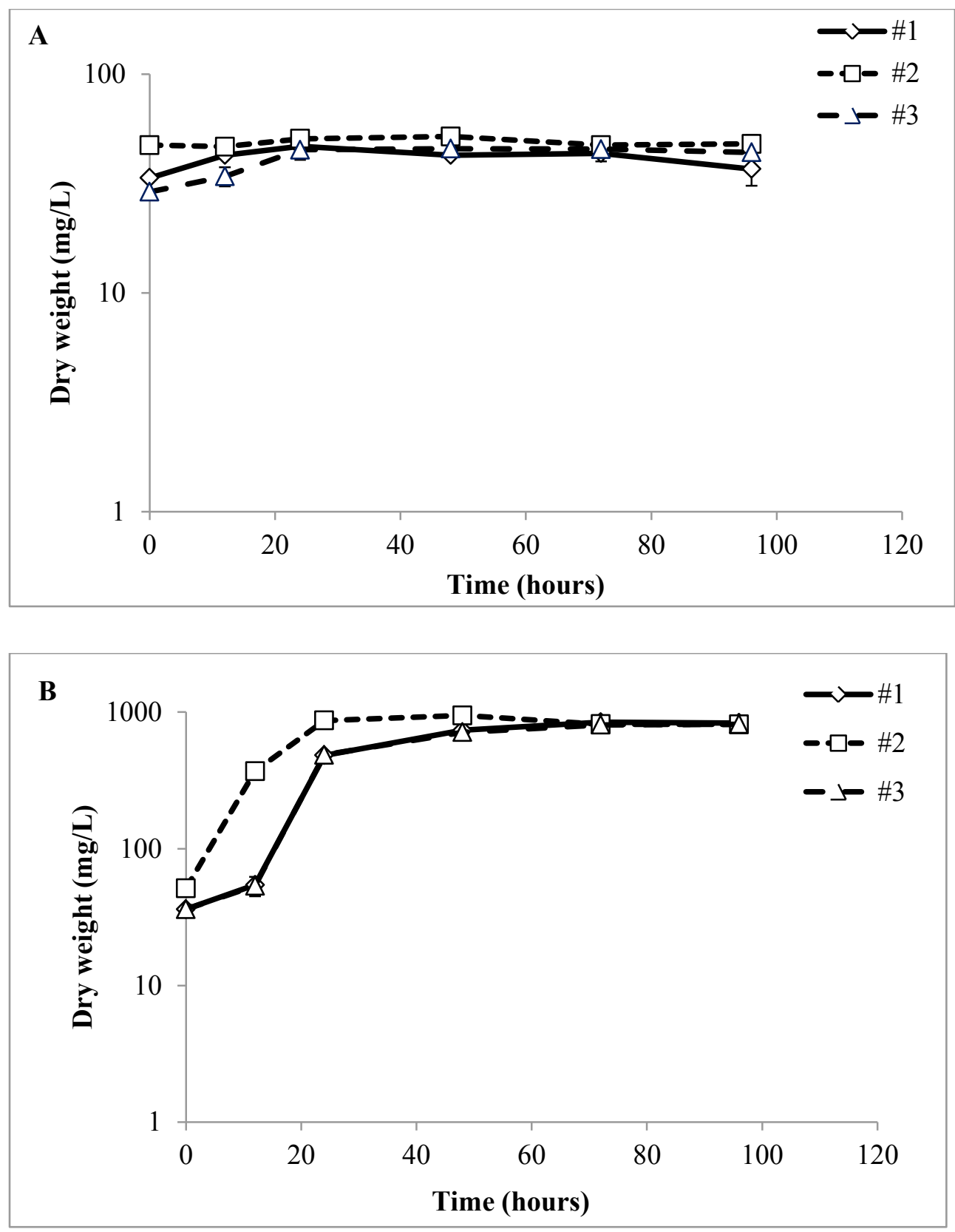

Figure B.3.1. Growth study result of bacteria \#1, \#2, and \#3 grown in A) SCS and B) TSB media supplemented with $50 \mathrm{ppm}$ of $\mathrm{TC}$ at $30^{\circ} \mathrm{C}, \mathrm{pH} 7,160 \mathrm{rpm}$. Results presented as mean of $n=3 \pm 1$ SD. 
Table B.3.1 below presents the detailed characterization (gram stain, colony morphology and basic biochemical characterization) of three TC-tolerant vetiver root-associated bacteria.

These three TC-tolerant were characterized (B.3.2) and identfied using 16S rRNA sequencing and MALDI-TOF (B.4). These bacteria were also naturally adapted over a period of $8-10$ weeks by streaking the bacteria colonies for isolation is R2A plates supplemented with high concentration of TC (100 ppm). These results are supplementary to the materials provided in Chapter 3. 
Table B.3.1. Basic bacterial characterization based on gram stain, colony morphology, and biochemical tests

\begin{tabular}{|c|c|c|c|c|c|c|c|c|c|c|}
\hline $\begin{array}{c}\text { Bacte } \\
\text { ria }\end{array}$ & $\begin{array}{c}\text { Gram } \\
\text { stain/sh } \\
\text { ape }\end{array}$ & Size & $\begin{array}{c}\text { Oxida } \\
\text { se }\end{array}$ & $\begin{array}{c}\text { Catala } \\
\text { se }\end{array}$ & Citrate & $\begin{array}{l}\text { Nitra } \\
\text { te }\end{array}$ & $\begin{array}{c}\text { OF } \\
\text { Test(glucose } \\
\text { ) }\end{array}$ & $\begin{array}{c}\text { Motili } \\
\text { ty }\end{array}$ & $\begin{array}{c}\text { Pigment } \\
\text { s }\end{array}$ & Colony Morphology \\
\hline$\# 1$ & $\begin{array}{l}-/ \\
\text { rod }\end{array}$ & $\begin{array}{c}1.5 \mathrm{x} \\
0.5 \mu \mathrm{m}\end{array}$ & - & + & + & + & $\begin{array}{l}\text { Open: Acid } \\
\text { Closed } \\
\text { (with oil): } \\
\text { Acid }\end{array}$ & + & Red & $\begin{array}{c}\text { Shape: round, Margin: } \\
\text { entire, Elevation: raised } \\
\text { Texture: mucoid, } \\
\text { Opacity: Opaque, } \\
\text { Colony Size: } 3.2 \mathrm{~mm}\end{array}$ \\
\hline \# 2 & $\begin{array}{l}-/ \\
\operatorname{rod}\end{array}$ & $\begin{array}{c}1 \times 0.5 \\
\mu \mathrm{m}\end{array}$ & + & + & + & + & $\begin{array}{l}\text { Open: Acid } \\
\text { Closed (with } \\
\text { oil): No } \\
\text { change }\end{array}$ & - & Yellow & $\begin{array}{c}\text { Shape: round, Margin: } \\
\text { entire, Elevation: } \\
\text { convex, Texture: } \\
\text { mucoid, } \underline{\text { Opacity: }} \\
\text { Opaque, } \underline{\text { Colony }} \\
\text { Size: } 2 \mathrm{~mm}\end{array}$ \\
\hline$\# \mathbf{3}$ & $\begin{array}{l}-1 \\
\text { rod }\end{array}$ & $\begin{array}{c}1 \times 0.5 \\
\mu \mathrm{m}\end{array}$ & - & + & + & + & $\begin{array}{l}\text { Open: Acid } \\
\text { Closed } \\
\text { (with oil): } \\
\text { Acid }\end{array}$ & + & White & $\begin{array}{l}\text { Shape: round, Margin: } \\
\text { entire, Elevation: flat, } \\
\text { Texture: dry, Opacity: } \\
\text { translucent, Colony } \\
\text { Size: } 1.5-2 \mathrm{~mm}\end{array}$ \\
\hline
\end{tabular}




\section{Appendix B.4- MALDI-TOF and $16 \mathrm{~S}$ rRNA sequencing information}

\section{Appendix B.4.1}

Table B.4.1. Results of MALDI-TOF conducted on unknown bacterial samples (\#1, \#2, \#3) (by MIDI labs, Inc, Delaware, NE)

\begin{tabular}{|c|c|c|c|c|c|}
\hline $\begin{array}{l}\text { Unknown } \\
\text { isolate \# }\end{array}$ & Rank & Score & Organism Source & $\begin{array}{l}\text { Closest } \\
\text { Match } \\
\end{array}$ & $\begin{array}{c}\text { Confidence } \\
\text { Level }\end{array}$ \\
\hline$\# 1$ & $\begin{array}{l}4 \\
5\end{array}$ & $\begin{array}{l}2.33 \\
2.20 \\
2.17 \\
2.15 \\
2.14\end{array}$ & $\begin{array}{c}\text { Serratia marcescens } \\
13103 \text { 1 CHB } \\
\text { Serratia marcescens ssp } \\
\text { marcescens DSM 30121T } \\
\text { DSM } \\
\text { Serratia marcescens (PX) } \\
24086109 \text { MLD } \\
\text { Serratia marcescens DSM } \\
30122 \text { DSM } \\
\text { Serratia marcescens DSM } \\
12485 \text { DSM } \\
\end{array}$ & $\begin{array}{c}\text { Serratia } \\
\text { marcescens }\end{array}$ & Species \\
\hline$\# 2$ & $\begin{array}{l}2 \\
3 \\
4 \\
5 \\
6 \\
7\end{array}$ & $\begin{array}{l}2.47 \\
2.43 \\
2.39 \\
2.39 \\
2.38 \\
2.30 \\
2.27\end{array}$ & $\begin{array}{c}\text { Burkholderia cepacia DSM } \\
\text { 7288T DSM } \\
\text { Burkholderia cepacia DSM } \\
\text { 9241 DSM } \\
\text { Burkholderia metallica } \\
\text { DSM 23519T DSM } \\
\text { Burkholderia seminalis } \\
\text { DSM 23518T DSM } \\
\text { Burkholderia cepacia DSM } \\
\text { 50181 DSM } \\
\text { Burkholderia lata } \text { DSM } \\
\text { 23089T DSM } \\
\text { Burkholderia cenocepacia } \\
\text { LMG 12614 HAM }\end{array}$ & $\begin{array}{c}\text { Burkholderia } \\
\text { cepacia }\end{array}$ & Species \\
\hline$\# 3$ & $\begin{array}{l}2 \\
3\end{array}$ & $\begin{array}{l}2.37 \\
2.35 \\
2.31\end{array}$ & $\begin{array}{c}\text { Serratia marcescens } \\
13103 \_1 \text { CHB } \\
\text { Serratia marcescens (PX) } \\
\text { 24086109 MLD } \\
\text { Serratia marcescens ssp } \\
\text { marcescens DSM 30121T } \\
\text { DSM }\end{array}$ & $\begin{array}{c}\text { Serratia } \\
\text { marcescens }\end{array}$ & Species \\
\hline
\end{tabular}


B.4.2. Results of $16 \mathrm{~S}$ rRNA conducted on unknown bacterial samples (\#1, \#2, \#3) (by MIDI labs, Inc, Delaware, NE)

Sequences were compared to the NCBI database using BLAST search and the results are reported below. Isolate \#1 and \#3 were both identified to be Serratia marcescens hence, only isolate \# 1 was selected along with isolate \#2 (identified as Burkholderia cepacia) for further studies. These results are supplementary to the materials provided in Chapter 3.

Bacterial Isolate \# $1>1304128647$ (sequence obtained from MIDI labs, Inc.) TGGAGAGTTTGATCCTGGCTCAGATTGAACGCTGGCGGCAGGCTTAACAC ATGCAAGTCGAGCGGTAGCACARGGGAGCTTGCTCCCYGGGTGACGAGCG GCGGACGGGTGAGTAATGTCTGGGAAACTGCCTGATGGAGGGGGATAACT ACTGGAAACGGTAGCTAATACCGCATAACGTCGCAAGACCAAAGAGGGGG ACCTTCGGGCCTCTTGCCATCAGATGTGCCCAGATGGGATTAGCTAGTAG GTGGGGTAATGGCTCACCTAGGCGACGATCCCTAGCTGGTCTGAGAGGAT GACCAGCCACACTGGAACTGAGACACGGTCCAGACTCCTACGGGAGGCAG CAGTGGGGAATATTGCACAATGGGCGCAAGCCTGATGCAGCCATGCCGCG TGTGTGAAGAAGGCCTTCGGGTTGTAAAGCACTTTCAGCGAGGAGGAAGG TGGTGAGCTTAATACGYTCATCAATTGACGTTACTCGCAGAAGAAGCACC GGCTAACTCCGTGCCAGCAGCCGCGGTA

Sequence (total 528 bp) matched with Basic Local Alignment Search Tool (BLAST) in ncbi.nlm.nih.gov

Max score: 959

Total score: 959

Query cover: 99\%

Identification with the database: $99 \%$

Matched with : Serratia marcescens strain XSJ7 
Bacterial Isolate \#2 >1304128648 (sequence obtained from MIDI labs, Inc.)

TGGAGAGTTTGATCCTGGCTCAGATTGAACGCTGGCGGCATGCCTTACAC ATGCAAGTCGAACGGCAGCACGGGTGCTTGCACCTGGTGGCGAGTGGCGA ACGGGTGAGTAATACATCGGAACATGTCCTGTAGTGGGGGATAGCCCGGC GAAAGCCGGATTAATACCGCATACGATCTACGGATGAAAGCGGGGGACCT TCGGGCCTCGCGCTATAGGGTTGGCCGATGGCTGATTAGCTAGTTGGTGG GGTAAAGGCCTACCAAGGCGACGATCAGTAGCTGGTCTGAGAGGACGACC AGCCACACTGGGACTGAGACACGGCCCAGACTCCTACGGGAGGCAGCAGT GGGGAATTTTGGACAATGGGCGAAAGCCTGATCCAGCAATGCCGCGTGTG TGAAGAAGGCCTTCGGGTTGTAAAGCACTTTTGTCCGGAAAGAAATCCTT GGCTCTAATACAGYCGGGGGATGACGGTACCGGAAGAATAAGCACCGGCT AACTACGTGCCAGCAGCCGCGGTa

Sequence (total 524 bp) matched with Basic Local Alignment Search Tool (BLAST) in ncbi.nlm.nih.gov

Max score: 965

Total score: 965

Query cover: 100\%

Identification with the database: $99 \%$

Matched with: Burkholderia cepacia 
Bacterial Isolate \#3 >1304128649 (sequence obtained from MIDI labs, Inc.)

TGGAGAGTTTGATCCTGGCTCAGATTGAACGCTGGCGGCAGGCTTAACAC ATGCAAGTCGAGCGGTAGCACAGGGGAGCTTGCTCCCCGGGTGACGAGCG GCGGACGGGTGAGTAATGTCTGGGAAACTGCCTGRTGGAGGGGGATAACT ACTGGAAACGGTAGCTAATACCGCATAACGTCGCAAGACCAAAGAGGGGG ACCTTCGGGCCTCTTGCCATCAGATGTGCCCAGATGGGATTAGCTAGTAG GTGGGGTAATGGCTCACCTAGGCGACGATCCCTAGCTGGTCTGAGAGGAT GACCAGCCACACTGGAACTGAGACACGGTCCAGACTCCTACGGGAGGCAG CAGTGGGGAATATTGCACAATGGGCGCAAGCCTGATGCAGCCATGCCGCG TGTGTGAAGAAGGCCTTCGGGTTGTAAAGCACTTTCAGCGAGGAGGAAGG TGGTGAACTTAATACGTTCATCAATTGACGTTACTCGCAGAAGAAGCACC GGCTAACTCCGTGCCAGCAGCCGCGGTA

Sequence (total 528 bp) matched with Basic Local Alignment Search Tool (BLAST) in ncbi.nlm.nih.gov

Max score: 968

Total score: 968

Query cover: $100 \%$

Identification with the database: $99 \%$

Matched with: Serratia sp. DC 2 
B.4.3. Phylogenetic tree constructed for isolate \# 1 (S. marcescens) and isolate \# 2 (B. cepacia) using 16S rRNA sequence obtained from MIDI Labs, Inc.

Phylogenetic tree was constructed for both isolates 1 and 2 (S. marcescens and B. cepacia respectively) using BLAST (ncbi.nlm.nih.gov). $16 \mathrm{~S}$ rRNA sequences, obtained for isolate \# 1 (S. marcescens) and isolate \# 2 (B. cepacia) were searched as queries (separately) using BLAST, uncultured sequences were excluded and highly similar sequences were included in the search and then megablast search was conducted. For generating phylogenetic trees (presented below in figures B.4.3.1 and B.4.3.2) 98\% similarity and above was selected between sequences (query vs. database) and neighbor joining alignment was conducted. 


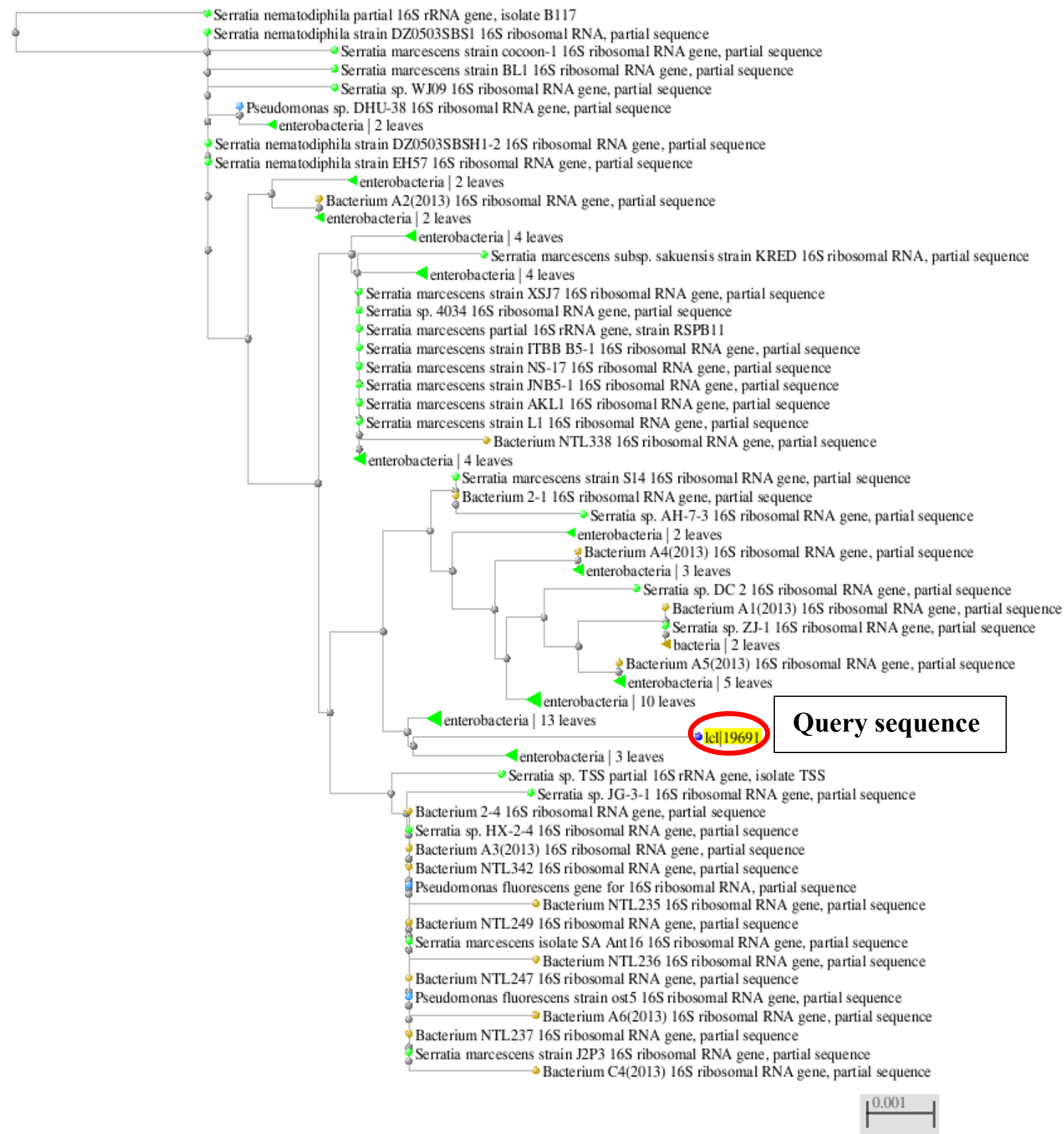

Figure B.4.3.1. Phylogenetic tree construction for S. marcescens (isolate \# 1) 


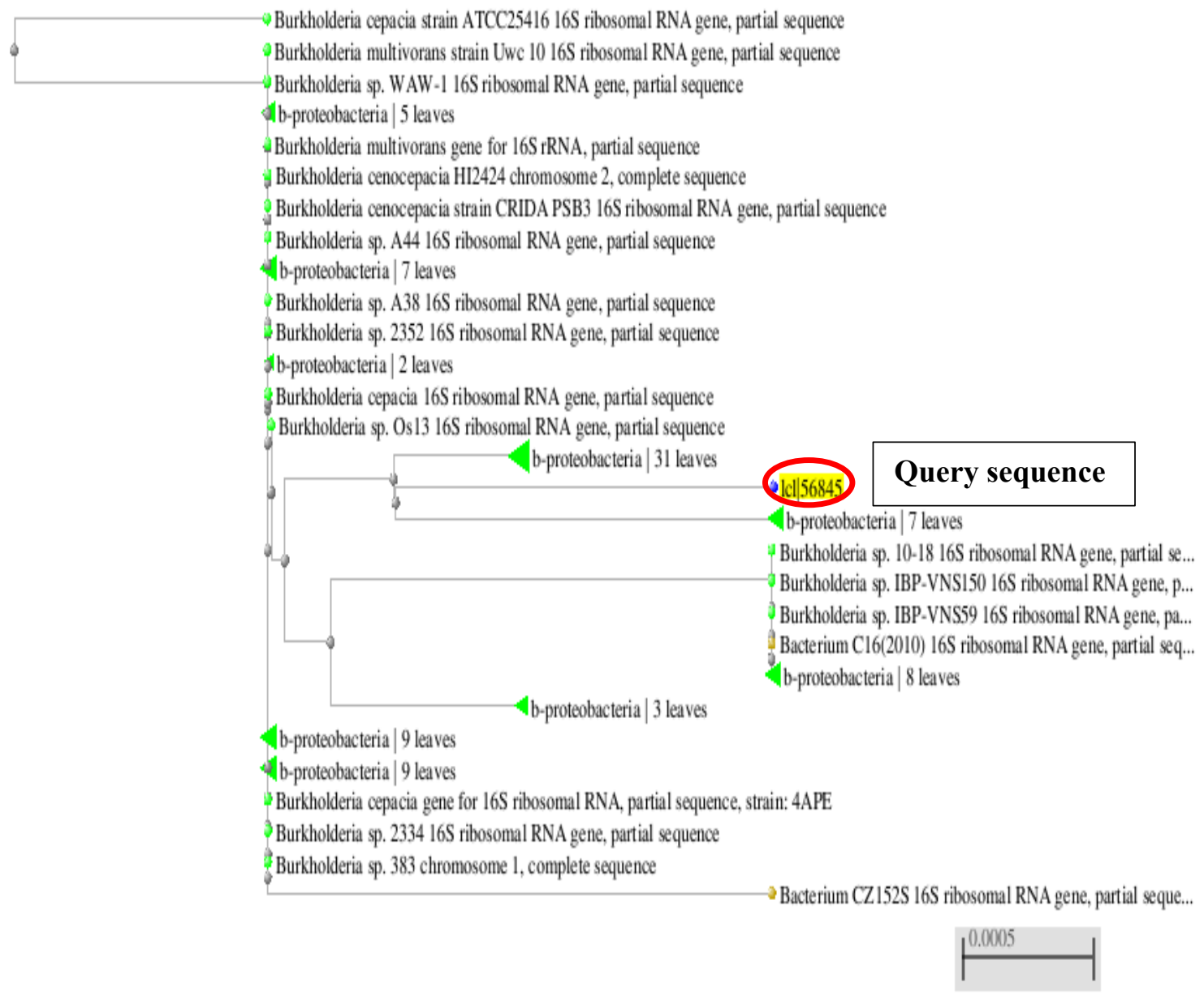

Figure B.4.3.2. Phylogenetic tree construction for B. cepacia (isolate \# 2) 


\section{Appendix B.5- Growth study results of Serratia marcescens and Burkholderia cepacia with different media (defined and enriched)}

Growth studies were conducted for Serratia marcescens and Burkholderia cepacia using different media (defined and enriched) with and without $\mathrm{TC}$ to understand the role/capability of these two TC-tolerant bacteria in using TC as a carbon source.

Growth studies were conducted using SCS media (composition in appendix B) supplemented with $1 \mathrm{~g} / \mathrm{L}$ of TC as the sole carbon source, SCS media supplemented with $1 \mathrm{~g} / \mathrm{L}$ of glucose as the single carbon source, and enriched media (ERM) without any TC. All the experiments were conducted at $30^{\circ} \mathrm{C}$ in aerobic condition with a $\mathrm{pH}$ of 7.0 (except for TSB media which is pre-made the $\mathrm{pH}$ of the media is 7.3 ) in gyratory shaker with a speed of $160 \mathrm{pm}$. These results are supplementary to the materials provided in Chapter 3 and Appendix D. 


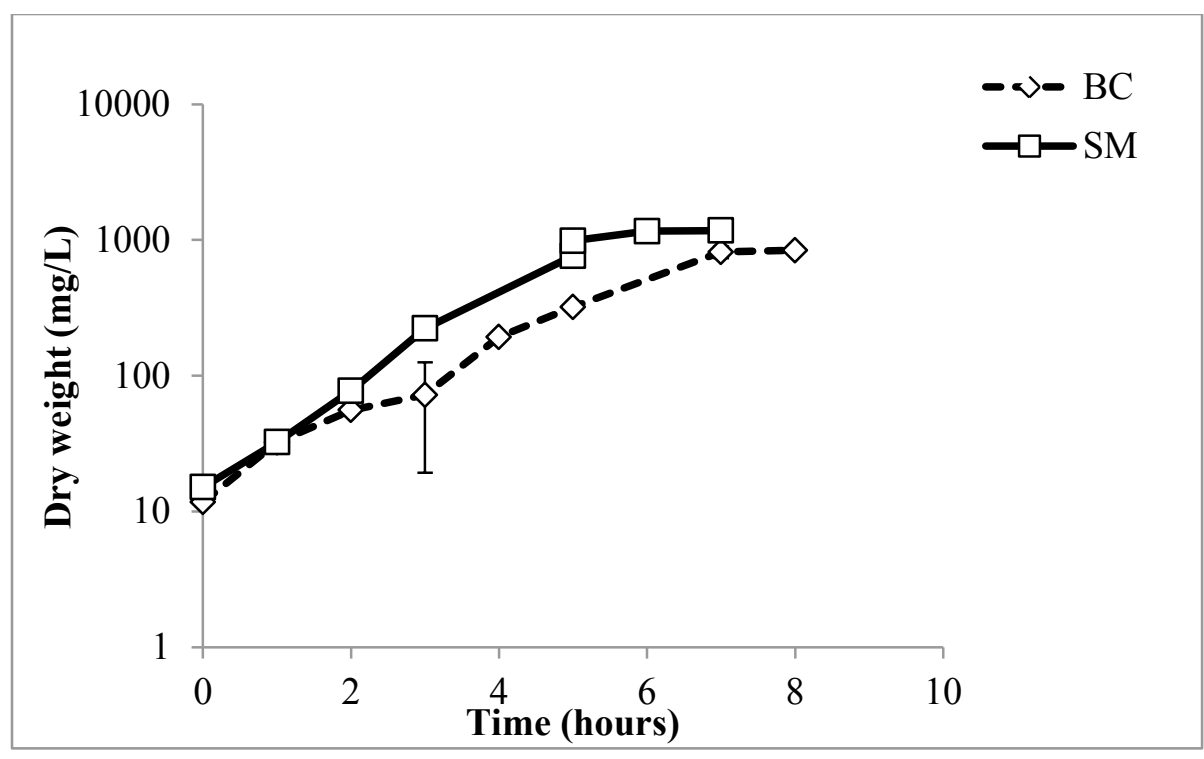

Figure B.5.1. Growth study result of bacteria SM and BC grown in TSB media without TC at $30^{\circ} \mathrm{C}, \mathrm{pH} 7$. Results presented as mean of $\mathrm{n}=3 \pm 1 \mathrm{SD}$.

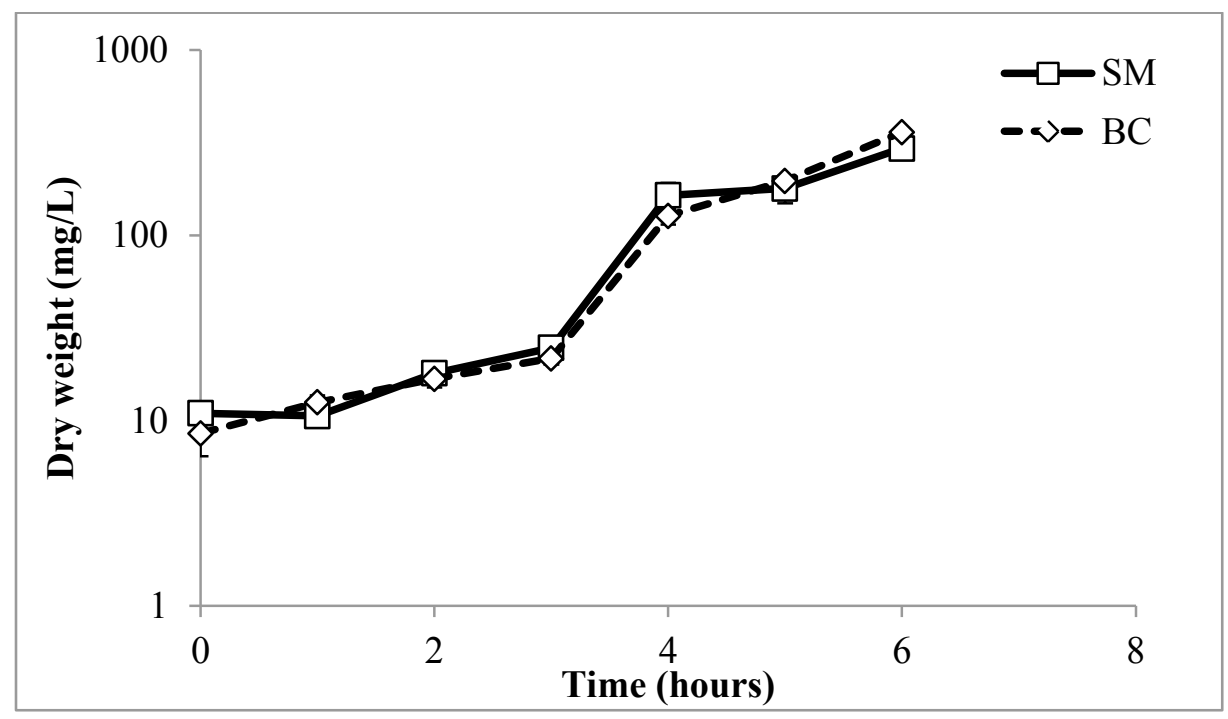

Figure B.5.2. Growth study result of bacteria SM and BC grown in SCS media supplemented with glucose $(1 \mathrm{~g} / \mathrm{L})$ (without TC) at $30^{\circ} \mathrm{C}, \mathrm{pH} 7$. Results presented as mean of $n=3 \pm 1$ SD. 
Appendix B.6- Data for Minimum inhibitory concentration (MIC) levels of TC for Serratia marcescens and Burkholderia cepacia

Minimum inhibitory concentration (MIC) of TC was evaluated for Serratia marcescens and Burkholderia cepacia using different concentrations of TC (15, 60, 250, 10000 ppm). The results show that there was no MIC recorded for these two bacteria under any of these TC concentration used. Both of these bacteria were highly tolerant to TC (as high as $1000 \mathrm{ppm})$. 


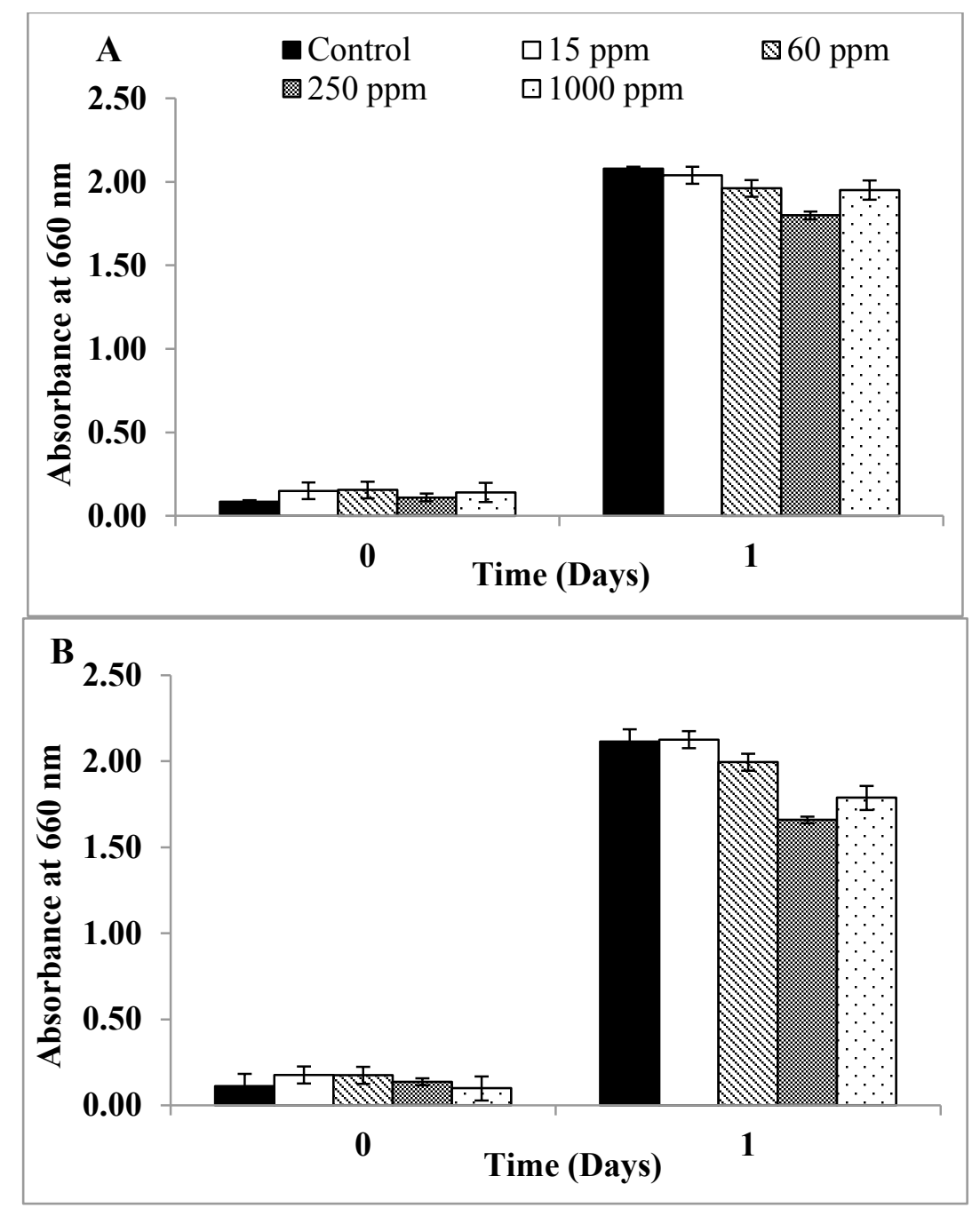

Figure B.6.1. Minimum inhibitory concentration (MIC) of TC for A) B. cepacia and, B) S. marcescens compared with control (no TC). The experiments were carried out at $30^{\circ} \mathrm{C}$, $\mathrm{pH}$ 7. Data presented as mean of $\mathrm{n}=3 \pm 1 \mathrm{SD}$. 
Appendix B.7- Growth rate data for different growth studies performed using different media (defined and enriched) with and without TCThe following tables show growth rate $\left(\mathrm{k} \mathrm{hr}^{-1}\right)$ data from different growth studies conducted on $S$. marcescens (SM) and B. cepacia (BC). These results are supplementary to the materials provided in Chapter 3 and Appendix D. (See abbreviations table for reference)

\begin{tabular}{l|lll}
$\begin{array}{l}\text { pH study (TSB media with } 75 \text { ppm } \\
\text { of TC) }\end{array}$ & $\mathbf{6}$ & $\mathbf{7 . 3}$ & $\mathbf{8 . 5}$ \\
\hline SM & 0.45 & 0.52 & 0.61 \\
BC & 0.697 & 0.72 & 0.80
\end{tabular}

\begin{tabular}{l|lll} 
pH study (enriched media; ERM made & \multicolumn{2}{l}{} \\
in lab with 75 ppm of TC) & $\mathbf{6}$ & $\mathbf{7}$ & $\mathbf{8 . 5}$ \\
\hline SM & 0.48 & 0.54 & 0.25 \\
BC & 0.62 & 0.63 & 0.21
\end{tabular}

\begin{tabular}{l|lll} 
SCS media (75 ppm of TC) & $\mathbf{6}$ & $\mathbf{7}$ & $\mathbf{8 . 5}$ \\
\hline SM & 0.23 & 0.4 & 0.01 \\
BC & 0.29 & 0.46 & 0.03
\end{tabular}

\begin{tabular}{l|ll} 
Details & SM & BC \\
\hline TC as SNS (1g/L) & 1.11 & 0.88 \\
TSB without TC & 1.30 & 0.86 \\
SCS with glucose & 1.02 & 0.97
\end{tabular}

\begin{tabular}{l|ll} 
Oxygen requirement study (SCS medium; 75 ppm TC) & Microaerophilic & Aerobic \\
\hline SM & 0.28 & 0.53 \\
BC & 0.29 & 0.68 \\
Temperature study (TSB medium; 75 ppm TC) & SM & BC \\
\hline $\mathbf{4}^{\circ} \mathbf{C}$ & 0.07 & 0.08 \\
$\mathbf{2 4}^{\circ} \mathbf{C}$ & 0.45 & 0.65 \\
$\mathbf{3 0}^{\circ} \mathbf{C}$ & 0.57 & 0.74 \\
$\mathbf{3 7}^{\circ} \mathbf{C}$ & 0.36 & 0.25 \\
$\mathbf{4 2}^{\circ} \mathbf{C}$ & 0.04 & 0.02
\end{tabular}


Appendix B.8. Statistical analysis details from 2-way Anova analysis and Tukey's HSD

Table B.8.1. Statistical detailed results for SCS media with TC using B. cepacia vs. abiotic treatment

Summary Table for p-values:

\begin{tabular}{c|c|c|c} 
Days & $\begin{array}{c}\text { p value } \\
\text { between } \\
\text { different } \\
\text { concentrations }\end{array}$ & $\begin{array}{c}\text { p value } \\
\text { between with } \\
\text { bacteria vs. } \\
\text { abitoic }\end{array}$ & $\begin{array}{c}\text { p value for } \\
\text { interaction }\end{array}$ \\
\hline Day 1 & $<.00001$ & 0.0004 & $<.00001$ \\
Day 2 & $<.00001$ & 0.5325 & $<.00001$ \\
Day 3 & $<.00001$ & $<.00001$ & $<.00001$ \\
Day 5 & $<.00001$ & $<.00001$ & $<.00001$ \\
Day 7 & $<.00001$ & $<.00001$ & $<.00001$
\end{tabular}

If the interaction was significant between factors, Tukey's HSD test was conducted and the analyses are presented below.

$\underline{\text { Day } 1}$

Analysis of Variance

$\begin{array}{lrrrr}\text { Source } & \text { DF } & \begin{array}{r}\text { Sum of } \\ \text { Squares }\end{array} & \text { Mean Square } & \text { F Ratio } \\ \text { Model } & 3 & 2907.4466 & 969.149 & 3904.578 \\ \text { Error } & 8 & 1.9857 & 0.248 & \text { Prob }>\text { F } \\ \text { C. Total } & 11 & 2909.4323 & & <.0001^{*}\end{array}$


Day 2

\begin{tabular}{lrrrr|}
\hline \multicolumn{5}{l}{ Analysis of Variance } \\
Source & DF & $\begin{array}{r}\text { Sum of } \\
\text { Squares }\end{array}$ & Mean Square & F Ratio \\
Model & 3 & 491.23883 & 163.746 & 8637.166 \\
Error & 8 & 0.15167 & 0.019 & Prob > F \\
C. Total & 11 & 491.39050 & & $<.0001^{*}$
\end{tabular}

Day 3

\begin{tabular}{|lrrrr|}
\hline \multicolumn{5}{|c|}{ Analysis of Variance } \\
Source & DF & $\begin{array}{r}\text { Sum of } \\
\text { Squares }\end{array}$ & Mean Square & F Ratio \\
Model & 3 & 241.54037 & 80.5135 & 27763.26 \\
Error & 8 & 0.02320 & 0.0029 & Prob $>$ F \\
C. Total & 11 & 241.56357 & & $<0001^{*}$
\end{tabular}

Day 5

\begin{tabular}{|lrrrr|}
\hline \multicolumn{5}{l|}{ Analysis of Variance } \\
Source & DF & $\begin{array}{r}\text { Sum of } \\
\text { Squares }\end{array}$ & Mean Square & F Ratio \\
Model & 3 & 111.89237 & 37.2975 & 1188.132 \\
Error & 8 & 0.25113 & 0.0314 & Prob $>$ F \\
C. Total & 11 & 112.14350 & & $<.0001^{*}$
\end{tabular}

Day 7

\begin{tabular}{lrrrr|}
\hline \multicolumn{5}{l|}{ Analysis of Variance } \\
Source & DF & $\begin{array}{r}\text { Sum of } \\
\text { Squares }\end{array}$ & Mean Square & F Ratio \\
Model & 3 & 66.870600 & 22.2902 & 25234.19 \\
Error & 8 & 0.007067 & 0.000883 & Prob > F \\
C. Total & 11 & 66.877667 & & $<.0001^{*}$
\end{tabular}


Table B.8.2. Statistical detailed results for TSB media with TC using B. cepacia vs. abiotic treatment

Summary Table for p-values:

\begin{tabular}{c|c|c|c} 
Days & $\begin{array}{c}\text { p value } \\
\text { between } \\
\text { different } \\
\text { concentrations }\end{array}$ & $\begin{array}{c}\text { p value } \\
\text { between with } \\
\text { bacteria vs. } \\
\text { abitoic }\end{array}$ & $\begin{array}{c}\text { p value for } \\
\text { interaction }\end{array}$ \\
\hline Day 1 & $<.00001$ & 0.0012 & $<.00001$ \\
Day 2 & $<.00001$ & 0.4545 & $<.00001$ \\
Day 3 & $<.00001$ & $<.00001$ & $<.00001$ \\
Day 5 & $<.00001$ & $<.00001$ & $<.00001$ \\
Day 7 & $<.00001$ & $<.00001$ & $<.00001$
\end{tabular}

If the interaction was significant between factors, Tukey's HSD test was conducted and the analyses are presented below.

Day 1

Analysis of Variance

Sum of

Source DF Squares Mean Square F Ratio

$\begin{array}{lllll}\text { Model } & 3 & 2830.2644 & 943.421 & 6045.959\end{array}$

Error $\quad 8 \quad 1.2483$

C. Total $\quad 112831.5127$

0.156 Prob $>\mathrm{F}$

$<.0001^{*}$ 
Day 2

\begin{tabular}{|lrrrr|}
\hline \multicolumn{5}{|c|}{ Analysis of Variance } \\
Source & DF & $\begin{array}{r}\text { Sum of } \\
\text { Squares }\end{array}$ & Mean Square & F Ratio \\
Model & 3 & 315.34330 & 105.114 & 138.0542 \\
Error & 8 & 6.09120 & 0.761 & Prob > F \\
C. Total & 11 & 321.43450 & & $<.0001^{*}$ \\
& & & & \\
\end{tabular}

Day 3

\begin{tabular}{lrrrr|}
\hline \multicolumn{5}{l|}{ Analysis of Variance } \\
Source & DF & $\begin{array}{r}\text { Sum of } \\
\text { Squares }\end{array}$ & Mean Square & F Ratio \\
Model & 3 & 106.89433 & 35.6314 & 1522.169 \\
Error & 8 & 0.18727 & 0.0234 & Prob $>$ F \\
C. Total & 11 & 107.08160 & & $<.0001^{*}$ \\
& & & & \\
& & & & \\
\end{tabular}

Day 5

\begin{tabular}{lrrrr|}
\hline \multicolumn{5}{|c|}{ Analysis of Variance } \\
Source & DF & $\begin{array}{r}\text { Sum of } \\
\text { Squares }\end{array}$ & Mean Square & F Ratio \\
Model & 3 & 106.89433 & 35.6314 & 1522.169 \\
Error & 8 & 0.18727 & 0.0234 & Prob $>$ F \\
C. Total & 11 & 107.08160 & & $<0001^{*}$
\end{tabular}

Day 7

\begin{tabular}{|lrrrr|}
\hline \multicolumn{5}{|c|}{ Analysis of Variance } \\
Source & DF & $\begin{array}{r}\text { Sum of } \\
\text { Squares }\end{array}$ & Mean Square & F Ratio \\
Model & 3 & 37.924633 & 12.6415 & 5834.559 \\
Error & 8 & 0.017333 & 0.0022 & Prob > F \\
C. Total & 11 & 37.941967 & & $<.0001^{*}$ \\
& & & & \\
& & & & \\
\end{tabular}


Table B.8.3. Statistical detailed results for SCS media with TC using $S$. marcescens vs. abiotic treatment

Summary Table for p-values:

\begin{tabular}{l|c|c|c} 
Days & $\begin{array}{c}\text { p value } \\
\text { between } \\
\text { different } \\
\text { concentrations }\end{array}$ & $\begin{array}{c}\text { p value } \\
\text { between with } \\
\text { bacteria vs. } \\
\text { abitoic }\end{array}$ & $\begin{array}{c}\text { p value for } \\
\text { interaction }\end{array}$ \\
\hline Day 1 & $<.00001$ & $<.00001$ & $<.00001$ \\
Day 2 & $<.00001$ & 0.0298 & $<.00001$ \\
Day 3 & $<.00001$ & 0.0041 & $<.00001$ \\
Day 5 & $<.00001$ & 0.0082 & $<.00001$ \\
Day 7 & $<.00001$ & $<.00001$ & $<.00001$
\end{tabular}

If the interaction was significant between factors, Tukey's HSD test was conducted and the analyses are presented below.

Day 1

\begin{tabular}{|lrrrr|}
\hline \multicolumn{5}{|l|}{ Analysis of Variance } \\
Source & DF & $\begin{array}{r}\text { Sum of } \\
\text { Squares }\end{array}$ & Mean Square & F Ratio \\
Model & 3 & 3201.3221 & 1067.11 & 9097.249 \\
Error & 8 & 0.9384 & 0.12 & Prob $>$ F \\
C. Total & 11 & 3202.2605 & & $<0001^{*}$ \\
\hline
\end{tabular}

Day 2

\begin{tabular}{lrrrrr|}
\hline \multicolumn{5}{|c|}{ Analysis of Variance } \\
Source & DF & $\begin{array}{r}\text { Sum of } \\
\text { Squares }\end{array}$ & Mean Square & F Ratio \\
Model & 3 & 434.35109 & 144.784 & 9452.690 \\
Error & 8 & 0.12253 & 0.015 & Prob $>$ F \\
C. Total & 11 & 434.47363 & & $<.0001^{*}$
\end{tabular}


Day 3

\begin{tabular}{|lrrrr|}
\hline \multicolumn{4}{|l|}{ Analysis of Variance } \\
Source & DF & $\begin{array}{r}\text { Sum of } \\
\text { Squares }\end{array}$ & Mean Square & F Ratio \\
Model & 3 & 159.02069 & 53.0069 & 4232.088 \\
Error & 8 & 0.10020 & 0.0125 & Prob $>$ F \\
C. Total & 11 & 159.12089 & & $<.0001^{*}$ \\
& & & & \\
& & & & \\
\hline
\end{tabular}

Day 5

\begin{tabular}{|lrrrr|}
\hline \multicolumn{5}{|c|}{ Analysis of Variance } \\
Source & DF & $\begin{array}{r}\text { Sum of } \\
\text { Squares }\end{array}$ & Mean Square & F Ratio \\
Model & 3 & 83.443867 & 27.8146 & 857.1532 \\
Error & 8 & 0.259600 & 0.0324 & Prob $>$ F \\
C. Total & 11 & 83.703467 & & $<.0001^{*}$
\end{tabular}

Day 7

\begin{tabular}{|lrrrr|}
\hline \multicolumn{5}{|c|}{ Analysis of Variance } \\
Source & DF & $\begin{array}{r}\text { Sum of } \\
\text { Squares }\end{array}$ & Mean Square & F Ratio \\
Model & 3 & 66.870600 & 22.2902 & 25234.19 \\
Error & 8 & 0.007067 & 0.000883 & Prob $>$ F \\
C. Total & 11 & 66.877667 & & $<.0001^{*}$
\end{tabular}


Table B.8.4. Statistical detailed results for TSB media with TC using $S$. marcescens vs. abiotic treatment

Summary Table for $\mathrm{p}$-values:

\begin{tabular}{l|c|c|c} 
Days & $\begin{array}{c}\text { p value } \\
\text { between } \\
\text { different } \\
\text { concentrations }\end{array}$ & $\begin{array}{c}\text { p value } \\
\text { between with } \\
\text { bacteria vs. } \\
\text { abitoic }\end{array}$ & $\begin{array}{c}\text { p value for } \\
\text { interaction }\end{array}$ \\
\hline Day 1 & $<.00001$ & 0.4282 & $<.00001$ \\
Day 2 & $<.00001$ & 0.6868 & $<.00001$ \\
Day 3 & $<.00001$ & $<.00001$ & $<.00001$ \\
Day 5 & $<.00001$ & 0.0002 & $<.00001$ \\
Day 7 & $<.00001$ & $<.00001$ & $<.00001$
\end{tabular}

If the interaction was significant between factors, Tukey's HSD test was conducted and the analyses are presented below.

Day 1

\begin{tabular}{lrrrr|}
\hline \multicolumn{5}{|c|}{ Analysis of Variance } \\
Source & DF & $\begin{array}{r}\text { Sum of } \\
\text { Squares }\end{array}$ & Mean Square & F Ratio \\
Model & 3 & 3115.5035 & 1038.50 & 5999.429 \\
Error & 8 & 1.3848 & 0.17 & Prob $>$ F \\
C. Total & 11 & 3116.8883 & & $<.0001^{*}$
\end{tabular}

Day 2

\begin{tabular}{|c|c|c|c|c|}
\hline \multicolumn{5}{|c|}{ Analysis of Variance } \\
\hline Source & DF & $\begin{array}{l}\text { Sum of } \\
\text { Squares }\end{array}$ & Mean Square & F Ratio \\
\hline Model & 3 & 307.05050 & 102.350 & 138.7219 \\
\hline Error & 8 & 5.90247 & 0.738 & Prob $>F$ \\
\hline C. Total & 11 & 312.95297 & & $<0001^{*}$ \\
\hline
\end{tabular}


Day 3

\begin{tabular}{|lrrrr|}
\hline \multicolumn{5}{|c|}{ Analysis of Variance } \\
Source & DF & $\begin{array}{r}\text { Sum of } \\
\text { Squares }\end{array}$ & Mean Square & F Ratio \\
Model & 3 & 177.38543 & 59.1285 & 4595.478 \\
Error & 8 & 0.10293 & 0.0129 & Prob $>$ F \\
C. Total & 11 & 177.48837 & & $<.0001^{*}$ \\
& & & & \\
& & & & \\
\end{tabular}

Day 5

\begin{tabular}{|lrrrr|}
\hline \multicolumn{5}{|c|}{ Analysis of Variance } \\
Source & DF & $\begin{array}{r}\text { Sum of } \\
\text { Squares }\end{array}$ & Mean Square & F Ratio \\
Model & 3 & 73.639358 & 24.5465 & 2602.097 \\
Error & 8 & 0.075467 & 0.0094 & Prob $>$ F \\
C. Total & 11 & 73.714825 & & $<.0001^{*}$
\end{tabular}

Day 7

Analysis of Variance

Sum of

Source DF Squares Mean Square F Ratio

$\begin{array}{llllll}\text { Model } & 3 & 37.924633 & 12.6415 & 5834.559\end{array}$

$\begin{array}{llllll}\text { Error } & 8 & 0.017333 & 0.0022 & \text { Prob }>F\end{array}$

$\begin{array}{llll}\text { C. Total } & 11 & 37.941967 & <.0001^{*}\end{array}$ 
APPENDIX C. Additional information for Chapter 3. Role of vetiver (Chrysopogon zizanoides L. Nash) root-associated microbes in tetracycline degradation root-zone

Appendix C.1- Data for TC removal study using TSB media supplemented with TC. Data for TC utilization/transformation study in TSB media supplemented with $75 \pm 5$ $\mathrm{mg} / \mathrm{L}$ of TC and $10 \pm 3 \mathrm{mg} / \mathrm{L}$ of tetracycline (TC) by $S$. marcescens and B. cepacia S.marcescens and B.cepacia were evaluated for their tetracycline (TC) utilization/ transformation capability in TSB media supplemented with $75 \pm 5 \mathrm{mg} / \mathrm{L}$ of TC and $10 \pm 3$ $\mathrm{mg} / \mathrm{L}$. These results are supplementary to the materials provided in Chapter 3 . 

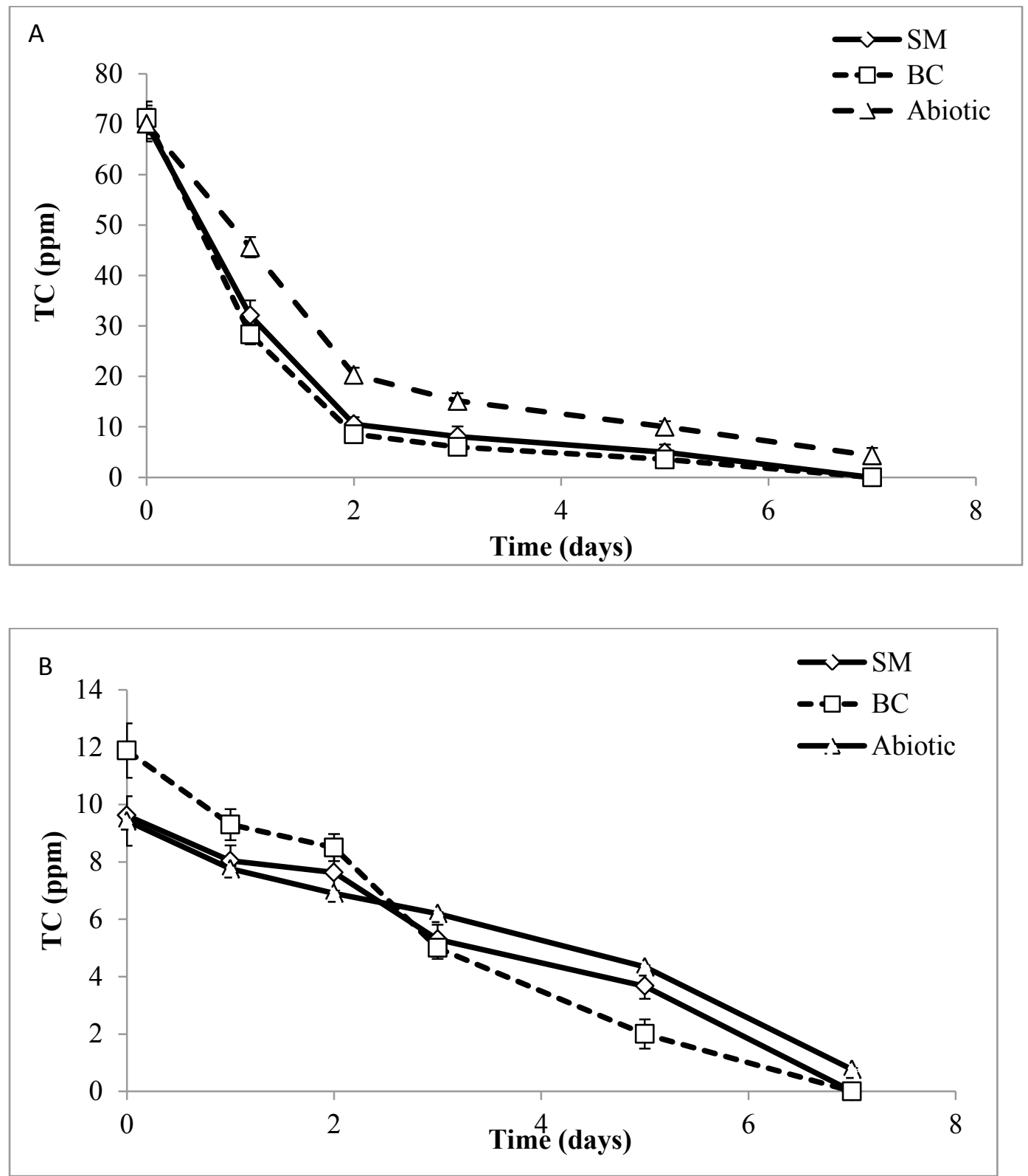

Figure C.1.1. TC removal from the media samples in different flasks treated by $S$. marcescens (\#1) and B. cepacia (\#2) and abiotic flasks (control) without any treatment in TSB media supplemented with TC (starting conc. A. 75 ppm of TC, mean ( $n=3)$ SD \pm 1 ; B. $10 \mathrm{ppm}$ of TC, mean $(\mathrm{n}=3) \mathrm{SD} \pm 1$. The experiments were carried out for 28 days at $30^{\circ} \mathrm{C}$, pH 7 (TC was not detected in samples beyond 7 days). 
Appendix C.2 - Data for TC transformation study using TSB media supplemented with TC.
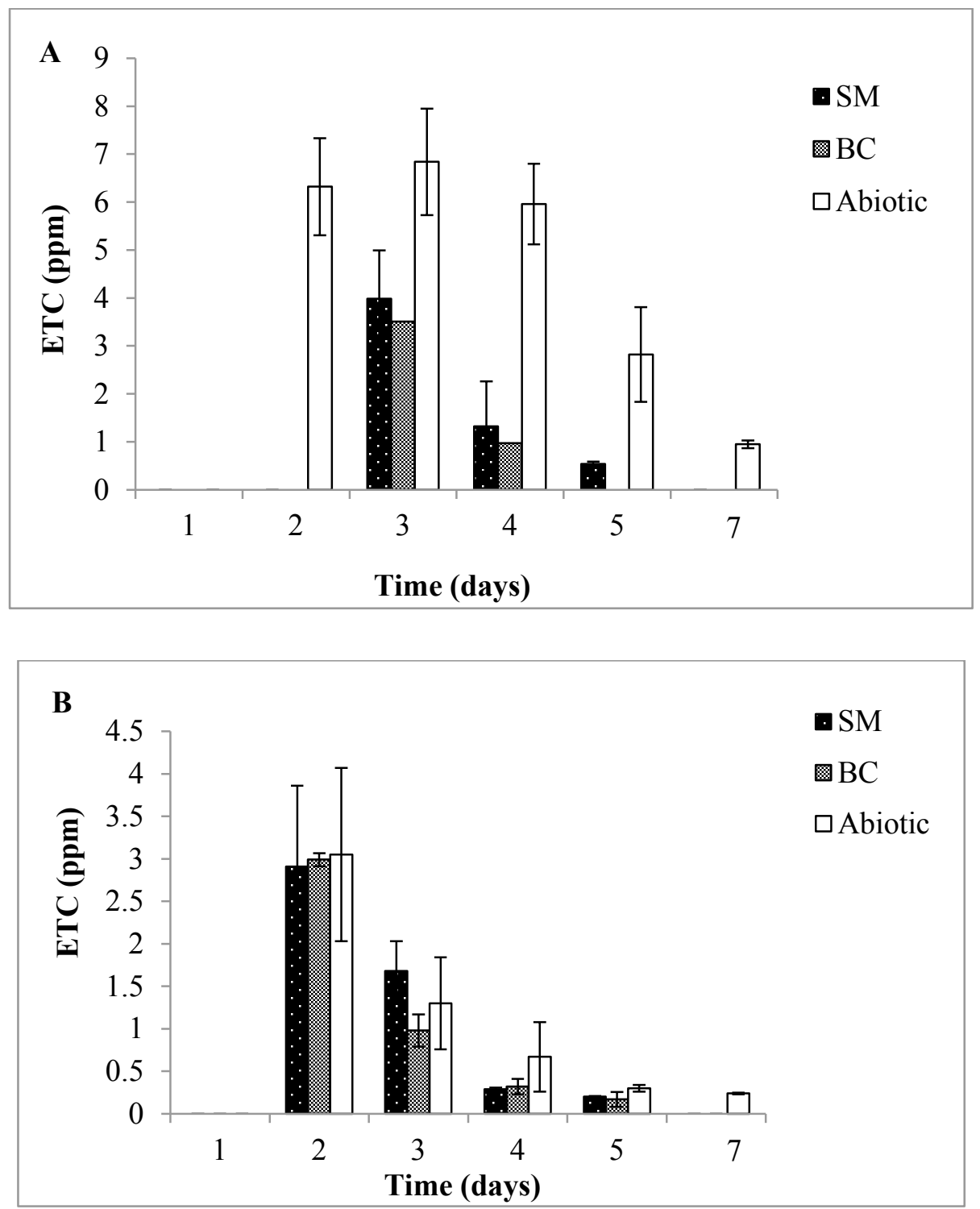

Figure C.2.1. TC transformation into ETC in the media in different flasks treated by $S$. marcescens (\#1) and B. cepacia (\#2) and abiotic flasks (control) without any treatment in TSB media supplemented with TC (starting conc. A. 75 ppm of TC; B. 10 ppm of TC). The experiments were carried out for 28 days at $30^{\circ} \mathrm{C}, \mathrm{pH} 7$ (ETC was not detected in samples beyond 7 days). Result presented in mean $(n=3) \pm 1$ SD. 


\section{Appendix C.3 - Data for intracellular and extracellular metabolomics study conducted in S.marcescens and B. cepacia.}

Data for an extracellular and metabolomics study conducted in B. cepacia (BC) and in S.marcescens $(\mathrm{SM})$ in presence of TC $(75 \pm 5 \mathrm{ppm})$ are presented below (Figures C.3.1 and C.3.2 respectively). Bacterial metabolomics was performed in an attempt to identify the TC degradation pathway used by TC-tolerant vetiver root-associated bacteria or any other significant pathway that is impacted during the TC degradation process. These results are supplementary to the materials provided in Chapter 3.

The compounds that matched the known pathways in KEGG and Metaboanalyst database were reported in Ch.3. There were multiple other compounds that were detected (but not statistically significant based on the metabolomics analysis) during both intra and extracellular metabolomics in both bacteria (B. cepacia and S. marcescens) during TC metabolism and those compounds are listed below (with fold change compared to the control, with their concentration level and if/not expressed in experimental flasks vs. control flask with no TC) 
Table C.3.1. B. cepacia (BC) metabolites recorded in abiotic and BC treated flasks in presence of TC. Results presented as mean ( $\mathrm{n}=3$ ) $\pm 1 \mathrm{SD}$.

\begin{tabular}{|c|c|c|c|c|c|}
\hline \multicolumn{3}{|l|}{ Intracellular Analysis } & \multicolumn{2}{|l|}{ ExtracellularAnalysis } & \multirow[b]{2}{*}{$\begin{array}{l}\text { Std. } \\
\text { Dev }\end{array}$} \\
\hline $\begin{array}{c}\text { Metabolites detected only in } \\
\text { abiotic flasks }\end{array}$ & Conc. mg/L & $\begin{array}{l}\text { Std. } \\
\text { Dev }\end{array}$ & $\begin{array}{c}\text { Metabolites detected only in } \\
\text { abiotic flasks }\end{array}$ & Conc. $\mathrm{mg} / \mathrm{L}$ & \\
\hline 3-Ethoxy-4-methoxyphenol & 0.33 & 0.02 & $\begin{array}{c}\text { 1,2-Benzenedicarboxylic acid, } \\
\text { diisooctyl ester }\end{array}$ & 0.16 & 0.01 \\
\hline & & & Octadecanoic acid, methyl ester & 0.13 & 0.04 \\
\hline $\begin{array}{c}\text { Hexadecane, } \\
2,6,10,14, \text { tetramethyl- }\end{array}$ & 0.17 & 0.04 & $\begin{array}{c}\text { Phenol, 2,4-bis(1,1- } \\
\text { dimethylethyl)- }\end{array}$ & 0.58 & 0.03 \\
\hline Octacosane & 0.07 & 0.01 & Phenol,3,5-dimethoxy- & 0.40 & 0.01 \\
\hline Propanedioic acid, phenyl- & 0.65 & 0.01 & & & \\
\hline $\begin{array}{c}\text { Metabolites detected only in BC } \\
\text {-treated flasks }\end{array}$ & $\begin{array}{l}\text { Conc. in } \\
\mathrm{mg} / \mathrm{L}\end{array}$ & & $\begin{array}{l}\text { Metabolites detected only in } \\
\text { BC- treated flasks }\end{array}$ & $\begin{array}{l}\text { Conc. in } \\
\mathrm{mg} / \mathrm{L}\end{array}$ & $\begin{array}{l}\text { Std. } \\
\text { Dev }\end{array}$ \\
\hline $\begin{array}{l}\text { 1,4-Benzenediol, 2,4-bis(1,1- } \\
\text { dimethylethyl)- }\end{array}$ & 0.08 & 0.05 & 1,1':3',1"-Terphenyl,5'-phenyl- & 0.77 & 0.05 \\
\hline 1-Phenylanthrenecarboxylic acid & 0.14 & 0.07 & Benzene, (isocyanomethyl)- & 0.07 & 0.02 \\
\hline $\begin{array}{l}\text { 2,5-Piperazinedione, 3-methyl-6- } \\
\text { (1-methylethyl)- }\end{array}$ & 0.1 & 0.01 & $\begin{array}{c}\text { Benzene, } 1,13 \text {-bis }(1,1- \\
\text { dimethylethyl)- }\end{array}$ & 0.03 & 0.0 \\
\hline 2-Coumaranone & 0.03 & 0.01 & Benzeneacetic acid & 0.65 & 0.04 \\
\hline 2-Ethoxy-4-methoxy phenol & 0.23 & 0.0 & Ocatdecanoic acid, methyl ester & 0.08 & 0.01 \\
\hline 2-Ethylprop-1-ene(1-3)sultine & 0.03 & 0.01 & & & \\
\hline $\begin{array}{c}4 \text { (3H)-Pyriminidone, 3-ethyl-2,6- } \\
\text { dimethyl- }\end{array}$ & 0.13 & 0.02 & & & \\
\hline $\begin{array}{l}\text { 5,10-Diethoxy-2,3,7,8-tetrahydro- } \\
\text { 1H,6H-dipyrrolo(1,2-a; 1",2"- } \\
\text { d)pyrazine }\end{array}$ & 0.65 & 0.01 & & & \\
\hline
\end{tabular}




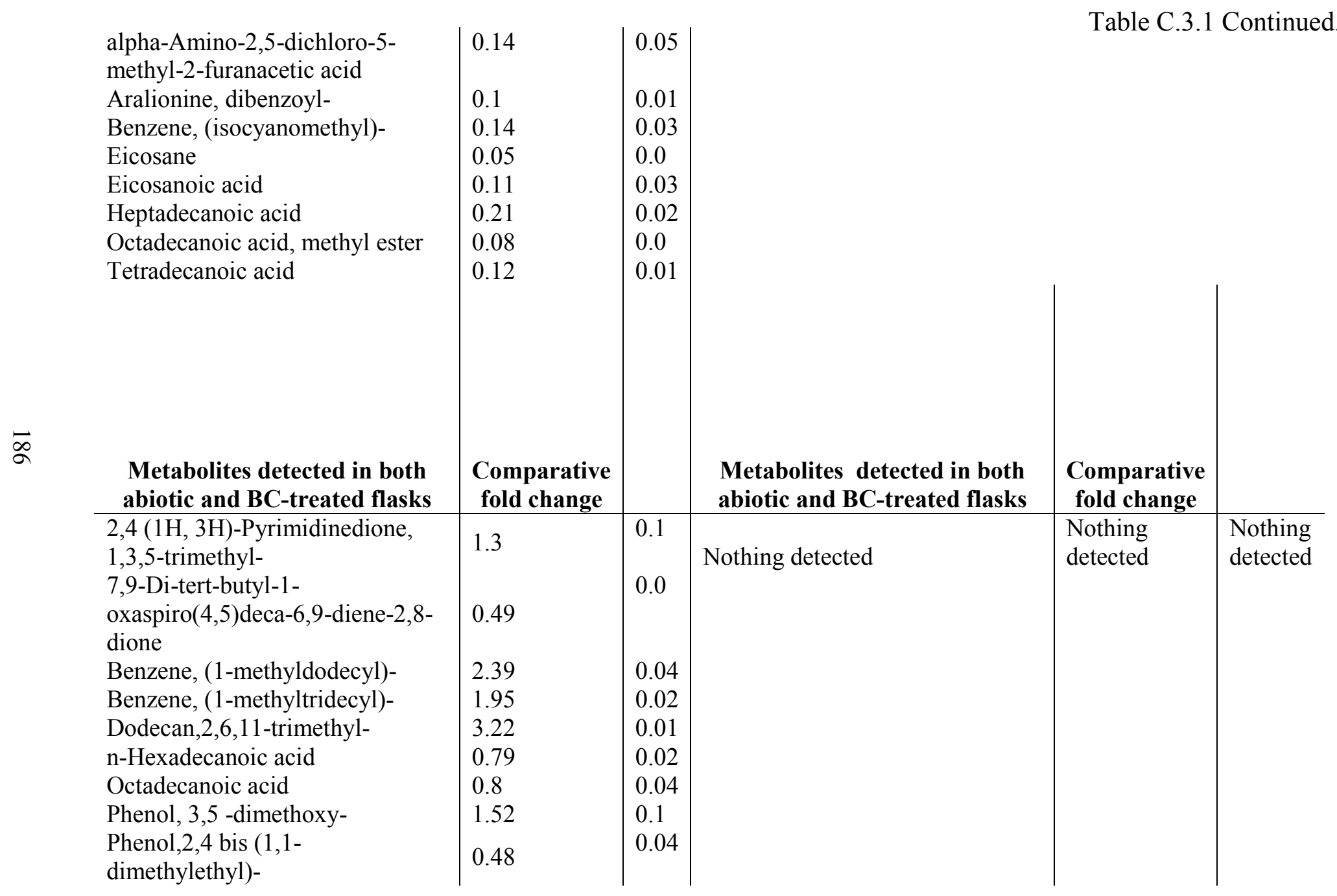


Table C.3.2. S. marcescens (SM) metabolites recorded in abiotic and SM-treated flasks in presence of TC. Results presented as mean $(\mathrm{n}=3) \pm 1$ SD.

Intracellular Analysis

\begin{tabular}{|c|c|c|c|c|c|}
\hline \multicolumn{2}{|l|}{ Intracellular Analysis } & \multicolumn{4}{|c|}{ ExtracellularAnalysis } \\
\hline Metabolites detected only in abiotic flasks & Conc. $\mathrm{mg} / \mathrm{L}$ & Std. Dev. & $\begin{array}{l}\text { Metabolites detected } \\
\text { only in abiotic flasks }\end{array}$ & $\begin{array}{l}\text { Conc. in } \\
\mathrm{mg} / \mathrm{L}\end{array}$ & $\begin{array}{l}\text { Std. } \\
\text { Dev }\end{array}$ \\
\hline $\begin{array}{l}\text { 2,4 }(1 \mathrm{H}, 3 \mathrm{H}) \text {-Pyrimidinedione, } 1,3,5- \\
\text { trimethyl }\end{array}$ & 1.12 & 0.06 & $\begin{array}{l}\text { Phenol, 2,4-bis(1,1- } \\
\text { dimethylethyl)- }\end{array}$ & 1.73 & 0.05 \\
\hline 3,6-Dibutyl-1,2-dihydro-1,2,4,5-tetrazine & 0.71 & 0.01 & $\begin{array}{l}\text { Octadecanoic acid, } \\
\text { methyl ester }\end{array}$ & 0.79 & 0.04 \\
\hline 3-Ethoxy-4-methoxyphenol & 0.33 & 0.04 & & & \\
\hline Benzene, (icocyanomethyl)- & 0.09 & 0.001 & & & \\
\hline Cyclopentadecannone, 2-hydroxy- & 0.22 & 0.02 & & & \\
\hline Cyclotetrasiloxane, octamethyl- & 0.07 & 0.001 & & & \\
\hline Propanedioic acid, phenyl- & 0.98 & 0.05 & & & \\
\hline $\begin{array}{l}\text { Metabolites detected only in SM- treated } \\
\text { flasks }\end{array}$ & $\begin{array}{l}\text { Conc. in } \\
\mathrm{mg} / \mathrm{L}\end{array}$ & & $\begin{array}{l}\text { Metabolites detected } \\
\text { only in SM -treated } \\
\text { flasks }\end{array}$ & $\begin{array}{l}\text { Conc. in } \\
\mathrm{mg} / \mathrm{L}\end{array}$ & \\
\hline $\begin{array}{l}\text { Phenol, 2, 2'-,methylenebis(6-1(1,1- } \\
\text { dimethylethyl)-4-ethyl- }\end{array}$ & 0.02 & & Benzeneacetic acid & 0.95 & 0.07 \\
\hline $\begin{array}{l}\text { 1,2-Benzenedicarboxylic acid, butyl 8- } \\
\text { methylnonyl ester }\end{array}$ & 0.01 & 0.001 & $\begin{array}{l}1,1^{\prime}: 3 ', 1^{\prime \prime}-\text { Terphenyl,5'- } \\
\text { phenyl- }\end{array}$ & 0.63 & 0.04 \\
\hline Benzene, (1-methyldodecyl)- & 0.01 & 0.003 & Benzeneacetic acid & 1.01 & 0.05 \\
\hline Benzene, (1-methyltridecyl)- & 0.01 & 0.001 & & & \\
\hline Benzeneacetaldehyde & 0.22 & 0.04 & & & \\
\hline
\end{tabular}


Table C.3.2 Continued.

\begin{tabular}{|c|c|c|c|c|c|}
\hline $\begin{array}{l}\text { Meatbolites detected in both abiotic and } \\
\text { SM treated flasks }\end{array}$ & \multicolumn{2}{|c|}{$\begin{array}{l}\text { Comparative } \\
\text { fold change }\end{array}$} & $\begin{array}{l}\text { Compound detected in } \\
\text { both abiotic and SM } \\
\text { treated flasks }\end{array}$ & \multicolumn{2}{|c|}{$\begin{array}{l}\text { Comparative } \\
\text { fold change }\end{array}$} \\
\hline $\begin{array}{l}\text { 7,9-Di-tert-butyl-1-1oxaspirol(4,5_deca-6,9- } \\
\text { diene-2,8-dione }\end{array}$ & 0.03 & 0.001 & $\begin{array}{l}\text { 7,9-Di-tert-butyl-1- } \\
\text { oxaspiro(4,5)deca-6,9- } \\
\text { diene-2,8-dione }\end{array}$ & 1.28 & 0.01 \\
\hline Cyclooctasiloxane, hexadecamethyl- & 0.02 & 0.00 & Phenol, 3,5 -dimethoxy- & 0.96 & 0.02 \\
\hline Hexadecane, 2,6,10,14,tetramethyl- & 0.02 & 0.00 & $\begin{array}{l}\text { Benzene, }(1- \\
\text { methyltridecyl)- }\end{array}$ & 1.47 & 0.06 \\
\hline n-Hexadecanoic acid & 0.04 & 0.002 & & & \\
\hline Octacosane & 0.04 & 0.001 & & & \\
\hline Octadecanoic acid & 0.42 & 0.04 & & & \\
\hline
\end{tabular}


C.3.1 Heat maps generated for $B$. cepacia and $S$. marcescens during intracellular and extracellular metbolomics analysis

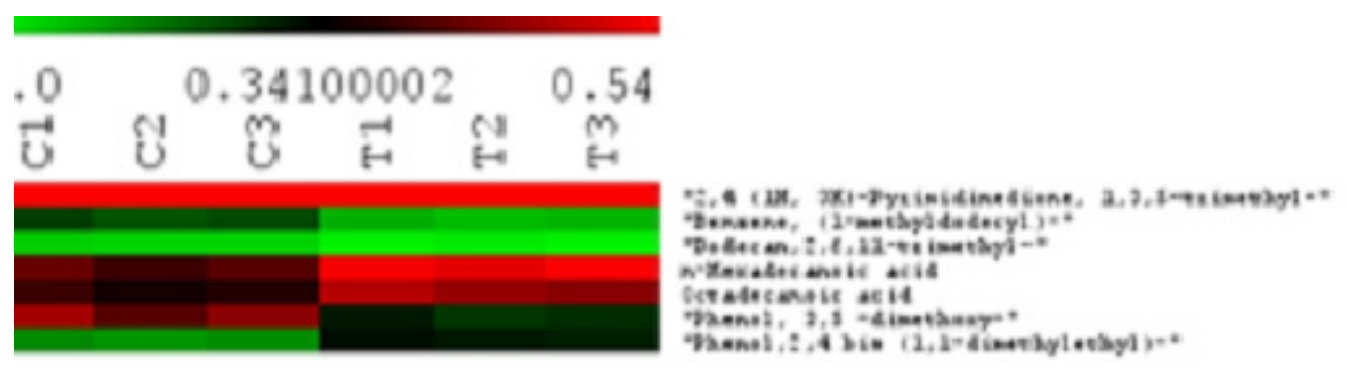

Figure C.3.1.1. B. cepacia extracellular metabolomics analysis
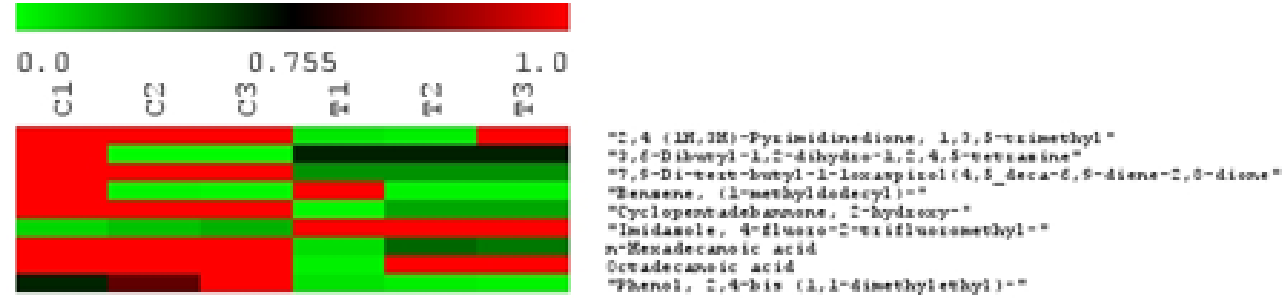

Figure C.3.1.2. B. cepacia intracellular metabolomics analysis

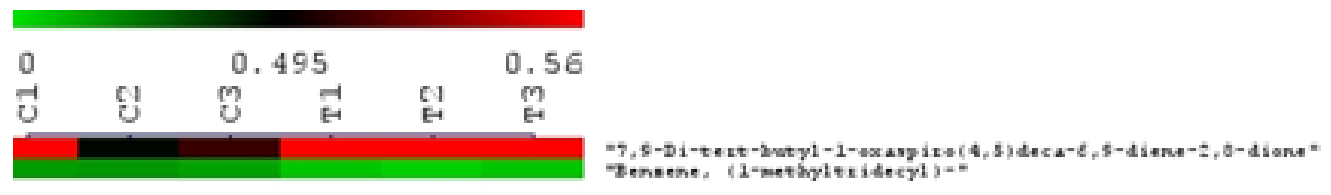

Figure C.3.1.3. S. marcescens extracellular metabolomics analysis

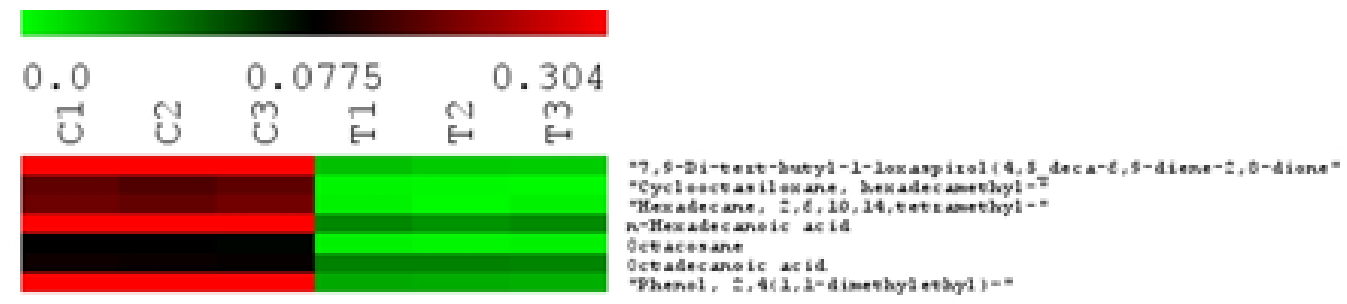

Figure C.3.1.4. S. marcescens intracellular metabolomics analysis 


\section{Appendix C.4 - Recipes of different media used in various experiments}

Composition of single carbon source (SCS), single nitrogen source (SNS) media, enriched media (ERM) and commercial tryptic soy broth media (TSB) used in different studies in chapter 3. Media composition modified from Dantas et al., (2008).

Table C.4.1.Composition of different media used ( to grow bacteria)

Table C.4.1. Media composition of single carbon source (Total volume 1L)

Magnesium Sulfate $\left(\mathrm{MgSO}_{4} \mathrm{SO}_{4} \cdot 7 \mathrm{H}_{2} \mathrm{O}\right): 0.2 \mathrm{~g} / \mathrm{L}$

Calcium Chloride $\left(\mathrm{CaCl}_{2}\right)$ : $\quad 0.02 \mathrm{~g} / \mathrm{L}$

Monopotassium phosphate $\left(\mathrm{KH}_{2} \mathrm{PO}_{4}\right): \quad 1 \mathrm{~g} / \mathrm{L}$

Dipotassium phosphate $\left(\mathrm{K}_{2} \mathrm{HPO}_{4}\right)$ : $\quad 1 \mathrm{~g} / \mathrm{L}$

Ammonium Nitrate $\left(\mathrm{NH}_{4} \mathrm{NO}_{3}\right)$ : $\quad 1 \mathrm{~g} / \mathrm{L}$

Ferric Chloride $\left(\mathrm{FeCl}_{3}\right)$ : $\quad 0.05 \mathrm{~g} / \mathrm{L}$

Add $1 \mathrm{~g}$ of tetracycline/ $1 \mathrm{~L}$ of media after autoclaving and mix thoroughly using autoclaved stir bar. Adjust the $\mathrm{pH}$ to be 7.0.

\section{Table C.4.2. Media for single nitrogen source (Total volume 1L)}

Magnesium Sulfate $\left(\mathrm{MgSO}_{4} \mathrm{SO}_{4} \cdot 7 \mathrm{H}_{2} \mathrm{O}\right): 0.2 \mathrm{~g} / \mathrm{L}$

Calcium Chloride $\left(\mathrm{CaCl}_{2}\right)$ : $\quad 0.02 \mathrm{~g} / \mathrm{L}$

Monopotassium phosphate $\left(\mathrm{KH}_{2} \mathrm{PO}_{4}\right): \quad 1 \mathrm{~g} / \mathrm{L}$

Dipotassium phosphate $\left(\mathrm{K}_{2} \mathrm{HPO}_{4}\right)$ : $\quad 1 \mathrm{~g} / \mathrm{L}$

Glucose: $\quad 1 \mathrm{~g} / \mathrm{L}$

Ferric Chloride $\left(\mathrm{FeCl}_{3}\right)$ : $\quad 0.05 \mathrm{~g} / \mathrm{L}$

Add $1 \mathrm{~g}$ of tetracycline/ $1 \mathrm{~L}$ of media after autoclaving and mix thoroughly using autoclaved stir bar. Adjust the $\mathrm{pH}$ to be 7.0. 


\section{C.4.3. Media composition of enriched media (ERM) broth (made in lab; buffer adjusted in the lab to attain desired pH) (Total volume 1L)}

Tryptone: $17 \mathrm{~g}$

Beef extract: $1 \mathrm{~g}$

Soymeal: $5 \mathrm{~g}$

$\mathrm{NaCl}: 5.0 \mathrm{~g}$

For neutral $\mathrm{pH}$

Adjust the $\mathrm{pH}$ to be 7.0 by adding monopotassium phosphate $\left(\mathrm{KH}_{2} \mathrm{PO}_{4}\right) 1 \mathrm{~g} / \mathrm{L}$ and dipotassium phosphate $\left(\mathrm{K}_{2} \mathrm{HPO}_{4}\right) 1 \mathrm{~g} / \mathrm{L}$. Add $1 \mathrm{~g}$ of tetracycline/ $1 \mathrm{~L}$ of media after autoclaving and mix thoroughly using autoclaved stir bar. Check the media before using and adjust the $\mathrm{pH}$ if necessary.

For basic $\mathrm{pH}$

Adjust the $\mathrm{pH}$ to be 8.5 by adding monopotassium phosphate $\left(\mathrm{KH}_{2} \mathrm{PO}_{4}\right) 3 \mathrm{~g} / \mathrm{L}$ and dipotassium phosphate $\left(\mathrm{K}_{2} \mathrm{HPO}_{4}\right) 3 \mathrm{~g} / \mathrm{L}$. Add $1 \mathrm{~g}$ of tetracycline/ $1 \mathrm{~L}$ of media after autoclaving and mix thoroughly using autoclaved stir bar. Check the media $\mathrm{pH}$ before using and adjust the $\mathrm{pH}$ if necessary.

For acidic $\mathrm{pH}$

Adjust the $\mathrm{pH}$ to be 6.0 by adding Monopotassium phosphate $\left(\mathrm{KH}_{2} \mathrm{PO}_{4}\right) 3 \mathrm{~g} / \mathrm{L}$ and Dipotassium phosphate $\left(\mathrm{K}_{2} \mathrm{HPO}_{4}\right) 3 \mathrm{~g} / \mathrm{L}$. Add $1 \mathrm{~g}$ of tetracycline/ $1 \mathrm{~L}$ of media after 
autoclaving and mix thoroughly using autoclaved stir bar. Check the media $\mathrm{pH}$ before using and adjust the $\mathrm{pH}$ if necessary.

\section{C.4.3. Media composition of commercial typtic soy broth medium (TSB) (Total} volume 1L)

Bacto Typtone:

$17.0 \mathrm{~g}$

Bacto Soytone:

$3.0 \mathrm{~g}$

Glucose:

$2.5 \mathrm{~g}$

$\mathrm{NaCl}$ :

$5.0 \mathrm{~g}$

Dipotassium phosphate $\left(\mathrm{K}_{2} \mathrm{HPO}_{4}\right): \quad 2.5 \mathrm{~g}$ 
APPENDIX D. Optimization of tetracycline-detoxification conditions of bacterial strains recovered from vetiver (Chrysopogon zizanioides) root-zone ${ }^{\text {a }}$

The study was designed and conducted by Aparupa Sengupta with guidance from Susan Bagley and Rupali Datta. The manuscript was written by Aparupa Sengupta. The other authors commented, guided, and supported in the preparation of the manuscript. All authors read and approved the final manuscript.

${ }^{\text {a }}$ The following document is to be submitted for publication in the Journal of Industrial Microbiology and Biotechnology. 


\title{
Appendix D. Optimization of tetracycline-detoxification conditions of bacterial strains recovered from vetiver (Chrysopogon zizanioides) root-zone
}

\begin{abstract}
Antibiotic contamination in water sources has led to adverse effects on microbial population, and human health. Vetiver (Chrysopogon zizanioides) root-associated bacteria have been recovered and cultured in our lab during a greenhouse hydroponic remediation study. Two highly TC-tolerant bacteria (minimum inhibitory concentration $>1000 \mathrm{ppm})$, Burkholderia cepacia and Serratia marcescens, that were cultured from the vetiver root-zone and could use TC as sole carbon and nitrogen source were selected for this study. The objective of this study was to optimize the best growth conditions for these bacteria $(\mathrm{pH}$, temperature, and oxygen requirement) in presence of TC. Growth studies were conducted using enriched and single carbon source media with various $\mathrm{pH}$, temperature and oxygen conditions in presence of TC. TC was also evaluated for both bacteria as a single carbon and/or nitrogen source supplemented at higher concentration $(1 \mathrm{~g} / \mathrm{L})$ in the media. Although glucose remained the first choice of carbon source (if present) in both of these bacteria, they could also utilize and grow on a very high concentration of TC $(1 \mathrm{~g} / \mathrm{L})$ as a result of natural adaptation to TC over 8-10 weeks of time. The optimized growth conditions determined in presence of TC were $28-30^{\circ} \mathrm{C}$ under aerobic conditions at $\mathrm{pH} 7-7.5$, which matches with the generic growth conditions of these bacteria.
\end{abstract}

Keywords: Antibiotic contamination, tetracycline, vetiver, Tetracycline (TC) - tolerant bacteria, hydroponic remediation, TC detoxification 


\section{Introduction}

Antibiotics are detected in wastewater effluents due to the inability of these wastewater facilities to remove these compounds $(1,35)$. These antibiotics are eventually released from wastewater facilities into surface water and end up in irrigation and drinking water sources $(19,17,7,11)$. Although antibiotics have been present in the environment for a long time, assessment of their impacts on the environment and human health were not carried out until recently $(12,14,15)$.

The conventional methods used to degrade antibiotics are sorption, hydrolysis, photolysis, oxidation and reduction $(14,15)$. However, there are some limitations associated with these methods. They are expensive, unsustainable and are all conditionbased (e.g., temperature and composition of matrix) $(14,15)$. There have been studies that indicate the role of bacteria in antibiotic resistance and transformation/degradation $(23,3)$. The study by Dantas et al., (2008), demonstrated the role of penicillin-resistant soil bacteria in complete degradation of penicillin and the study by Ooishi and Tosa (2010) demonstrated the role of TC-resistant bacteria in degradation of TC from water sources. These studies indicate that the bacteria that are resistant to antibiotics can also use them as sole carbon source and use some transformation mechanism to detoxify these organic compounds $(3,25)$. A recent study (34) disputes the finding of an earlier study (3) stating that antibiotic-resistant bacteria that grow on antibiotics as sole carbon source do not have the ability to degrade those antibiotics.

In our lab, a phytoremediation study with vetiver grass (Chrysopogon zizanioides) in invitro hydroponic tanks showed transformation/detoxification of TC in the water during 
the 30-day remediation trial (28). The results indicate a possible and significant role of the plant in the transformation process. However, it still needs to be established if the detoxification/transformation of TC was carried out by the plant itself or with assistance from the root-associated bacteria. In another study in our lab, it was observed that the five root-associated bacteria recovered and cultured in the lab were able to utilize TC as sole carbon and nitrogen source (Ch. 3 and Appendix B of thesis) (29). Amongst these bacteria, S. marcescens and B.cepacia showed highest tolerance to TC (>1000 ppm) and could use TC as sole carbon and nitrogen source and hence, were selected for this growth optimization study to determine the best growth conditions of these bacteria in presence of TC (Appendix C).

Materials and Methods

Growth and optimization studies

Bacterial colonies that were selected for the optimization study were streaked for isolation on R2A plates supplemented with $100 \mathrm{ppm} \mathrm{TC}$, to ensure the purity of the culture. For all growth and optimization studies (involving tryptic soy broth and enriched media), bacterial inoculum was grown in tryptic soy broth (TSB) supplemented with 100 ppm TC overnight at $30^{\circ} \mathrm{C}$ in a gyratory shaker at $160 \mathrm{rpm}$. The inoculum flasks were centrifuged individually and the pellet was washed with buffer twice to eliminate any nutrient transfer in the flasks set-up for growth and optimization studies. For all growth and optimization studies (involving single carbon source media), bacterial inoculum was grown in tryptic soy broth (TSB) supplemented with $100 \mathrm{ppm}$ TC overnight at $30^{\circ} \mathrm{C}$ in a 
gyratory shaker at $160 \mathrm{rpm}$ and centrifuged (as discussed above) then transferred repeatedly (at least 3 times) in SCS media (to minimize nutrient carry over) before inoculating the SCS media flasks for experiments. Three flasks were inoculated for each bacterium with each type of media; single carbon source (SCS) with TC as the only carbon source ( $\mathrm{pH} 7$ ), media with no TC, and single nitrogen source with TC as the only nitrogen source and enriched media (ERM) plus with TC as carbon source (media compositions modified from Dantas et al., 2008; presented in Appendix C.4 of thesis). SCS medium was modified from Dantas et al., 2008 to eliminate any additional carbon source (such as EDTA) from the medium. For bacterial growth and optimization studies, $\mathrm{pH}(6,7$, and 8.5 to determine acidic/neutral/ alkaliphilic preference), and temperature $\left(4^{\circ}, 24^{\circ}, 30^{\circ}, 35^{\circ}, 37^{\circ}, 42^{\circ} \mathrm{C}\right)$ were evaluated. For oxygen requirements, microaerophilic and aerobic conditions was set-up using $250 \mathrm{~mL}$ erlenmeyer flask with $50 \mathrm{~mL}$ of media for aerobic condition and $125 \mathrm{~mL}$ of flask with $50 \mathrm{~mL}$ of media for microaerophilic condition. Each condition was set-up in replicates of three and the flasks were sampled up to stationary phase. All absorbance values were measured at $660 \mathrm{~nm}$ using spectrophotometer and converted to dry weight $(\mathrm{mg} / \mathrm{L})$ using the formula $\left[\left((364.74 *\right.\right.$ Absorbance $)+\left(6.7 *\right.$ Absorbance $\left.\left.\left.{ }^{2}\right)\right)\right]($ Handbook of Microbiology) .

Results and Discussion

Vetiver root-associated tetracycline-tolerant bacteria were successfully recovered and cultured in our lab, from hydroponic tanks during a 30-day remediation trial (29). Previously, a study (23) has reported detection of TC-resistant bacteria in wastewater effluent and their TC degrading capability. S. marcescens and B. cepacia were identified 
using 16S rRNA sequencing and MALDI-TOF (appendix B.4) and then evaluated for their optimal growth conditions.

Figure D.2 (A and B) shows results of S. marcescens and B. cepacia grown in different pHs $(6,7.3$, and 8.5$)$ to identify optimal $\mathrm{pH}$ in presence of TC in enriched media (TSB). Both bacteria showed imilar growth under different $\mathrm{pH}$ conditions, with highest growth rate constant $\left(\mathrm{k} \mathrm{hr}^{-1}\right)$ at $\mathrm{pH} 8.5$ followed by $\mathrm{pH} 7$ and $\mathrm{pH} 6$ (growth rates reported in table B.7). Overall, B. cepacia showed higher growth rate compared to S. marcescens (appendix B.7). The results above showed that the optimal $\mathrm{pH}$ condition for both bacteria were 8.5. However, based on the literature, it was evident that both of these bacteria ( $S$. marcescens and B. cepacia) were not alkaliphilic $(10,8)$. The same growth study was then conducted in SCS media with TC as sole carbon source $(1 \mathrm{~g} / \mathrm{L})$. The results (Figures D.1 A and B) showed highest growth rate constant $\left(\mathrm{k} \mathrm{hr}^{-1}\right)$ for both bacteria at about $\mathrm{pH} 7$ followed by pH 6 and with little to no growth at pH 8.5 (Figure D.9).

The difference in the composition of the media could be the prime reason for the differences in the results between enriched and SCS media. The enriched media was premade and the $\mathrm{pH}$ was adjusted later using acid and base solutions. It may be possible that different components (present already in the media) were buffering the $\mathrm{pH}$ during the course of the growth study $(\mathrm{pH}$ was monitored during some sampling points randomly but not at the end), hence there was no effect observed based on $\mathrm{pH}$ differences. However, the SCS media was not pre-made and the difference in $\mathrm{pH}$ was made by adding different concentration of $\mathrm{K}_{2} \mathrm{HPO}_{4}$, when making the media. To confirm the results of SCS $(\mathrm{pH})$ experiment, a growth study was conducted using enriched media (composition 
in table C.4), however the media was made in the lab (causing the $\mathrm{pH}$ differences by adding different concentration of $\mathrm{KH}_{2} \mathrm{PO}_{4}$ ) and the results (Figure D.3 A and B) were similar to what was found in the SCS media above. Hence, it was concluded based on the above study that these bacteria have the ability to grow on wide range of $\mathrm{pH}$. However, the optimal $\mathrm{pH}$ for growth in presence of TC was about 7.

Figure D.4 shows results of $S$. marcescens and B. cepacia grown in TSB media, evaluated for optimal temperatures $\left(4^{\circ}, 24^{\circ}, 30^{\circ}, 37^{\circ} \mathrm{C}, 42^{\circ} \mathrm{C}\right)$ conditions in presence of TC. Both bacteria showed the similar trend of highest growth rate constant $\left(\mathrm{k} \mathrm{hr}^{-1}\right)$ at $30^{\circ} \mathrm{C}$ followed by $24^{\circ} \mathrm{C}$ and $37^{\circ} \mathrm{C}$. There was little to no growth observed at $4{ }^{\circ} \mathrm{C}$ and 42 ${ }^{\circ} \mathrm{C}$ (Figure D.6). The growth rates constant are listed in appendix B.7. Overall, B. cepacia showed higher growth rate compared to S. marcescens (Appendix B.7). It was concluded that these TC-tolerant bacteria were psychrotrophic as their optimum range of growth varied between $28-30^{\circ} \mathrm{C}$.

Growth study results from two different oxygen requirement conditions (aerobic and microaerophilic) conducted in SCS medium supplemented with TC (75 ppm). The amount of oxygen present in the flask was controlled by using different sized flask (250 $\mathrm{mL}$ erlenmeyer flask with $50 \mathrm{~mL}$ media for aerobic condition and $100 \mathrm{~mL}$ erlenmeyer flask with $50 \mathrm{~mL}$ media for microaerophilic condition). Results show that aerobic condition produced higher growth rate (appendix B.7) in both bacteria (Figure D.5).

The growth study with control medium showed that there was no growth observed in both $S$. marcescens and B. cepacia in absence of TC in single carbon source media (data 
not presented here because there was no change in absorbance from 0 hour to 24 hours) establishing the role of these bacteria in utilizing TC. The growth rate data suggest (Table B.7) that although glucose is the preferred carbon source (Figures D.11 and D.12) for both the bacteria, they still can tolerate a very high concentration of TC and grow in presence of TC (as high as $1 \mathrm{~g} / \mathrm{L}$ ) as the sole carbon and nitrogen source. The results also demonstrate that by increasing TC concentration in the SCS media (from $50 \mathrm{mg} / \mathrm{L}$ to 1 $\mathrm{g} / \mathrm{L}$ ), the rate of growth increases for both bacteria (Figures B.2, B.3, and Table B.7). The effect of natural adaptation by transferring the bacteria every week on R2A media plates supplemented with TC $(100 \mathrm{mg} / \mathrm{L})$ for about $8-10$ weeks also had a positive impact on growth of these bacteria in the presence of TC.

These results, not only complement the other studies which demonstrate antibioticresistant bacteria can use antibiotic as sole carbon source $(3,25)$, but also establishes the optimal growth conditions for these bacteria under TC influence that could be potentially used in the future for TC remediation studies. A recent study (Walsh et al. 2013) challenges the concept of Dantas et al., 2008 by stating that the antibiotic resistant bacteria that can grow using antibiotic as sole carbon source may not be involved in their degradation process. These results are in agreement with the results of Dantas et al., 2008, which show penicillin- resistant bacteria can use penicillin as sole carbon source. However as Walsh et al., 2013 showed that these penicillin-resistant bacteria can still grow when penicillin is not present in the single carbon source media, this study shows this TC-tolerant does not like to grow in the SCS media when TC is not present as either carbon or nitrogen source. 
Along with aerobic conditions, $\mathrm{pH} 7$ and $28-30^{\circ} \mathrm{C}$ were determined to be the optimal condition for these tetracycline-tolerant bacteria. This information could be very useful in the future, in constructing a biological system using vetiver and rhizospheric TCtolerant bacteria to remediate TC from aquatic systems. The TC-tolerant bacteria $B$. cepacia, recovered from hydroponic tanks and evaluated for TC remediation, has been previously reported and established as an important bioremediation tool in earlier studies (22). Both B. cepacia and S. marcescens are commonly recovered antibiotic-resistant bacteria, which may also use/ degrade antibiotics (3). These bacteria can potentially be used as TC remediation tool in controlled systems.

\section{Conclusions}

This is the first time that vetiver root-associated bacteria were evaluated for their ability of growth in presence of TC and evaluated for their optimal growth conditions in the presence of TC. These results exhibit that the optimal growth conditions for both TCtolerant bacteria (S. marcescens and B. cepacia) were $28-30^{\circ} \mathrm{C}, \mathrm{pH} 7$ under aerobic condition (but could function under a much broader range of conditions) confirming the fact that these bacteria were acclimated to the similar conditions that they were recovered from (during the hydroponic remediation trial). If these bacteria are found to have some role in TC detoxification process they could be used effectively used as remediation tools (with optimized growth conditions) along with vetiver plant in TC remediation from water sources. 


\section{References}

1. Batt AL, Bruce IB, Aga D (2006) Evaluating the vulnerability of surface waters to antibiotic contamination from varying wastewater treatment plant discharges. Environ. Pollut. 142:295-302.

2. Boxall ABA (2004) The environmental side effects of medication. EMBO J. 5:1110-1116.

3. Dantas G, Sommer MOA, Oluwasegun RD, Church GM (2008) Bacteria subsisting on antibiotics. Science. 320:100-103.

4. Datta R, Das P, Smith S, Punamiya P, Ramanathan DM, Reddy R, Sarkar D (2013) Phytoremdiation potential of tetracycline by vetiver grass (Chrysopogan zizanioides(L.) for tetracycline. Int. J. Phytorem. 15:343-351.

5. Ding C, He J (2010) Effect of antibiotics in the environment on microbial populations. Appl. Microbiol Biot. 87:925-941.

6. Du L, Liu W (2012) Occurrence, fate, and ecotoxicity of antibiotics in agroecosystems. A review. Agron. Sustain Dev. 32:309-327.

7. Fatta-Kassinos D, Meric S, Nikolaou A (2011) Pharmaceutical residues in environmental waters and wastewater: current state of knowledge and future research. Anal. Bioanal. Chem. 399:251-275. 
8. Govan, J.R.W., Hughes, Jayne E., Vandamme, P. 1996. Burkholderia cepacia:medical, taxonomic and ecological issues. J. Med. Microbiol. 45: 395407.

9. Halling Sorenson B, Sengelov G, Tjornelund J (2002) Toxicity of tetracycline degradation products to environmentally relevant bacteria, including selected tetracycline resistant bacteria. Arch. Environ. Contam. Toxicol. 42: 263-271.

10. Hejazi A, Falkiner FR (1997) Serratia marcescens. J. Med. Microbiol. 46:903912.

11. Hu X, Zhou Q, Luo Y (2010) Occurrence and source analysis of typical veterinary antibiotics in manure, soil, vegetables and ground water from organic vegetable bases, northern China. Environ. Pollut. 158:2992-2998.

12. Kim K-R, Owens G, Kwon S-I, So K-H, Lee D-B, Ok YS (2011) Occurrence and environmental fate of veterinary antibiotics in the terrestrial environment. Water Air Soil Poll. 214:163-174.

13. Kong WD, Zhu YG, Liang YC, Zhang J, Smith FA, Yang M (2007) Uptake of oxytetracycline and its phytotoxicity to alfalfa (Medicago sativa L.). Environ. Pollut. 147:187-193.

14. Kummerer K (2009 a) Antibiotics in the aquatic environment-A review-Part I. Chemosphere. 75:417-434. 
15. Kummerer K (2009 b). The presence of pharmaceuticals in the environment due to human use-present knowledge and future challenges. J. Environ. Manage. 90:2354-2366.

16. Kummerer K (2004) Resistance in the environment. J Antimicrob Chemother. 54:311-320.Liu L, Liu Y-H, Liu C-X, Wang Z, Dong J, Zhu G-F, Huang X (2013) Potential effect and accumulation of veterinary antibiotics in Phragmites australis under hydroponic conditions. Ecol. Eng. 53:138-143.

17. Le-Minh N, Khan SJ, Drews JE, Stuetz RM (2010) Fate of antibiotics during municipal water recycling treatment processes. Water Res. 44:4295-4323.

18. Martinez JL (2009) Environmental pollution by antibiotics and by antibiotic resistance determinants. Environ. Pollut. 157:2893-2902.

19. Michael I, Rizzo L, McArdell CS, Manaiad CM, Merline C, Schwartz T, Dagot C, Fatta-Kassinos D (2013) Urban wastewater treatment plants as hotspots for the release of antibiotics in the environment: A review. Water Res. 47:957-995.

20. Nicolaou SA, Gaida SM, Papoutsakis ET (2010) A comparative view of metabolite and substrate stress and tolerance in microbial bioprocessing: From biofuels and chemicals, to biocatalysis and bioremediation. Metab. Eng. 12:307331.

21. Nnenna F-P, Lekiah P, Obemeata O (2011) Degradation of antibiotics by bacteria and fungi from the aquatic environment. J. Toxicol. Env. Health. 3:275-285. 
22. O’Sullivan LA, Mahenthirallingam E (2005) Biotechnological potential within the genus Burkholderia. Lett. Appl. Microbiol. 4:8-11.

23. Ooishi T, Tosa K (2010) Occurrence of tetracycline-resistant and tetracyclinedegrading bacteria in wastewater treatment plant effluent and environmental water systems. J. Water Envrion. Technol. 8:321-327.

24. Park H, Choung YK (2010) Evaluation of the biodegradation feasibility of antibiotics by three bacteria involving glutathione S-transferases. Can. J. Civil Eng. 37:814-819.

25. Perlman D, Sebek OK (1971) Microbial transformations of antibiotics. Adv. Appl. Microbiol. 14:637-348.

26. Rehman MSU, Rashid N, Ashfaq M, Saif A, Ahmad N, Han JI (2013) Global risk of pharmaceutical contamination from highly populated developing countries. Chemosphere. In press, http://dx.doi.org/10.1016/j.chemosphere.2013.02.036.

27. Sarmah, AK, Meyer MT, Boxall AB. (2006) A global perspective on the use, sales, exposure pathways, occurrence, fate and effects of veterinary antibiotics (Vas) in the environment. Chemosphere 65:725-759.

28. Sengupta A, Waring K, Sarkar D, Bagley S, and Datta R. (2013) Tetracycline degradation in aqueous systems using vetiver grass and identification of tetracycline Metabolites in the plant. Manuscript in progress.

29. Sengupta A, Datta R, and Bagley S. (2013) Tetracycline detoxification capability of bacterial strains isolated from vetiver root-zone. Manuscript in progress. 
30. Sharafi SM, Rasooli I, Beheshti-Maal K (2010) Isolation, characterization and optimization of indigenous acetic acid bacteria and evaluation of their preservation methods. Iran J. Microbiol. 2: 38-45.

31. Stefanowicz A (2006) The biolog plate technique as a tool in ecological studies of microbial communities. Polish J. Environ. Stud. 15:669-676.

32. Trapp S, Ücisik AS, Romano PD, Larsen M (2007) The role of plants and bacteria in phytoremediation - kinetic aspects, p.41-49. In H.J Heipieper (ed.), Bioremediation of Soils Contaminated with Aromatic Compounds. Springer.

33. Trivedi P, Spann T, Wang N (2011) Isolation and characterization of beneficial bacteria associated with citrus roots in Florida. Microbial Ecol. 62:324-336.

34. Walsh F, Amyes SGB, Duffy B (2013) Challenging the concept of bacteria subsisting on antibiotics. Int. J. Antimicrob. Ag. 41:558-563.

35. Watkinson AJ, Murby EJ, Kolpin DW, Costanzo SD (2009) The occurrence of antibiotics in an urban watershed: From wastewater to drinking water. Sci. Total Environ. 407: 2711-2723. 

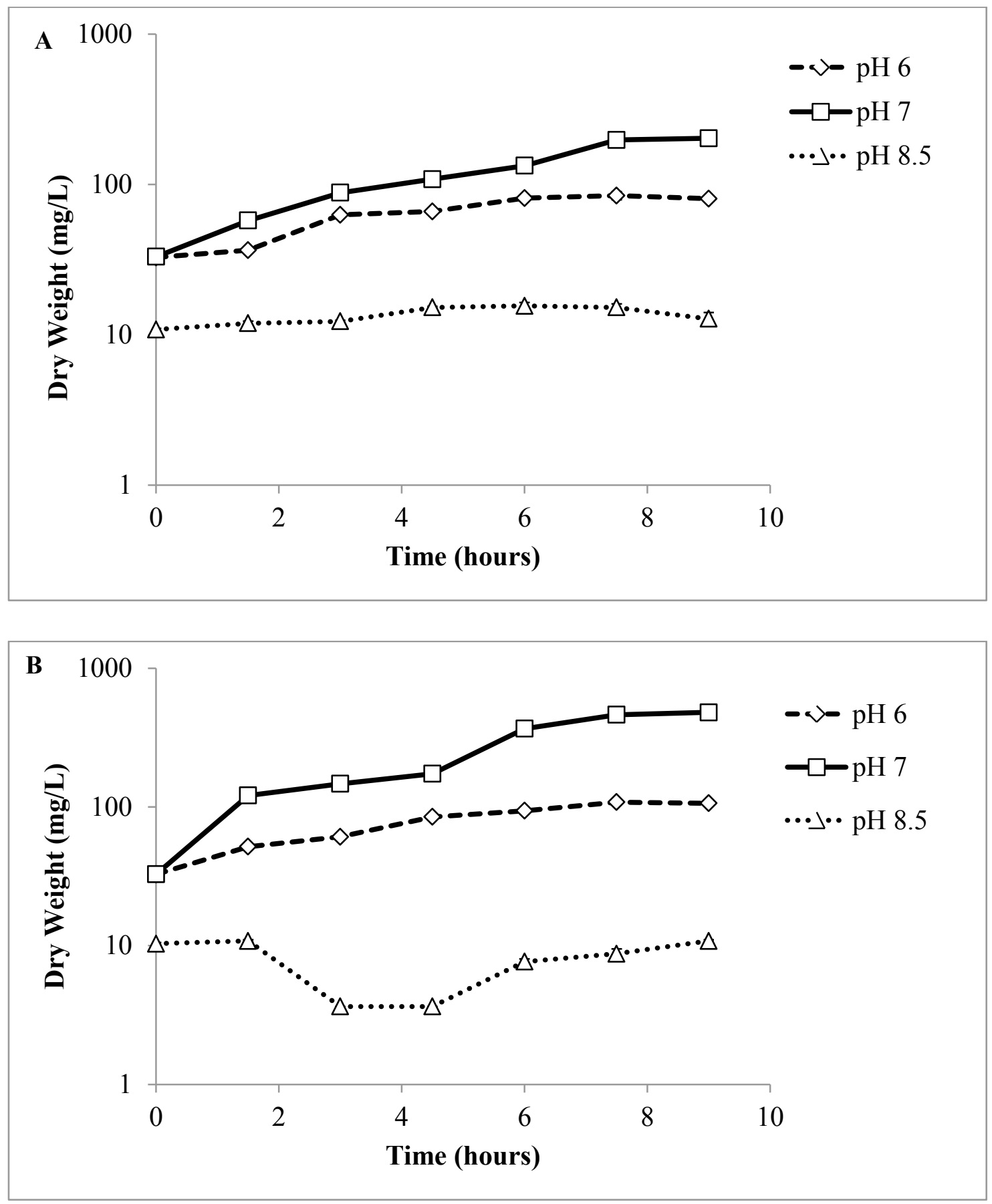

Figure D.1. Optimization results for A) S. marcescens and B) B. cepacia for selecting optimum $\mathrm{pH}$ condition SCS supplemented with TC $(75 \mathrm{ppm})$ for growth (at $30^{\circ} \mathrm{C}$, aerobic) Results presented as mean $(n=3) \pm 1$ SD 

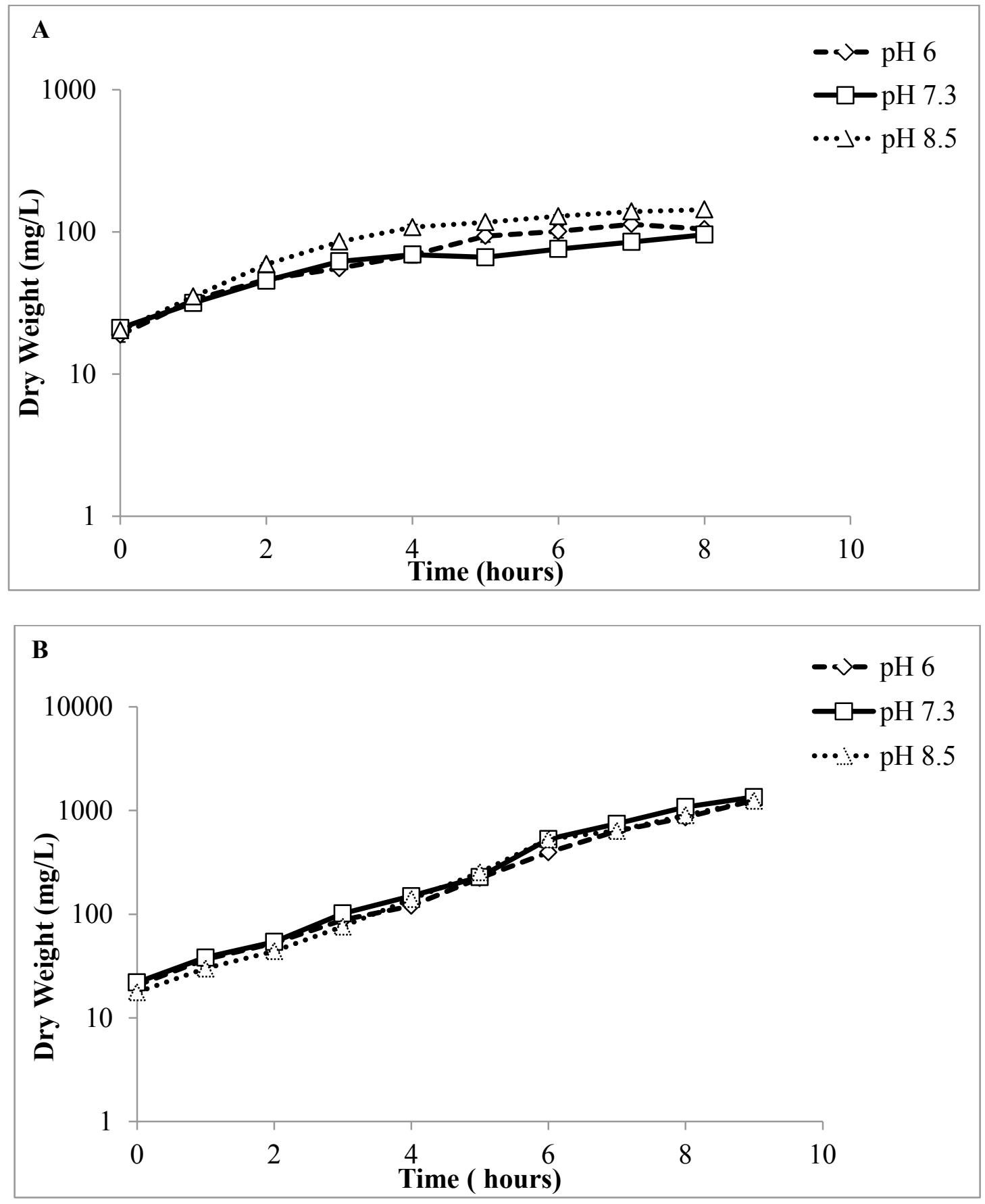

Figure D.2. Optimization results for A) S. marcescens and B) B. cepacia for selecting optimum $\mathrm{pH}$ condition in TSB medium supplemented with TC (75 ppm) for growth ( at $30^{\circ} \mathrm{C}$, aerobic). Results presented as mean $(n=3) \pm 1 \mathrm{SD}$ 

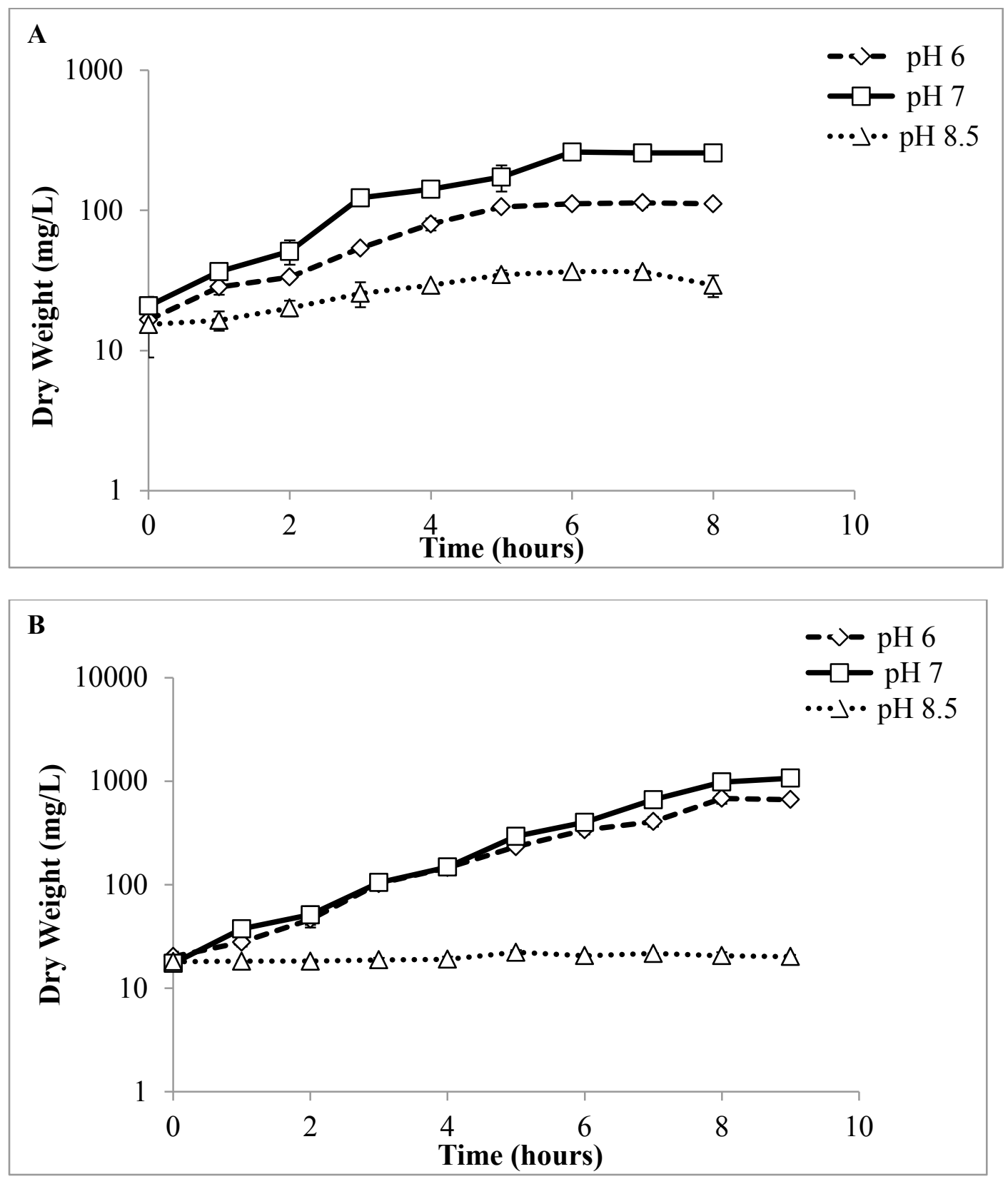

Figure D.3. Optimization results for A) S. marcescens and B) B. cepacia for selecting optimum pH condition in enriched medium (ERM) supplemented with TC ( 75 ppm at $30^{\circ} \mathrm{C}$, aerobic). Results presented as mean $(n=3) \pm 1$ SD 

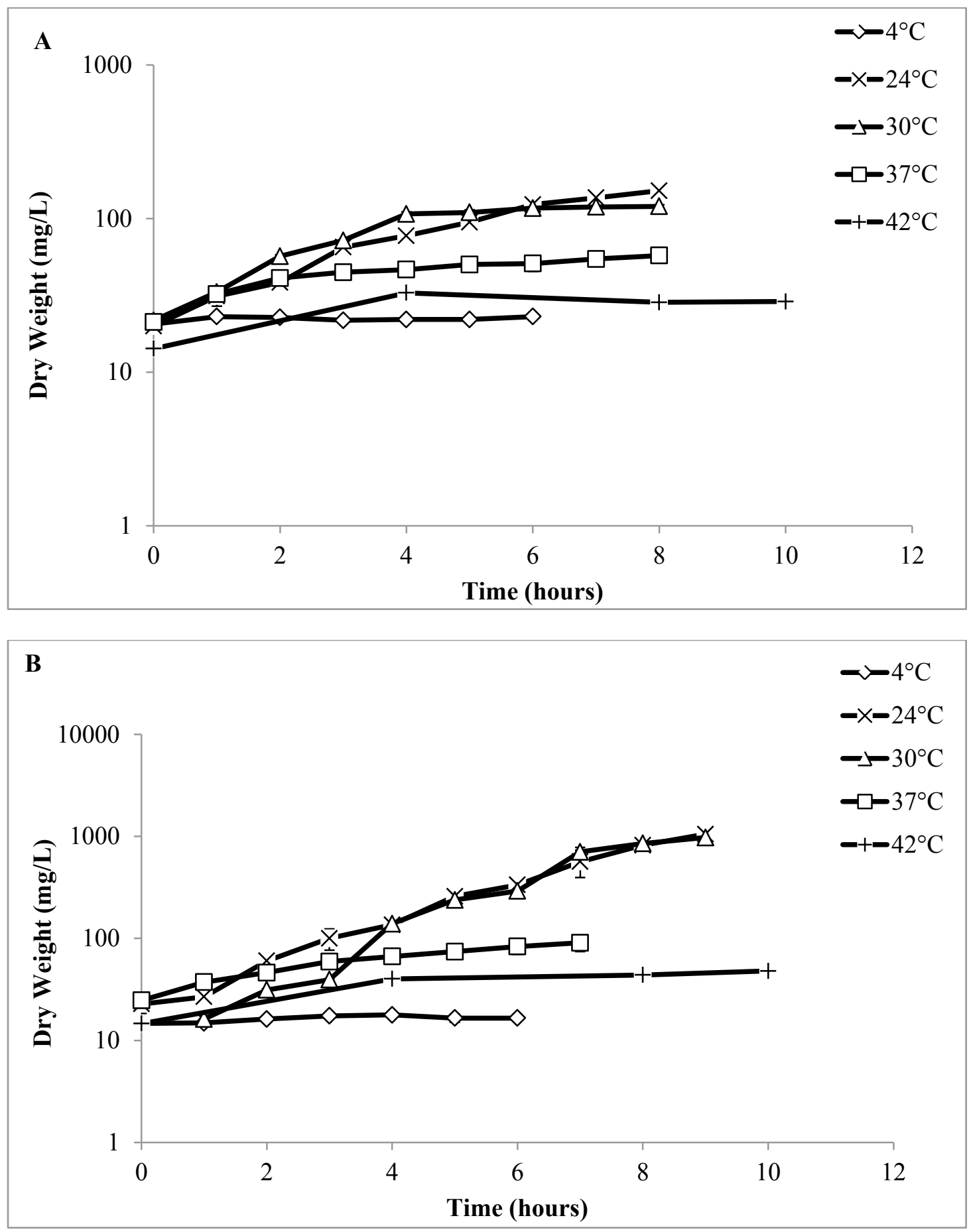

Figure D.4. Optimization results for A) S. marcescens and B) B. cepacia for selecting the optimum temperature in TSB medium supplemented with TC ( $75 \mathrm{ppm}$ at pH $7 \pm 0.5$, aerobic). Results presented as mean $(n=3) \pm 1$ SD 

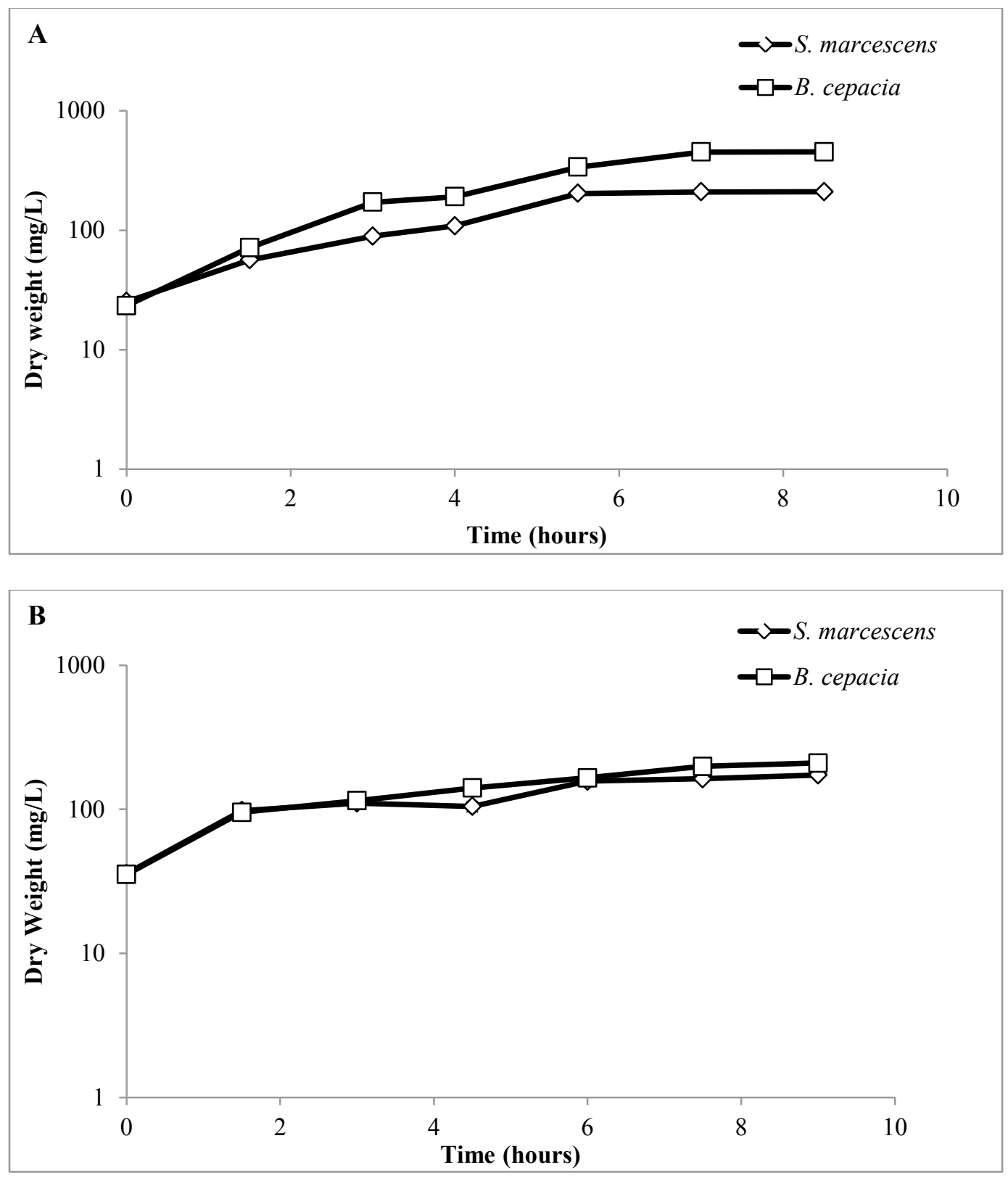

Figure D.5. Optimization results for oxygen requirements A) Aerobic, B) Microaerophilic conditions in S. marcescens and B. cepacia grown in SCS medium supplemented with $\mathrm{TC}\left(75 \mathrm{ppm}\right.$ at $\left.30^{\circ} \mathrm{C}, \mathrm{pH} 7\right)$. Results presented as mean $(\mathrm{n}=3) \pm 1 \mathrm{SD}$ 

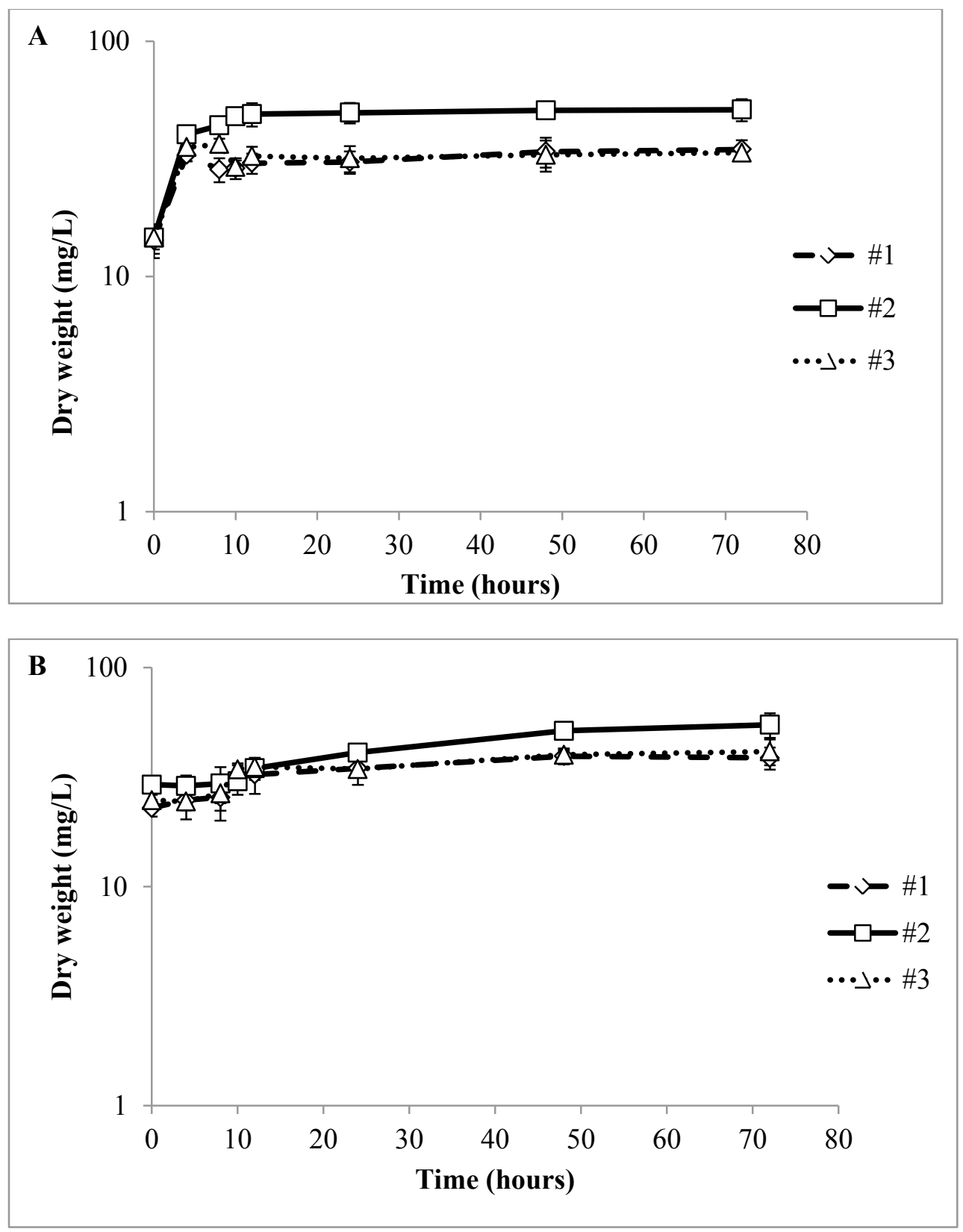

Figure D.6. Growth results for bacterium \#1 (S. marcescens), \#2 (B. cepacia), and \#3 (S. marcescens) at $42^{\circ} \mathrm{C}$ in A) TSB medium, B) SCS medium supplemented with TC (50 ppm, aerobic, $\mathrm{pH} 7)$. Results presented as mean $(\mathrm{n}=3) \pm 1$ SD 

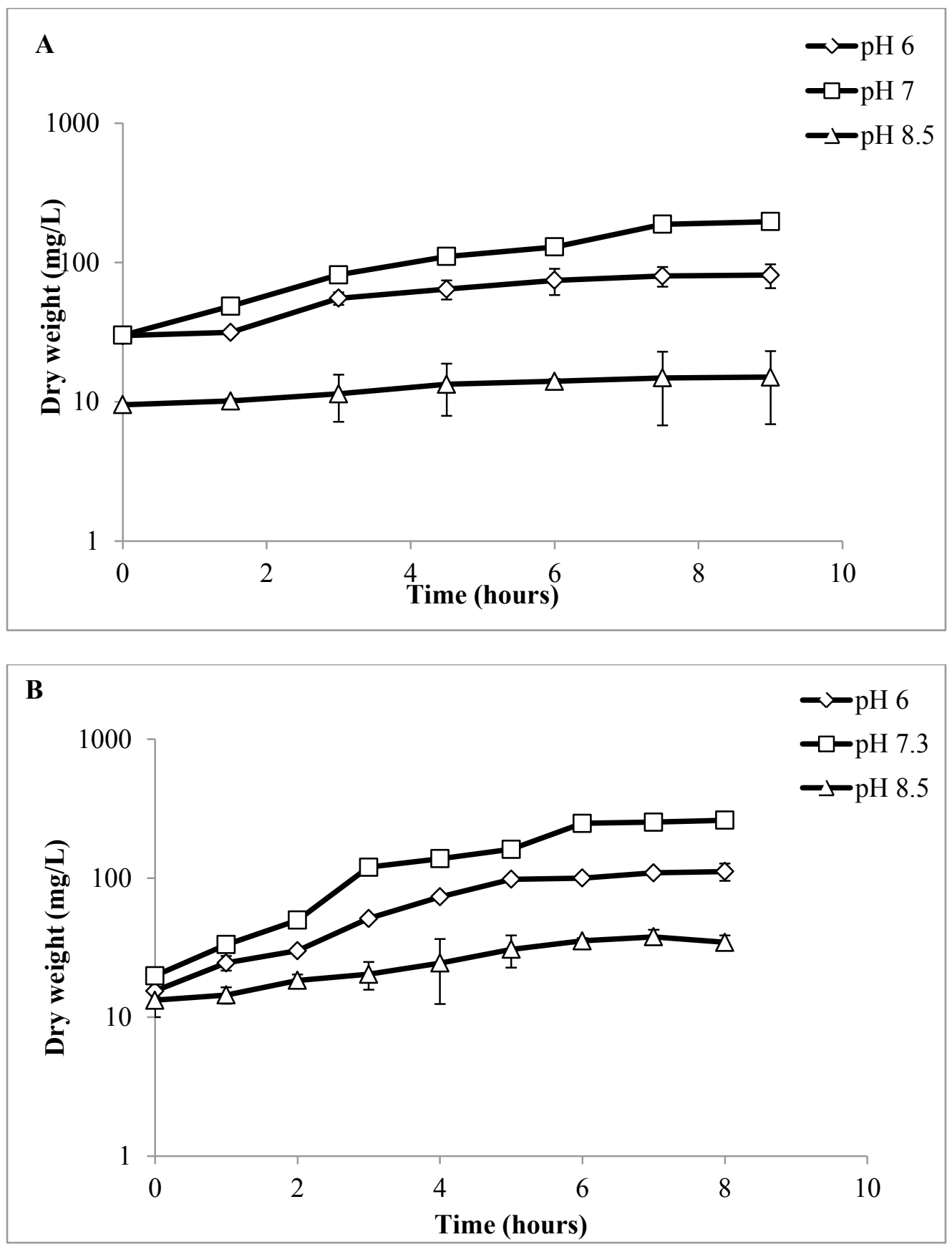

Figure D.7. Growth results for for isolate \#3 (S. marcescens) for $\mathrm{pH}$ optimization in A) SCS medium, B) TSB medium supplemented with $\mathrm{TC}$ ( $75 \mathrm{ppm}$ at $30^{\circ} \mathrm{C}$, aerobic). Results presented as mean $(n=3) \pm 1$ SD 


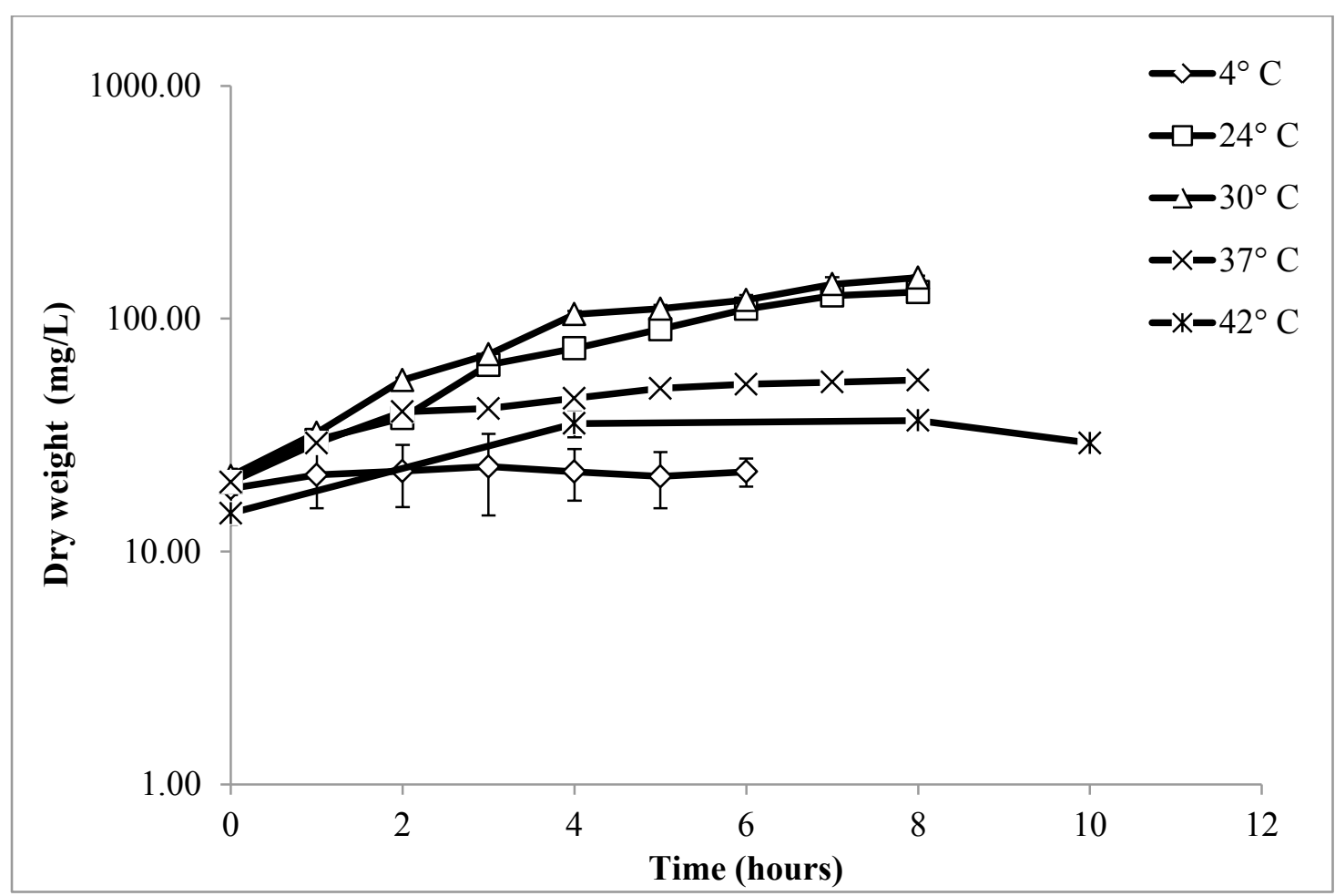

Figure D.8. Growth results for for isolate \#3 (S. marcescens) in TSB medium supplemented with TC ( 75 ppm, $\mathrm{pH} \mathrm{7,} \mathrm{aerobic)} \mathrm{for} \mathrm{temperature} \mathrm{optimization.} \mathrm{Results}$ presented as mean $(n=3) \pm 1$ SD 

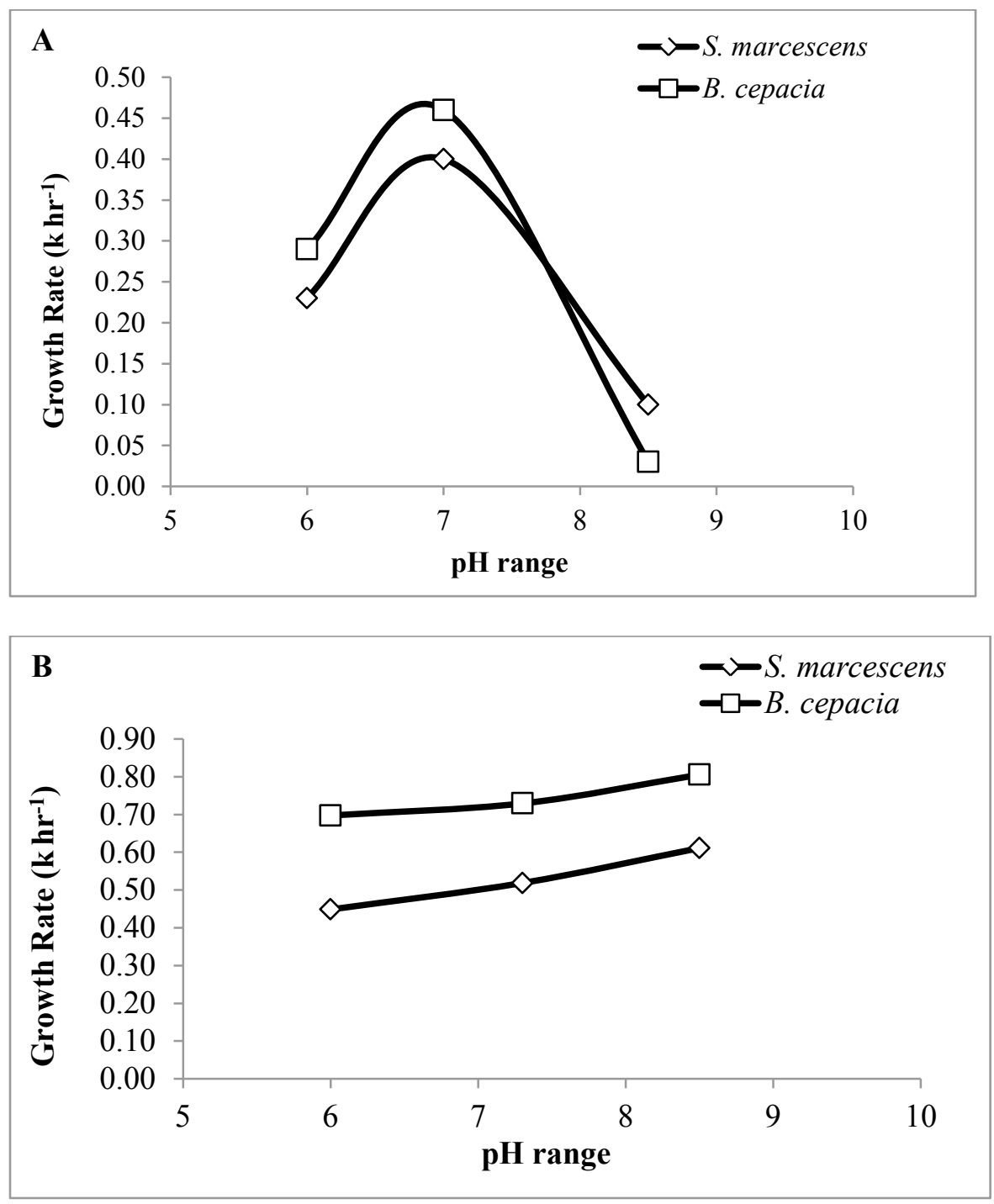

Figure D.9. Calculated growth rate constant $\left(\mathrm{k} \mathrm{hr}^{-1}\right)$ for $\mathrm{pH}$ optimization studies for $S$. marcescens and B. cepacia in A) SCS media, and B) TSB media supplemented with TC $(75 \mathrm{mg} / \mathrm{L})$. 

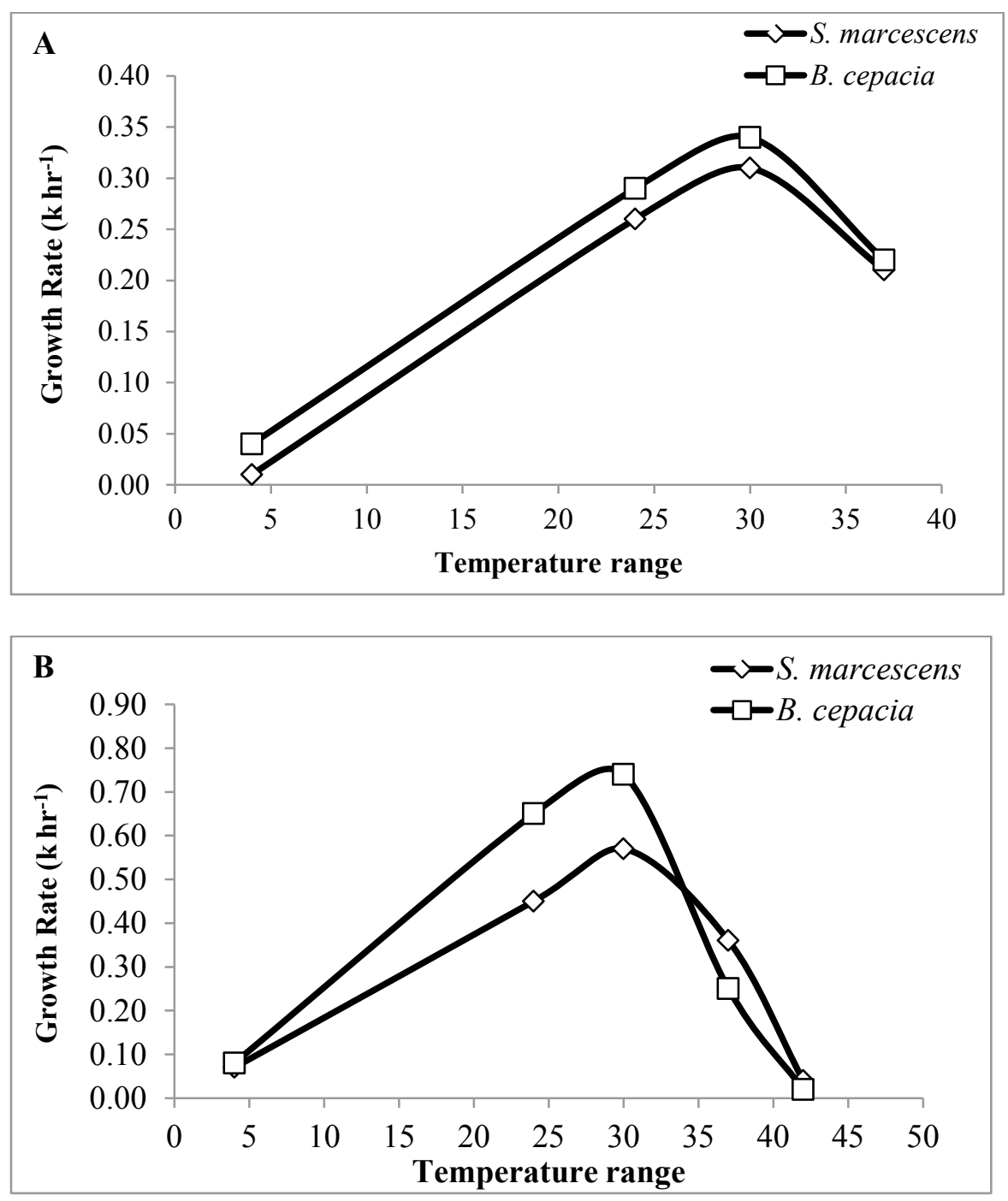

Figure D.10. Calculated growth rate constant $\left(\mathrm{k} \mathrm{hr}^{-1}\right)$ for temperature optimization studies for S. marcescens and B. cepacia in A) SCS media supplemented with TC (75 mg/L), and B) TSB media supplemented with TC (75 mg/L). 


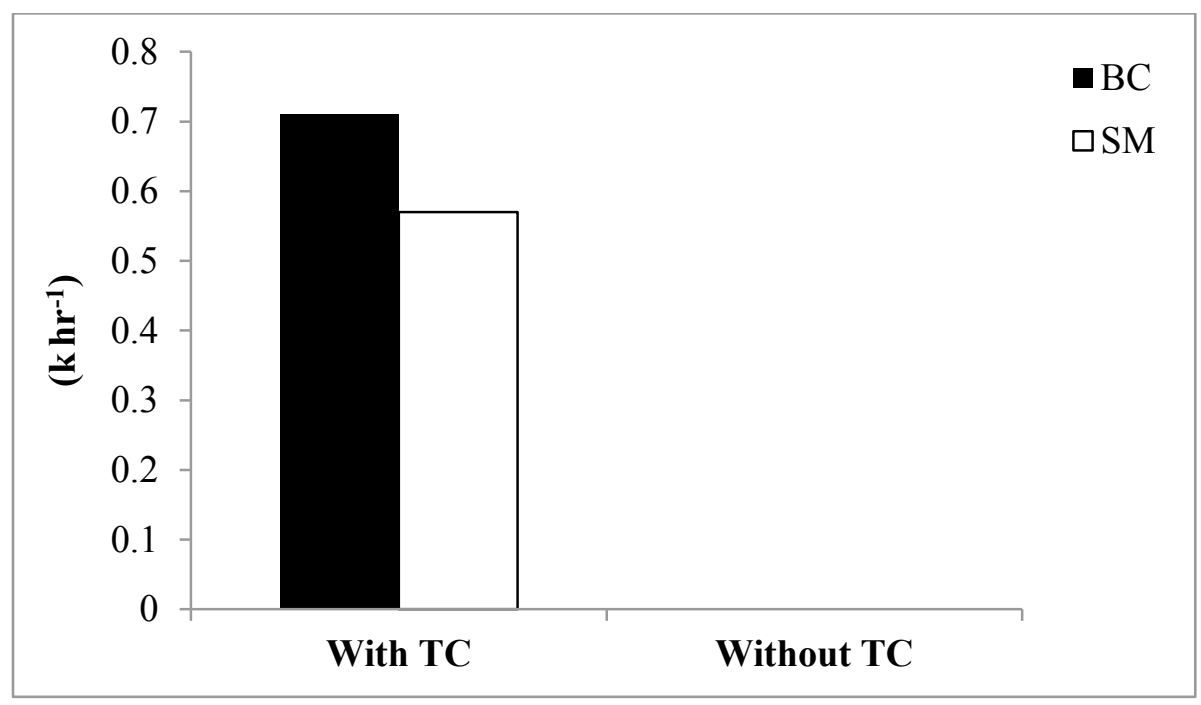

Figure D.11. Calculated growth rate constant $\left(\mathrm{k} \mathrm{hr}^{-1}\right)$ for $S$. marcescens $(\mathrm{SM})$ and $B$. cepacia $(\mathrm{BC})$ in SCS media supplemented with and without TC $(1 \mathrm{~g} / \mathrm{L})$ at their optimized conditions ( $\mathrm{pH} 7,30^{\circ} \mathrm{C}$, aerobic condition).

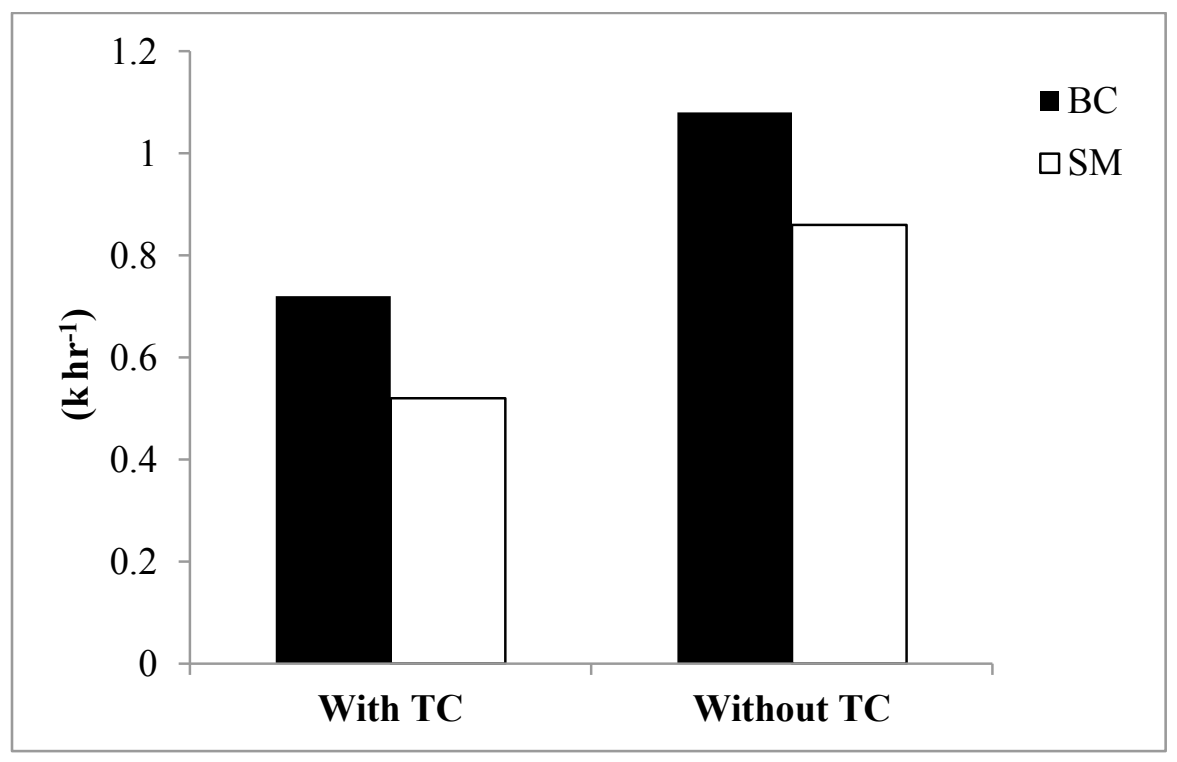

Figure D.12. Calculated growth rate constant $\left(\mathrm{k} \mathrm{hr}^{-1}\right)$ for $S$. marcescens $(\mathrm{SM})$ and $B$. cepacia $(\mathrm{BC})$ in enriched media (ERM) supplemented with and without TC $(75 \mathrm{mg} / \mathrm{L})$ at

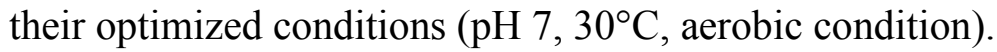


APPENDIX E. Additional information for Chapter 4. Role of bacterial and vetiver antioxidant enzymes in tetracycline detoxification ${ }^{\mathrm{a}}$

\section{Catalase Activity Assay:}

Following the method from Gujrathi and Linden 2005, 0.5g root samples were ground with a sterilized mortar and pestle using liquid nitrogen to ensure that the sample was kept cold, and then mixed with sample buffer (50 mM sodium phosphate buffer, $\mathrm{pH} 7$; containing $0.2 \mathrm{mM}$ EDTA and $10 \mathrm{~g} / \mathrm{L}$ polyvinylpyrrolidone). The mixture was filtered through Whatmann filter paper (no.1) and was centrifuged at $8000 \mathrm{x}$ rpm for $15 \mathrm{mins}$ at $4^{\circ} \mathrm{C}$. To measure the activity of the enzyme, the reaction mixture was prepared by mixing $40 \mu \mathrm{L}$ of $62.5 \mathrm{mM} \mathrm{H}_{2} \mathrm{O}_{2}, 1 \mathrm{~mL}$ of $25 \mathrm{mM}$ sodium phosphate buffer ( $\mathrm{pH} 7$ ) and 25 $\mu \mathrm{L}$ of enzyme extract. The absorbance was measured at $240 \mathrm{~nm}$ for $10 \mathrm{~min}$ in a spectrophotometer. The enzyme concentration was calculated and reported in $\mathrm{mM} / \mathrm{min}$ $\mathrm{X}$ g. protein.

The results for catalase activity (Table E.1) show no measurable catalase activity, as there was no change is absorbance observed in either sample, treated with TC (TR $75 \mathrm{ppm}$ TC) or untreated (UTR Control). The experiment was repeated three times and similar results were observed each time, confirming that there was no detectable catalase activity during TC treatment. Since no absorbance differences were detected in the samples, the activity of the enzyme could not be determined. The level of $\mathrm{H}_{2} \mathrm{O}_{2}$ was measured to assess if the catalase assay was working, but there was no change in absorbance observed in the standards. 


\section{Appendix E.1. Data for CAT activity recorded in vetiver root}

Catalase absorbance values were recorded from total protein extracted from vetiver root during days $0,1,2,3$, and 5 of experiment; treated with TC (TR $75 \mathrm{ppm}$ TC) and untreated control (UTR Control). Change of absorbance values (initial to final time in minutes) represents the activity of the enzyme in different samples. Change in absorbance values in table C.1 denotes no measurable change and hence catalase activity could not be calculated for TC treated and control root samples (collected on different days of experiment. These results are supplementary to the materials provided in Chapter 3.

Table E.1. CAT activity recorded in vetiver root. Absorbance values are averages of three runs recorded for $10 \mathrm{~min} /$ run at $240 \mathrm{~nm}$ using the spectrophotometer. Results presented as mean $(\mathrm{n}=3)$ and standard deviation $( \pm 0.01)$.

\begin{tabular}{c|cccccccccc} 
& \multicolumn{7}{c}{ Minutes } \\
Sample Type & $\mathbf{0}$ & $\mathbf{1}$ & $\mathbf{2}$ & $\mathbf{4}$ & $\mathbf{5}$ & $\mathbf{6}$ & $\mathbf{7}$ & $\mathbf{8}$ & $\mathbf{9}$ & $\mathbf{1 0}$ \\
\hline $\begin{array}{c}\text { TR 75 ppm TC - } \\
\text { Day 1 } \\
\begin{array}{c}\text { UTR Control- } \\
\text { Day 1 }\end{array}\end{array}$ & 2.82 & 2.81 & 2.80 & 2.80 & 2.81 & 2.82 & 2.81 & 2.80 & 2.82 & 2.82 \\
\hline $\begin{array}{c}\text { TR 75 ppm TC - } \\
\text { Day 2 }\end{array}$ & 2.01 & 3.00 & 3.01 & 3.00 & 3.02 & 3.00 & 3.02 & 3.00 & 3.00 & 3.08 \\
$\begin{array}{c}\text { UTR Control- } \\
\text { Day 2 }\end{array}$ & 3.80 & 2.79 & 2.86 & 2.80 & 2.78 & 2.80 & 2.87 & 2.89 & 2.81 & 2.89 \\
\hline $\begin{array}{c}\text { TR 75 ppm TC - } \\
\text { Day 3 }\end{array}$ & 2.98 & 2.01 & 2.91 & 2.98 & 3.00 & 3.02 & 3.01 & 3.02 & 3.02 \\
$\begin{array}{c}\text { UTR Control- } \\
\text { Day 3 }\end{array}$ & 2.86 & 2.68 & 2.85 & 2.80 & 2.81 & 2.80 & 2.86 & 2.86 & 2.85 & 2.85 \\
\hline $\begin{array}{c}\text { TR 75 ppm TC - } \\
\text { Day 5 }\end{array}$ & 2.86 & 2.95 & 2.90 & 2.98 & 2.99 & 3.01 & 2.89 & 2.86 & 2.86 & 2.85 \\
$\begin{array}{c}\text { UTR Control- } \\
\text { Day 5 }\end{array}$ & 2.90 & 2.84 & 2.87 & 2.86 & 3.01 & 2.99 & 3.01 & 3.01 & 3.00 & 2.90
\end{tabular}


Standard tests with increasing levels of $\mathrm{H}_{2} \mathrm{O}_{2}$ only recorded no change in absorbance confirming that the assay actually did not work. The activity could not be calculated as there was no change in absorbance observed.

\section{Appendix E.2.}

Equations for calculating antioxidant enzyme activities (Farkas et al., 2007)

\section{Equation for calculating GST activity}

$$
\frac{\left(\triangle \mathbf{A}_{340}\right) / \mathrm{min} * \mathrm{~V}(\mathrm{ml}) * \mathrm{dil}}{\varepsilon_{\mathrm{mM}} * V_{\mathrm{enz}}(\mathrm{ml})}=\mu \mathrm{mol} / \mathrm{ml} / \mathrm{min}
$$

Where,

$$
\begin{aligned}
& \left(\Delta \mathrm{A}_{340}\right) / \mathrm{min}=\underline{\mathrm{A}_{340}} \underline{\text { (final read })-\mathrm{A}_{340}} \underline{\text { (initial read })} \\
& \text { reaction time (min.) } \\
& \mathrm{V}(\mathrm{ml})=\text { reaction volume }(0.2 \mathrm{ml}) \\
& \varepsilon \mathrm{mM}(\text { for GST })=5.3 \mathrm{mM}^{-1} \mathrm{~cm}^{-1}
\end{aligned}
$$

$V_{\text {enz }}=$ the volume of the enzyme sample tested

\section{Equation for calculating GPX activity}

$$
\begin{aligned}
& \left(\triangle \mathrm{A}_{420}\right) / \mathrm{min} * \mathrm{~V}(\mathrm{ml}) * \mathrm{dil}=\mu \mathrm{mol} / \mathrm{ml} / \mathrm{min} \\
& \varepsilon_{\mathrm{mM}} * \mathrm{~V}_{\mathrm{enz}}(\mathrm{ml})
\end{aligned}
$$

Where,

$$
\begin{aligned}
& \left(\Delta \mathrm{A}_{420}\right) / \mathrm{min}=\underline{\mathrm{A}_{420}} \underline{(\text { final read })-\mathrm{A}_{420}} \underline{\text { (initial read })} \\
& \text { reaction time }(\text { min. }) \\
& \mathrm{V}(\mathrm{ml})=\text { reaction volume }(0.2 \mathrm{ml}) \\
& \varepsilon \mathrm{mM}(\text { for GST })=26.6 \mathrm{mM}^{-1} \mathrm{~cm}^{-1}
\end{aligned}
$$$$
\mathrm{V}_{\mathrm{enz}}=\text { the volume of the enzyme sample tested }
$$ 


\section{Data for GST activity recorded in B. cepacia in its late-log phase}

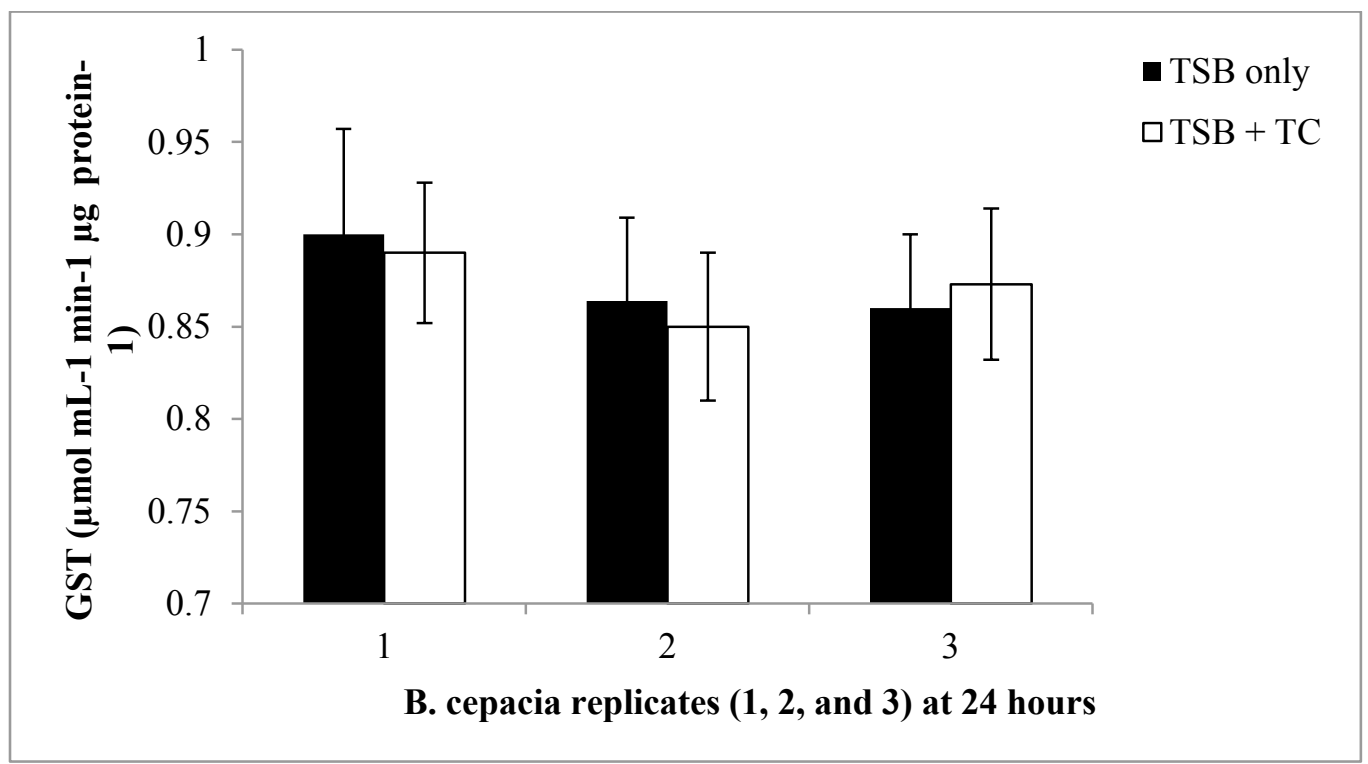

Figure E.2.1. Glutathione S-transferase activities recorded in B. cepacia during late log phase of growth $\left(24^{\text {th }}\right.$ hour from start of growth) in TSB medium supplemented with TC $(75 \mathrm{mg} / \mathrm{L})$ Results are normalized with data collected on $0 \mathrm{hr}$. and presented as mean $\mathrm{n}=3$ $\pm 1 \mathrm{SD}$. 
Appendix E.3.Table of $p$ values from statistical analysis (for GST enzyme activities)

Table E.3.1. $p$ value results from statistical analysis for bacterial samples for GST enzyme activity

\begin{tabular}{c|cc} 
& $\begin{array}{c}\text { Samples collected during log-phase } \\
\text { Bacteria }\end{array}$ & TSB (p values) \\
\hline Serratia marcescens & 0.12 & 0.005 \\
Burkholderia cepacia & 0.04 & 0.02
\end{tabular}

Table E.3.2 p value results from statistical analysis for vetiver root samples for GST enzyme activity

\begin{tabular}{c|c} 
Sampling days for vetiver root & p values \\
\hline Day 1 & 0.10 \\
Day 2 & 0.01 \\
Day 3 & 0.50 \\
Day 5 & 0.25 \\
Day 7 & 0.25
\end{tabular}


APPENDIX F. Preparation of hairy root culture for vetiver grass (Chrysopogon zizanoides L. Nash)

The experiments listed in Appendix F were conducted with the purpose of developing hairy root culture of vetiver grass (Chrysopogon zizanoides L. Nash).

\section{Objective:}

The objective of this experiment was to increase the root surface area of vetiver by producing hairy root culture with the aid of bacterium Agrobacterium rhizogenes ATCC 15834 with an overall goal of accelerated oxidative degradation of tetracycline (TC) and its isomers Epi-TC (ETC) and Anhydro-TC (ATC).

\section{Introduction:}

Vetiver is a subtropical grass commonly used for remediation of various contaminants (Troung et al., 2010). It has been previously reported that hairy root culture of other plants results in enhanced remediation of different contaminants. Hairy root culture is formed by an infection caused by a plant pathogen Agrobacterium rhizogenes that causes formation of dense roots in plants when co-cultivated with the bacteria (Gujarathi et al., 2005 b). A. rhizogenes causes genetic transformation in the plant by transferring its $\mathrm{Ri}$ (root inducing) plasmid to the T-DNA of the plant, causing the formation of hairy roots (Kumar et al., 2006).

Multiple studies (Gujrathi et al., $2005 \mathrm{a}, \mathrm{b}$ ) have shown that under stress conditions, hairy roots of Helianathus annuus produce antioxidants. Some of the antioxidant enzymes are ascorbate peroxidase(APX), catalase (CAT), guaiacol peroxidase (GPX). Gujrathi et al., (2005 a), indicated that reactive oxygen species (ROS) associated with roots are involved 223 
in oxidative degradation of TCs. This was shown by the increase in the native antioxidant enzyme activity of the plant species.

Based on literature reviews, attempts of developing hairy root culture of vetiver grass with Agrobacterium rhizogenes ATCC 15834 were made for the very first time as per our knowledge. As vetiver grass has already demonstrated its role in TC uptake in a hydroponic experiment (Ch.2; Sengupta et al., 2013), the hairy root development in vetiver is speculated to considerably increase the uptake of TC and its isomers (Epi-TC, anhydro-TC).

\section{Culturing and propagating vetiver hairy root culture by Agrobacterium rhizogenes}

\section{ATCC 15834)}

There were three trials of the experiment with slight modification of the method each time (listed below). However, none of trials were successful in developing hairy roots in vetiver grass.

\section{Trial I:}

Sterile vetiver cultivar (C. zizanioides) were used in this study was purchased from from Agriflora Tropicals, Puerto Rico (http://agrifloratropicals.com/) as small plantlets and were grown in the green house. The plants were propagated by splitting mature vetiver clumps into bare root slips. The method for hairy root culture was followed from Gujrathi et al. (2005 b) and protocol by Kumar et al., (2006) with slight modifications, as described below. 
The root-shoot junction (where the young shoot propagates) was selected in three young vetiver plantlets. Using a sterile scalpel, $2 \times 2 \mathrm{~cm}$ square of the section was collected from three different plantlets. The plant section was surface sterilized with $0.1 \%$ mercuric chloride and placed in MS (Murashige and Skoog) agar plates (Mehrotra et al., 2008). The plant section was wounded using a sterile scalpel and then infected with Agrobacterium rhizogenes ATCC 15834 (which was grown overnight in a gyratory shaker at $28^{\circ} \mathrm{C}$ at a speed of $160 \mathrm{rpm}$ in nutrient broth media) using a sterile needle. The agar plate (co-cultivated with the plant section and the bacteria) was parafilmed and then wrapped carefully in a black cloth and incubated at $28^{\circ} \mathrm{C}$ for $3-4$ weeks in dark.

\section{Trial II:}

All set-ups remained similar in the second trial (from the first one) besides MS broth media was used instead of using MS agar plates. For the infection process, $10^{5}$ cells $/ \mathrm{mL}$ of Agrobacterium rhizogenes ATCC 15834 were added to the MS broth medium.

\section{Trial III:}

All set-ups remained similar in the third trial (from the second one) except for acetosyringone $(1 \mathrm{~mL})$ which was added into the MS broth medium for this trial. Acetosyringone increases the efficiency of transformation and the process of hairy root production (Sheikholeslam and Weeks 1987). 
Result and Discussion:

The result from trial I demonstrated no growth of hairy root after 6 weeks of incubation. Hence, the experiment was repeated two more times by slightly modifying the method (as mentioned above). However, hairy root formation was not observed. Important observations were made, such as all other studies used seedlings of plants to be transformed by the bacterium whereas, for this study vetiver plantlets were used as vetiver seedlings are not commercially available. This could be the prime reason of failure of the experiment as the bacterium possibly couldn't invade the growth root surface and cause the infection.

\section{Conclusion:}

There has been good progress in setting up the experiment and development of a standard operating procedure (SOP) for vetiver hairy root production. However, the actual reason for failure still needs to be identified and mended. We are currently in process of identifying the cause and re-running the experiment to get successful result with hairy root production of vetiver grass. 


\section{References}

1. Gujrathi NP, Linden JC (2005 a) Oxytetracycline inactivation by putative reactive oxygen species released to nutrient medium of Helianthus annus hairy root cultures. Biotechnol and Bioengg. 92: 393-402.

2. Gujarathi NP, Haney BJ, Park HJ, Wickramsinghe SR, Linden JC (2005 b) Hairy roots of Helianthus annus: A model system to study phytoremediation of tetracycline and oxytetracycline. Biotechnol. Prog. 21: 775-780.

3. Kumar V, Sharma A, Prasad BCN, Gururaj HB, Ravishankar GA (2006) Agrobacterium rhizogenes mediated genetic transformation resulting in hairy root formation is enhanced by ultrasonication and acetosyringone treatment. Electron. J. Biotechen. 9: 349-357.

4. Mehrotra S, Kukreja AK, Khanuja SPS, Mishra BN (2008) Genetic transformation studies and scale up of hairy root culture of Glycyrrhiza glabra in bioreactor. Electron. J. Biotechen. 11: 1-7.

5. Sengupta A, Waring K, Sarkar D, Bagley S, and Datta R (2013) Tetracycline degradation in aqueous systems using vetiver grass and identification of tetracycline Metabolites in the plant. (Chapter 2 of thesis) Manuscript in progress to be published in International J. Phytorem.

6. Sheikholeslam SN, and Weeks DP (1987) Actetosyringone promotes high efficiency transformation of Arabidopsis thaliana explants by Agrobacterium tumefaciens. Plant Mol. Biol. 8: 291-298. 
7. Truong PNV, Foong YK, Guthrie M, Hung Y-T (2010) Phytoremediation of heavy metal contaminated soils and water using vetiver grass. Environ. Bioeng (Handbook of Environ. Eng.). 11:233-275.

8. Velde WVD, Mergeay J, Holsters M, Goormachtig S (2003) Agrobacterium rhizogenes-mediated transformation of Sesbania Rostrata. Plant Sci. 165.6: 1281288. 